\title{
DIESEL SOOT OXIDATION UNDER CONTROLLED CONDITIONS
}

A thesis submitted for the degree of Doctor of Philosophy

by

\author{
Haiwen Song
}

Department of Mechanical Engineering

Brunel University

Aug. 2003 


\section{For the attention of candidates who have completed Part $\Lambda$}

i) Attention is drawn to the fact that the copyright, of a thesis rests with its author.

ii) A copy of a candidate's thesis is supplied to the Library on condition that anyone who consults it is understood to recognise that its copyright rests with its author and that no quotation fror the thesis and no information derived from it may be published without the prior written consent of the author or University. as appropriate.

Requests for such permission should be addressed in the first instance to the Head of Library Services. 


\section{ACKNOWLEDGEMENTS}

I would like to thank my supervisors Professor Nicos Ladommatos and Professor Hua

Zhao for their guidance throughout this project. Without their indefatigable support and help, this thesis would not have been possible. I would also like to thank the EPSRC for the financial support for the project.

I would also like to thank the Beijing Institute of Special Mechanical and Electronic Technology for supporting my study in the UK and for their concern for the well being of my family.

My thanks are also due to $\mathrm{Dr}$ Yufeng $\mathrm{Li}$ for his assistance with engine tests and Messrs Bob Webb, John Langdon, Andrew Selway, John Tierney, Clive Barrett, Ian Hutchby, Doug Clancy, Len Soanes, and other staff members in the Department of Mechanical Engineering for their help.

Finally, but not least, I would like to thank my parents, my wife and my lovely daughter for their enduring support, concern, encouragement and help during my stay in the UK for this project.

The work reported in this thesis was funded by EPSRC, Grant No. GR/L67288/01 


\section{ABSTRACT}

In order to improve understanding of diesel soot oxidation, an experimental rig was designed and set up, in which the soot oxidation conditions, such as temperature, oxygen partial pressure, and $\mathrm{CO}_{2}$ partial pressure, could be varied independently of each other. The oxidizing gas flow in the oxidizer was under laminar condition. This test rig comprised a naturally-aspirated single cylinder engine which acted as the soot generator, and a separate premixed oxidation burner system in which soot extracted from the engine was oxidized under controlled conditions. Diesel soot was extracted from the engine exhaust pipe and from the engine pre-combustion chamber, and the soot-laden gas was then conveyed to the burner where it was oxidized. The burner was positioned vertically and it had a flat flame whose thickness was only a few millimetres. The hot gases from the flame flew upwards through a quartz transparent tube which acted as the soot oxidation duct. The soot-laden gas from the engine was premixed with the feedgas (itself a premixed mixture of methane, air, oxygen, and nitrogen) to the burner. The soot particles passed vertically through the flame front and continued burning in the post-flame gas flowing through the quartz tube oxidation duct. The oxygen concentration and temperature of the post-flame soot oxidation gas were controllable by adjusting the flowrate and composition of the burner feedgas. Diesel soot particles were sampled at different heights along the centreline of the quartz tube above the burner. Profiles of oxygen concentration, temperature, and soot particle velocity in the oxidation zone were thus measured. Morphology and size distributions of the sampled diesel 
soot particles were analyzed by means of Transmission Electron Microscopy (TEM) and a computer software called ImagePro Plus. Subsequently, the specific surface oxidation rates of the soot particles were worked out based on soot particle size distributions.

The TEM micrographs obtained in this study showed that the diesel soot agglomerates existed in forms of clusters and chains, each containing between a small number and thousands of individual, mostly spherical tiny particles. Of order 97\% of the individual spherical particles (spherules) had a size range from 10 to 80 $\mathrm{nm}$. Occasionally, individual spherules of about $150 \mathrm{~nm}$ in diameter could be observed. The diesel soot particles sampled from the pre-chamber of the engine had different size distributions from those sampled from the exhaust of the engine, indicating that the soot underwent an oxidation process in the combustion chamber. Soot oxidation experiments were performed in the burner post-flame gas under oxygen partial pressures ranging from 0.010 to 0.050 atm and temperatures from 1520 to $1820 \mathrm{~K}$. The test results showed that the oxidation rates of the diesel soot extracted from the diesel engine were generally lower than those predicted by the well-known Nagle and Strickland-Constable formula; however, the measured oxidation rates were higher than the predictions made with another well-known formula - the Lee formula. The soot extracted from the engine pre-chamber appeared not to oxidize as fast as the soot extracted from the exhaust of the engine. $\mathrm{CO}_{2}$ gas injection to the post-flame oxidation gas at constant oxygen partial pressure and oxidation temperature seemed to have accelerated the diesel soot oxidation rate. 
Based on the experimental results of this study and the results of other researchers, modifications to the Nagle and Strickland-Constable formula and to the Lee formula were accomplished. Also, an empirical expression, as an alternative to semi-empirical formulae, was worked out and presented in the thesis. 


\section{CONTENTS}

\section{ABSTRACT}

ACKNOWLEDGEMENTS

GLOSSARY

Chapter 1 - Introduction 1

1.1 Particulate Emission from Diesel Engines 1

1.2 Diesel Soot Oxidation and Critical Appraisal of Previous Research 2

1.3 Objectives and Outline of Methodology Used 4

1.4 Outline of the Thesis 5

Chapter 2 - Literature Review 7

2.1 Particulate Matter and Soot $\quad 7$

$\begin{array}{ll}2.2 \text { Soot Formation } & 8\end{array}$

2.2.1 Combustion process in diesel engines $\quad 8$

2.2.2 Sub-processes of soot formation 9

2.3 Diesel Soot Structure 13

2.3.1 Diesel soot clusters, chains, and spherules 13

$\begin{array}{ll}\text { 2.3.2 Microstructure of diesel soot spherules } & 14\end{array}$

2.4 Chemical, Physical, and Geometrical Properties of Diesel Soot 16

2.4.1 Composition of diesel soot 16

2.4.2 Density, porosity, and surface/mass ratio of diesel soot particles 17

2.4.3 Reactivity of diesel soot 17

2.5 Oxidation of Diesel Soot $\quad 18$

$\begin{array}{ll}\text { 2.5.1 Oxidants } & 18\end{array}$

2.5.2 Previous research methods for carbon oxidation 18

2.5.3 Soot oxidation kinetics and modeling 21

2.5.3.1 The Nagle and Strickland-Constable formula

2.5.3.2 The Lee formula

2.5.3.3 Models of oxidation for other oxidants 
Chapter 3 - Test Rig Design and Instrumentation

$\begin{array}{ll}\text { 3.1 Test Rig Design } & 27\end{array}$

3.1.1 General description $\quad 27$

3.1.2 The diesel engine used to produce soot 30

3.1.3 The burner system used to oxidize the diesel soot 31

3.1.3.1 Burner

3.1.3.2 Quartz soot oxidation duct

3.1.3.3 3-D burner traverse system

3.1.4 Gas supply and mixing system $\quad 34$

3.1.5 Sampling-probe/thermocouple assembly 35

3.1.6 Filter holder and copper grid 36

3.2 Instrumentation 37

3.2.1 Oxygen concentration measurement 37

3.2.2 Carbon dioxide measurement 38

3.2.3 Temperature measurement $\quad 39$

3.2.4 Particle velocity measurement with laser Doppler anemometry $\quad 41$

3.2.5 Particle sizing and morphology 43

3.3 Estimation of the Distance between Diesel Particulates in Burner Post- $\quad 43$

flame Gas and Determination of the Gas Flow Type

Chapter 4 - Experimental Methodology

4.1 General Procedure 46

4.2 Setting and Measuring Oxidation Conditions in the Oxidation Burner 46

4.3 Sampling Soot Particles from the Post-Flame Gas Flow in the Burner 47

4.4 Measuring Soot Spherule Size Distributions 47

4.5 Calculating Soot Spherule Diameter Recession and Oxidation Rates 50

4.6 Comparing Experimental Soot Oxidation Rates with Predictions 54

4.7 Summary $\quad 57$

Chapter 5 - Analysis of Morphology of Diesel Soot 58

5.1 Introduction $\quad 58$

$\begin{array}{ll}\text { 5.2 Diesel Soot Morphology } & 58\end{array}$ 
5.2.1 Morphology of engine pre-chamber raw soot sampled during the combustion stroke

5.2.2 Morphology of engine pre-chamber raw soot sampled during the 60 exhaust stroke

5.2.3 Morphology of raw exhaust soot 60

5.2.4 Morphology of soot partially oxidized in the burner post-flame gas 61

5.3 Discussion

5.3.1 Comparison of the raw soot from the pre-chamber and exhaust gas 62

5.3.2 Comparison of burned soot with raw soot 65

5.3.3 Surface/mass ratio of diesel soot 65

5.3.4 Influence of the aggregation of diesel soot particles on oxidation rate 67 5.4 Summary 68

Chapter 6 - Experimental Results and Discussion 70

6.1 Introduction 70

6.2 Measured Oxidation Rates of Exhaust Diesel Soot and Comparisons with 70 Predictions

6.3 Oxidation Rates for the Pre-Chamber Diesel Soot and Comparison with 73 the Rates for the Exhaust Diesel Soot

6.4 Oxidation Rates with Different $\mathrm{CO}_{2}$ Partial Pressures 75

6.5 Discussion on the Effects of Oxidants Other than Carbon Dioxide on Soot 77 Oxidation

6.6 Discussion of the Effect of Total Oxidation Stream Pressure on Diesel

Soot Oxidation Rate

6.7 Comparison of the Oxidation of porous and Non-porous Carbons

6.8 Comparison of Experimental Oxidation Rates from Various Studies with 82

Predictions Made by the Nagle and Strickland-Constable Formula and the Lee Formula

6.9 Conclusions 
Chapter 7 - Improvement in Existing Correlations for Soot 85

Oxidation

$\begin{array}{ll}7.1 \text { Introduction } & 85\end{array}$

7.2 Comparison of the Nagle and Strickland-Constable Formula and the Lee 85

Formula

7.3 Modifying the Nagle and Strickland-Constable formula 88

7.4 Modifying the Lee formula $\quad 90$

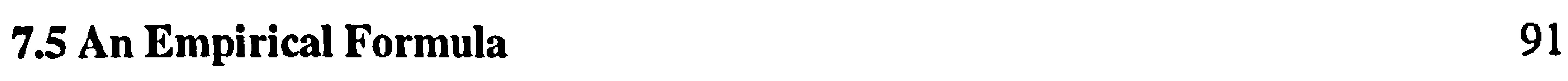

$\begin{array}{ll}\text { 7.6 Conclusion } & 93\end{array}$

Chapter 8 - Conclusions and Suggestions for Further Work 94

$\begin{array}{ll}\text { 8.1 Conclusions } & 94\end{array}$

8.2 Suggestions for Further Work 96

$\begin{array}{ll}\text { References } & 98\end{array}$

Tables, Figures, and Pictures

Appendixes

Visual Basic Programme for Calculation of Soot Spherule Diameter

Recession 


\section{GLOSSARY}

\section{Symbols}

$d \quad$ Diameter of thermocouple junction bead

Diameter of individual soot spherules

$k \quad$ Rate constant in the Nagle and Strickland-Constable formula

$p \quad$ Pressure

$r \quad$ Radius

$t \quad$ Time

$w \quad$ Specific oxidation rate

$x \quad$ Fraction of soot particle surface occupied by type $A$ sites

A Relatively reactive site on carbon surface

F Cumulative size distribution function

$N \quad$ Total number of soot particles

$R \quad$ Universal gas constant

T Temperature

$\varepsilon \quad$ Emissivity

$\lambda$. thermal conductivity

$\rho$ Density

$\sigma \quad$ Stefan-Boltzmann constant

\section{Subscripts}

1,2 Height (above burner) numbers

A, B, T, Z Rate constant subscripts in the Nagle and Strickland-Constable formula g Gas 


$\begin{array}{cl}j & \text { Thermocouple junction bead } \\ \max & \text { Maximum } \\ \min & \text { Minimum } \\ \mathrm{O}_{2} & \text { Oxygen } \\ \mathrm{S} & \text { Surviving soot particles } \\ w & \text { Surrounding wall }\end{array}$

\section{Notation}

$\Delta \quad$ Recession

\section{Abbreviations}

DPF Diesel particulate filter

DPM Diesel particulate matter

EAA Electrical aerosol analysis

EPA the Environment Protection Agency

FFF Field-flow fraction

LDA Laser Doppler anemometer

LII laser-induced incandescence

NSC Nagle and Strickland-Constable

PAH polycyclic aromatic hydrocarbons

PCS Photon correlation spectroscopy

SMPS Scanning mobility particle sizing

SOF Soluble organic fraction

TEM Transmission electron microscope 


\section{Chapter 1 Introduction}

\subsection{Particulate Emission from Diesel Engines}

Traditionally the diesel has been viewed as efficient, reliable and durable with low operating costs. The diesel engine has up to $25 \%$ percent better efficiency than its counterpart petrol engine [Arcoumanis and Schindler, 1997]. And, as a result of the higher efficiency, diesel engine emits lower carbon dioxide per unit of power output, which is a major contributor to the global warming effect. Diesel engines have been playing an important role in various fields for many years, including buses, trucks, marine applications, electrical power generators, and increasingly passenger cars.

However, harmful emissions from diesel engines especially diesel-powered vehicles is a major threat to human health and the environment. As for petrol engines, the major pollutants from diesel engines are oxides of nitrogen (NOx), carbon monoxide (CO), carbon dioxide $\left(\mathrm{CO}_{2}\right)$, unburned hydrocarbons (UHC), and carbonaceous particulate matter (PM). Diesel engines emit greater amounts of NOx and particulate matter than equivalent petrol engines per unit of power output. Particulate matter emitted from diesel engines consists principally of combustion-generated carbonaceous soot [Amann and Siegla, 1982]. The particulate matter is increasingly being associated with irritation and illnesses of the human pulmonary system and other damage to the environment. About $90 \%$ of diesel particulate matter is within a size range from 0.075 to $1.0 \mu \mathrm{m}$. The particulate matter emitted from diesel engines is, therefore, important in terms of potential health impacts due to the ability of the particles to be inhaled deep into respiratory system and eventually become trapped in the bronchial passage and alveoli of the lungs [Sakamoto et al, 1997]. Diesel 
particulate matter has also been shown to contain compounds that exhibit mutagenic and possibly carcinogenic activity in animals. The emission of particulate matter and oxides of nitrogen from diesel engines, particularly in passenger vehicles, has become a worldwide concern. Legislators are responding with increasingly severe legislative and fiscal measures, whilst vehicle manufacturers continue to improve engine technologies that are reducing both the engine-out and tail-pipe emissions.

\subsection{Diesel Soot Oxidation and Critical Appraisal of Previous Research}

The composition of diesel particulate is dominated by solid carbonaceous material (soot). Generally speaking, the strategies for reducing particulate emission from diesel engines into the atmosphere can be divided into three main aspects:

- Reducing the formation of soot in the engine cylinder;

- Improving the oxidation of soot during the combustion process in the engine cylinder;

- Trapping the remaining particulates in the exhaust system before flowing out of the exhaust pipe.

The concentration of particulates emitted from the diesel engine cylinder is the net result of two simultaneously occurring processes: the formation of soot and its oxidation in the combustion chamber. The diesel soot oxidation process has at least as much importance to the final particulate emission from the diesel engine cylinder as the soot formation process.

Many parameters affect soot oxidation process in the diesel engine combustion chamber, such as overall oxygen concentration, flow turbulence level, and temperature. Due to the complexity of the chemical and physical processes involved, the detailed oxidation mechanism for diesel soot is not well known, though a number 
of researchers have been working on improving understanding of diesel soot oxidation.

Published data on oxidation of diesel soot particles is quite rare. This is due to a number of reasons. Firstly, there are substantial technical difficulties in gaining physical and optical access to the combustion chamber of a running diesel engine. Secondly, diesel soot generation and oxidation mostly take place at the same time and at the same locations in the engine combustion chamber, making the isolation of soot oxidation very difficult. Thirdly, the pressure, local temperature, oxygen concentration, and flow conditions in the chamber change rapidly and uncontrollably during combustion.

Although diesel soot has certain similarities with other carbons such as graphite, carbon blacks, and soot from laboratory flames, it is questionable whether results for oxidation of such substances apply to diesel soot oxidation due to great differences in their chemical and physical characteristics.

Some of the research in diesel soot oxidation was conducted in normally running diesel engines [Fujimoto et al, 1998; Khan and Greeves, 1974; Ladommatos et al, 1998; Ladommatos et al, 1996a; Ladommatos et al, 1996b; Murayama et al, 1992; Pischinger et al, 1994; Plee et al, 1981; Spicher and Dresen-Rausch, 1992]. As mentioned above, the major disadvantage of this method is that the soot oxidation process cannot be distinguished and determined separately from the formation process. Usually, these studies can only provide general information on the trends of smoke (particulates) and other emissions with varying the engine intake or running conditions or fuel composition. 
Isolation of the oxidation process of diesel soot was achieved in a diesel engine cylinder by Khan et al [1971] by generating soot in two cylinders of a four-cylinder engine and recycling it in one of the other two cylinders, which ran without fuel injection, where the recycled soot underwent oxidation under elevated temperatures generated by the compression of the soot bearing gas. However, the in-cylinder oxidation temperature varied widely during the compression and expansion processes, from $630-722 \mathrm{~K}$ to the peak compression temperatures of $1330-1520 \mathrm{~K}$, with a simultaneous rapid change in cylinder gas pressure. This made it difficult to determine the correlation between soot oxidation and temperature and the effect of gas pressure.

Some studies on oxidation were carried out on diesel soot deposits but these were at low temperatures ranging from 573 to $1073 \mathrm{~K}$ [Ahlström and Odenbrand, 1989; Marcuccilli et al, 1994; Neeft et al, 1997; Otto et al, 1980]. These studies could not provide information on the oxidation of suspended diesel soot at higher temperatures similar to those in diesel engine combustion chambers.

Because of various shortcomings with previous studies, it became necessary to develop novel techniques which would allow investigation of diesel soot oxidation under controllable oxidation-only conditions.

\subsection{Objectives and Outline of Methodology Used}

The aims of this project were:

- Establishing a new technique that could be used to investigate the oxidation rate of suspended diesel soot particles under controllable oxidation conditions and without any interference from soot formation; 
- Finding out the quantitative correlation between the oxidation rate of diesel soot and the oxidation conditions, such as temperature and oxygen partial pressure;

- Setting up a formula for calculating diesel soot oxidation rate which would be used in phenomenological or computational models of diesel engine combustion.

A new technique was developed during this work. Diesel soot particles were extracted from a diesel engine and sent to a newly established test rig, where the combustion of the soot particles took place while passing through the post-flame gas of a laminar premixed burner operating under controlled conditions. A sampling unit collected soot particles at different positions along the oxidation zone. The size distributions of the collected soot particles were determined by means of electron transmission microscope (TEM) and image analysis software. The specific surface oxidation rates of the soot particles were subsequently calculated from the size distributions and related to the oxidation conditions (mainly temperature and oxygen partial pressure). Based on the experimental results from this study and other studies, modifications have been made to two widely quoted carbon oxidation models in order to improve their accuracy. In addition, an empirical formula relating soot oxidation rate to oxidation conditions was developed.

\subsection{Outline of the Thesis}

In this thesis, the present chapter is an overview of the study and the thesis.

Chapter 2 is a literature survey and which presents information from a substantial number of other studies on soot formation, structure, chemical and physical characteristics, oxidation, previous research methods, and modelling. 
Chapter 3 describes the soot oxidation test rig and instrumentation in detail.

Chapter 4 introduces the experimental procedures and the analytical methods used. A new method for calculating soot particle surface oxidation rate from the size distributions, allowing for the complete burn-off of small particles during the oxidation process, was developed and is introduced in this chapter.

TEM morphologies of the diesel soot particles, both from the exhaust gas and the prechamber of the diesel engine, are presented in chapter 5.

Chapter 6 presents experimental results from this study on the effects of the following parameters on soot particle oxidation rate: oxidation temperature, oxygen partial pressure, and $\mathrm{CO}_{2}$ partial pressure. A comparison of the oxidation rates of the exhaust diesel soot with those of the engine pre-chamber soot can also be found in this chapter. Also, this chapter discusses the effects on the oxidation rate of: temperature, different oxidants, oxidizing gas stream total pressure, and porosity of the carbon particles.

Chapter 7 describes modifications made during this study to the two widely quoted carbon oxidation formulae, the first developed by Nagle and Strickland-Constable [1962], and the second by Lee et al [1962]. Finally, an empirical formula is introduced, which fits well experimental soot oxidation rates from this and other studies over large oxygen partial pressure and temperature ranges.

Chapter 8 summarizes the conclusions of this study and offers suggestions for further work. 


\section{Chapter 2 Literature Survey}

\subsection{Particulate Matter and Soot}

Diesel engines are an important source of particulate matter emitted into the atmosphere. The so called diesel engine exhaust particulate matter (DPM), as defined by the Environment Protection Agency (EPA) regulations and sampling procedures, is any material collected on a filter paper placed in the diluted engine exhaust stream that is cooled and diluted below $52^{\circ} \mathrm{C}$ [Abdul-Khalek and Kittelson, 1995].

The DPM consists of solid and volatile matter. The solid material is called soot, which is formed during the combustion process in the engine combustion chamber. Soot consists mainly of carbon and a small amount of inorganic ash, which is derived mostly from the lubricant, with trace contributions from fuel additives and engine wear [Eastwood, 2000]. The soot is also usually referred to "insoluble" fraction of DPM.

The volatile material can be divided into commonly called "Soluble Organic Fraction (SOF)" and sulphates $\left(\mathrm{SO}_{4}{ }^{2}\right)$. The SOF is an immensely complex cocktail of high molecular weight organic compounds derived from both the fuel and lubricant. The major groupings are unburned hydrocarbons (alkanes, alkenes, aromatics), oxygenated hydrocarbons (ketones, esters, ethers, organic acids) and polycyclic aromatic hydrocarbons (PAH).

Diesel particulate matter exists in the form of agglomerates of mainly carbonaceous soot particles that also include absorbed hydrocarbon and traces of other materials. The agglomerates are usually in the shape of clusters and chains comprising from a 
few to thousands of primary tiny individual spherical carbonaceous soot particles. These individual spherical primary soot particles are called spherules, or simply particles. The diameter of the spherules varies mostly between 10 and $80 \mathrm{~nm}$, and the sizes of their agglomerates may range from about $0.01 \mu \mathrm{m}$ to about $30 \mu \mathrm{m}$ [Dolan et $a l, 1980]$ with most in the fine $(<2.5 \mu \mathrm{m})$ and ultrafine $(<0.1 \mu \mathrm{m})$ size range [EPA, 2000].

A passenger car powered with diesel engine conforming to the "Euro 3" standard can emit up to $0.05 \mathrm{~g} \mathrm{~km}^{-1}$ DPM. The composition of the particulate material depends largely on the conditions prevailing in the engine exhaust and in the particulate collection system. Particulate samples collected from diesel powered passenger cars at exhausts temperatures above $500^{\circ} \mathrm{C}$ consist mainly of collections of carbonaceous soot particles. As temperatures decrease below $500^{\circ} \mathrm{C}$, the particles become coated with adsorbed and condensed volatile materials as described above [Degobert, 1995; Heywood, 1988].

\subsection{Soot Formation}

\subsubsection{Combustion process in diesel engines}

The diesel combustion process can thus be divided into three different phases [Arcoumanis and Schindler, 1997]:

1. Premixed combustion During mixture formation the fuel is injected into the cylinder and mixed with highly compressed air. Depending on ignition delay and the injected mass, a considerable amount of fuel evaporates and form fuel/air mixture. Measurements have confirmed that auto-ignition starts in premixed zones with $\lambda \approx 0.7$. Once ignition has occurred, the soot appears in 
less than $1 \mathrm{~ms}$ in all parts of the fuel jet and mostly in fuel rich regions of the spray [Dec and Espey, 1992; Dec and Espey, 1995; Degobert, 1995].

2. Main phase of combustion Following auto-ignition the remaining fuel is injected into burning or burned gas and combustion takes place as a partially premixed diffusion flame. By mixing with combustion gas, mixture elements may reach high temperatures and low air/fuel ratio states at the same time. These conditions yield to a high soot formation.

3. Burn-out During diesel combustion a burn out of just formed soot particles may happen towards the end of the process. Most of the soot formed during the first and second combustion phases can completely burn out but some survive. The survived soot particles will be emitted along with the exhaust gas and form particulates from the tail pipe.

Generally, Soot formation takes place in the diesel combustion environment which has temperatures between about 1000 and $2800 \mathrm{~K}$, pressures of 50 to $100 \mathrm{bar}$, and sufficient air overall to burn fully all the fuel. The peak soot concentration has been reported to appear at about $10^{\circ} \mathrm{CA}$ ATDC, varying with engine and operation conditions [Murayama et al, 1992; Pischinger et al, 1994; Spicher and DresenRausch, 1992]. Soot formation and burn-out co-exist throughout the combustion process. The final soot quantity appear in the exhaust pipe is a trade-off of its formation and oxidation.

\subsubsection{Sub-processes of soot formation}

Looking in more detail, the formation of diesel soot involves a complex series of chemical and physical processes. The formation processes of diesel soot include 
nucleation, surface growth, agglomeration and adsorption/condensation [Amann and Siegla, 1982; Haynes and Wagner, 1981; Heywood, 1988]. All these sub-processes of soot formation may overlap or occur concurrently in a given elemental mixture packet within the diesel combustion space. In addition, dehydrogenation and oxidation accompany the formation process throughout. The sub-processes are described in detail bellow.

\section{Dehydrogenation}

The H/C ratio of the pyrolyzing fuel decreases continuously during formation of soot in a flame. Commercial diesel fuel has an atomic $\mathrm{H} / \mathrm{C}$ ratio just under 2.0 while the dry soot has a $\mathrm{H} / \mathrm{C}$ ratio of $0.21-0.27$ [Amann and Siegla, 1982]. This reflects the departure of $85-90 \%$ of the hydrogen in the original fuel from the dry soot, which makes carbonaceous matter the predominant component in the composition of soot.

\section{Nucleation}

It is widely accepted that nucleation of radical species produced by combustion gives rise to the precursors of soot spherules. First condensed phase material arises from new polymerised molecules which have been produced from the original fuel molecules by oxidation and/or pyrolysis. These polymerised molecules typically include various unsaturated hydrocarbons, particularly acetylene and its higher analogues $\left(\mathrm{C}_{\mathrm{n}} \mathrm{H}_{2 \mathrm{n}-2}\right)$, and polycyclic aromatic hydrocarbons (PAH). These two types of polymerised molecules are rather stable and considered to be the most likely precursors of soot in flame. The condensation reactions of such polymerised species, which are initially in the gas phase, lead to the appearance of the first recognisable soot particles (often called nuclei), which have very small size $(\mathrm{d}<2 \mathrm{~nm}$ ). As the 
number of established nuclei increases, enough dispersed surface area becomes available for deposition of gaseous hydrocarbon intermediates. In this way, soot particles grow from the initial nuclei, and the probability of generating new nuclei falls to zero, i.e. the nucleation process terminates.

\section{Surface growth and agglomeration}

Once nucleation terminates, continued increase in soot mass is attributable to surface growth, which involves the gas phase deposition of hydrocarbon intermediates on the surface of the spherules that develop from the nuclei. Surface growth that takes place on nuclei results in individual growing spherules, which become somewhat distorted shape, resembling warped concentric shells. These shells constitute the outer portions of the individual spherules and are somewhat distinct from the spherule centres which appear to be less organised structurally. As soon as a few mobile individual particles appear in the combustion space - be they well-developed soot spherules or subspherules - interparticle collisions lead to their agglomeration [Amann and Siegla, 1982]. Several fine particles of 3 to $4 \mathrm{~nm}$ in diameter, grown from nuclei, could join together to form a bigger individual spherule [Ishiguro et al, 1997] which carry on being consolidated by further surface deposition until a larger individual particle has formed, which subsumed the original smaller particles. Thus, collision of two or more spherical particles cause them to combine into a single particle which then grows by further surface deposition. This is suggested by the non-spherical silhouettes of some of the larger particles and by the disordered array of crystallites in the centres of spherules as revealed by phase-contrast electron microscopy. Although, after collision and agglomeration of two or more small particles the resulting shape is not spherical, often, rapid surface growth quickly restores the agglomerate to 
spherical shape [Amann and Siegla, 1982]. This process that restores spherical shape usually occurs up to diameters of about $10 \mathrm{~nm}$ [Heywood, 1988]. At the beginning of soot formation nearly all particles have been found to be smaller than $10 \mathrm{~nm}(80 \%$ in the range between 3 and $5 \mathrm{~nm}, 20 \%$ between 6 and 9nm) [Pischinger et al, 1994]. During the combustion and expansion process of about $4.5 \mathrm{~ms}$, the individual particles grow. Nearly all individual particles are smaller than $100 \mathrm{~nm}$. Only $30 \%$ are in the range from 3 to $5 \mathrm{~nm}$ and $65 \%$ in the range 6 to $9 \mathrm{~nm}$. The rest of the particles are larger than $10 \mathrm{~nm}$.

On the other hand, if individual spherules have had the opportunity to grow and to solidify before they suffer a collision, then if they collide with other particles they can combine together in aggregates, held together by electric charge force, and produce clusters. The original spherules tend to retain much of their individual identities.

Some deposition of gas phase species may occur on these clustered particles and may partially fill the crevices at the junctures of adjoining spherules to provide peanut-like configuration.

It must be born in mind that surface oxidation can occur throughout each of the above stages of soot particle and cluster formation. For example, soot precursors and soot spherules, or clusters are burned in the presence of oxidizing species to form gaseous products such as $\mathrm{CO}$ and $\mathrm{CO}_{2}$. Therefore, the eventual emission of soot from the engine will depend on the balance between these processes of formation and oxidation. 


\section{Adsorption and condensation}

The final process in the particulate formation sequence is adsorption and condensation of hydrocarbons. This occurs primarily after the cylinder gases have been exhausted from the engine into the exhaust system, or, while these exhaust gases are diluted with air. Adsorption involves the adherence of unburned hydrocarbons to the surface of the soot particles. The hydrocarbons most likely to condense are those of low volatility, mainly from the high-boiling-point end of the fuel, unburned hydrocarbons that have been pyrolyzed but not consumed in the combustion process, and the lubricating oil [Amann and Siegla, 1982; Heywood, 1988]. These adsorbed and condensed materials onto the particulate are solvent-extractable. Typically, the extractable hydrocarbons comprise $10-30 \%$ of the particulate mass. On average, over half of the extractable fraction is traceable to lubricating oil, the range of that contribution extending from $16 \%$ to $80 \%$ [Amann and Siegla, 1982].

The processes described above are represented sequentially in figure 2-1. Although they are illustrated as discrete processes, they may tend to overlap or to occur concurrently in a given elemental mixture packet within the diesel combustion space.

\subsection{Diesel Soot Structure}

\subsubsection{Diesel soot clusters, chains, and spherules}

Diesel soot exists almost entirely in the forms of clusters and chains of individual primary soot particles (spherules). Clusters may contain as many as 4000 individual spherules, making the cluster size mostly within the range from 0.075 to $1.0 \mu \mathrm{m}$ [Heywood, 1988; Sakamoto et al, 1997]. The number of spherules that a cluster contains was observed to vary with the total air/fuel ratio over a range from 22 to 100 
in a diesel engine [Roessler et al, 1981]. Clusters produced at lower air/fuel ratios are more highly agglomerated, and vice versa.

A single spherule contains $10^{5}$ to $10^{6}$ carbon atoms [Heywood, 1988]. The diameter of individual spherules varies between 10 and $80 \mathrm{~nm}$, with most spherules having a diameter in the range of $15-30 \mathrm{~nm}$. The number-mean diameter $\left(\sum \mathrm{N}_{\mathrm{i}} \mathrm{d}_{\mathrm{i}} / \mathrm{N}\right)$ of sampled diesel soot spherules has been reported to be around 26 to $28 \mathrm{~nm}$ [Amann and Siegla, 1982; Vuk et al, 1976] and volume-mean diameter, $\left(\sum \mathrm{N}_{\mathrm{i}} \mathrm{d}_{\mathrm{i}}^{3} \mathrm{~N}\right)^{1 / 3}$, is $31 \mathrm{~nm}$ [Amann and Siegla, 1982]. Figure 2-2 shows typical distributions of diesel soot individual spherule diameter and volume.

Smaller spherules were measured in diesel soot deposits collected by Marcuccilli et al [1994]. Most of their spherules were in a diameter range between 7 and $45 \mathrm{~nm}$, with the mean around $19 \mathrm{~nm}$. The spherule size has been found to be relatively insensitive to combustion pressure over a wide range of values $\left(10^{3}\right.$ to $\left.10^{7} \mathrm{~Pa}\right)$ and, in the case of diesel soot spherules, to engine operating conditions [Roessler et al, 1981].

\subsubsection{Microstructure of diesel soot spherules}

The structure of diesel soot spherules has strong similarities to that of oil furnace carbon blacks and natural graphite. A significant difference, however, is that diesel soot contains considerably more soluble organic fraction [Amann and Siegla, 1982]. As shown in figure 2-3a, the spherule comprises an onion-like arrangement of concentric lamellae which are wrapped around the center part of the spherule. The lamellae seem somewhat less oriented at the spherule centers.

The carbon atoms in diesel soot and in carbon black are chemically bonded together in a hexagonal network contained within plane layers, as shown in figure 2-4. Each of 
those plane layers, if it is only one atom thick, is called a platelet. Typically, a platelet contains a few hundred carbon atoms [Heywood, 1988; Park and Appleton, 1973]. These platelets appear to be the basic structural "building blocks" of individual small soot spherules [Park and Appleton, 1973].

Usually, three to five of these platelets are stacked on the top of one another, roughly parallel and equidistant, and thus form a crystallite. A crystallite is also illustrated in figure 2-4. The spacing between these platelets in carbon black ranges from 0.35 to $0.36 \mathrm{~nm}$, whereas in graphite it is somewhat smaller at $0.335 \mathrm{~nm}$ [Amann and Siegla, 1982]. Murayama and co-workers have reported an interplatelet spacing distance of $0.350 \mathrm{~nm}$ for diesel soot [Murayama et al, 1992]. This value is within the range of the platelet spacing for carbon black. The crystallites in furnace black used for the manufacture of car tyre treads typically have a thickness of $1.5 \mathrm{~nm}$ and a length of $2-3$ nm across. These crystallites make up the concentric lamellae that are wrapped around the centres of the spherules, the later having diameters from 18 to $30 \mathrm{~nm}$ [Amann and Siegla, 1982].

TEM soot microstructure studies have shown somewhat different structure near the core of a spherule compared with the structure at the surface of the spherule [Faeth and Köylü, 1995; Ishiguro et al, 1997]. Figure 2-3b shows a schematic of the microstucture of diesel soot spherules. From this schematic is can be seen that diesel soot spherules have an inner core with the diameter of ca. $10 \mathrm{~nm}$ at the central region of the spherule and an outer shell enclosing the core [Ishiguro et al, 1997]. Furthermore, the inner core is composed of several very small fine particles of ca. 3 to $4 \mathrm{~nm}$ in diameter, with distinct round boundaries. The outer shell is composed of microcrystallites with periodic orientation of carbon sheets, or a so-called graphitic 
structure. Almost all the crystallites are plannar in shape, ca. $1 \mathrm{~nm}$ thick and ca. 3.5 $\mathrm{nm}$ wide, and are oriented perpendicular to the radius of the spherule.

\subsection{Chemical, Physical, and Geometrical Properties of Diesel Soot}

Diesel soot has chemical and physical characteristics that differ from those of both graphite and activated carbon [Ahlström and Odenbrand, 1989].

\subsubsection{Composition of diesel particulate matter}

Diesel particulate matter found in the exhaust of the engine has a highly complex composition that could even depend on the combustion conditions in the diesel engine and on the fuel composition [Ahlström and Odenbrand, 1989]. Generally speaking, however, diesel particulate matter consists primarily of carbonaceous soot with adsorbed/condensed hydrocarbons, ash, and sulfates [Konstandopoulos and Kostoglou, 2000]. Part of the extractable mass is traceable to engine lubricating oil [Heywood, 1988].

Elementary analysis of diesel particulate matter [Ahlström and Odenbrand, 1989] shows that it also contains hydrogen, nitrogen, oxygen, sulfur, and a number of other elements in trace amounts. A representative diesel particulate matter contains approximately $70 \mathrm{wt} \% \mathrm{C}, 20 \mathrm{wt} \% \mathrm{O}, 3 \mathrm{wt} \% \mathrm{~S}, 1.5 \mathrm{wt} \% \mathrm{H},<1 \mathrm{wt} \% \mathrm{~N}$, and $<1 \mathrm{wt} \%$ trace elements. Small amounts of metallic compounds have also been reported [Roessler et al, 1981].

Mayer et al [1980] found that up to $25 \%$ of the total mass of their particulate matter came from the engine oil, the amount varying with engine operating condition. 


\subsubsection{Density, porosity, and surface/mass ratio of diesel soot particles}

The physical properties of individual diesel soot particles (spherules), such as composition, density, and porosity, are generally similar to those of carbon blacks with two major exceptions: soot particles surviving the last stages of oxidation have significant porosity, even extending to the presence of hollow cenospheres; and soot particles from some internal engine combustion processes (like diesel engines at heavily sooting conditions) contain high levels of volatile matter. Otherwise, diesel soot densities are similar to those of carbon blacks, having values in the range 1.82 $2.05 \mathrm{~g} \mathrm{~cm}^{-3}$ [Faeth and Köylü, 1995]. The density of diesel soot particles is usually taken as $2 \mathrm{~g} \mathrm{~cm}^{-3}$ [Amann and Siegla, 1982; Heywood, 1988; Otto et al, 1980].

Diesel soot particles sampled from diesel engine exhausts, as well as soot from other flames, have low porosity. However, the formation of pores and cenospheres in diesel soot particles at high levels of soot oxidation have been reported [Amann and Siegla, 1982; Faeth et al, 1995; Neoh et al, 1984]. The surface/mass ratio can be as small as $80 \mathrm{~m}^{2} \mathrm{~g}^{-1}$ for freshly devolatilized diesel soot deposit, and becomes as large as $400 \mathrm{~m}^{2}$ $\mathrm{g}^{-1}$ when $70 \%$ of the soot deposit sample had been oxidized in hot air [Otto et al, 1980].

\subsubsection{Reactivity of diesel soot}

Carbons of various origins have shown a wide range of reactivities towards oxygen. The reactivities per unit external surface area for the non-porous carbons, such as carbon blacks and other flame soot, were generally higher than the intrinsic reactivities of the porous carbons [Smith, 1978]. Heat treatment temperature is 
considered to be a major factor controlling the reactivities of pure carbons [Marsh $e t$ al, 1991].

Composition probably affects the reactivities of impure carbons such as diesel soot. Otto et al [1980] obtained results showing that in hot air with oxygen partial pressure of $0.21 \mathrm{~atm}$ and temperature range of $600-1000 \mathrm{~K}$, the combustion rates for diesel soot deposit at $70 \%$ burn-off were approximately 100 times higher than for spectroscopically pure SP1 graphite, which is known to be a carbon of very low reactivity. With increasing oxidation, a decline in the specific oxidation rate of diesel soot deposit was observed, whereas the rate for the graphite remained constant as the oxidation process proceeded.

\subsection{Oxidation of Diesel Soot}

\subsubsection{Oxidants}

In addition to $\mathrm{O}_{2}$, some other species such as $\mathrm{OH}, \mathrm{CO}_{2}, \mathrm{O}, \mathrm{H}, \mathrm{H}_{2} \mathrm{O}$ have also been reported to be carbon oxidants [Bradley et al,1984; Chelliah, 1996; Fenimore and Jones, 1967; Radcliffe and Appleton, 1971].

\subsubsection{Previous research methods on carbon oxidation}

Considerable previous research has been conducted on the oxidation of diesel soot and other carbons. These researches can be divided into the following groups according to the methodology used:

Bulk graphite sample method: Nagle and Strickland-Constable [1962] and Makino et al [1994] used graphite rods in their experiments for oxidation studies. Electric current passing through them controlled the temperature of the rods. Air or 
oxygen/nitrogen mixture was used as oxidant, flowing from a jet and impinging onto the graphite rod. The surface mass oxidation rates of the graphite rod were recorded against rod temperature and oxygen partial pressure.

The advantage of this method is that the oxidation conditions such as temperature and oxidant composition can be controlled easily. However, it is questionable that oxidation rates of bulk carbon can be applied to the airborne tiny diesel soot particles of different chemical and physical characteristics being oxidised in the engine cylinder.

Burner flame method: Extensive studies of soot formation and oxidation have been carried out in burner flames fuelled with propane, methane, ethane $\left(\mathrm{C}_{2} \mathrm{H}_{6}\right)$, etc. [Coelho and Carvalho, 1995; Feugier, 1974; Huth and Leuckel, 1990]. Most of such studies suffered from soot formation and oxidation processes co-existing in the same flame [Coelho and Carvalho, 1995; Feugier, 1974]. Fenimore and Jones [1967] and Neoh et al [1981] separated the soot generation and oxidation stages by using a fuelrich primary flame to generate soot and a secondary flame to burn the soot. The fuels in their first and second flame were ethylene $\left(\mathrm{C}_{2} \mathrm{H}_{4}\right)$ and methane $\left(\mathrm{CH}_{4}\right)$, respectively. In some other studies, commercial carbon blacks or graphite particles were introduced and burned in the flames and their "pure" oxidation rates were measured [Bradley et $a l, 1984 ;$ Rybak et al, 1991]. Diesel fuel spray flames in laboratories have been used to simulate combustion in diesel engine combustion chambers so as to investigate diesel soot oxidation [Hiroyasu et al, 1980; Kadota and Henein, 1981]. However, the coexistence of soot formation and oxidation in the same combustion zone is still unavoidable under these conditions. 
Shock tubes: Park and Appleton [1973] studied the oxidation rate of carbon blacks by means of shock tubes. Carbon black particles were mixed with oxidant gas mixture in an aspirator and then sent to the shock tube, where they were oxidised under high pressures and high temperatures. No reports have been found in the literature on the application of this technique to diesel soot oxidation.

Diesel engines: Studies on diesel soot oxidation directly conducted on diesel engines suffer from great difficulties because the soot formation and oxidation processes take place at the same time and at the same locations in the engine combustion chamber. This makes the isolation of soot oxidation very difficult. Furthermore, the pressure, local temperature, and the local oxygen concentration in the chamber change rapidly and simultaneously.

In order to isolate the oxidation of diesel soot from its formation, Khan et al [1971] generated soot in two normally working cylinders of a four-cylinder engine and recycled the exhaust gas into another non-firing cylinder. At the inlet of this oxidation cylinder, the temperature of the exhaust gases and the oxygen concentration was varied by changing fueling and injection timing in the two normally working cylinders. The recycled soot-laden gas was subjected to a temperature cycle by undergoing compression. With this technique, the in-cylinder oxidation temperature varied from an initial value in the range $630-722 \mathrm{~K}$ to the peak compression temperatures in the range $1330-1520 \mathrm{~K}$, with a simultaneous rapid change in pressure. This made it difficult to determine an accurate relationship between soot oxidation rate and oxygen partial pressure and temperature.

Another in-engine oxidation-only approach by Kittelson et al [1992] was to introduce carbon black particle bearing aerosol into normally running diesel engine cylinder and 
thus simulate the oxidation process of diesel soot agglomerates recirculated from the exhaust to the engine through an electrostatic agglomerator. Here, the carbon black particles are not a good simulator for the diesel soot generated during engine combustion due to the differences in the size and properties.

Diesel soot deposit: Collected diesel soot deposits have been oxidized in oxygen-rich atmosphere at low temperatures $\left(\leq 900^{\circ} \mathrm{C}\right)$ [Ahlström and Odenbrand, 1989; Marcuccilli et al, 1994; Neeft et al, 1997; Otto et al, 1980]. In these studies, the diesel soot deposit underwent pure oxidation and the oxygen concentration and temperature could be controlled independently. However, the temperatures used in all these studies were much lower than the temperatures found in a diesel engine combustion chamber; also, the soot deposits could behave differently from airborne small particles. It is therefore not clear to what extent the use of deposits can simulate realistically the oxidation of airborne diesel soot particles, which, after all, are widely dispersed in the diesel combustion chamber within the gas phase.

\subsubsection{Soot oxidation kinetics and modelling}

Researchers have been spending much effort on the study of the chemical kinetics involved in the oxidation of carbonaceous matter. An outcome of these studies is a number of models for the quantitative prediction of carbon oxidation. The resulting carbon, and soot oxidation models are often in the form of semi-empirical correlations. These semi-empirical models are based on kinetic rate expressions of carbon or soot oxidation and are calibrated using experimental data, such as, the values of the reaction rates of graphite, flame soot, and carbon blacks [Bradley et al,1984; Chelliah, et al, 1996; Chelliah, 1996; Coelho and Carvalho, 1995; Feugier, 1974; Kennedy, 1997; Khan et al, 1971; Lee et al, 1962; Marcuccilli et al, 1994; 
Nagle and Strickland-Constable, 1962; Rybak et al, 1991]. Two such semi-empirical correlations or formulae have been quoted widely in the literatures and have found wide use in predicting diesel soot oxidation rate. These two formulae were worked out, respectively, by Nagle and Strickland-Constable [1962] and by Lee and coworkers [1962] and provide a measure of calculating carbon and soot oxidation rate as functions of oxygen partial pressure and temperature. These two formulae and the basic concepts underlying them are described below.

\subsubsection{The Nagle and Strickland-Constable oxidation formula}

In early years, Blyholder and co-workers [1958] noticed the differences between the experimental oxidation rates of carbonised filaments by various researchers. Interestingly, several unusual general features of reaction rate were found: within a low temperature region $\left(750-1000^{\circ} \mathrm{C}\right)$, the oxidation rate increases exponentially against temperature; within a intermediate region $\left(1000-1700^{\circ} \mathrm{C}\right)$, the reaction rate reaches a maximum value at from 1000 to $1400^{\circ} \mathrm{C}$ and then decreases more or less exponentially; beyond this region, the reaction rate increases exponentially again.

Blyholder et al believed that the different reaction behaviours were due to that the carbonised filaments used by different workers were not pure graphite but were a partially graphitised material and therefore could be expected to have somewhat different surface area, porosities, extent of graphitisation, crystallite size, and impurities. In this state the filaments may be roughly regarded as graphite with hydrogen as an impurity disrupting the graphite structure throughout the entire filament. The surface site, namely type $A$, of this hydrocarbon material is hence easier to oxidise than the surface site, namely type $B$, of the pure graphite lattice that is not 
disturbed by hydrogen or other impurities. During the oxidation process, besides direct gasification, hydrogen leaves off from type $A$ sites and after that the carbon atoms organize themselves into graphite structure. This can convert the type $A$ sites into type $B$ sites. On the contrast, due to the decomposition of the type $A$ oxide, the lattice will be disrupted to extent that type B sites can become type $A$ sites.

Based on their "two-site-types" concept, Blyholder and co-workers developed a mathematical model to describe the experimentally observed reaction trends of the carbonized filaments used by various researchers. Later, according to the experimental work on the oxidation rate of pyro-graphite rod at temperature of 1000 $2000^{\circ} \mathrm{C}$ and at oxygen partial pressure of about $0.2 \mathrm{~atm}$, Nagle and StricklandConstable [1962] adapted this "two-site-types" concept with modification and worked out the well-known semi-empirical formula for the carbon surface mass oxidation rate, $w$, in $\mathrm{g} \mathrm{cm}^{-2} \mathrm{~s}^{-1}$ :

$$
\frac{w}{12}=\left[\frac{k_{A} p_{O_{2}}}{1+k_{z} p_{O_{2}}}\right] x+k_{B} p_{O_{2}}(1-x)
$$

Where $x$ is the fraction of the surface occupied by type $A$ site:

$$
x=\left[1+\frac{k_{T}}{p_{O_{2}} k_{B}}\right]^{-1}
$$

$k_{A}, k_{B}, k_{T}$ and $k z$ are the converting related rate constants, which are functions of oxidation temperature:

$$
\begin{aligned}
& k_{\mathrm{A}}=20 \exp (-15,000 / \mathrm{T}), \mathrm{g} \mathrm{cm}^{-2} \mathrm{~s}^{-1} \mathrm{~atm}^{-1} \\
& k_{B}=4.46 \times 10^{-3} \exp (-7,640 / \mathrm{T}), \mathrm{g} \mathrm{cm}^{-2} \mathrm{~s}^{-1} \mathrm{~atm}^{-1} \\
& k_{T}=1.51 \times 10^{5} \exp (-48,800 / \mathrm{T}), \mathrm{g} \mathrm{cm}^{-2} \mathrm{~s}^{-1}
\end{aligned}
$$




$$
k_{Z}=21.3 \exp (2,060), \mathrm{atm}^{-1}
$$

\subsubsection{The Lee oxidation formula}

Lee et al [1962] investigated the theory of chemical kinetics of surface reaction and performed soot combustion experiments in a laminar diffusion flame.

According to the surface reaction kinetics theory that their work was based on, any heterogeneous reaction can be broken down into four steps:

(1) Transport of the reactant to the surface;

(2) Chemisorption of the reactant on the surface;

(3) De-sorption of the products of reaction from the surface;

(4) Transport of the products of reaction away from the surface.

A boundary layer surrounding an oxidising particle offers resistance to the diffusion of reactants to and the products from the particle surface. The thickness of an "effective" boundary layer surrounding the oxidising particle is proportional to the particle size, and this boundary layer is responsible for the diffusion resistance. When the particle is large, the transport resistance to the surface becomes the oxidation-ratedetermining step, that is, the slowest step amongst the above four steps. But for very small particles, the "effective" boundary layer decreases so that the "diffusion resistance" diminishes.

Lee et al used a gaseous hydrocarbon mixture $\left(\mathrm{C}_{3} \mathrm{H}_{8} 70 \%, \mathrm{C}_{2} \mathrm{H}_{4} 10 \%\right.$ and $\left.\mathrm{C}_{3} \mathrm{H}_{6} 20 \%\right)$ as the soot generating fuel in their experiments. The oxidant was oxygen-enriched air. The soot particles were burned at oxygen partial pressures in the range of 0.05 to 0.1 atm and temperatures of 1350 to $1650 \mathrm{~K}$. 
Lee at $e l$. then developed the following semi-empirical equation for soot particle combustion rate:

$$
\frac{\rho d_{0}}{6 m_{0}^{1 / 3} m^{2 / 3}} \frac{d m}{d t}=1.085 \times 10^{4} \frac{p_{O_{2}}}{T^{1 / 2}} \exp \left(-\frac{39300}{R T}\right)
$$

Where

$\rho$ denotes the density of soot, $2 \mathrm{~g} \mathrm{~cm}^{-2}$

$d_{0}$ is the initial diameter of soot, $400 \AA$

$m_{0}$ is the initial soot particle mass flow, $\mathrm{g} \mathrm{s}^{-1}$

$m$ is the soot particle mass flow after time $t, \mathrm{~g} \mathrm{~s}^{-1}$

$p_{O 2}$ is the partial pressure of oxygen, atm

$T$ is the temperature, $\mathrm{K}$

$R$ is the universal gas constant, $\mathrm{cal} \mathrm{g}^{-1} \mathrm{~mol}^{-1} \mathrm{~K}^{-1}$

\subsubsection{Models of oxidation for other oxidants}

Besides reaction rates with $\mathrm{O}_{2}$ as the oxidant, rates with other species such as $\mathrm{OH}$, $\mathrm{CO}_{2}, \mathrm{O}, \mathrm{H}, \mathrm{H}_{2} \mathrm{O}$ have been summarized in the literature by Bradley et al [1984]. Chelliah [1996] listed a number of formulae for oxidation rates of porous graphite with oxidants similar to those listed by Bradley et al.

When carbon is oxidised by more than one oxidants, the total oxidation rate can be described by:

$$
w_{\text {total }}=\sum w_{i}
$$

where $w_{i}$ is the oxidation rate caused by oxidant $i$. 


\subsection{Summary}

Because the soot oxidation rate is important in deciding the final particulate emission level from diesel engines, it is necessary to determine quantitative correlations between diesel soot oxidation rate and the combustion conditions. Despite considerable basic research on soot formation and oxidation, the mechanisms controlling diesel combustion are still inadequately understood. All the previous studies on or related to diesel soot oxidation had at least one of the following limitations:

1. The nature of the carbons used in the studies differed from those of diesel soot.

2. The soot oxidation process co-existed with the soot formation process.

3. The oxidation conditions could not be controlled and varied independently. So, it is still necessary to develop new research techniques for better understanding of diesel soot oxidation. New techniques should be able to:

1. Isolate diesel soot oxidation and measure its value without interference from soot formation;

2. Allow the oxidation conditions to be controlled independently so as to establish the quantitative correlations between the diesel soot oxidation rate and the most important individual oxidation variables, such as temperature and oxidant partial pressure;

3. Control the conditions of the flow of the oxidising gas. 


\section{Chapter 3 Test Rig Design and Instrumentation}

\subsection{Test Rig Design}

\subsubsection{General description}

A test rig was designed for the investigation of soot oxidation under controlled conditions. The basic requirements were:

(a) to oxidize diesel soot while the soot particles were dispersed and in suspension in the oxidizing stream;

(b) to isolate soot oxidation so that only oxidation takes place, without any soot formation being present;

(c) to control the oxidation environment with respect to oxidant partial pressure and oxidation temperature which should reach at least $1800 \mathrm{~K}$;

(d) to measure the oxidation rate and the values of various parameters relating to the oxidation environment.

To achieve the above objectives, an experimental system was set up which had two main sub-systems. The first sub-system consisted of a diesel engine as the soot generator, from which soot laden gas could be extracted either from the exhaust or the engine combustion chamber (see Picture 3-1, 3-2, and 3-3). The second sub-system consisted of a hot gas stream into which the soot-laden gas was introduced and where the soot particles oxidized. The hot gas stream was produced by a flat laminar premixed burner. Associated components included the laminar burner control unit, a soot particle sampling device, and instrumentation for flame temperature, oxygen concentration, and particle velocity measurement (for working out the residence time 
of the soot oxidation). Figure 3-1 shows the overall scheme of the experimental setup. The burner produced a pre-mixed flat flame fed by a methane/air/oxygen/nitrogen mixture. In some experiments, bottled $\mathrm{CO}_{2}$ gas was added to the mixture for the purpose of investigating the effect of $\mathrm{CO}_{2}$ on the soot oxidation.

It was necessary to ensure that all the soot being oxidized came from the engine and that no extraneous soot particles or unburned hydrocarbon species were generated in the laminar burner itself. This was achieved, firstly, by using a lean fuel/oxidant ratio in the burner; secondly, by pre-mixing the fuel and oxidant streams thoroughly by means of the Venturi mixers 1 and 2 (see Figure 3-1 and Picture 3-4). The mixture supplied to the premixed flame always had excess oxygen in order to ensure that the $\mathrm{C} / \mathrm{O}$ ratio of this mixture was always lower than the methane soot formation threshold limit $(C / O=0.45)$ [d'Alessio et al, 1994]. This avoided generation of soot or unburned hydrocarbons from the methane fuel supplied to the burner. In this way, the flat-flame burner was always operating in the pre-mixed lean regime, without generating methane-derived extraneous soot particles and unburned hydrocarbons which could have mixed up with the diesel soot particles introduced in the post-flame gas. The premixed flame itself was always blue and non-luminous; the luminosity only occurred when the diesel soot particles were introduced and being oxidized in the high temperature flame and post-flame gas stream. Pictures 3-5 and 3-6 show, respectively, the difference between the fuel-lean methane flames without any introduced diesel soot particles and with burning diesel soot particles introduced from the diesel engine. The former picture was a blue flame and the later one shows the luminous burning diesel soot particles. 
Likewise, unburned engine-derived hydrocarbons, contained in the exhaust sample, also burned in this lean premixed flame regime without the generation of extraneous soot particles in the burner. The amount of each gas used to form the mixture supplied to the burner was adjusted so as to get the desired oxidant concentration and postflame gas temperature. Diesel soot particles were introduced from either the exhaust pipe or the pre-chamber of the running diesel engine into the burner system, and their oxidation process in the post-flame gas was observed. The soot-laden gas from the engine was actually pre-mixed with the pre-mixed gas mixture fed to the burner, so that only a single overall pre-mixed stream was supplied to the burner. This single stream was actually the fuel/oxidant mixture plus the soot-laden gas from the diesel engine.

Premixing the soot-laden gas from the engine with the fuel/oxidant stream had several advantages. For example, this arrangement ensured that the temperature of the premixed soot-laden-gas/fuel/oxidant mixture rose almost instantly as it passed through the flame front. As a consequence, on passing through the flame, the soot particles were surrounded, within a few millimetres above the flame, by the postflame gas stream which had both a uniform temperature distribution and uniform composition. Because the laminar flame front was very thin (few millimetres), the soot particles readily survived their passage through the flame. An alternative approach would have been to introduce the soot-laden gas stream into the post-flame gases above the flame. This approach would have had several disadvantages, as follows. Computational fluid dynamics analysis showed that the exhaust stream would have traveled a considerable distance above the flame before becoming thoroughly mixed with the post-flame gases and attaining a uniform temperature and 
mass distribution. Thus, during this mixing period, the individual soot particles would have been burned considerably in an unknown local atmosphere of highly variable oxygen concentration and temperature distribution.

Returning to Figure 3-1, the oxidant/fuel mixture was prepared by mixing compressed dried air with bottled methane gas. Bottled oxygen and nitrogen could be added to the soot-laden-gas/methane/air mixture, so as to increase or decrease the oxygen concentration of the mixture burned at the flat flame. In this way, the oxygen concentration in the post-flame gases was adjusted to any desired value from zero to $10 \%$ or more. The temperature of the post-flame gases was controlled independently of the oxygen concentration, by carefully metered increases in both the bottled oxygen and nitrogen flow rates. This had the effect of increasing the fuel dilution and lowering the flame temperature, without altering the oxygen concentration in the postflame gases.

The details of each part of the test rig are described in the following sections.

\subsubsection{The diesel engine used to produce soot}

The diesel engine, as shown in Picture 3-1, was a single cylinder, naturally aspirated, pre-chamber design manufactured by Waukesha Engine Division, Dresser Industries, Inc. (CFR model F-5). The engine was operated at its rated speed of $900 \mathrm{r} / \mathrm{min}$ and at near full load conditions. The specifications of the engine are shown in table 3-1. Commercial diesel fuel for road vehicles was used for all tests (see table 3-2 for specification).

A large chamber was installed in the engine exhaust pipeline to dampen pressure fluctuation in the exhaust flow. When exhaust soot was investigated, a $5 \mathrm{~mm}$ inner- 
diameter probe was immersed in the exhaust gas stream, downstream of the engine exhaust damping chamber (see Figure 3-1 and Picture 3-2), for the purpose of extracting exhaust soot and introducing it to the burner system. The probe was connected to the Venturi-type mixer 2 (see Figure 3-1) through a heated sample line, which was kept at $190^{\circ} \mathrm{C}$ in all tests to prevent water and gaseous hydrocarbon compounds in the soot-laden gas from condensing in this sample line (see Picture 32).

Also, a high-speed, timed sampling valve was installed in the pre-chamber of the engine and used for extraction of diesel soot from the engine combustion chamber. The opening timing of this sampling valve was electronically controlled so as to occur at a pre-determined crank angle during the combustion period, the valve remaining open for around $3^{\circ}$ crank angle. Further details on the sampling valve have been reported elsewhere [Zhao et al, 1996]. In this study, the electronic control system of the valve was modified to allow digital control of the opening timing of the valve, which could be set and read directly in degrees crank angle. The digital control unit also controlled the opening duration of the valve. When soot was extracted from the combustion chamber, the exit of the sampling valve was connected to the heated line mentioned above (see Picture 3-3), which directed the soot-laden gas sample to the laminar burner via the Venturi mixer (see Picture 3-4).

\subsubsection{The burner system used to oxidize the diesel soot}

The burner system consisted of a flat flame burner with associated gas mixing system and a quartz duct containing the post-flame gases. A burner traverse device was constructed for gas sampling and used for measurement of gas temperature and composition and soot particle velocity at various positions above the flame. A probe 
and thermocouple assembly was constructed and used for simultaneous gas sampling and temperature measurement. A filter unit was used to collect soot sample.

\subsubsection{Burner}

The flat-flame methane burner was made of a brass disc, having an outside diameter of $50 \mathrm{~mm}$ and a thickness of $10 \mathrm{~mm}$. The central region of this disc, up to a radius of $19 \mathrm{~mm}$, was perforated with 225 uniformly distributed holes of $0.8 \mathrm{~mm}$ diameter each, which helped straighten the mixture flow. The manufacturing drawing of the burner disc is shown in Figure 3-2.

The burner was water-cooled. The burner assembly, including the cooling arrangement, is shown in Figure 3-3.

The following calculation shows that the premixed gas flow in the burner holes was in the laminar flow regime.

Assuming the temperature of the burner disc is kept at $300 \mathrm{~K}$ (laboratory water at about $300 \mathrm{~K}$ was used as coolant), and the mixed gas passing through the burner disc holes is an ideal gas, its density is approximately the same as that of air, and the pressure of the mixture passing through the holes is approximately atmospheric at 1 bar.

The density of the mixture $\rho=1.161 \mathrm{~kg} \mathrm{~m}^{-3}$ (at $1 \mathrm{bar}, 300 \mathrm{~K}$ )

The dynamic viscosity $\mu=1.846 \times 10^{-5} \mathrm{~kg} \mathrm{~m}^{-1} \mathrm{~s}^{-1}$

The diameter of the burner holes $d=0.8 \mathrm{~mm}$

Using a typical flowrate of the mixed gas through the burner disc of $6 \mathrm{~L} \mathrm{~min}^{-1}$, gives the gas velocity in the holes $V=1.6 \mathrm{~m} \mathrm{~s}^{-1}$; then the Reynolds number $(\mathrm{Re})$ is: 
$R e=d V \rho / \mu=81$, which is much smaller than the laminar to turbulent transition value of around 2000 . So, the flow in the burner holes is laminar.

The length for full development of laminar flow, $x$, can be calculated as: $x=0.06 \mathrm{dRe}=$ $3.9 \mathrm{~mm}$, which is considerably smaller than the $10 \mathrm{~mm}$ length of each burner hole.

The reaction zones above each tiny hole merged so as to form a blanket of flat flame. The thickness of the flat flame was so small that no long enough residence time available for the soot particles to change their properties while traveling through the flame.

\subsubsection{Quartz soot oxidation duct}

As can be seen in Figure 3-3 and Pictures 3-5 and 3-6, the flat flame and post-flame gases above the flame were contained within and shielded by a $54 \mathrm{~mm}$ inner diameter, $250 \mathrm{~mm}$ long, quartz tube. This tube prevented the flame, and particularly the central part of the post-flame gas stream, from being affected by entrainment of the surrounding laboratory air. The gap between the quartz tube and the seat on the burner was sealed with silicon rubber compound. A cone-shaped cap made of ceramic tape was positioned at the exit of the quartz tube above the flame so as to avoid air entrainment that might have been caused by convection currents near the exit of the quartz tube. The cone shaped cap had a hole of $20 \mathrm{~mm}$ diameter which allowed the combustion gases to escape to the atmosphere while at the same time allowed the probe-and-thermocouple assembly (described in later sections) to be insert as shown in Pictures 3-5, 3-6, and 3-7. The cap could be re-located along the quartz tube when necessary. 
The transparent wall of the quartz tube allowed the beams of the laser Doppler anemometer to traverse the flame and measure the velocity of the diesel soot particles traveling with the post-flame gases inside the quartz tube.

\subsubsection{3-D burner traverse system}

The burner, together with the quartz tube, were placed on a 3-D traverse system and thus could be moved in three dimensions so as to allow the rigidly mounted sampling probe-and-thermocouple assembly and laser beams to move radially and vertically in the post-flame gas stream in the quartz tube. The traversing distances of the burner in three dimensions were monitored from graduated scales on the traversing system. Each scale had a resolution of $1 \mathrm{~mm}$.

\subsubsection{Gas supply and mixing system}

Refering to Figure 3-1, methane, oxygen and nitrogen (and/or carbon dioxide in some experiments) from compressed gas cylinders were supplied via high pressure regulators to the burner, and their flow rates were controlled with three needle valves. These gases were fed to the Venturi mixer 1 (see Figure 3-1). Laboratory compressed air was also supplied to the mixer 1 after being dried with a silica gel dryer.

Mixer 1 ensured that the gases mixed thoroughly. Downstream of mixer 1 was another Venturi mixer 2, which was connected to the heated line that introduced soot from either the exhaust pipe or the pre-chamber of the diesel engine.

The design of the two identical mixers 1 and 2 was based partly on Venturi orifice principles and the mixers were made in the departmental workshop. Figure 3-4 shows the assembly plan of the mixers. The flammable fuel/oxidant mixture flows through jet $\mathrm{A}$ and emerges from the mixer as jet $\mathrm{B}$. The nozzle in jet $\mathrm{A}$, with its decreasing 
diameter, causes a rise in the flow velocity and, consequently, a pressure decrease in the annular low-pressure chamber. Thus, soot-laden gas is sucked into this chamber via inlet $\mathrm{B}$. The diameter of the jet $\mathrm{A}(1.2 \mathrm{~mm})$ was about half that of the jet $\mathrm{B}(2.5$ $\mathrm{mm})$. The secondary gas, sucked in through inlet $\mathrm{B}$, is thoroughly mixed with the primary gas from jet A (see Figure 3-4). By carefully adjusting the gap of the conical passage between jet $A$ and jet $B$, it was ensured that a sufficient suction action was always maintained at inlet $B$.

Mixer 2 was positioned downstream of mixer 1 and it was connected to the heated line that introduced soot-laden gas from either the engine exhaust pipe or the engine pre-chamber. A flow control valve allowed the flow rate of the soot-laden gas supplied to mixer 2 to be regulated. Two electrical cartridge heaters installed in mixer 2 heated the mixer and the flow control valve so as to avoid water condensation and loss of soot particles, and blockage by soot.

\subsubsection{Sampling-probe/thermocouple assembly}

A probe was designed for sampling diesel soot particles from the post-flame gas stream above the burner. The probe consisted of two concentric stainless steel tubes. The innermost tube had inner and outer diameters of 3 and $4 \mathrm{~mm}$ respectively. The outermost tube had inner and outer diameters of 5 and $7 \mathrm{~mm}$ respectively. Cooling water ran through the annular gap between the two tubes to cool the probe and quench the oxidation of the soot particles when sucked into the probe. The probe tip was cone-shaped to minimise the disturbance to the post-flame gas flow. The sampling flow rate could also be adjusted to minimise the influence of the sample flow on the flame and the post-flame gas stream flowing past at the probe inlet. 
A Pt/13\%/Rh-Pt type $\mathrm{R}$ thermocouple with exposed junction and made of wires with diameter of $75 \mu \mathrm{m}$ was assembled together with the probe. At short distance from the thermocouple tip, the thermocouple wires were shielded by a stainless steel tube with inner diameter $2 \mathrm{~mm}$ and outer diameter $3 \mathrm{~mm}$, within which the wires were electrically insulated by means of a ceramic material. The thermocouple stainless steel shield tube was fixed beside the sampling probe (See Figure 3-1 and 3-5), with the thermocouple bead being a few millimeters below the gas sampling probe tip.

At about $20 \mathrm{~mm}$ downstream of the gas sampling probe was the filter holder, where the soot extracted from the post-flame gas stream was separated from the post-flame gas, and collected onto special small copper grids used for electron microscopy.

\subsubsection{Filter holder and copper grid}

Figures $3-6$ to $3-8$ show the filter holder assembly and the component design drawings. The filter holder was designed by the author and made of aluminum. It was composed of an upper part and a bottom part. When sampling was taking place, sootladen post-flame gas was sucked through the filter holder by a vacuum pump and soot particles were deposited onto small copper grids attached to a glass fibre filter. Two $20 \mathrm{~W}$ cartridge heaters were embedded in the upper part of the holder to keep the holder hot enough to avoid water condensation on the copper grids. The copper grids were of $3 \mathrm{~mm}$ in diameter, coated with carbon film and they were needed for TEM microscopy. The soot particles settling onto the copper grids were subsequently analyzed by means of TEM microscopy and computer software, described in later sections in this thesis. 


\subsection{Instrumentation}

\subsubsection{Oxygen concentration measurement}

The oxygen concentration of the gases entering the sampling probe was measured using a Cussons Lamdascan ( $\lambda$-scan) unit. This instrument was designed to measure oxygen concentration and, also, to estimate the air/fuel ratio. For the latter quantification, a catalyst was built inside the instrument to burn out any residual unburned fuel. However, in the case of the investigation described here, the presence of this catalyst could have caused errors in oxygen concentration measurement above the flat flame. These errors could have arisen due to the consumption of a small amount of oxygen in the catalyst for the oxidation of any unburned residual fuel escaping from the flat flame. This small amount of oxygen would have been present for soot oxidation in the post flame gases but would not have been measured by the instrument. In order to avoid such errors, the catalyst was removed.

Relevant specifications of the Lamdascan Control Unit are shown in Table 3-3.

As an example of the measurement of oxygen partial pressure, Figure 3-9 shows the measured values of oxygen partial pressure along the centreline of the oxidation quartz tube. The data were from the oxidation tests for diesel soot extracted from the engine exhaust. Before the ceramic cap was made and applied in the quartz tube, the measured oxygen partial pressure was found to increase slightly with the height above the burner along the quartz tube centreline, as shown by the diamond symbols in Figure 3-9(a) for test Exh-1. This was due to air entrainment from the top of the tube. Positioning the ceramic cap at the exit of the quartz tube minimized this increase in oxygen partial pressure with height above the burner. Because the amount of diesel 
soot in the oxidising gas stream was very small, the consumption of oxygen during the soot oxidation process was very little. For this reason, the oxygen partial pressure is seen to be nearly unchanged along the centreline of the quartz oxidiser, as shown by the other symbols in Figure 3-9(a) for the other tests.

\subsubsection{Carbon dioxide measurement}

$\mathrm{CO}_{2}$ concentration was measured using an OLIVER K650 non-dispersive infra-red (NDIR) analyzer. Its $\mathrm{CO}_{2}$ measurement range is $0-20 \% \mathrm{CO}_{2}$ volume fraction, with $0.1 \%$ display resolution, and the maximum permissible error $\pm 0.5 \%$ vol. or $\pm 0.5 \%$ of the maximum measurable value (whichever greater).

The flow rate required by the $\mathrm{K} 650$ Emissions Analyzer measurement is about 5 litres $\min ^{-1}$. Such a high flow rate would have disturbed the burner. So, in order to avoid this problem, $\mathrm{CO}_{2}$ was not sampled and fed to the analyzer in real time. Instead, postflame gases were sampled at a lower rate than 5 litres $\min ^{-1}$, simultaneously with sampling of particulates. This post flame gas sampled at lower flow rate was stored in a PTFE sample bag of 10-liter volume for subsequent analysis with the OLIVER $\mathrm{K} 650$ analyser. The sampling bag had an inlet and an outlet. Its inlet was connected to the exit of the burner vacuum pump that extracted the post-flame gases for diesel soot particle analysis (Figure 3-1) and its outlet to the K650 analyzer. Before sampling, the inlet of the sampling bag was closed and its contents were emptied by the K650 analyzer vacuum pump. The connection between the bag and the analyzer was then closed and its inlet from the burner vacuum pump opened. This allowed the sampled post-flame gas from the burner to be pumped into the sample bag by the burner vacuum pump while, simultaneously, the soot particles were deposited on the copper 
grids in the filter holder (see Figure 3-1). When enough gas had been stored in the bag, the bag inlet was closed and its outlet connection to the analyzer was opened so that the $\mathrm{CO}_{2}$ concentration was measured by the $\mathrm{K} 650$ analyzer.

As in the case of the oxygen partial pressure, the $\mathrm{CO}_{2}$ partial pressure was also approximately constant along the quartz tube centerline.

\subsubsection{Temperature measurement}

A Pt/13\%/Rh-Pt type $\mathrm{R}$ thermocouple with exposed junction and $75 \mu \mathrm{m}$ diameter wires was used for temperature measurement. The design of this thermocouple has been described previously in section 3.1.5. Heat conduction lost via the $75 \mu \mathrm{m}$ wires can be neglected [Mcenally et al, 1997]. The actual temperature was calculated by correcting the temperature measured by the thermocouple for heat lost by radiation from the junction bead, using the equation below [Fristrom, 1995].

$$
T_{g}-T_{j}=\frac{\operatorname{cod}\left(T_{j}^{4}-T_{w}^{4}\right)}{2 \lambda}
$$

where $T_{g}$ is the gas temperature, $T_{j}$ is the temperature of the thermocouple junction, $T_{w}$ the temperature of the surrounding walls, $\varepsilon$ the emissivity of the thermocouple junction, $\sigma=5.67 \times 10-8 \mathrm{~W} \mathrm{~m}^{-2} \mathrm{~K}^{-4}$ the Stefan-Boltzmann constant, $\lambda$ the thermal conductivity of the gas. The above equation originates from the energy balance for the thermocouple bead, whereby the heat transfer by convection to the bead is balanced by heat transfer from the bead by radiation. The value of the Nusselt number for the bead was taken to be equal to 2 due to the low Reynolds number for the flow past the bead (Reynolds number calculated to be in the range 0.6 to 2.3 from measured flow velocities using LDA and measured diameter of the thermocouple bead) [Cengel, 
1998]. Manipulation of the energy balance equation gives equation (3-1) above [Fristrom, 1995].

The emissivity of the bead of the $\mathrm{Pt} / 13 \% / \mathrm{Rh}-\mathrm{Pt}$ thermocouple can be calculated using the following formula, which was regressed from the experimental data listed in Caldwell's report [Caldwell et al, 1962].

$$
\varepsilon=9.4962 \times 10^{-5} T+2.8415 \times 10^{-2}
$$

where $T$ is the temperature of the thermocouple bead in $\mathrm{K}$.

Examples of the measured temperature profiles in the quartz oxidizer are illustrated in Figure 3-9(b). Due to heat transfer through the walls of the quartz tube, the temperature of the post-flame gas stream dropped with the height above the burner. The temperature drop over the height range of $20 \mathrm{~mm}$ was in the range of $54-93 \mathrm{~K}$. This temperature drop was taken into account in the calculation of the predictions using the Nagle and Strickland-Constable formula and the Lee formula, when comparing the experimental results with the predicted data. This is described in a later section 4.6.

Temperatures along the radius of the quartz duct section were also measured. Figure 3-10 shows typical profiles of the temperatures along the quartz tube radius at different heights above the burner. It can be seen that the temperature change was small within $\pm 3 \mathrm{~mm}$ of the tube centreline. This means that small deviation of the thermocouple bead and the tip of the soot-sampling probe from the quartz tube centreline could be tolerated without significant error in the measured results. Nevertheless, during the experimental programme, attention was always paid to 
maintaining the thermocouple and sampling probe inlet along the quartz tube centreline.

\subsubsection{Particle velocity measurement with laser Doppler anemometry}

The soot particle velocity in the oxidizing post-flame gas is a critical parameter for the investigation of the time that the soot particles were subjected to oxidation. By measuring the particle velocity between two successive sampling points, the oxidation period could be obtained. Having measured the reduction in the soot spherule diameter between these sampling points, this oxidation period allowed the oxidation rate of the soot spherule to be determined. The Laser Doppler Anemometry (LDA) technique was employed for the particle velocity measurement. The laser employed for velocity measurement in this work was a $400 \mathrm{~mW}$ argon ion laser system supplied by DANTEC Electronics Ltd.

Since the diesel soot particulates were small (the exhaust soot spherule size ranged from $10 \mathrm{~nm}$ to $80 \mathrm{~nm}$ and the clusters were a few micrometers), the light scattering of the particulates could not be detected reliably at the higher positions above the burner, when the particulates burnt quickly under oxygen-rich conditions. For this reason a small amount of titanium dioxide $\left(\mathrm{TiO}_{2}\right)$ powder was added upstream of the burner for brief periods when a reliable velocity measurement was needed. When needed, the $\mathrm{TiO}_{2}$ powder was added into the gas mixture flow which was supplied to the burner, by gently tapping a tiny container so that the flame and the post-flame gas stream would not be disturbed. The size of the $\mathrm{TiO}_{2}$ powder particles were around 400 to $1000 \mathrm{~nm}$ (see Picture 3-8) but not bigger than 5 microns. According to Stoke's law [Lowell and Shields, 1991] both the diesel soot particles and the $\mathrm{TiO}_{2}$ particles were 
able to follow the gas flow in the flame accurately (without slip) under the conditions in this study. Also, since the $\mathrm{TiO}_{2}$ particles were much bigger than the primary diesel soot spherules, they could not be confused with diesel soot in soot image analysis (see Picture 3-8). Moreover, measurement of soot particle velocity was usually carried out after the sampling process had finished.

Measured soot $\left(\mathrm{TiO}_{2}\right)$ particle velocity profiles can be seen in Figure 3-9(c). The soot particle velocity decreased slightly with the height above the burner due to the cooling down of the post-flame gas stream. This decrease in soot particle velocity was taken into account when calculating the residence time of the diesel soot particles travelling between two successive sampling positions.

The gas velocity was also measured radially at various heights above the burner. However, the radial velocity component of the flow was found to be very close to zero, implying that the flow in the measurement region was predominantly along the flame axis and, therefore, laminar. This is confirmed by the calculation below which shows that the post-flame gas flow in the quartz tube was laminar. The determination about the flow type in the burner oxidizer is discussed in section 3.3.

The measured temperature of the post-flame gas ranged from 1500 to $1850 \mathrm{~K}$.

The measured post-flame gas velocity was no higher than $4 \mathrm{~m} \mathrm{~s}^{-1}$.

The density of the post-flame gas (using dry air properties) $\rho_{8}=0.2353 \mathrm{~kg} \mathrm{~m}^{-3}$ (at 1 bar, $1500 \mathrm{~K}$ ) and $0.1910 \mathrm{~kg} \mathrm{~m}^{-3}$ (at $1 \mathrm{bar}, 1850 \mathrm{~K}$ ).

The dynamic viscosity $\mu=5.264 \times 10^{-5} \mathrm{~kg} \mathrm{~m}^{-1} \mathrm{~s}^{-1}$ (at $1 \mathrm{bar}, 1500 \mathrm{~K}$ ) and $5.919 \times 10^{-5}$ $\mathrm{kg} \mathrm{m}^{-1} \mathrm{~s}^{-1}$ (at $\left.1 \mathrm{bar}, 1850 \mathrm{~K}\right)$.

The inner diameter of the quartz tube $D=54 \mathrm{~mm}$ 
$R e=\mathrm{D} V \rho / \mu \leq 965($ at $1500 \mathrm{~K})$ or $\leq 697($ at $1850 \mathrm{~K})$

Both these values are well below the $\operatorname{Re}$ transition value of 2000 .

So, the flow in the quartz tube was laminar at between 1500 and $1850 \mathrm{~K}$.

\subsubsection{Particle sizing and morphology}

Post-flame gas, carrying burning diesel soot particles, was sucked through the watercooled probe and the filter system (described previously in sections 3.1.5 and 3.1.6). Diesel soot particles were collected on special ( $3 \mathrm{~mm}$ diameter) copper grids for TEM microscopy using a JEOL 2000FX Transmission Electron Microscope. The pictures of diesel soot particles were then analyzed using the computer software ImagePro Plus 4.0 and Microsoft Excel to get soot spherule size distributions. In order to obtain soot spherule size distribution, it was found that the size of at least 600 randomly selected spherules was needed. Beyond a sample size of 600 spherules, the size distribution remained relatively unaltered. Nevertheless, in order to ensure reliable soot spherule size distributions, sample size of around 1000 spherules were measured for each experiment carried out.

\subsection{Estimation of the Distances between the Diesel Particle Clusters in the Burner Post-flame Gas and Determination of the Gas Flow Type}

If the burning diesel soot particles are not to interfere with each other, it is necessary for them to have an adequate distance between neighboring particles. Table 3-4 shows that an average distance of $2.79 \times 10^{4} \mathrm{~nm}$ was available between the neighboring diesel soot clusters in the post-flame gas above the burner. Even if all of the clusters were to contain as many as 4000 primary soot spherules with volume mean diameter 
of $31 \mathrm{~nm}$ [Heywood, 1988], this distance would still be about 57 times the size of the clusters. That means the particle clusters had very little chance to collide with each other, or, in other words, the oxidation process of each soot particle cluster was very unlikely to be disturbed by other clusters. However, it should be pointed out that the oxidation of individual spherules within a particulate cluster could have been influenced by oxidation of other spherules in the same cluster.

The long distance between the neighbouring soot particles also guarantees that there is always sufficient oxidant available at the soot particle surface for oxidation. This is evidenced by the constant measured oxygen and $\mathrm{CO}_{2}$ concentration profiles along the burner oxidizer central line.

Turbulent flow plays an important role in improving combustion in diesel engines. In the soot oxidation phase, it helps in-cylinder soot oxidation by enhancing the mixing the soot particles with fresh air, to enable the particles to burn with sufficient surrounding oxidants. In other words, turbulent flow acts as a soot oxidation enhancer on a relatively macroscopic scale, compared with the soot particle size.

Looking at a single soot particle on a microscopic scale, its surface-burning rate is usually determined by both kinetic control and diffusion control. When a particle is below $1 \mu \mathrm{m}$, the molecular diffusion resistance in the gaseous phase around the particle surface is minimal and soot oxidation is only kinetically controlled [Amann et al, 1980; Lee et al, 1962]. Measurements [Pischinger, et al, 1994; Pungs et al, 2000] have shown that all most all the diesel soot particles in the engine cylinder are no bigger than $1 \mu \mathrm{m}$. Therefore, the flow type of the surrounding oxidant does not affect the oxidation rate of a diesel soot particle. The soot particle surface oxidation rate is determined by the partial pressures of the surrounding oxidants and the oxidation 
temperature, assuming they uniformly distribute on the soot particle surface in all the direction. This assumption is analogous to the assumption for a single spherical fuel droplet burning in turbulent flame, which cab be modelled as an ensemble of laminar flames [Warnatz et al, 1999].

In this study, as already discussed previously, the diesel soot particles sampled from the engine were diluted to a very low concentration in the oxidizing gas flow in the burner oxidizer. The distance between neighbouring particles was big enough and the oxidant concentration was high enough to guarantee sufficient oxidant available for each particle to oxidize throughout the oxidation process. Under this precondition, oxidizing gas flow type has no influence on the oxidation rate of the diesel soot particles. A laminar flow in the burner oxidizer was chosen mainly due to the considerations of suitable gas flow velocity and gas supply amount. 


\section{Chapter 4 Experimental Methodology}

\subsection{General Procedure}

In order to investigate the oxidation rates of the diesel soot, the following procedure was carried out for each test run:

a) Setting and measuring the oxidation conditions

b) Sampling diesel soot particles from different heights above the burner

c) Measuring soot spherule size and obtaining size distributions

d) Calculating soot spherule diameter recession rate and oxidation rate

In addition, the experimental data for soot oxidation rate were compared with the predictions by the Nagle and Strickland-Constable formula and the Lee formula, which have been mentioned previously.

\subsection{Setting and Measuring the Oxidation Conditions in the Oxidation Burner}

As described in chapter 3, the oxygen concentration and the temperature in the postflame gas could be set independently as desired, by controlling the supply rates of the various gases, including that for the diesel soot laden gas from the exhaust pipe or the pre-chamber of the diesel engine. In a few tests, additional bottled $\mathrm{CO}_{2}$ gas was added to the pre-mixed gas to observe the effect of $\mathrm{CO}_{2}$ partial pressure on diesel soot oxidation.

Methods for measuring $\mathrm{O}_{2}, \mathrm{CO}_{2}$, temperature, and soot velocity have already been described in chapter 3 . 
Since the post-flame gas in the quartz tube was very close to the atmosphere pressure, the partial pressures of $\mathrm{O}_{2}$ and $\mathrm{CO}_{2}$ could be determined from the measured concentrations in the quartz tube.

\subsection{Sampling Soot Particles from the Post-Flame Gas Flow in the Burner}

In each test, diesel soot particles were sampled from two different heights above the burner exit. The distance between the two heights varied from 15 to $20 \mathrm{~mm}$. The time for the soot particles traveling from the lower height to the upper height ranged from 5 to $17 \mathrm{~ms}$. The soot-laden gas sampled above the burner flame passed through the filter in the filter holder (section 3.1.6, figure 3-1), where some of the diesel soot particles deposited onto the small ( $3 \mathrm{~mm}$ diameter) copper grids which were attached on the glass fibre filter, for TEM analysis.

\subsection{Measuring Soot Spherule Size Distributions}

In order to measure specific surface oxidation rate of a soot spherule, it is necessary to first measure its size before and after oxidation. However, not all diesel soot spherules are of the same size; most soot spherules have diameters in the range of 10 to $80 \mathrm{~nm}$. Therefore, in order to measure the soot oxidation rate, it is first necessary to measure the size distributions of the soot spherules both before and after oxidation.

Existing techniques for determining particle size, and size distributions, include transmission electron microscopy (TEM), scanning mobility particle sizing (SMPS), electrical aerosol analysis (EAA), field-flow fraction (FFF), photon correlation spectroscopy (PCS), etc. [Abdul-Khalek et al, 1998; Barth and Flippen, 1995; Kim et al, 1999; Lee et al, 1996] 
TEM has a unique advantage over all other techniques in that it provides images of soot particles from which the size of individual primary soot spherules can be estimated. A major disadvantage of this technique is that it is very tedious and timeconsuming.

The other techniques cited above rely on correlating the size of the particles with a physical characteristic of the particle, such as its mass, or electrical charge, or optical cross section. They are generally substantially less time-consuming than the TEM technique. For instance, SMPS can complete a particle size distribution measurement in as little as 30 seconds, although a few minutes is more typical [Abdul-Khalek, 1998]. However, unlike TEM, none of these techniques is able to distinguish individual primary spherules from the clusters and chains which contain the spherules. Although the smallest size these non-TEM techniques can measure can be as small as $3 \mathrm{~nm}$, almost all diesel soot spherules exist within clusters and chains. Therefore, what these techniques measure is, in fact, a fictitious "size" or "equivalent diameter" of the diesel soot clusters and chains. As a result, they are not suitable for accurate determination of the soot oxidation rate. Their application to oxidation rate measurement would have given highly inaccurate and misleading results.

Along with the developments in the optical diagnostic techniques in recent years, the Laser-induced incandescence (LII) technique has been found useful in quantitative on-line measurement of the size of primary diesel soot spherules in the soot aggregates, even under very low sooting conditions [Schraml et al, 1999; Tree and Foster, 1994; Vander Wal, et al, 1999]. Wander Wal et al [1999] achieved good agreement between the predicted primary particle size based on the LII signal and 
TEM measurements within the oxidation region (high axial positions) of an ethylene gas-jet diffusion flame.

Apparently, the size measured so far using this technique is the mean diameter of the soot spherules within the clusters. There are still difficulties in acquiring accurate size distributions of primary diesel soot spherules whose sizes vary from 10 to $80 \mathrm{~nm}$.

After careful consideration, the TEM technique, which is available at Brunel University, was chosen for measuring diesel soot spherule size distributions and surface oxidation rates.

The TEM pictures of the soot particles collected on the copper grids were taken with a JEOL 2000FX Transmission Electron Microscope (TEM) with magnitude of 80k $120 \mathrm{k}$ in most cases.

The primary diesel soot particles were basically spherules. The diameter of the individual soot spherules on the TEM pictures was measured by means of ImagePro Plus 4.0 computer software. For each spherule, the software measured, repeatedly, its diameter at two-degree intervals, each diameter passing through the centroid of the spherule's image; thus, 90 diameters were measured and the average spherule diameter was then calculated. The diameter of around 1000 individual spherules was measured at each sampling position above the burner. This allowed the size distribution of the soot spherules at each sampling position to be plotted.

Because the computer software was not able to distinguish overlapping spherules, the outline of the spherules had to be drawn with a mouse manually by the author of this thesis. This was a very time-consuming and tedious task. Usually, it took several days to manually trace around 1000 spherules and work out their size distribution. 


\subsection{Calculating Spherule Diameter Recession and Oxidation Rates}

For each test, the primary diesel soot spherules sampled at different heights above the burner had different size distributions. Figure 4-1 shows typical diesel soot spherule size distributions along the burner centerline at 10 and $30 \mathrm{~mm}$, respectively, above the burner flame. It can be seen that at the higher sampling position, oxidation caused the peak of the size distribution density to shift to a smaller spherule diameter and the range of the distribution density curve to become narrower. Correspondingly, the cumulative spherule size distribution curve moved to smaller sizes as well. This indicates that the size of the spherules became smaller due to oxidation when traveling upwards in the post-flame gas.

Since the diesel soot spherules were not of uniform size, small spherules could burn away completely in the hot post-flame gas, somewhere between two consecutive sampling heights. If this occurred, the number mean diameters of the spherules sampled from different flame locations could not represent the recession in the diameters of the soot spherules and, thereby, the soot oxidation rate. Complete burn out of smaller spherules is the most probable reason why some other researchers reported that the mean spherule diameter could increase with soot concentration decreasing [Kadota and Henein, 1981; Prado et al, 1976]. For this reason, a new methodology has been developed in this thesis, which allowed for the disappearance of smaller spherules due to complete burnout between two successive measuring heights along the flame centerline. An explanation of this methodology follows. Firstly, a new term "diameter recession" needs to be defined. This is defined as "the reduction in the diameter of a soot spherule due to its oxidation". The methodology relied on working out the mean recession in diameter of soot spherules due to 
oxidation, by comparing two different spherule size distributions that corresponded, respectively, to two sampling positions above the burner. Therefore, the two sampling positions of different heights above the burner can be defined as the start and end points of an oxidation period, respectively. Soot spherules sampled from each position had a statistical size distribution.

For a spherical particle, the mass-burning rate per unit surface area $\left(\mathrm{g} \mathrm{cm}^{-2} \mathrm{~s}^{-1}\right)$ can be converted to a diameter recession rate, and vice versa [Heywood, 1988]. When soot spherules are smaller than $1 \mu \mathrm{m}$, the molecular diffusion resistance in the gaseous phase around the spherule surface is minimal and soot oxidation is kinetically controlled [Amann et al, 1980]. Typically, as described previously in this thesis, most of the diesel soot spherules are smaller than $80 \mathrm{~nm}$. Therefore, it can be assumed that the specific mass oxidation rate of the diesel soot spherules is kinetically controlled and it is independent of their diameter (i.e., oxidation is a surface phenomenon with a rate that is independent of diameter). The diameter recession rate will, therefore, be independent of diameter as well (i.e., every soot spherule at a given height above the flame undergoes the same recession rate in diameter during the same oxidation period). Thus, the size distribution measurcd at the end point of the oxidation period (i.e., at the upper height sampled) can be deemed to have been transformed from the distribution corresponding to the start point (i.e., at the lower height sampled) because of oxidation and diameter recession. This means that there exists a mathematical relationship between the two statistical distribution functions, whatever the form of the functions might be. Diesel soot spherule size distributions can be described as lognormal [Lahaye and Prado, 1981; Neoh et al, 1981; Vuk et al, 1976]. However, it is quite complex to estimate the parameters in the lognormal distribution functions, and, 
furthermore, the calculation of the diameter recession using these functions is difficult. It is simpler to work out the diameter recession of soot spherules directly from the plots of the measured size distributions. The steps of the method are as follows:

Referring to figure 4-2, let

$d$ be the diameter of any detectable primary soot spherule.

$d_{\min }$ the diameter of the smallest detectable spherule; in this project $d_{\min }$ was taken as $5 \mathrm{~nm}$ (the resolution of TEM images was $3 \mathrm{~nm}$ ).

$\Delta d$ the recession in diameter of an individual soot spherule.

$F_{l}(d)=$ (number of detectable spherules whose diameter $\left.\leq \mathrm{d}\right) /($ total number of detectable spherules) at sampling height 1.

$F_{2}(d)=$ (number of detectable spherules whose diameter $\left.\leq \mathrm{d}\right) /($ total number of detectable spherules) at sampling height 2 .

Assuming that the specific surface oxidation rate of the soot spherules is independent of their size, and subsequently every soot spherule has the same reduction in diameter during the same oxidation period, then, statistically, $F_{2}(d)$ can be deemed to have been converted from $F_{1}(d)$ due to oxidation. Thus they can have the following relationship:

$$
F_{2}(d-\Delta d)-F_{2}\left(d_{\min }\right)=\frac{F_{1}(d)-F_{1}\left(d_{\min }+\Delta d\right)}{1-\left[F_{1}\left(d_{\min }+\Delta d\right)-F_{1}\left(d_{\min }\right)\right]}
$$

Since any spherules whose diameter is smaller than $d_{\min }$ are undetectable, $F_{l}\left(d_{\min }\right)=$ $F_{2}\left(d_{\min }\right)=0$. Equation (A-1) can be rewritten as 


$$
F_{2}(d-\Delta d)=\frac{F_{1}(d)-F_{1}\left(d_{\min }+\Delta d\right)}{1-F_{1}\left(d_{\min }+\Delta d\right)}
$$

Theoretically, there exists a $\Delta d$ that satisfies the equation 4-2, corresponding to any value of $d$ within the soot spherule size range. In practice, due to variation, the $\Delta d$ that satisfies the above equation could vary when different values of $d$ are used in the equation. In this case an average value of the $\Delta d$ s should be calculated for a few $d$ values.

Based on the above analysis, a computing program in Visual Basic, which used trialand-error approach, was edited and used to calculate the average $\Delta d$.

Based on the experimental soot spherule diameter recession rates, by assuming the spherules did not contact each other and have a density of $2 \mathrm{~g} \mathrm{~cm}^{-3}$, the corresponding specific surface oxidation rate was determined as:

$$
w=-\frac{\rho \Delta d}{2 \Delta t}
$$

The error caused by the assumption that "the spherules did not contact each other" and possible differences in density between the pre-chamber soot and the exhaust soot will be discussed in later sections of this thesis.

Also, a relationship between the mass concentrations and the spherule size distributions can be set up as follows:

Let $\mathrm{C}_{\mathrm{N} 1}$ and $\mathrm{C}_{\mathrm{N} 2}$ be the soot spherule number concentrations at height 1 and height 2 , respectively. They have the following relationship:

$$
C_{N 2}=C_{N 1}\left[1-F_{1}(d \min +\Delta d)\right]
$$

Then, 


$$
\frac{C_{m 1}-C_{m 2}}{C_{m 1}}=1-\frac{\left[1-F_{1}\left(d_{\min }+\Delta d\right)\right] \sum_{d_{\min }}^{d_{2 m x}} f_{2 i} d_{i}^{3}}{\sum_{d_{\operatorname{man}}}^{d_{1 i}} f_{1 i} d_{1}^{3}}
$$

where

$C_{m l}, C_{m 2}$ are the mass concentration at the two different heights above the burner respectively.

$F_{l}$ is the cumulative size distribution function for soot spherules, measured at height 1 above the burner.

$f_{1}, f_{2}$ are the size distribution density functions for soot spherules, measured at height 1 and 2 above the burner, respectively.

So, if the mass concentrations and the size distributions are known, the size recession can be calculated by using equation (4-5). Or, from $\Delta d$, the relative mass combustion rate can be estimated.

\subsection{Comparing Experimental Soot Oxidation Rates with Predictions}

Comparison of the experimental diesel soot oxidation rates with predicted values was made in this thesis. The predicted oxidation rates were calculated, respectively, using two most widely quoted carbon oxidation semi-empirical formulae, the Nagle and Strickland-Constable formula [Nagle and Strickland-Constable, 1962] and the Lee formula, [Lee et al, 1962].

Along the centerline of the quartz tube, the temperature and soot particle velocity decreased somewhat with the height above the burner. The $\mathrm{O}_{2}$ and $\mathrm{CO}_{2}$ concentrations varied slightly too; and, the oxidation rate is not a linear function of oxidation temperature in either the Nagle and Strickland-Constable formula or the Lee formula. Therefore, in order to predict the overall diameter recession of the soot spherules 
between two successive sampling points, integration of the diameter recession of the soot spherules, along the centerline of the oxidation quartz tube and between the two successive sampling positions, was carried out. As soon as the soot spherule diameter recession was calculated, the oxidation rate was easily estimated.

The steps involved in the above predictive calculation are as follows:

Let

$z$ be the height above the burner surface,

$t$ be the time,

$r$ be the radius of a soot spherule at sampling height $z$ and time $t$,

$w(z)$ be the calculated oxidation rate at height $z$,

$\rho$ be the density of the diesel soot spherules,

$v(z)=d z / d t$ the velocity of the soot particles at height $z$.

The rate of radius recession of the soot spherules is:

$$
\frac{d r}{d t}=-\frac{w(z)}{\rho}
$$

Equation (4-6) can also be written as

$$
\frac{d r}{d z} \frac{d z}{d t}=-\frac{w(z)}{\rho}
$$

Sine $d z / d t=v(z)$, equation (4-7) can be converted to

$$
\frac{d r}{d z}=-\frac{1}{\rho} \frac{w(z)}{v(z)}
$$


At any arbitrary height, $w / v$ can be taken as one variable, denoted as $f(z)$. The recession in the radius of the spherule over the traveling distance from $z_{l}$ to $z_{2}$ will be

$$
\Delta r=-\frac{1}{\rho} \int_{z_{1}}^{z_{2}} f(z) d z
$$

In this study, the function $f(z)$ in equation (4-9) for each test run could be a regressed function in the form of

$$
f(z)=a z^{2}+b z+c
$$

where $a, b$, and $c$ were constants having different values for different test runs.

The residence time $t_{r}$ for the soot particles traveling from height $z_{1}$ to $z_{2}$ is

$$
t_{r}=\int_{z_{1}}^{z_{2}} \frac{1}{v(z)} d z
$$

In this study, the measured velocity data in each test were linear functions of the height above the burner (see figure 3-9)

$$
v(z)=e z+g
$$

where $e$ and $g$ were again constants with different values for different test runs.

The average predicted oxidation rate $w$ could then be derived using the above results, from:

$$
w=-\rho \frac{\Delta r}{t_{r}}
$$

The predicted soot spherule diameter recession calculated by (4-9) and the surface oxidation rate calculated from (4-13) could then be compared with the experimental results worked out using the method described in section 4.5. 


\subsection{Summary}

A prominent advantage of the novel analysis described in this chapter is that it allows for complete burn-off of smaller soot spherules. This methodology, therefore, gives more accurate experimental results for soot oxidation rate than previous works which simply used the mean diameters of the soot spherules at different sampling positions [Lee et al, 1962; Fenimore and Jones, 1967].

An automatic soot spherule sizing instrument was not available for this project. The author of this thesis therefore had to use TEM to get soot spherule micrographs, develop the negatives, print the photos, scan the photos and convert them into digital images, and finally measure the size of thousands of soot spherules, including a tremendous amount of manual work. It usually took one week to accomplish the measurement of the diameter of around 1000 spherules for each sampling position. Working out the experimental oxidation rate for each test run needed about two weeks. This placed a limit on the ultimate number of test runs that could be made and analysed for this project. 


\section{Chapter 5 Morphology of Diesel Soot}

\subsection{Introduction}

A large number of micrographs of diesel soot particles were taken during this study using the Transmission Electron Microscope (TEM). The diesel soot samples included:

- Raw soot from the engine pre-chamber during the engine combustion stroke;

- Raw soot from the engine pre-chamber during the exhaust stroke;

- Raw soot from the engine exhaust pipe;

- Soot sampled from the burner oxidation zone in the quartz tube at different heights above the burner and under different oxidation conditions.

The so-called "raw soot" in this thesis refers to the soot sampled from the engine prechamber or exhaust pipe without burning in the burner post-flame gas. The diesel engine was running at $900 \mathrm{rmin}^{-1}$ and nearly full load in all the tests.

\subsection{Diesel Soot Morphology}

5.2.1 Morphology of engine pre-chamber raw soot sampled during the combustion stroke

Pictures 5-1, 5-2, and 5-3 are micrographs of raw soot sampled from the engine prechamber during the combustion stroke. The high-speed electromagnetic sampling valve started to open at $60^{\circ} \mathrm{CA}$ ATDC and was kept open for $3^{\circ} \mathrm{CA}$. 
Picture 5-1 shows the soot clusters and chains with TEM magnification 15,000. The clusters and chains of soot particles collected on the copper grid are shown to be composed of primary spherules, each cluster or chain having from just a few to thousands of spherules. The biggest cluster in the pictures taken was around $3.3 \mu \mathrm{m}$. It is interesting to observe that, almost invariably, the individual primary particles had a nearly spherical shape.

Picture 5-2 shows two small clusters. Each of them contained less than 100 primary spherules sized from 7 to $107 \mathrm{~nm}$. It can be seen that the primary soot spherules were joined either tightly or loosely together to form clusters or chains. Some joints between the linked particles were thin necks. Some necks were thick. A small particle could bridge two bigger ones.

Figure 5-1 shows the size distribution of 1298 primary spherule particles sampled from the engine pre-chamber during the combustion stroke. This size distribution (and all the others that will be discussed in following sections in this chapter) appeared to be roughly lognormal. Of order $96 \%$ of the spherules had diameters ranging from 10 to $80 \mathrm{~nm}$. The number mean diameter of the primary spherules was $43 \mathrm{~nm}$ and the volume mean diameter was $50 \mathrm{~nm}$. If the spherules had been dispersed as individual free particles, their specific surface area would have been $52 \mathrm{~m}^{2} \mathrm{~g}^{-1}$ (soot density taken as $\left.2 \mathrm{~g} \mathrm{~cm}^{-3}\right)$.

The microstructure of the soot spherules can be seen in pictures 5-3 and 5-4. Picture 5-4 shows the enlarged images of two spherules in picture 5-3. Concentric lamellate layers can be seen at the outer zones. The distance between the lamellate layers was of order $1 \mathrm{~nm}$, and it is similar to that of the diesel soot sampled from the main engine combustion chamber by Murayama et al [1992] (figure 14b of Murayama et al). The 
lamellae in the diesel soot particles in this study appeared not to be arranged as densely as in the carbon black shown in the micrograph of Marsh [1986]. The lamellae in picture 5-4 appeared somewhat less oriented at the spherule center.

\subsubsection{Morphology of engine pre-chamber raw soot sampled during the exhaust stroke}

When sampling raw soot from the pre-chamber during the exhaust stroke, the highspeed electromagnetic sampling valve opened at $20^{\circ} \mathrm{CA} \mathrm{ABDC}$ and also kept open for $3^{\circ} \mathrm{CA}$. The extracted remaining soot particles in the pre-chamber at this phase are expected to have experienced partial oxidation, which could affect their features and reactivity.

Pictures 5-5, 5-6, and 5-7 show the images of the soot particles with TEM magnifications of $80,000,100,000$, and 150,000 respectively. The particles also gathered together to form clusters and chains.

Figure 5-2 shows the size distribution of the primary spherule particles sampled from the pre-chamber during the exhaust stroke. Again, of order $98 \%$ of the spherules sized from 10 to $80 \mathrm{~nm}$. The number mean diameter of the primary spherules was $42 \mathrm{~nm}$ and the volume mean diameter was $47 \mathrm{~nm}$. The calculated average specific surface area for all the individual spherules was $57 \mathrm{~m}^{2} \mathrm{~g}^{-1}$.

\subsubsection{Morphology of raw engine exhaust soot}

From picture 5-8 (magnification 150,000) it can be seen that the raw exhaust soot particles collected on the copper grid also existed in the forms of clusters or chains. Each cluster or chain could contain tens or thousands of primary particles that were 
basically spherules. Picture 5-9 and 5-10 show a small cluster and a chain respectively. Some of the links between the primary particles in the clusters and in the chains seemed so tight that the particles looked as if they were fused together.

Picture 5-11 shows a few soot spherules at high TEM magnification of 500,000, from which the lamellate structure of the soot spherule can bee seen again.

About $99 \%$ of the primary spherules of the diesel soot extracted from the engine exhaust gas were in the size range of 10 to $80 \mathrm{~nm}$. The number mean diameter of the primary spherules was $36 \mathrm{~nm}$ and the volume mean diameter $41 \mathrm{~nm}$. The calculated average specific surface area for all the individual spherules was $65 \mathrm{~m}^{2} \mathrm{~g}^{-1}$.

Reflecting on the results of sections 5.2.1, 5.2.2, and 5.2.3 above, it can be seen that the spherule mean volume diameter decreased from $50 \mathrm{~nm}$ in the engine pre-chamber during the engine combustion stroke, to $47 \mathrm{~nm}$ in the pre-chamber during the exhaust stroke, down to $41 \mathrm{~nm}$ in the engine exhaust; the corresponding specific area increased from 52 to 57 , and finally, $65 \mathrm{~m}^{2} \mathrm{~g}^{-1}$. Further discussions will be made in section 5.3.

\subsubsection{Morphology of soot oxidised in the burner post-flame gas}

A large number of TEM pictures were taken for diesel soot particles oxidised in the burner post-flame gas.

Picture 5-12 shows oxidised diesel soot clusters and chains sampled from the postflame oxidation zone in the quartz tube. Although, theoretically, the soot clusters and chains could break up into smaller ones, many large clusters were still observed in the sample of oxidised soot, for instance, as in picture 5-13. 
An interesting string-like structure linking soot spherules together to form chains was also observed. This can be seen in picture 5-14(a) and its enlarged portion in picture 5-14(b). These structures were optically observed in a few cases and their composition and origin are still unknown.

It was quite common to see small soot spherules attached onto a big one, indicating that the electrical attraction forces might be responsible for soot aggregation. A typical case is shown in picture 5-15.

Soot particles can also link together to form complete rings, as shown in picture 5-16.

The number mean diameter of the primary spherules sampled at $50 \mathrm{~mm}$ above the burner in test exh-3 was $24 \mathrm{~nm}$ and the volume mean diameter was $29 \mathrm{~nm}$. The calculated average specific surface area for all the individual spherules was $87 \mathrm{~m}^{2} \mathrm{~g}^{-1}$.

\subsection{Discussion}

\subsubsection{Comparison of the raw soot sampled from the pre-chamber and from the} exhaust gas

Considering the structures of the primary spherules, clusters, and chains, virtually no differences in morphology can be distinguished by eye between the pre-chamber soot and the exhaust soot; or between the raw diesel soot and the oxidised soot, or in the soot sampled from different heights above the burner under various oxidation conditions. However, by closer examination, an impression is gained from the micrographs that the edges of the pre-chamber raw soot spherules seemed smoother and clearer than those of the exhaust ones. Furthermore, the raw soot sampled from the pre-chamber during the combustion stroke appears to be in more tightly-bonded clusters than those for the exhaust raw soot. This suggests that some clusters have 
formed in the pre-chamber by collision of individual spherules before they were solidified, and may have undergone further surface growth by deposition while in a cluster form. As described earlier in section 2.2, collisions take place between soot spherules and subspherules, as soon as they appear in the combustion space, to combine themselves together and thus form clusters and chains.

Figure 5-3(a) illustrates the size distributions of the soot particles sampled from: (A) engine pre-chamber during the combustion stroke; (B) from the pre-chamber during the exhaust stroke; and (C) from the engine exhaust. It can be seen that the curve peak for the exhaust soot was on the left side of the two peaks for the pre-chamber soot. It is possible that the soot spherules in the exhaust gas are generally smaller than those in the pre-chamber, partly due to oxidation in the main engine combustion chamber. The difference in the spherule size distributions of the raw soot sampled from the prechamber at $20-23^{\circ} \mathrm{CA} \mathrm{ABDC}$ and at $60-63^{\circ} \mathrm{CA}$ ATDC was small. This suggests that oxidation in the pre-chamber was not as dominant as in the main combustion chamber. Using the analytical method described in section 4.5 , the diameter recession for the soot spherules was as follows: in the pre-chamber between $60-63^{\circ} \mathrm{CA}$ ATDC and $20-23^{\circ} \mathrm{CA} \mathrm{ABDC}$ it was $3 \mathrm{~nm}$ and $11 \mathrm{~nm}$ between the pre-chamber at $60-63^{\circ} \mathrm{CA}$ ATDC and exhaust soot. This clearly shows that oxidation was dominant in the main chamber of the engine and not in the pre-chamber, as expected.

The number mean diameter, volume mean diameter, and surface/mass ratio of the different raw soots are compared in figure 5-3(b). The surface/mass ratio is the value of the total surface area of all the individual soot spherules whose size was measured, divided by the total mass of all the individual spherules. In the calculations, the density of all the diesel soot spherules was assumed to be $2 \mathrm{~g} \mathrm{~cm}^{-3}$ and the individual 
soot spherules were assumed to exist separately and with smooth surface. It can be seen from figure 5-3(b) that the soot spherules sampled from the pre-chamber at different parts of the combustion process had roughly similar values of number mean and volume diameters, but their surface area/mass ratios were quite different due to differences in the shape of their size distribution curves (see figure 5.3(a) and 5.3(b)). On the other hand, the exhaust soot spherules had number mean and volume mean diameters which were both smaller than those of the pre-chamber soot, whereas its surface/mass ratio was bigger (again, because the exhaust soot was dominated even more by smaller-diameter spherules).

Murayama and co-workers [1992] reported differences between the soot spherules sampled from the pre-chamber and the main chamber of a diesel engine. Their spherule size distributions show that the spherules sampled from the pre-chamber between $10^{\circ} \mathrm{CA}$ BTDC and TDC were generally bigger than those sampled at $60^{\circ}$ $70^{\circ}$ CA ATDC. Similarly, their results show that the spherules sampled from the main chamber between $10^{\circ} \mathrm{CA}$ BTDC and TDC were bigger than those sampled from the main chamber at $60^{\circ}-70^{\circ} \mathrm{CA}$ ATDC. This indicates that both the pre-chamber soot and the main chamber soot experienced oxidation.

Using high magnification micrographs, Murayama et al [1992] concluded that the internal structure of the soot spherules sampled from the main chamber was rougher than that of the soot spherules from the pre-chamber, and this was explained as the result of intrinsic oxidation of soot spherules during combustion in the main chamber. However, during the work for this thesis, no recognizable differences were found in the internal microstructures of diesel engine raw soot spherules sampled from various positions. The only differences found in the diesel engine raw soot spherules were in 
the size distributions and slightly in the appearance of the edges of the spherules, under higher TEM magnifications.

\subsubsection{Comparisons of oxidised soot with raw soot}

Figures 5-4, 5-5, and 5-6 compare the oxidised soot with the raw soot extracted from the engine under the following three conditions: from the engine pre-chamber during the combustion stroke (figure 5-4); from the pre-chamber during the exhaust stroke (figure 5-5); and from the engine exhaust gas (figure 5-6). In all three cases, both the number mean and volume mean diameters of the soot spherules decreased in the quartz tube due to the oxidation process. Table 5-1 shows that, on average, the decreases in both the number mean and volume mean diameters measured simply from the TEM micrographs were smaller than the diameter recessions worked out using the analytical method described in section 4.5 . This is because the micrographs do not include the small soot spherules that burn off completely between successive measuring heights above the burner flame. In contrast, the analytical mathod described in section 4.5 takes the burnout of the small spherules into account in calculating the diameter recession. The bigger the diameter recession, the more small particles burned off completely and the bigger were the differences between the simply measured mean diameter decreases and the calculated diameter recessions.

\subsubsection{Surface/mass ratio of diesel soot}

In this section, the results for surface/mass ratio are discussed in more detail.

The surface/mass ratio of a sample of individual soot spherules can be calculated in three different ways, as follows: 
(a) The first method assumes a fictitious soot spherule whose diameter is equal to the number mean diameter of the soot spherule sample, then the surface/mass ratio of this spherule is called the number mean diameter surface/mass ratio;

(b) The second method is identical to the first, except that the volume mean diameter is used instead of the number mean diameter;

(c) The third method simply adds up the surface areas and masses of each sampled soot spherule, respectively. Then the total surface area is divided by the total mass. This ratio is called the statistical surface/mass ratio.

From table 5-2 and figure 5-7 it can be seen that the resulting three surface/mass ratios have somewhat different values for soot extracted from the engine and from the burner. The highest value was calculated with the first method above and the lowest was calculated with the third method. However, irrespective of whichever of the three methods is used, the surface to mass ratio can be seen to increase with increasing oxidation.

The number based mean diameter surface/mass ratio has been discussed by several researchers in studies on diesel soot properties [Amann et al,1982; Heywood, 1988; Marcuccilli et al, 1994; Otto et al, 1980]. However, these researchers seem to have neglected two important facts. The first, the size distribution of diesel soot spherules is often lognormal. This means that the number mean diameter surface/mass ratio cannot represent the total surface/mass ratio of individual soot spherules. A better representation could be, instead, the calculated statistical surface/mass ratio (method (c) above). How large the difference between the two values is, depends on the profile of the particle size distribution. In this study, the statistical surface/mass ratio was 
greatly smaller than the corresponding number mean surface/mass ratio by $20 \%$ to $30 \%$.

Secondly, another neglected fact is that the soot spherule surface/mass ratio increases during oxidation due to the reduction of diameter of the spherules. It is mathematically obvious that a smaller spherule has lager surface/mass ratio than a bigger spherule. But, some literatures [Marcuccilli et al, 1994; Otto et al, 1980] have attributed the increase in the measured surface/mass ratio solely to the development of porosity on the soot spherule surface (porosity is usually measured using gas adsorption techniques). The results in this thesis shown in table 5-2 and figure 5-7 allow the increase in surface/mass ratio to be explained, mainly, by the recession in diameter due to oxidation.

\subsubsection{Influence of the aggregation of diesel soot particles on oxidation rate}

Diesel soot spherules are usually combined in clusters, chains, and less commonly, rings of irregular shapes. When an individual spherule is combined in these ways with other spherules, only part of its surface is exposed to the oxidant. How big the proportion of the exposed surface of an individual spherule is, depends on how that particular spherule is connected with neighbouring spherules.

When spherules are joined together, the oxidative attack and the dispersion of oxidation products become more difficult around the joints between spherules, and this hampers the oxidation process of individual soot spherules. Picture 5-17(a) shows a few spherules being joined approximately in a series. The outline of this series of spherules was of somewhat tapering shape and thus looked like a "bamboo shoot". The spherule at the tip of the "bamboo shoot" had the smallest diameter and the spherule at the root part was the largest. Another spherule with irregular shape is 
shown in picture 5-17(b). This spherule was not spherical. Instead, it had a sharp tip and this made the spherule look like a "peach". More "peach tip" and "bamboo shoot" shaped primary particles or particle combinations were found in the samples taken from higher positions above the burner than from lower ones. Also, soot particles shaped in this manner were even rarer in the samples extracted from the engine prechamber and exhaust, before being introduced to the burner. Possible reasons for the formation of the "bamboo shoot" and "peach-tip" shapes may be as follows:

- spherules at the edge of a cluster have a lager surface area exposed to the oxidant and may, therefore, have more opportunity to react with the oxidant;

- in addition, for such spherules at the edges of a cluster, both the heat and mass transfer rates between the soot particle surface and the surrounding oxidant environment can be expected to be higher.

\subsection{Summary}

1. As the combustion process proceeded, the soot spherules in the engine prechamber shrank slower than those in the main chamber. This is likely to have been due to lower oxidation rate of the pre-chamber soot, due to poorer oxidation conditions (less oxygen and lower temperature) than in the main chamber. Also, size growth of the soot particles could be expected in the pre-chamber due to fuel rich conditions and species deposition.

2. The diesel soot particles that were partly oxidised in the burner post-flame gas seemed to have coarser surface texture than the raw soot extracted from the engine pre-chamber and exhaust pipe. This suggests that pores or pits may have developed on the soot particle surface due to surface oxidation. But, the 
micrographs taken during this study did not show evidence of intrinsic combustion inside the diesel soot spherules (ie, no cenospherules were found).

3. The number mean and volume mean diameters of the soot spherules, calculated from the raw micrograph measurement, decreased during the oxidation process. However, the reductions in these two mean diameters were usually smaller than the diameter recession which was evaluated after allowing for complete burnout of smaller spherules.

4. The statistical surface/mass ratios of the soot spherules, calculated from the raw micrograph measurements, were smaller than the corresponding values of the surface/mass ratio calculated using the number mean and volume mean diameters. However, whichever method is used to calculate the surface/mass ratio, its value was observed to increase with the oxidation process (due to the diameter recession of the oxidised spherules).

5. The oxidation rate of individual diesel soot spherules is lowered by aggregation of the spherules into clusters and chains, which reduces the surface area of each spherule exposed to the oxidant. 


\section{Chapter 6 Experimental Results and Discussion}

\subsection{Introduction}

Experiments were carried out in order to determine:

a) The effect of oxygen partial pressure and gas stream temperature on diesel soot oxidation rate;

b) Any differences between the oxidation rates of soot in the engine exhaust and soot in the engine pre-chamber;

c) Any differences between the oxidation rates of soot extracted from the engine prechamber during the combustion stroke and during the exhaust stroke;

d) Any effect on the oxidation rate of exhaust diesel soot when $\mathrm{CO}_{2}$ was added to the oxidant stream.

This chapter also includes a discussion of the effects of the following factors on oxidation rate: various oxidants; total pressure of the oxidation gas stream; and the reactivity of different carbons.

\subsection{Measured Oxidation Rates of Exhaust Diesel Soot and Comparisons with Predictions}

Experiments were carried out using soot extracted from the engine exhaust and from the engine pre-chamber. The soot was oxidised in the burner quartz tube under the conditions shown in tables 6-1 and 6-2. The oxidation stream temperature ranged from 1530 to 1825 $\mathrm{K}$ and the oxygen partial pressure in the oxidation stream ranged from 0.01 to $0.05 \mathrm{~atm}$. 
The oxidation period in the oxidiser (quartz tube) for the particles travelling between the lower and the upper sampling locations varied from 5 to $13 \mathrm{~ms}$.

Figure 6-1 shows the soot particle size distributions for each of the eight tests when soot from the engine exhaust was oxidised in the quartz tube of the oxidising burner. As described in Chapter 5, for each test, the soot spherules had different size distributions for different sampling heights in the quartz tube above the burner. This reflected a reduction in spherule diameter with increasing height above the burner due to oxidation. For each of the eight tests shown in figure 6-1, the corresponding experimental oxidation rates were calculated and shown in table 6-1. This table also shows theoretical estimates of the oxidation rate predicted using the Nagle and Strickland-Constable formula and the Lee formula.

Looking at the experimental oxidation rates in table 6-1, it can be seen that these rates show an obvious dependence of the oxidation rate on both oxygen partial pressure and temperature. Compared with the predictions using the Nagle and Strickland-Constable formula and the Lee formula, the experimental oxidation rates appear to be more sensitive to temperature. Furthermore, close observation shows that the experimental oxidation rates appear to be also more sensitive to the oxygen partial pressure in comparison to the rates predicted by the Nagle and Strickland-Constable formula. On the other hand, the experimental rates are less sensitive to oxygen partial pressure than the predictions made with the Lee formula. As for the experimental oxidation rates, the measured values were about $0.1-0.7$ times the predictions from the Nagle and 
Strickland-Constable formula, whereas they were $1.3-3.3$ times those predicted with the Lee formula.

Figure 6-2 shows a more detailed comparison between the experimental oxidation rates from this work and the predictions by the Nagle and Strickland-Constable (NSC) formula and the Lee formula. This figure shows the ratio of: predicted oxidation rate/experimental oxidation rate, plotted against the experimental oxidation rate. It can be seen that at lower experimental oxidation rate values, the experimental results were closer to the predictions made by the Lee formula, but not those made by the NSC formula; however, the reverse is true at higher experimental oxidation rates: the experimental results were closer to the predictions made by the NSC formula but not those made by the Lee formula. In other words, the Lee formula appears to predict reasonably well the experimental results of this study at lower oxidation rates but not at higher ones; while the reverse is true in the case of the NSC formula, which appears to predict reasonably well the experimental results at higher oxidation rates but not at lower ones.

Figure 6-3 attempts to make a comprehensive comparison between experimental oxidation rates and predicted values obtained by the two formulae (i.e. that by Nagle and Strickland-Constable and that by Lee $e t a l)$. The figure includes the experimental results not only from this study, but also those published by other researchers for a variety of materials including pyrographites, carbon blacks, as well as soots [Bradley et al,1984; Fenimore and Jones, 1967; Park and Appleton, 1973].

Figure 6.3 shows a number of interesting trends: 
(i) The experimental results for the oxidation rate of diesel soot extracted from the engine exhaust in this study appear to be lower than the trend of the experimental results for oxidation rates for graphite powder [Bradley et $a l, 1984]$ and carbonaceous flame soot [Fenimore and Jones, 1967], and to be in-between the values predicted by the NSC formula and the predicted values made by the Lee formula.

(ii) The NSC formula under-predicts oxidation rates at very high oxidation temperatures.

(iii) The Lee formula also under-predicts the experimental oxidation rates obtained in this study and by other researchers [Bradley et al,1984; Fenimore and Jones, 1967] at lower temperatures.

\subsection{Oxidation Rates for the Pre-Chamber Diesel Soot and Comparison with the} Rates for the Exhaust Diesel Soot

Figures 6-4 and 6-5 show the spherule size distributions of the diesel soot extracted from the engine pre-chamber at $60^{\circ}-63^{\circ} \mathrm{CA}$ ATDC during the combustion stroke and $20^{\circ}$ $23^{\circ} \mathrm{CA} \mathrm{ABTC}$ during the exhaust stroke, respectively, and oxidized in the post-flame oxidizing gas stream. The oxidation rates of the soot are shown in both table 6-2 and figure 6-6. The oxygen partial pressure in the burner oxidation zone ranged from 0.027 to 0.048 atm respectively, while the temperature varied comparatively less, from 1745 to $1800 \mathrm{~K}$. 
The experimental results showed that, at given oxygen partial pressure and temperature, the oxidation rate of the pre-chamber soot was lower than that of the exhaust soot (compare tables 6-1 and 6-2). Furthermore, Table 6-2 shows that the pre-chamber soot sampled during the combustion stroke had a lower oxidation rate than the soot sampled during the exhaust stroke. A possible reason for these differences in oxidation rate might be that the pre-chamber soot may have lower specific surface area than that of the exhaust soot. The basis for this conjecture is that the pre-chamber soot surface appeared smoother in the TEM images. It is noteworthy that the soot particles sampled from the pre-chamber during the combustion stroke were also smoother than those sampled during the exhaust stroke. Another possible reason for the higher exhaust soot oxidation rate might be that unburned hydrocarbons in the exhaust condensing on the soot particles may help accelerate their oxidation in the burner quartz tube oxidiser.

Interestingly, Murayama et al [1992] reported that soot particles sampled from the main chamber of a diesel engine had a coarser internal structure than that of the soot from the pre-chamber. They attributed this difference to the internal oxidation of soot spherules in the high temperature and excess oxygen environment of the main chamber. As described in Chapter 5, no evidence of internal oxidation was found in the study presented in this thesis; however, pores or pits could develop at the soot particle surface during oxidation, which could make the lamellae on the surface easier to pare off. This might explain why the soot from the exhaust gas in this study was easier to oxidize than that from the prechamber. 


\subsection{Oxidation Rates with Different $\mathrm{CO}_{2}$ Partial Pressures}

$\mathrm{CO}_{2}$ has been considered by some researchers to be an oxidant of soot [Bradley et $a l, 1984]$. A semi-empirical formula, quoted in Bradley et al, calculates the oxidation rate caused by $\mathrm{CO}_{2}$ as a function of temperature and $\mathrm{CO}_{2}$ partial pressure:

$$
w_{C O_{2}}=A P_{C O_{2}}^{0.5} \exp (-E / R T)
$$

where $w_{c 02}$ is the oxidation rate caused by $\mathrm{CO}_{2}, \mathrm{~kg} \mathrm{~m}^{-2} \mathrm{~s}^{-1}$;

$A$ is reaction rate parameter, $\mathrm{kg} \mathrm{m}^{-2} \mathrm{~s}^{-1} \mathrm{~atm}^{-0.5}$;

$P_{\mathrm{CO}_{2}}$ is $\mathrm{CO}_{2}$ partial pressure, atm;

$E$ is the activation energy, $\mathrm{kJ}$ mole $\mathrm{e}^{-1}$;

$R$ is the universal gas constant, $8.314 \mathrm{~kJ} \mathrm{kmole}^{-1} \mathrm{~K}^{-1}$;

$T$ is oxidation temperature, $\mathrm{K}$.

Hiroyasu et al [1980] studied the effect of $\mathrm{CO}_{2}$ in a diesel open spray flame. The experimental results showed that addition of $5 \%, 10 \%$, and $15 \%$ (by volume) $\mathrm{CO}_{2}$ to the spray flame resulted in an increase in the flame length by $14 \%, 24 \%$, and $34 \%$, respectively (data from figure 22 of Hiroyasu et al). The additional $\mathrm{CO}_{2}$ gas flow could have affected the spray flame in a number of ways: it could have resulted in an increase in flame velocity and thus lengthen the flame; it could have absorbed heat from the flame and lowered the flame temperature, thus affecting the combustion reactions; or, it could have interfered with the $\mathrm{O}_{2} /$ fuel mixing process. The same proportion of additional $\mathrm{N}_{2}$ instead of $\mathrm{CO}_{2}$ caused smaller increases in the flame length, which might partly be due to $\mathrm{N}_{2}$ having lower specific heat capacity than $\mathrm{CO}_{2}$. 
In experiments on a high-speed DI diesel engine, Ladommatos and co-workers [1998] kept the $\mathrm{O}_{2} /$ fuel ratio unaltered while $1 \mathrm{~g} / \mathrm{s}$ per cylinder of $\mathrm{CO}_{2}$ was added at constant per cylinder air flowrate of $10 \mathrm{~g} / \mathrm{s}$. Because $\mathrm{CO}_{2}$ can increase the heat absorbing capacity of the inlet charge and hence lower the ignition temperature, this addition of $\mathrm{CO}_{2}$ was found to prolong the ignition delay from about 8 to $9.8{ }^{\circ} \mathrm{CA}$. Under this condition, the particulate emission increased by about $30 \%$. When the increase in the ignition delay was restored back to $8^{\circ} \mathrm{CA}$ by adding ignition improver to the fuel, the particulate emissions with or without the additional $\mathrm{CO}_{2}$ were at about the same level. This could have resulted from the trade-off between the chemical enhancement of $\mathrm{CO}_{2}$ to the soot oxidation and the suppression on the soot oxidation due to the $\mathrm{CO}_{2}$ increased the heat absorbing capacity of the cylinder gas charge and lowered the combustion temperature.

In the study presented in this thesis, the effect of $\mathrm{CO}_{2}$ on diesel soot oxidation was investigated by oxidising the exhaust diesel soot particles in the burner post-flame gas with different $\mathrm{CO}_{2}$ concentrations. In order to raise $\mathrm{CO}_{2}$ concentration, additional bottled $\mathrm{CO}_{2}$ gas was added into the burner feed gas mixture, while $\mathrm{O}_{2}$ concentration and temperature in the oxidizer were kept constant by carefully controlling $\mathrm{O}_{2}, \mathrm{~N}_{2}$, and air flowrates. The size distributions for the exhaust soot oxidized with additional $\mathrm{CO}_{2}$ are shown in figure 6-7. Table 6-3 and figure 6-8 show the comparison of the oxidation rates for the exhaust soot with and without $\mathrm{CO}_{2}$ additions.

In the tests labeled $\mathrm{CO}_{2}-1$ and $\mathrm{CO}_{2}-2$, the oxygen partial pressure and oxidation temperature were kept very nearly constant at $0.051-0.053$ atm and $1766-1771 \mathrm{~K}$, respectively, while the $\mathrm{CO}_{2}$ partial pressure was altered from 0.111 atm (test $\mathrm{CO}_{2}-2$ ) to 
$0.157 \mathrm{~atm}\left(\right.$ test $\left.\mathrm{CO}_{2}-1\right)$. As a result, the measured oxidation rate changed from $7.032 \times$ $10^{-5} \mathrm{~g} \mathrm{~cm}^{-2} \mathrm{~s}^{-1}$ to $9.323 \times 10^{-5} \mathrm{~g} \mathrm{~cm}^{-2} \mathrm{~s}^{-1}$, an increase of $32.6 \%$. It is true that both the oxygen partial pressure and the oxidation temperature in test $\mathrm{CO}_{2}-1$ were slightly higher than those in Test $\mathrm{CO}_{2}-2$, but the corresponding higher oxidation rate caused by these slightly higher values should only have been about $3.6 \%$ or $7.4 \%$, according to the NSC formula and the Lee formula, respectively. On the other hand, the increase in the oxidation rate caused by the $\mathrm{CO}_{2}$ addition, according to the formula quoted by Bradley $e t$ al [1984], should have been $28.4 \%$. Therefore, it is very likely that during these particular tests, the $\mathrm{CO}_{2}$ addition has helped accelerate oxidation of the diesel soot.

Comparing test $\mathrm{CO}_{2}-3$ with test Exh-2 (oxygen partial pressure was kept at $0.030-0.031$ atm), the addition of $\mathrm{CO}_{2}$ seems to have reduced the oxidation rate during these tests. Similarly, the oxidation rate for test $\mathrm{CO}_{2}-2$ was lower than that for test Exh-1 $\left(\mathrm{O}_{2}\right.$ partial pressure and oxidation temperature kept at about the same levels with and without additional $\mathrm{CO}_{2}$ ). It must be pointed out that the $\mathrm{CO}_{2}$ partial pressure values for tests without additional $\mathrm{CO}_{2}$ were not measured but estimated by calculation and therefore can be inaccurate.

\subsection{Discussion on the Effects of Oxidants Other than Carbon Dioxide on Soot Oxidation}

Effects of other oxidants, such as $\mathrm{OH}, \mathrm{O}, \mathrm{H}, \mathrm{H}_{2} \mathrm{O}$, and $\mathrm{NO}$, on carbon oxidation have been widely studied by other researchers [Bradley et al,1984; Chelliah, 1996; Coelho et al, 1995; Fenimore and Jones, 1967; Fujimoto et al, 1998; Haynes and Wagner, 1981; 
Suuberg et al, 1990]. Among these, the effect of $\mathrm{OH}$ on soot oxidation might be the most controversial.

Fenimore and Jones [1967] examined the oxidation of soot in a premixed flame supplied with ethylene $\left(\mathrm{C}_{2} \mathrm{H}_{4}\right)$, oxygen, hydrogen, and carbon dioxide, and reported that, for oxygen partial pressures from $10^{-4}$ to 0.3 atm and temperatures between 1530 and 1890 $\mathrm{K}$, the oxidation rate was only weakly dependent on oxygen concentration. They therefore concluded that the $\mathrm{OH}$ radical is very important for the oxidation of soot. They postulated that $10 \%$ of the collisions between an $\mathrm{OH}$ radical and carbon surface result in oxidation of a carbon atom. There have been numerous other researchers commenting on the effect of the $\mathrm{OH}$ radical, some supporting its importance on soot oxidation [Moss et al, 1995; Neoh et al, 1981; Puri et al, 1994] while others did not consider it to be important in carbon oxidation [Radcliffe and Appleton, 1971; Rosner and Allendorf, 1968]. Moss et al [1995] reported that the principal oxidizing species for the soot formed in a laminar diffusion ethylene/oxygen/nitrogen/argon flame was $\mathrm{OH}$. Their evidence for that was simply the fact that their experimental data for oxidation rate agreed well with the predictions made using the Fenimore and Jones oxidation model. Fujimoto et al [1998] presented measurements showing that $\mathrm{OH}$ radicals appeared later than the soot generation stage, with the peak of $\mathrm{OH}$ concentration appearing later than the peak of the soot concentration in the diesel engine cylinder. Rosner and Allendorf [1968] observed that $\mathrm{OH}$ removed a carbon atom from isotropic graphite less frequently than once every hundred collisions with the surface, which is well below the $10 \%$ efficiency that Fenimore and Jones postulated. Radcliffe and Appleton [1971] argued that the rates of 
$10 \%$ of successful $\mathrm{OH}$ collisions that Fenimore and Jones measured in rich flames may be due to traces of oxygen greater than their equilibrium estimates, but still too small to measure.

Since the above observations are quite conflicting, the effect of $\mathrm{OH}$ on carbon oxidation rate remains uncertain.

\subsection{Discussion on the Effect of Total Pressure on Diesel Soot Oxidation}

For non-porous and non-compressible carbons, the oxidation reaction takes place at the carbon surface. The partial pressure of the oxidant gas solely determines the number (concentration) of oxidant molecules available for attacking the carbon particle surface per unit surface area of the particle. So, for a given temperature, the oxidation rate of the non-porous carbon will be higher if the partial pressure of the oxidant is higher, since there are more oxidant molecules for oxidation attack. However, in contrast, the total pressure of the gas stream in which the oxidant is diluted is not important. This is demonstrated below:

Considering the total gas stream and the oxidant diluted within the gas stream to behave as ideal gases, the law of partial pressure can be expressed by the following equation (when the oxidant is oxygen):

$$
\frac{n_{o_{2}}}{n_{T}}=\frac{p_{o_{2}}}{p_{T}}
$$

where $n_{02}$ is the number of moles of oxygen in the total gas stream;

$n_{T}$ is the number of moles of the total gas stream; 
$p_{o 2}$ is oxygen partial pressure;

$p_{T}$ is the total pressure of the total gas stream.

The ideal gas law gives:

$$
p_{T}=n_{T} R T_{T}
$$

where $R$ is the universal gas constant;

$T_{T}$ is the temperature of the oxidizing gas.

Equation (6-1) becomes

$$
n_{O_{2}}=\frac{p_{O_{2}}}{R T_{T}}
$$

Equation (6-3) shows clearly that for a given mass and temperature of the total gas stream, the number of $\mathrm{O}_{2}$ molecules available for oxidation attack depends only on the oxygen partial pressure and it is totally independent of total gas stream pressure.

However, the total pressure was reported by Monson et al [1995] to affect the burning rate of porous coal chars having low densities of $0.43,0.80$, and $0.86 \mathrm{~g} \mathrm{~cm}^{-3}$. This is because, firstly, the oxygen partial pressure increased along with the total pressure with the oxygen molar fraction remaining constant. Secondly, when the char particles were fed into the high-pressure reactor from the low-pressure feeder, the high-pressure oxidant gas could penetrate into the pores of the char and cause the char to burn more quickly. 


\subsection{Comparison of the Oxidation of porous and Non-porous Carbons}

Carbons can be divided into porous and non-porous ones. Usually, carbon blacks, soot, and pyrolytic graphite are non-porous carbons. Some artificial graphites can be porous. Carbon blacks and soot have been observed to become increasingly porous with progressive oxidation [Lahaye and Prado, 1981; Marcuccilli et al, 1994; Neoh et al, 1984; Otto et al, 1980].

Neeft and co-workers [1997] found that the oxidation rates of diesel soot and that of a commercial Printex-U flame soot were similar at a temperature around $800 \mathrm{~K}$ and oxygen partial pressures in the range of 0.05 to $0.15 \mathrm{~atm}$.

Smith [1978] summarized the oxidation rates of various carbons, porous and non-porous. Corrected to a common oxygen partial pressure of $0.10 \mathrm{~atm}(101 \mathrm{kPa})$, the oxidation rates for flame soot obtained experimentally by Park and Appleton [1973], Lee et al [1962], and Fenimore and Jones [1967] followed a trend very close to the Arrhenius plot in Smith's report. On another plot in the same report, the oxidation rates of 6 different highly purified non-porous carbons were also nearly on the same trend line. By contrast, the oxidation rates of various porous carbons showed considerably greater scatter on a similar plot.

The experimental oxidation rates of porous artificial graphite [Makino et al, 1994] and char [Monson et al, 1995] appear to be remarkably higher than those of non-porous carbons and less sensitive to temperature. 
The above observations from the literature suggest that the levels of impurity and porosity of carbons affect their oxidation rate substantially at a given oxygen partial pressure and temperature.

\subsection{Comparison of Experimental Oxidation Rates from Various Studies with} Predictions Made by the Nagle and Strickland-Constable Formula and the Lee

\section{Formula}

Taken together, the predictions by the NSC formula, the experimental results of this work (exhaust soot oxidation), extensive studies on oxidation of carbon black particles [Park and Appleton, 1973; Rybak et al, 1991], graphite particles [Bradley et al, 1984], flame soot [Fenimore and Jones, 1967], and diesel soot deposits [Marcuccilli et al, 1994; Neeft et al, 1997; Otto et al, 1980] together suggest a remarkable trend: at temperatures higher than about $1880 \mathrm{~K}$, the Nagle and Strickland-Constable formula underestimates the oxidation rate; at temperatures lower than $1880 \mathrm{~K}$, the NSC formula tends to overestimate the oxidation rate. In particular, if the NSC formula is applied to diesel soot deposits oxidized at temperatures below $1100 \mathrm{~K}$ [Marcuccilli et al, 1994; Neeft et al, 1997; Otto et al, 1980], the predicted oxidation rates can be tens or hundreds of times greater than the experimental results.

In contrast, the oxidation rates predicted by the Lee formula shows the opposite trend: when temperature is above about $1800 \mathrm{~K}$, the Lee formula tends to over-estimate oxidation rate; at temperatures between 1500 and $1800 \mathrm{~K}$, the Lee formula tends to under-estimate oxidation rate. Generally, with the Lee formula, the difference between the predictions and the experimental results becomes smaller at lower temperatures. 
In summary, the NSC formula tends to under-estimate the oxidation rate at oxidation temperatures higher than $1880 \mathrm{~K}$, but tends to over-estimate the oxidation rate when the temperature is below $1880 \mathrm{~K}$; the lower the temperature is, the more the NSC formula over-estimates. As for the Lee formula, it tends to over-estimate the oxidation rate at high temperatures in the range $2000-4000 \mathrm{~K}$. Within the temperature range of $1100-2000 \mathrm{~K}$, the Lee formula tends to under-estimate the oxidation rate; and at temperatures below $1100 \mathrm{~K}$, the Lee formula tends to over-estimate the oxidation rate again.

\subsection{Conclusions}

1. The experimental results obtained in this study have shown that the oxidation rate of diesel soot from the exhaust gas had strong dependence on both oxygen partial pressure and temperature.

2. The oxidation rates of the diesel soot from the exhaust gas were lower than the predictions by the Nagle and Strickland-Constable formula but higher than the predictions by the Lee formula within the oxygen partial pressure range of 0.01 to $0.05 \mathrm{~atm}$ and the temperature range of 1530 to $1825 \mathrm{~K}$.

3. The pre-chamber soot particles had lower oxidation rate than the exhaust soot. This might be because the pre-chamber soot, which was generated at the early combustion stages, had higher density and had a less porous surface; it is also possible that condensed hydrocarbons on the exhaust soot help accelerate the oxidation rate.

4. The pre-chamber soot extracted at the early stages of the combustion stroke had lower oxidation rates than the pre-chamber soot extracted during the exhaust stroke. 
5. Additional $\mathrm{CO}_{2}$ injection to the burner feed gas mixture was likely to have helped accelerate diesel soot oxidation.

6. The effect of $\mathrm{OH}$ as an oxidant to diesel soot is not clear; reports in the literature are conflicting.

7. Total pressure of the gas in which the oxidants are diluted has little influence on the oxidation of the non-porous diesel soot particles.

8. The porosity and impurity of carbon particles can be two important factors responsible for different oxidation behavior.

9. Both the Nagle and Strickland-Constable formula and the Lee formula are inadequate in predicting the oxidation rate. 


\section{Chapter 7 Improvement in Existing Correlations for Soot Oxidation}

\subsection{Introduction}

As discussed in Chapter 6, the two well-known oxidation rate formulae, those proposed by Nagle and Strickland-Constable and by Lee et al seem to have inadequacies in predicting oxidation rate for flame soot, especially diesel soot. In this chapter, the author attempts to modify these two semi-empirical formulae to bring the predictions closer to the experimental results obtained from this and other investigations. An additional empirical formula is also worked out for this purpose.

\subsection{Comparison of the Nagle and Strickland-Constable Formula and the Lee}

\section{Formula}

The Nagle and Strickland-Constable formula and the Lee formula, as introduced in chapter 2, are the two most well-known among various models for carbon oxidation. Each of these two formulae has its strengths and weaknesses.

Peaks on the oxidation rate plots Figure $7-1$ shows prediction curves generated by the Nagle and Strickland-Constable formula and by the Lee formula. These large ranges of oxygen partial pressures and temperatures predictions are compared with experimental oxidation rates obtained from this and other studies. It can be seen that the most significant aspect of the Nagle and Strickland-Constable formula is that the prediction of the maximum oxidation rate agrees well with the experimental data [Nagle and Strickland-Constable, 1962; Walls and Strickland-Constable, 1964]. The existence of the maxima in the carbon oxidation rates has also been supported by 
various other studies [Field et al, 1967; Park and Appleton, 1973; Radcliffe and Appleton, 1971].

The reason for this phenomenon is explained in the Nagle and Strickland-Constable's paper [1962]. As described in earlier sections of this thesis, it is assumed that there are two types of site on the carbon surface, namely type A, a more reactive site type, and type B, a less reactive site type. The surface is entirely type A at low temperatures. As the temperature increases at a given oxygen partial pressure, the oxidation rate rises; however, at the same time, thermal rearrangement of the carbon surface produces an increasing proportion of type B sites on the surface. Since the B sites are less reactive than $\mathrm{A}$, at sufficiently high temperature the reaction rate ceases to rise and then begins to fall. This behaviour gives rise to the maximum reaction rate for a given oxygen partial pressure (see figure 7-1). At still higher temperatures, the surface is wholly covered with $\mathrm{B}$, the reaction is of first order at all oxygen partial pressures, and the reaction rate again rises with increasing temperature. At different oxygen partial pressures, these oxidation rate peaks take place at different temperatures. Radcliffe and Appleton's [1971] experimental results for diesel flame soot at an oxygen partial pressure of $4 \times 10^{-5} \mathrm{~atm}$ showed such a peak at about $1810 \mathrm{~K}$. Generally, at higher oxygen partial pressures the temperature at which the peak occurs becomes greater.

The Lee formula was derived for oxidation temperatures from 1300 to $1700 \mathrm{~K}$ and oxygen partial pressure from 0.04 to 1.12 atm. It does not show such peaks in oxidation rate. In this respect, the Nagle and Strickland-Constable formula is superior.

At high temperatures Park and Appleton [1973] measured the oxidation rate of carbon black powders in a shock-tube over the temperature range of $1700-4000 \mathrm{~K}$ and oxygen partial pressure range of $0.05-13$ atm. Their results showed that the 
measured specific surface oxidation rates were slightly higher than those predicted by the Nagle and Strickland-Constable formula. The Lee formula overestimates the oxidation rates and is also unable to simulate the trends in the oxidation rate well. So, at high temperatures, the Nagle and Strickland-Constable formula predicts soot oxidation better than the Lee formula.

At low temperatures Both the Nagle and Strickland-Constable and the Lee plots seen on figure 7-1 tend to be straight lines; however, the Lee plots have steeper slopes. At temperatures bellow $1000 \mathrm{~K}$, both formulae tend to overestimate the oxidation rates of diesel soot [Marcuccilli et al, 1994; Neeft et al, 1997; Otto et al, 1980] but the Lee predictions are closer to the experimental values.

Dependence of oxidation rate on oxygen partial pressure The Nagle and Strickland-Constable formula tends to underestimate the dependence of oxidation rate on oxygen partial pressure at lower temperatures especially when oxygen partial pressures are below 0.03 atm.

So, the Nagle and Strickland-Constable formula is superior to the Lee formula in that it predicts the peaks in oxidation rates. On the other hand, the Lee formula simulates the oxygen partial pressure dependence and temperature dependence of the oxidation rate of non-porous carbons at lower temperatures better than the Nagle and Strickland-Constable one. An ideal formula should:

a. Predict the trend described by Nagle and Strickland-Constable and confirmed by other researchers, i.e., there exist peaks in the oxidation rate at certain temperatures; and the value of such peaks and the corresponding temperature variation with oxygen partial pressure. 
b. Predict higher values for the oxidation rate than the original Nagle and Strickland-Constable formula at higher temperatures.

c. Have higher sensitivity than the Nagle and Strickland-Constable formula to both oxygen partial pressure and temperature; but also lower oxidation rates at low temperatures.

In the study presented in this thesis, efforts were made in both modifying the semiempirical Nagle and Strickland-Constable formula and working out an empirical polynomial formula.

\subsection{Modifying the Nagle and Strickland-Constable formula}

The Nagle and Strickland-Constable formula was modified by adjusting the four rate constants, so as to reduce the disparity between the predicted and the experimental results from this and other studies [Bradley et al, 1984; Fenimore and Jones, 1967; Marcuccilli et al, 1994; Neeft et al, 1997; Otto et al, 1980; Park and Appleton, 1973; Radcliffe and Appleton, 1971]. The four constants were modified as follows:

$$
\begin{aligned}
& k_{A}=30 \mathrm{e}^{-(15,800 / 7)} \mathrm{g} \mathrm{cm}^{-2} \mathrm{~s}^{-1} \mathrm{~atm}^{-1} \\
& k_{B}=8.0 \times 10^{-3} \mathrm{e}^{-(7,640 / 7)} \mathrm{g} \mathrm{cm}^{-2} \mathrm{~s}^{-1} \mathrm{~atm}^{-1} \\
& k_{T}=1.51 \times 10^{5} \mathrm{e}^{-(49,800 / 7)} \mathrm{g} \mathrm{cm}^{-2} \mathrm{~s}^{-1} \\
& k_{Z}=27.0 \mathrm{e}^{(3,000 / 7)} \mathrm{atm}^{-1}
\end{aligned}
$$

The modifications to the four constants were carried out by trial and error, each trial involving a modification of the value of one or more constants in order to improve the fit between the formula predictions and the combined experimental data from this study and those of others [Bradley et al, 1984; Fenimore and Jones, 1967; Marcuccilli et al, 1994; Neeft et al, 1997; Otto et al, 1980; Park and Appleton, 1973; Radcliffe 
and Appleton, 1971]. Due to the complex nature of the formula, it was found necessary to carry out numerous trials, which resulted in all four rate constants being altered. The improvement or otherwise of each modification was assessed from plots of predicted against experimental oxidation rates. As a result of the modifications to the four rate constants, the formula predictions agreed better with the experimental data. The formula predictions also became somewhat more sensitive to temperature due to changes in the exponent values in the rate constants.

After these modifications, as can be seen in figure 7-2, the peak oxidation rates kept approximately similar values corresponding to similar temperatures. At the left hand side of these peaks, the modified formula predicts higher values than the original formula, and these fit Park and Appleton's [1973] experimental data for carbon black oxidation rates better. At the right hand side of the peaks, the predictions with the modified formula are lower than those of the original ones and are also more sensitive to temperature; thus, they are in better agreement with the experimental results of this work, those of Lee et al [1962], and those of other researchers for diesel soot deposits at lower temperatures [Marcuccilli et al, 1994; Neeft et al, 1997; Otto et al, 1980].

Figure 7-3 compares the values of oxidation rate predicted using the modified formula with the experimental results of this and other studies. It can be seen from figures 73(a) and 7-3(b) that these modified rate constants provide a worthwhile improvement to the predictive capability of the Nagle and Strickland-Constable formula. The chief improvement has been in lessening (but not eliminating) the over-prediction at low oxidation rates.

Statistical analysis shows that the value of $R^{2}$ (the square of the Pearson product moment correlation coefficient) remains unchanged at 0.817 . This is because the 
predicted oxidation rates by the modified formula become worse near and below the temperatures corresponding to the peak oxidation rates. However, at all other temperatures, the modified formula has improved the predicted oxidation rates.

\subsection{Modifying the Lee formula}

The original Lee formula is:

$$
w=a \times \frac{p_{o_{2}}}{T^{1 / 2}} \exp \left(-\frac{E}{R T}\right)
$$

where

$w$ denotes the specific soot oxidation rate $\left(\mathrm{g} \mathrm{cm}^{-2} \mathrm{~s}^{-1}\right)$

$a$ is a constant, valued $1.085 \times 10^{4}$

$\mathrm{Po}_{2}$ is the partial pressure of oxygen (atm)

$T$ is the temperature (K)

$E$ is the activation energy, valued $165,026 \mathrm{~J} \mathrm{~mol}^{-1}$

$R$ is the universal gas constant $\left(\mathrm{J} \mathrm{mol}^{-1} \mathrm{~K}^{-1}\right)$

Modification of the Lee formula was carried out by the following steps:

1) First, a plot of $\ln \left(w T^{1 / 2} / P o_{2}\right)$ versus $1 / T$ was made using the experimental oxidation rates from this work (exhaust soot) and those of other studies [Bradley et al, 1984; Fenimore and Jones, 1967; Marcuccilli et al, 1994; Neeft et al, 1997; Otto et al, 1980; Park and Appleton, 1973; Radcliffe and Appleton, 1971], as shown in figure 7-4.

2) Then, a straight trend line was regressed, giving the regressed equation:

$$
\ln \left(w T^{1 / 2} / P o_{2}\right)=-18568 \times 1 / T+7.5405
$$

3) Comparing (7-2) and (7-3), gives:

and

$$
E=18568 R=154,380 \mathrm{~J} \mathrm{~mol}^{-1}
$$




$$
a=e^{7.5405}=1882.8
$$

Hence, the Lee formula can be modified to:

$$
w=1.8828 \times 10^{3} \times \frac{p_{o_{2}}}{T^{1 / 2}} e^{-\left(\frac{154,380}{R T}\right)}
$$

Figures 7-5 and 7-6 illustrate the effect of the modification of the Lee formula on the prediction fitness. It can be seen from these two figures that the predictive capability of the modified Lee formula appears better than the original one.

\subsection{An Empirical Formula}

Because of the complex dependence of soot oxidation on temperature and oxygen partial pressure, it is difficult for semi-empirical formulae to predict diesel soot oxidation rate accurately over very wide range of temperatures and oxygen partial pressures.

An empirical formula for oxidation rate was painstakingly worked out using regression analysis, in order to get better agreement with existing experimental results for diesel soot, other soot (e.g. derived from carbonaceous flames) and carbon blacks [Marcuccilli et al, 1994; Neeft et al, 1997; Otto et al, 1980; Park and Appleton, 1973]. The resulting empirical formula is as follows:

$$
\begin{aligned}
& w=P_{O_{2}}^{\left[-0.9340+2.1906 / T^{(1 / 4)}-8.0182 / T^{(2 / 7)}+1.3170 / T^{(3 / 11)}-1.0902 / T^{(4 / 14)}+4.4756 / T^{(5 / 16)}-7.2555 / T^{(6 / 18)}\right]} \times \\
& \exp \left[.0290-5.1607 T^{(1 / 4)}+2.1649 T^{(2 / 8)}-4.377 V T^{(3 / 11)}+4.0914 T^{(4 / 14)}-1.8279 T^{(5 / 17)}+3.1598 T^{(6 / 19)}\right](7-4)
\end{aligned}
$$

The steps to work out the above empirical formula are:

1. Drawing a series curves on the Arrhenius chart and making them adequately fit the experimental oxidation rates at corresponding temperatures and oxygen partial pressures (see figure 7-7); 
2. Regressing each curve to get a series of equations. In this work, each regressed equation was made in the following form:

$$
\operatorname{Ln}(w)=\mathrm{a}_{0}+\mathrm{a}_{1} / T+\mathrm{a}_{2} / T^{2}+\mathrm{a}_{3} / T^{3}+\mathrm{a}_{4} / T^{4}+\mathrm{a}_{5} / T^{5}+\mathrm{a}_{6} / T^{6}
$$

The constants $a_{0}$ to $a_{6}$ in each regressed equation for the curve corresponding to each given oxygen partial pressure have different values listed below:

$\begin{array}{lccccccc}\mathrm{Po}_{2} & \mathrm{a}_{0} & \mathrm{a}_{1} & \mathrm{a}_{2} & \mathrm{a}_{3} & \mathrm{a}_{4} & \mathrm{a}_{5} & \mathrm{a}_{6} \\ 0.50 & 1.8815 \mathrm{E}+00 & -7.0215 \mathrm{E}+04 & 2.8344 \mathrm{E}+08 & -5.4467 \mathrm{E}+11 & 4.9466 \mathrm{E}+14 & -2.1671 \mathrm{E}+17 & 3.6929 \mathrm{E}+19 \\ 0.21 & 5.0774 \mathrm{E}+00 & -1.0621 \mathrm{E}+05 & 3.9747 \mathrm{E}+08 & -7.1392 \mathrm{E}+11 & 6.2371 \mathrm{E}+14 & -2.6580 \mathrm{E}+17 & 4.4317 \mathrm{E}+19 \\ 0.15 & 2.9761 \mathrm{E}+00 & -9.0962 \mathrm{E}+04 & 3.5215 \mathrm{E}+08 & -6.4998 \mathrm{E}+11 & 5.7749 \mathrm{E}+14 & -2.4948 \mathrm{E}+17 & 4.2116 \mathrm{E}+19 \\ 0.10 & 7.9037 \mathrm{E}-01 & -8.4671 \mathrm{E}+04 & 3.5224 \mathrm{E}+08 & -6.7385 \mathrm{E}+11 & 6.1169 \mathrm{E}+14 & -2.6808 \mathrm{E}+17 & 4.5687 \mathrm{E}+19 \\ 0.05 & 3.8163 \mathrm{E}+00 & -1.1824 \mathrm{E}+05 & 4.6489 \mathrm{E}+08 & -8.5184 \mathrm{E}+11 & 7.5689 \mathrm{E}+14 & -3.2744 \mathrm{E}+17 & 5.5323 \mathrm{E}+19 \\ 0.03 & 5.5795 \mathrm{E}+00 & -1.4203 \mathrm{E}+05 & 5.4970 \mathrm{E}+08 & -9.9122 \mathrm{E}+11 & 8.7333 \mathrm{E}+14 & -3.7553 \mathrm{E}+17 & 6.3118 \mathrm{E}+19 \\ 0.01 & 2.7180 \mathrm{E}+00 & -1.2526 \mathrm{E}+05 & 5.0048 \mathrm{E}+08 & -9.2360 \mathrm{E}+11 & 8.2586 \mathrm{E}+14 & -3.5929 \mathrm{E}+17 & 6.1025 \mathrm{E}+19 \\ 4 \mathrm{E}-05 & 1.1352 \mathrm{E}+01 & -2.8180 \mathrm{E}+05 & 1.0516 \mathrm{E}+09 & -1.7990 \mathrm{E}+12 & 1.5281 \mathrm{E}+15 & -6.3918 \mathrm{E}+17 & 1.0516 \mathrm{E}+20\end{array}$

3. Regressing $a_{0}$ to $a_{6}$ individually as functions of oxygen partial pressure, as follows:

$$
\begin{aligned}
& \mathrm{a}_{0}=-9.3396 \mathrm{E}-01 \ln \left(\mathrm{Po}_{2}\right)+1.0290 \mathrm{E}+00 \\
& \mathrm{a}_{1}=2.1906 \mathrm{E}+04 \ln \left(\mathrm{Po}_{2}\right)-5.1607 \mathrm{E}+04 \\
& \mathrm{a}_{2}=-8.0182 \mathrm{E}+07 \ln \left(\mathrm{Po}_{2}\right)+2.1649 \mathrm{E}+08 \\
& \mathrm{a}_{3}=1.3170 \mathrm{E}+11 \ln \left(\mathrm{Po}_{2}\right)-4.3771 \mathrm{E}+11 \\
& \mathrm{a}_{4}=-1.0902 \mathrm{E}+14 \ln \left(\mathrm{Po}_{2}\right)+4.0914 \mathrm{E}+14 \\
& \mathrm{a}_{5}=4.4756 \mathrm{E}+16 \ln \left(\mathrm{Po}_{2}\right)-1.8279 \mathrm{E}+17 \\
& \mathrm{a}_{6}=-7.2555 \mathrm{E}+18 \ln \left(\mathrm{Po}_{2}\right)+3.1598 \mathrm{E}+19
\end{aligned}
$$

4. Combining the above constants, regressed as functions of oxygen partial pressure, with equation 7-5, gave:

$$
\begin{aligned}
& w=P_{O_{2}}^{\left[-0.9340+2.1906 / T^{(1 / 4)}-8.0182 / T^{(2 / 7)}+1.3170 / T^{(3 / 11)}-1.0902 / T^{(4 / 14)}+4.4756 / T^{(5 / 16)}-7.2555 / T^{(6 / 18)}\right]} \times \\
& \left.\times \exp 1.0290-5.1607 /^{(1 / 4)}+2.1649 / T^{(2 / 8)}-4.377 V T^{(3 / 11)}+4.0914 T^{(4 / 14)}-1.8279 / T^{(5 / 17)}+3.1598 / T^{(6 / 19)}\right]
\end{aligned}
$$

Figure 7-9 shows that the new empirical formula fits substantially better the experimental results of various researchers in comparison with the original Nagle and Strickland formula and the original Lee formula. Using this new empirical formula, the peaks of the oxidation rates have similar values with the predictions by the Nagle and Strickland-Constable formula. However, at higher temperatures, the predicted 
oxidation rates are higher than those by the Nagle and Strickland-Constable formula, thus agreeing better with experimental data [Park and Appleton, 1973]. Furthermore, at lower temperatures (i.e. on the right hand side of the peaks), the predicted oxidation rate is more sensitive to both oxygen partial pressure and temperature, ad this fits the experimental results more closely [Marcuccilli et al, 1994; Neeft et al, 1997; Otto et $a l, 1980]$.

Figure 7-10 compares the predicted values for the oxidation rates by the empirical formula with the experimental data of this and other studies. Analysis shows that $R^{2}$ has a value of 0.859 , which is remarkably higher than 0.817 and 0.491 , respectively, for the original NSC formula and the original Lee formula, and also higher than 0.817 and 0.514 for the modified NSC formula and the modified Lee formula.

\subsection{Conclusion}

The modified Nagle and Strickland-Constable formula, the modified Lee formula, and the newly derived empirical formula all improved the prediction of experimental results for various carbons and soots. 


\section{Chapter 8 Conclusions and Suggestions for Further Work}

\subsection{Conclusions}

1. The experimental techniques developed in this study allow diesel soot extracted from a running engine to be oxidized, while in suspension in the oxidant stream, under independently controlled oxidant temperature and composition.

2. Examination of the soot extracted from the running diesel engine showed that nearly all soot spherules were in the forms of clusters and chains containing a few to thousands of primary spherules. Geometrical properties of the soot spherules extracted from the engine pre-chamber and from the exhaust were as follows:

\begin{tabular}{lcccc}
\multicolumn{1}{c}{ Soot source } & $\begin{array}{c}\text { \% of spherules in size } \\
\text { range 10-80 } \mathbf{~ m m}\end{array}$ & $\begin{array}{c}\text { Number mean } \\
\text { diameter, } \mathrm{nm}\end{array}$ & $\begin{array}{c}\text { Volume mean } \\
\text { diameter, } \mathrm{nm}\end{array}$ & $\begin{array}{c}\text { Surface/mass } \\
\text { ratio, } \mathbf{m}^{\mathbf{2}} \mathbf{g}^{-1}\end{array}$ \\
$\begin{array}{l}\text { 1. Pre-chamber, } \mathbf{6 0 - 6 3 ^ { \circ }} \\
\begin{array}{l}\text { CA ATDC (combustion } \\
\text { stroke) }\end{array}\end{array}$ & 96 & 43 & 50 & 52 \\
$\begin{array}{l}\text { 2. Pre-chamber, 20 - 230 } \\
\text { CA ABDC (exhaust stroke) }\end{array}$ & 98 & 42 & 47 & 57 \\
3. Engine exhaust & 99 & 36 & 41 & 65
\end{tabular}

3. Diesel soot extracted from the engine exhaust gas appeared to be oxidized faster than the soot extracted from the pre-chamber. This might be because the exhaust soot had a lower density and a relatively more porous surface due to oxidation attack during the combustion process in the engine cylinder; it is also possible that condensed hydrocarbons on the exhaust soot help accelerate the oxidation rate. 
4. Both the oxygen partial pressure and the temperature play important roles in diesel soot oxidation (oxygen partial pressure range of 0.01 to 0.05 atm and temperature range 1530 to $1830 \mathrm{~K})$.

5. Additional $\mathrm{CO}_{2}$ injection to the burner feed gas mixture is likely to have helped accelerate diesel soot oxidation.

6. The total oxidant stream pressure does not affect the soot oxidation rate substantially when the oxygen partial pressure stays constant.

7. Both the Nagle and Strickland-Constable formula and the Lee formula have substantial inadequacies in predicting the soot oxidation rate. Within the oxygen partial pressure range of 0.01 to 0.05 atm and temperature range 1530 to $1830 \mathrm{~K}$, the Nagle and Strickland-Constable formula tends to over-estimate the oxidation rate of the diesel soot that was extracted from the engine exhaust; whereas the Lee formula tends to under-estimate the oxidation rate for the same diesel soot.

8. The modifications in this study to the Nagle and Strickland-Constable formula and to the Lee formula have improved their predictive accuracy for the oxidation rate of diesel soot and other non-porous carbons. Furthermore, an empirical formula newly derived in this study gives even better agreement with the experimental results than the modified Nagle and Strickland-Constable formula and the modified Lee formula. 


\subsection{Suggestions for Further Work}

1. The methodology for measuring soot oxidation rate developed in this study has a major difficulty in acquiring large quantity of experimental data, which involve a lot of manual work in estimating soot spherule size distributions. Fortunately, laser-induced incandescence (LII) has shown great potential in the measurement of primary soot spherule size. Another option could be the improvement in computer software that can recognise individual spherules and measure their size automatically. When either one of these two techniques become available, relevant research can continue and more experimental results could be obtained with much less labor and time.

2. The empirical formula worked out in this thesis could be embedded in the diesel engine computer simulation software to verify its accuracy under a wide range of operating conditions.

3. Post-injection is one of the methods to accelerate soot oxidation in the diesel engine cylinder. The basic principle of this method is to raise the oxidation temperature and strengthen the turbulence in the cylinder in order to improve the mixing of the soot particles and unburned fuel droplets with fresh air. But, at the same time, the injected fuel could consume more oxidants and thus reduce the concentrations of the oxidants. Therefore, optimisation of the post-injection quantity and timing can be carried out with the help of the correlation between the soot oxidation rate and the oxidation conditions that has been worked out in this study. 
4. Standard on diesel engine particulate emission have been becoming more and more restrict. Diesel particulate filter (DPF) technique will become popular for diesel engine after-treatment. DPF regeneration is still an interest of engineers. Therefore, further research on diesel soot oxidation at lower temperatures, catalytic and non-catalytic, would be helpful to further understanding and improving diesel particulate after-treatment. 


\section{References}

Abdul-Khalek, I. S. and Kittelson, D. B., Real Time Measurement of Volatile and Solid Exhaust particles Using a catalytic Stripper, SAE 950236, 1995

Abdul-Khalek, I. S., Kittelson, D.B., Graskow, B. R., Wei Q., and Brear, F., Diesel Exhaust Particle Size: Measurement Issues and Trends, SAE Special Publications, Paper No. 980525, 1998

Ahlström, A. F. and Odenbrand, C. U. I., Combustion Characteristics of Soot Deposits from Diesel Engines, Carbon, Vol. 27, No. 3, 475-483, 1989

Amann, C. A. and Siegla, D. C., Diesel Particles - What They Are and Why, Aerosol Science and Technology, 1:73-101 (1982)

Amann, C. A., Stivender, D. L., Plee, S. L., and MacDonald, J. S., Some Rudiments of Diesel Particulate Emissions, SAE paper 800251, SAE Trans., vol. 89, 1980

Arcoumanis, C. and Schindler, K. P., Mixture Formation and Combustion in the Dl Diesel Engine, SAE 972681, 1972

Barth, H., G. and Flippen, R. B., Particle Size Analysis, Analytical Chemistry, Vol. 67, No. 12, June 15, 257R - 272R, 1995

Blyholder, G., Binford, J. S., and Eyring, H., A Kinetic Theory for the Oxidation of Carbonised Filaments, Journal of Physical Chemistry, 62:263 1958

Bradley, D., Dixon-Lewis., G., Habik, S. El-Din, and Mushi, E. M. J., The Oxidation of Graphite Powder in Flame Reaction Zones, Twentieth Symposium (International) on Combustion/The Combustion Institute, 931-940, 1984

Caldwell, F. R., Thermocouple Materials, in Temperature, its Measurement and Control in Science and Industry (Herzfeld, C. M. Ed.), Reinhold, Newyork, Vol. 3, Part 2, p. 81-134, 1962 
Cengel, Y.A., Heat Transfer, A Practical Approach, McGraw-Hill, 1998

Chelliah, H. K., Makino, A., Kato, I., Araki, N., and Law, C. K., Modeling of Graphite Oxidation in a Stagnation-Point Flow Field Using Detailed Homogeneous and Semiglobal Heterogeneous Mechanisms with Comparisons to Experiments, Combustion and Flame, 104:496-480 (1996)

Chelliah, H. K., The Influence of Heterogeneous Kinetics and Thermal Radiation on the Oxidation of Graphite Particles, Combustion and Flame, 104: $81-94$ (1996)

Coelho, P. J. and Carvalho, M. G., Modeling of Soot Formation and Oxidation in Turbulent Diffusion Flames, Journal of Thermophysics and Heat Transfer, Vol. 9, No. 4, October-December, 644-652, 1995

d'Alessio, A., Gambi, G., Minutolo, P., Russo, S., and D'Anna, A., Optical Characterization of Rich Premixed $\mathrm{CH}_{4} / \mathrm{O}_{2}$ Flames across the Soot Formation Threshold, Twenty-Fifth Symposium (International) on Combustion Institute, pp. 645-651, 1994

Dec, J. E. and Espey, C., Soot and Fuel Distributions in a D.I. Diesel Engine via 2-D Imaging, SAE 922307, 1992

Dec, J. E. and Espey, C., Ignition and Early Soot Formation in a DI Diesel Engine Using Multiple 2-D Imaging Diagnostics, SAE 950456, 1995

Degobert, P., Automobiles and Pollution, SAE, 1995

Dolan, D. F., Kittelson, D. B., and Pui, D. Y. H., Diesel Exhaust Particle Size Distribution Measurement Techniques, SAE paper 800187, 1980

EPA, draft Technical Support Document: Control of Emissions of Hazardous Air Pollutants from Motor Vehicles and Motor Vehicle Fuels, EPA420-D-00-003, July 2000

Eastwood, P., Critical Topics in Exhaust Gas Aftertreatment, Research Studies Press Ltd., 2000 
Faeth, G. M. and Köylü, Ü. Ö., Soot Morphology and Optical Properties in NonpremiFaexed Turbulent Flame Environments, Combustion Science and Technology, v 108, 4-6, p 207-229, (1995)

Fenimore, C. P. and Jones, G. W., Oxidation of Soot by Hydroxyl Radicals, Journal of Physical Chemistry, Vol. 71, No. 3, 1967

Feugier, A., Soot Oxidation in Laminar Hygrocarbon Flames, in Heat Transfer in Flames, ed. by Afgan, N. H. and Beer, J. M., Scripta Book Company, 1974

Field, M. A., Gill, D. W., Morgan, B. B., and Hawksley, P. G. W., ed. Combustion of Pulverised Coal, The British Coal Utilisation Research Association, Leatherhead, 1967

Fristrom, R. M., Flame Structure and Processes, Oxford University Press, 1995

Fujimoto, H., Kurata, K., Asai, G. And Senda, J., OH Radical Generation and Soot Formation/Oxidation in DI Diesel Engine, SAE paper No. 982630, 1998

Haynes, B. S. and Wagner, H. Gg., Soot Formation, Prog. Energy Combust. Sci., Vol. 7, 229-273, Pergamon Press Ltd., 1981

Heywood J. B. Internal combustion Engine Fundmentals, McGraw-Hill International Editions, 1988

Hiroyasu, H., Arai, M., and Nakanishi, K., Soot Formation and Oxidation in Diesel Engines, SAE paper, 800252, 1980

Huth, M. and Leuckel, W., Experiments on Soot Formation from Propane under Partial Oxidation Conditions in a Tubulent Plug-flow Reactor, Twenty-Third Symposium (International) on Combustion/The Combustion Institute, 1493-1499, 1990

Ishiguro, T., Takatori, Y., and Akihama, K., Microstructure of Diesel Soot Particles Probed by Electron Microscopy: First Observation of Inner Core and Outer Shell, Combustion and Flame, 108: 231-234 (1997) 
Kadota, T. and Henein, N. A., Time-resolved Soot Particulates in Diesel Spray Combustion, in Particulate Carbon - Formation during Combustion, ed. Siegla, D. and Smith, G. W., Plenum Press, pp.391-419, 1981

Kennedy, I. M., Models of Soot Formation and Oxidation, Prog. Energy Combust. Sci. Vol. 23, pp. 95-132, 1997

Khan, I. M. and Greeves, G., A Method for Calculating the Formation and Combustion of Soot in Diesel Engines, in Heat Transfer in Flames, ed. by Afgan, $\mathrm{N}$. H. and Beer, J. M., Scripta Book Company, 1974

Khan, I. M., Wang, C. H. T., and Langridge, B. E., Coagulation and Combustion of Soot Particles in Diesel Engines, Combustion and Flame, 17: 409-419 (1971)

Kim, W., Park, Y. H., Shin, J. Y., and Lee, D. W., Size Determination of Diesel Soot Particles Using Flow and Sedimentation Field-Flow fractionation, Analytical Chemistry, Vol. 71, No. 15, 3265-3272, 1999

Kittelson, D. B., Sun, R., Blackshear, P. L., and Brehob, D. D., Oxidation of Soot Agglomerates in a Direct Injection Diesel Engine, SAE 920111,1992

Konstandopoulos, A. G. and Kostoglou, M., Reciprocating Flow Regeneration of Soot Filters, Combustion and Flame, 121:488-500 (2000)

Ladommatos, N., Abdelhalim, S. M., Zhao, H., and Hu, Z., The Dilution, Chemical, and Thermal Effects of Exhaust Gas Recirculation on Diesel Engine Emissions - Part 1: Effect of Reducing Inlet Charge Oxygen, SAE paper 961165 , 1996

Ladommatos, N., Abdelhalim, S. M., Zhao, H., and Hu, Z., The Dilution, Chemical, and Thermal Effects of Exhaust Gas Recirculation on Diesel Engine Emissions - Part 2: Effect of Carbon Dioxide, SAE paper 961167, 1996

Ladommatos, N., Abdelhalim, S. M., Zhao, H., and Hu, Z., The Effects of Carbon Dioxide in Exhaust Gas Recirculation on Diesel Engine Emissions, Proc. Instn. Mech. Engrs., Vol. 212, Part D, pp. 25-42 (1998) 
Lahaye, J. and Prado, G., Morphology and Internal Structure of Soot and Carbon Blacks, in Particulate Carbon - Formation during Combustion, ed. Siegla, D. And Smith, G. W., Plenum Press, 1981

Lee, K. B., Thring, M. W. and Beér, J. M., On the Rate of Combustion of Soot in a Laminar Soot Flame, Combustion and Flame, Vol.6, 137-145 (1962)

Lee, S., Rao, S. P., Moon, M., H., and Giddings, J., C., Determination of Mean Diameter and Particle Size Distribution of Acrylate Latex Using Flow Field-Flow Fractionation, Photon Correlation Spectroscopy, and Electron Microscopy, Analytical Chemistry, Vol. 68, No. 9, May 1, 1545-1549, 1996

Lowell, S. and Shields, J. E., Powder Surface Area and Porosity, Chapman \& Hall, 1991

Makino, A., Araki, N., and Mihara, Y., Combustion of Artificial Graphite in Stagnation Flow: Estimation of Global Kinetic Parameters from Experimental Results, Combustion and Flame, 96:261-274 (1994)

Marcuccilli, F., Gilot, P., Stanmore, B., and Prado, G., Experimental and Theoretical Study of Diesel Soot Reactivity, Twenty-Fifth Symposium (International) on Combustion Institute, pp. 619-626, 1994

Marsh, H., Diez, M. A., and Kuo, K., Specific Reactivities of Pure Carbon of Diverse Origins, in Fundamental Issues in Control of Carbon Gasification Reactivity, edited by Lahaye, J., and Ehrburger, P., Kluwer Academic Publishers, 1991, 205-220

Marsh, H., Structure in Carbons, in Carbon and Coal Gasification, edited by Figueiredo, J. L. And Moulijn, J. A., Martinus Nijhoff Publishers, 1986

Mayer, W. J., Lechman, D. C., and Hilden, D. L., SAE Paper 800256, Society of Automotive Engineer, Warrendal PA, February, 1980

Mcenally, C. S., Köylü, Ü. Ö., Pfefferle, L. D. and Rosner, D. E., Soot Volume Fraction and Temperature Measurements in Laminar Nonpremixed Flames Using Thermocouples, Combustion and Flame, 109: $701-720$ (1997) 
Monson, C. R., Germane, G. J., Blackham, A. U., and Smoot, L. D., Char Oxidation at Elevated Pressures, Combustion and Flame, 100: 669-683 (1995)

Moss, J. B., Stewart, C. D. and Young, K. J., Modeling Soot Formation and Burnout in a High Temperature Laminar Diffusion Flame Burning under Oxygen-Enriched Conditions, Combustion and Flame, 101: $491-500$ (1995)

Murayama, T., Fujiwara, Y., and Tosaka, S., The Properties, Formation, and Oxidation of Soot Particulate in Diesel Engines, ICE-Vol. 17, Diesel Engine Process: Turbocharging, Combustion and Emission, ASME pp. 69-76, 1992

Nagle, J. and Strickland-Constable, R. F., Oxidation of Carbon between $1000-2000^{\circ} \mathrm{C}$, Proceedings of the Fifth Carbon Conference, Pergamon, Oxford, Vol. 1, 154-164, 1962

Neeft, J. P. A., Nijhuis, T. X., Smakman, ., Makkee M. and Moulijn, J. A., Kinetics of the oxidation of diesel soot, Fuel Vol. 76 No. 12, 1129-1136, 1997

Neoh, K. G., Howard, J. B. and Sarofim, A. F., Effect of Oxidation on the Physical Structure of Soot, Twentyth Symposium (International) on Combustion, 951-957, 1984

Neoh, K. G., Howard, J. B. and Sarofim, A. F., Soot Oxidation in Flames, in Particulate Carbon - Formation during Combustion, ed. Siegla, D. and Smith, G. W., Plenum Press, 1981

Otto, K., Sieg, M. H., Zinbo, M., and Bartosiewicz, L., The Oxidation of Soot Deposits from Diesel Engines, SAE paper 800336, SAE Trans. 89:1399, 1980

Park, C. and Appleton, J. P., Shock-Tube Measurements of Soot Oxidation Rates, Combustion and Flame, 20:369-379 (1973)

Pischinger, F., Lepperhoff, G. and Houben, M., Soot Formation and Oxidation in Diesel Engines, in Soot Formation in Combustion, ed. Bockhorn, Springer-Verlag, pp. 382-395, 1994 
Plee, S. L., Ahmad, T., Myers, J. P., and Siegla, D. C., Effects of Flame Temperature and Air-fuel Mixing on Emission of Particulate Carbon from a Divided-chamber Diesel Engine, in Particulate Carbon - Formation during Combustion, ed. Siegla, D. and Smith, G. W., Plenum Press, pp.423-487, 1981

Prado, G. P., Lee, M. L., Hites, R. A., Hoult, D. P., and Howard, J. B., Soot and Hydrocarbon Formation in A Turbulent Diffusion Flame, Sixteenth Symposium on Combustion, pp 649-661, 1976

Pungs, A., Pischinger, S., Bäcker, H., and Lepperhoff, G., Analysis of the Particle Size Distribution in the Cylinder of a Common Rail DI Diesel Engine During Combustion and Expansion, SAE 2000-01-1999, 2000

Puri, R., Santoro, R. J., and Smyth, K. C., The Oxidation of Soot and Carbon Monoxide in Hydrocarbon Diffusion Flames, Combustion and Flame, 97: 125-144 (1994)

Radcliffe, S. W. and Appleton, J. P., Soot Oxidation Rates in Gas Turbine Engines, Combustion Science and Technology, Vol.4, pp. 171-175 (1971)

Roessler, D. M., Faxvog, F. R., Stevenson, R., and Smith, G. W., Optical Properties and Morphology of Particulate Carbon: Variation with Air/Fuel Ratio, in Particulate Carbon - Formation during Combustion, ed. Siegla, D. and Smith, G. W., Plenum Press, pp. 57-89, 1981

Rosner, D. E. and Allendorf, H. D., AIAA Journal, Vol. 6, p.650-654, (1968)

Rybak, W., Ehrburger-Dolle, F. and Jacques Lahaye, Carbon Black Oxidation in An Ethylene/Air Premixed Flame, Extended Abstracts and Program Biennial Conference on Carbon, 446-447, 1991

Sakamoto, S., Saito, J., Kishimoto, T., and Ishida, K., Particulate Characterization of Automotive Emissions by Helium Microwave-Induced Plasma Atomic Emission Spectrometry, SAE paper 971017,1997 
Schraml, S. Will, S., and Leipertz, A., Simultaneous Measurement of Soot Mass Concentration and Primary Particle Size in the Exhaust of a DI Diesel Engine by Time-Resolved Laser-Induced Incandescence (TIRE-LII), SAE 1999-01-0146, 1999

Smith, I. W., The Intrinsic Reactivity of Carbons to Oxygen, Fuel, Vol. 57, 409-414, 1978

Spicher, U. and Dresen-Rausch, J., Soot Formation Analysis within the Combustion Chamber of Diesel Engine by Optical Fibers, ICE-Vol. 17, Diesel Engine Process: Turbocharging, Combustion and Emission, ASME, pp. 53-59, 1992 Suuberg, E. M., Teng, H. and Calo, J. M., Studies on the Kinetics and Mechanism of the Reaction of NO with Carbon, Twenty-Third Symposium (International) on Combustion/The Combustion Institute, pp. 1199-1205, 1990

Tree, D. R. and Foster, D. E., Optical Measurements of Soot Particle Size, Number Density, and Temperature in a Direct Injection Diesel Engine as a Function of Speed and Load, SAE 940270, 1994

Vander Wal, R. L., Ticich, T. M., and Stephens, A. B., Can Soot Primary Particle Size be Determined Using Laser-Induced Incandescence? Combustion and Flame 116:291-296 (1999)

Vuk, C. T., Jones, M. A. and Johnson, J. H., The Measurement and Analysis of the Physical Character of Diesel Particulate Emissions, SAE Technical Paper, 760131, 1976

Walls, J. R. and Strickland-Constable, R. F., Oxidation of Carbon between 1000-2400 ${ }^{\circ}$, Carbon, Vol.1, pp. 333-338 (1964)

Warnatz, J., Maas, U., and Dibble, R. W., Combustion, Springer, 1999

Zhao, H., Lowry, G., and Ladommatos, N., Time-Resolved Measurements and Analysis of In-Cylinder Gases and Particulates in Compression-Ignition Engines, SAE paper 961168,1996 


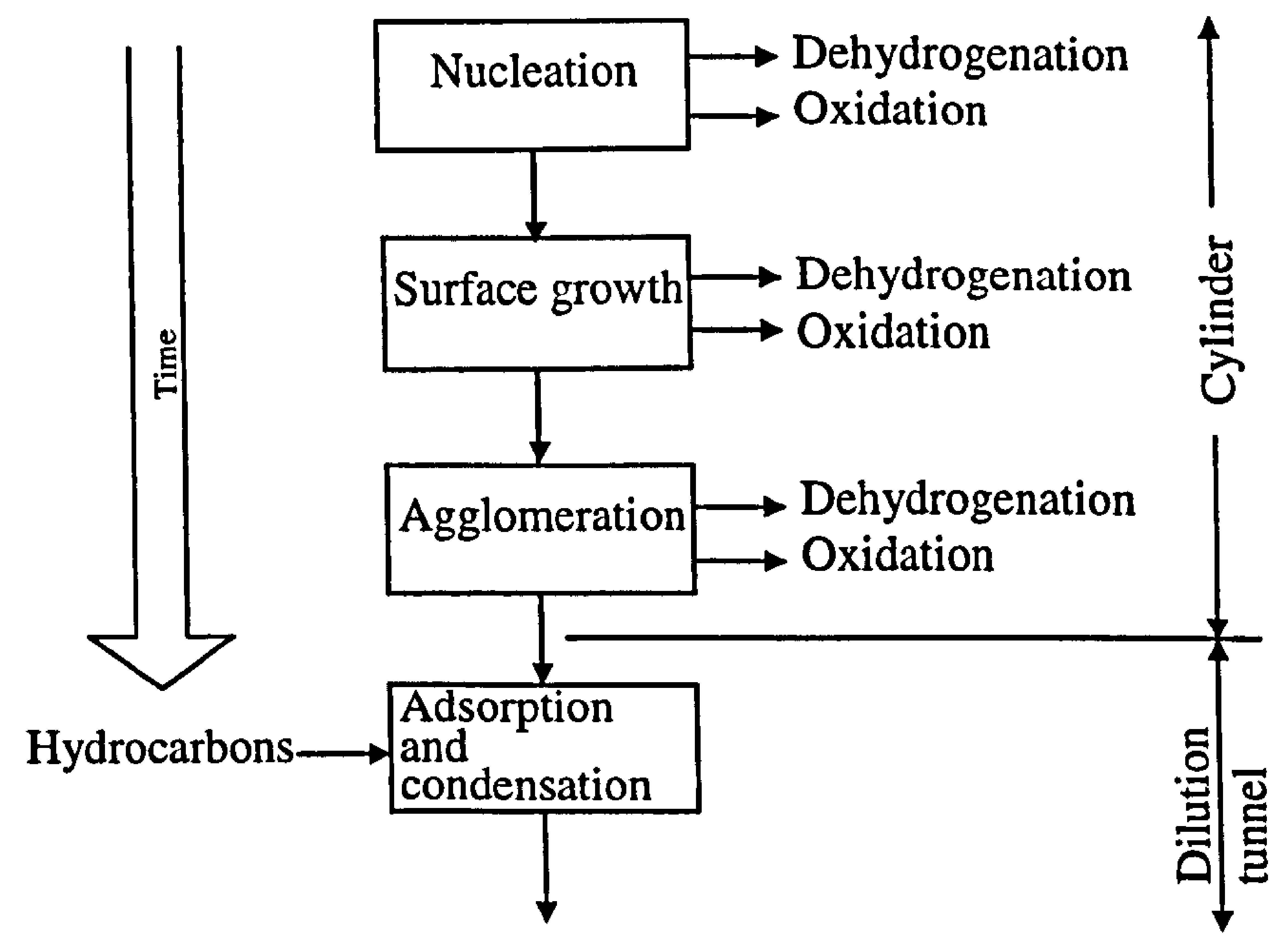

Fig. 2-1 Processes leading to net production of diesel particulates [Amann and Siegla, 1982]

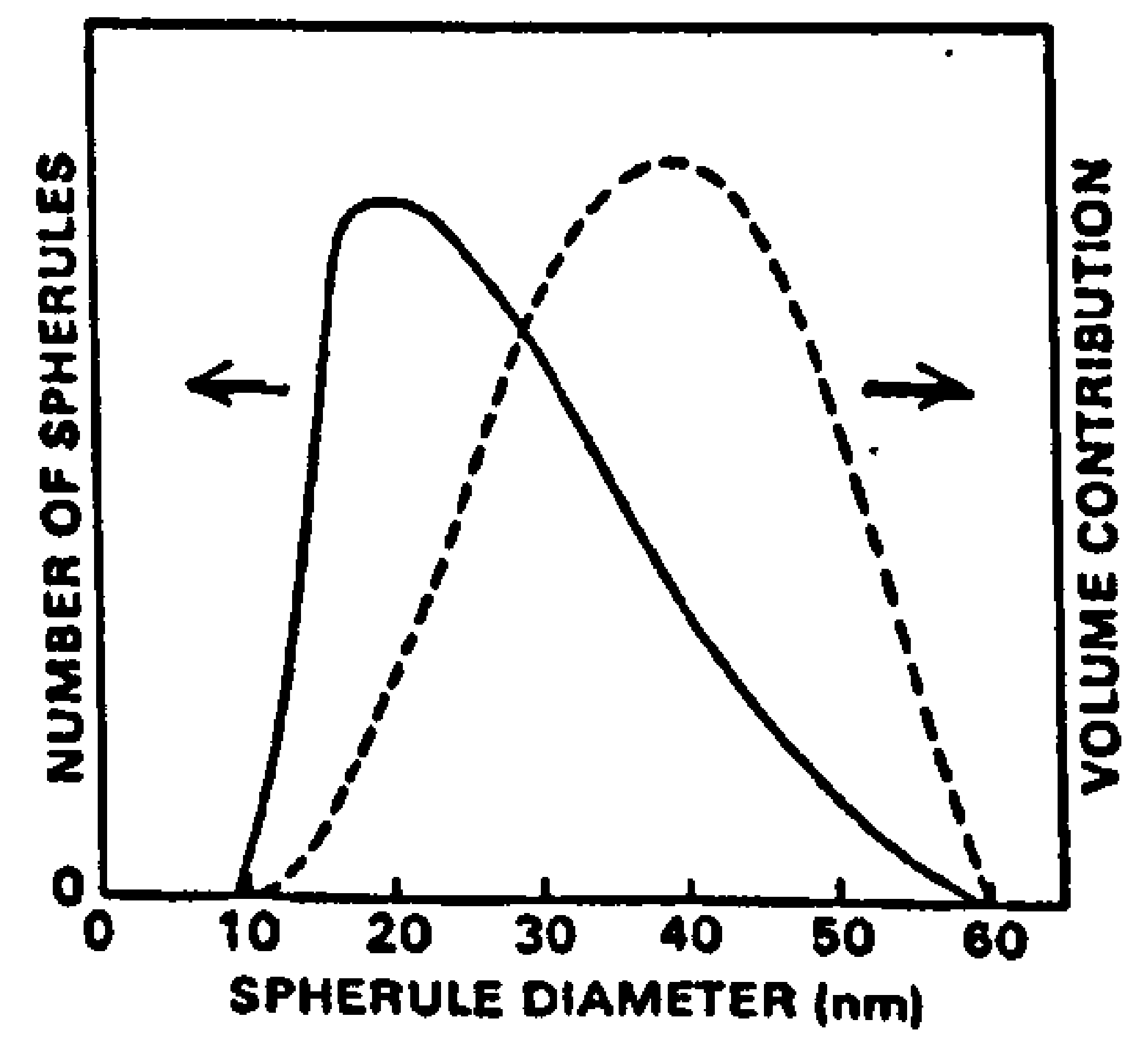

Fig. 2-2 Typical distributions of diesel soot spherule diameter and volume [Amann and Siegla, 1982] 

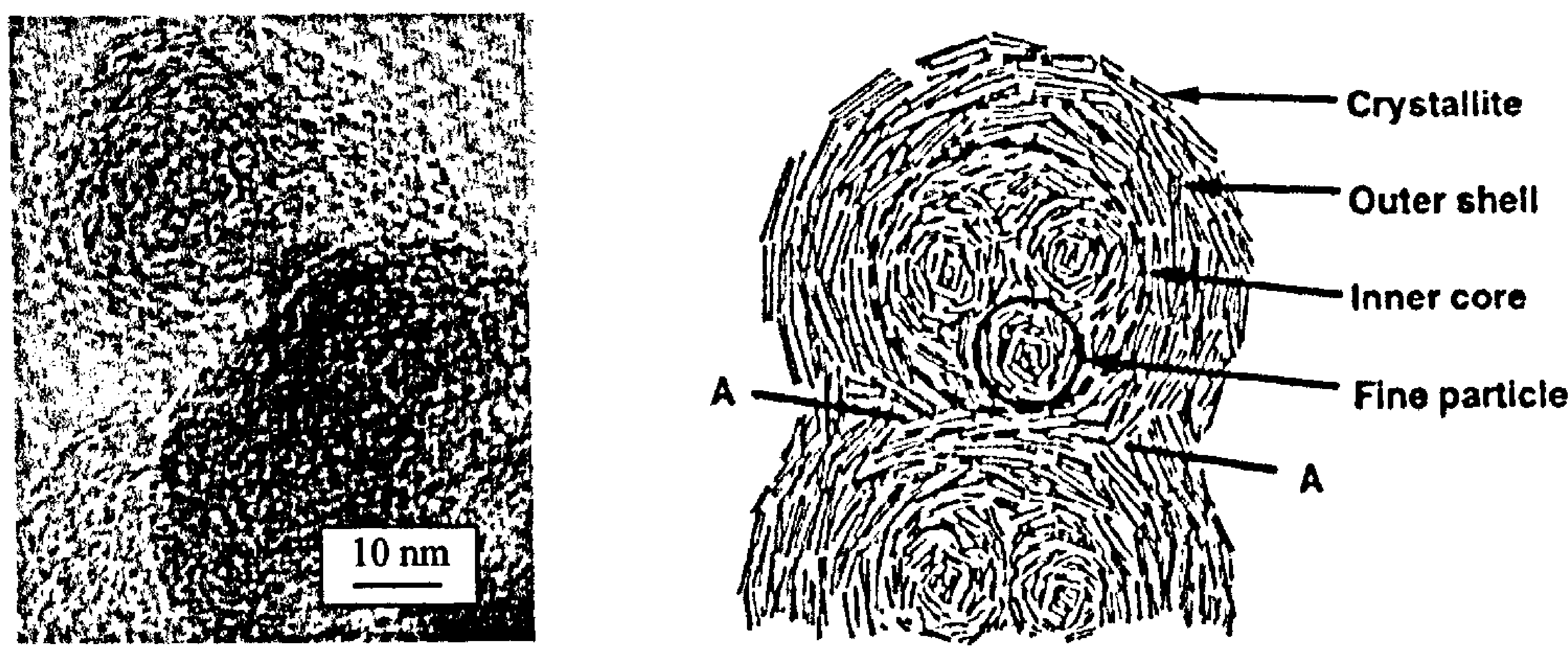

Fig 2-3 Microstructure of diesel soot

Left: electron micrograph of diesel soot spherules [Lahaye and Prado, 1981]

Right: A schematic model of microstructure of the diesel soot spherule [Ishiguro et al, 1997]

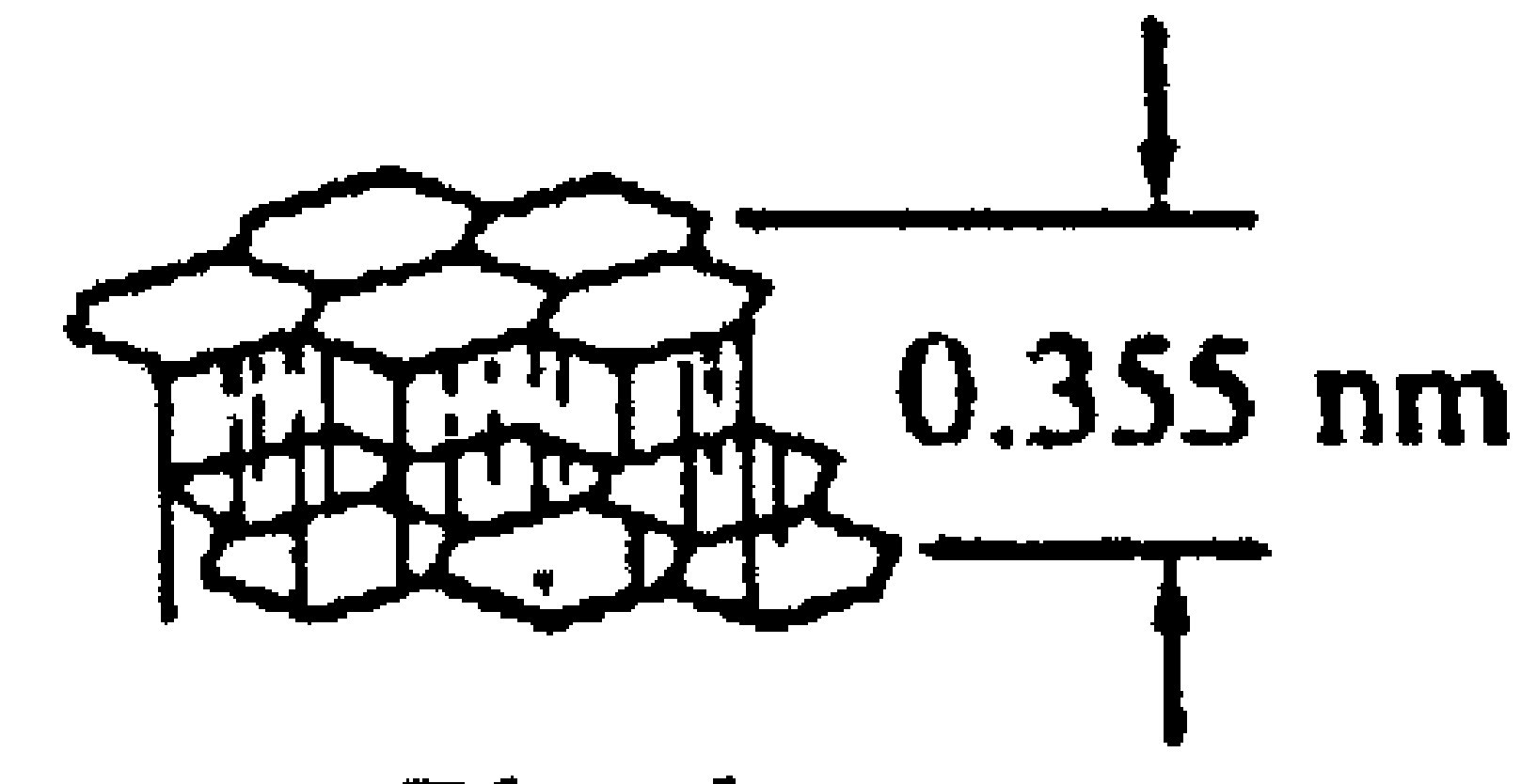

Platelet

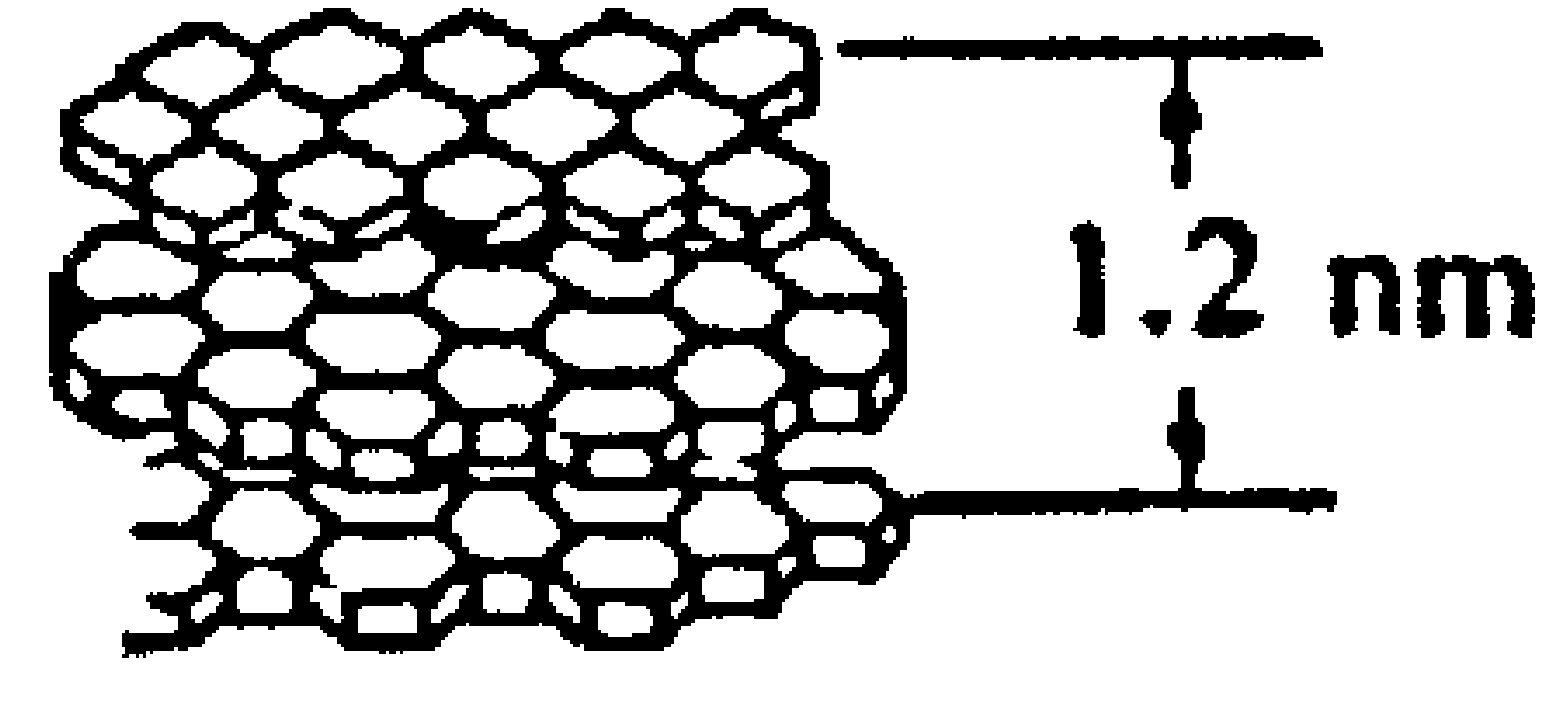

Crystallite

Fig. 2-4 Carbon platelet and crystallite in diesel soot [Heywood, 1988] 
Table 3-1 Specifications of the CFR diesel engine

\begin{tabular}{l|l}
\hline \multicolumn{1}{c|}{ Parameters } & \multicolumn{1}{c}{ Description } \\
\hline Model & CFR F-5 cylinder pre-combustion chamber \\
Type & Single chatle \\
& naturally aspirated \\
Rated speed (r/min) & 900 \\
Injection flow rate at rated speed (m//min) & 13.0 \\
Cylinder bore (mm) & 82.6 \\
Stroke (mm) & 114.3 \\
Compression & Adjustable 8:1 to 36:1 (fixed at 19.2 in this study) \\
Injection timing (deg BTDC) & 13 \\
Displacement (l) & 0.612 \\
\hline
\end{tabular}

Table 3-2 Specifications of Brunel Laboratory Diesel Fuel

\begin{tabular}{|c|c|c|c|}
\hline$\overline{\text { Parameter }}$ & Test Method & $\overline{\text { Specification }}$ & Analysis Result \\
\hline Flash Point, ${ }^{\circ} \mathrm{C}$ & $\overline{\text { IP } 34}$ & $55 \mathrm{~min}$ & 71 \\
\hline Carbon Residue on $10 \%$ Residue, $\%(\mathrm{~m} / \mathrm{m})$ & IP 14 & $0.30 \max$ & 0.20 \\
\hline Ash Content, $\%(\mathrm{~m} / \mathrm{m})$ & IP 4 & $0.01 \max$ & $<0.005$ \\
\hline Water Content, $(\mathrm{mg} / \mathrm{kg})$ & ASTM D1744 & $200 \max$ & 61 \\
\hline Particulates, (mg/kg) & DIN 51419 & $24 \max$ & 13 \\
\hline Oxidation Stability, $\left(\mathrm{g} / \mathrm{m}^{3}\right)$ & ASTM D2274 & $25 \max$ & 14 \\
\hline Sulphur, $\%(\mathrm{~m} / \mathrm{m})$ & IP 336 & $0.20 \max$ & 0.19 \\
\hline Density @ $15^{\circ} \mathrm{C},\left(\mathrm{kg} / \mathrm{m}^{3}\right)$ & ASTM D4052 & $820-860$ & 853.8 \\
\hline Cetane Number & ASTM D613 & $49 \mathrm{~min}$ & 49.1 \\
\hline Cetane Index & ISO 4264 & $46 \mathrm{~min}$ & 47.3 \\
\hline Carbon $\%(\mathrm{~m} / \mathrm{m})$ & ASTM D5291 & & 86.2 \\
\hline Hydrogen $\%(\mathrm{~m} / \mathrm{m})$ & ASTM D5291 & & 13.4 \\
\hline Aromatics $\%(v / v)$ & IP 156 & & 25.1 \\
\hline Olefins $\%(v / v)$ & IP 156 & & 2.5 \\
\hline Saturates \% (v/v) & IP 156 & & 72.4 \\
\hline 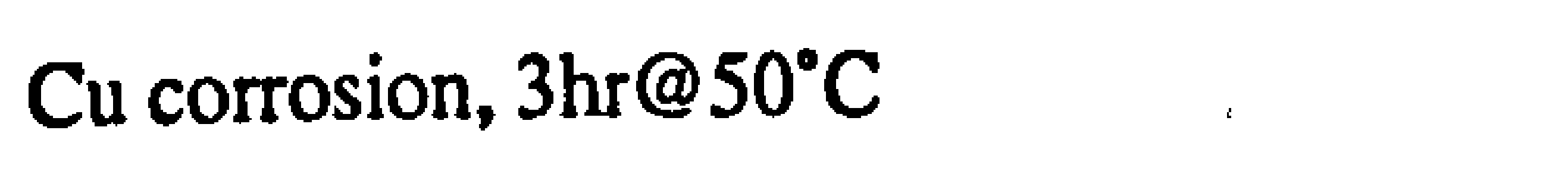 & IP154 & $1 \max$ & 1 \\
\hline Water \& Sediment, $\%[\mathrm{v} / \mathrm{v}]$ & Visual & & Nil \\
\hline
\end{tabular}

Analysis carried out by British Petroleum (BP) Sunbury Research Centre 
Table 3-3 Specifications of P1300 Lamdascan Control Unit

\begin{tabular}{l|l}
\hline \multicolumn{1}{c|}{ Parameters } & \multicolumn{1}{c}{ Performance } \\
\hline Accuracy & $\pm 0.04 \%$ vol $\mathrm{O}_{2}$ \\
Stability & Better than $\pm 0.02 \%$ vol $\mathrm{O}_{2}$ over $2 \mathrm{hr}$ measurement period \\
Resolution & $\pm 0.01 \%$ vol $\mathrm{O}_{2}$ \\
Repeatability & Better than $\pm 0.02 \%$ vol $\mathrm{O}_{2}$ \\
Lag time & Less than 1 second \\
\hline
\end{tabular}

Table 3-4 Estimation of the distance between the diesel soot clusters in the burner flame

\begin{tabular}{|c|c|c|c|}
\hline & Symbol & Equation & Value \\
\hline \multicolumn{4}{|l|}{ Soot concentration in exhaust gas: } \\
\hline Bosh Number (assumed) & $\mathrm{Bn}$ & & 5 \\
\hline Soot mass Concentration & $C_{m}$ & & $0.474 \mathrm{~g} \mathrm{~m}^{-3} *$ \\
\hline $\begin{array}{l}\text { Volume mean diameter of primary soot } \\
\text { particles }\end{array}$ & $d_{m}$ & & $31 \mathrm{~nm} * *$ \\
\hline Density of diesel soot particles & $\rho$ & & $2 \mathrm{~g} \mathrm{~cm}^{-3 * *}$ \\
\hline Soot number concentration in exhaust & $\mathrm{Cn}_{\mathrm{ex}}$ & $\mathrm{Cn}_{\mathrm{ex}}=6 \mathrm{Cm} /\left(\pi \mathrm{dm}^{3}\right)$ & $1.519 \times 10^{16} \mathrm{~m}^{-3}$ \\
\hline \multicolumn{4}{|l|}{ Soot concentration upstream burner: } \\
\hline Typical air flow rate (at ATP) & Vair & & $5.7 \mathrm{~L} \min ^{-1}$ \\
\hline Typical methane flow rate (at ATP) & $\mathrm{V}_{\mathrm{CH} 4}$ & & $0.2 \mathrm{~L} \mathrm{~min}^{-1}$ \\
\hline Exhaust flow rate (at ATP, estimated) & $\mathrm{V}_{\mathrm{ex}}$ & & $0.1 \mathrm{~L} \mathrm{~min}^{-1}$ \\
\hline Soot number concentration in mixture & $\mathrm{Cn}_{\text {mix }}$ & $\mathrm{Cn}_{\mathrm{mix}}=\mathrm{Cn}_{\mathrm{ex}} \mathrm{V}_{\mathrm{ex}} /\left(\mathrm{Vair}+\mathrm{V}_{\mathrm{CH} 4}+\mathrm{V}_{\mathrm{ex}}\right)$ & $2.532 \times 10^{11} \mathrm{~L}^{-1}$ \\
\hline \multicolumn{4}{|l|}{$\begin{array}{l}\text { Soot concentration in burner flame: } \\
\text { Take the flame gas as ideal gas, neglect the } \\
\text { pressure difference between upstream } \\
\text { burner and in the flame } \\
\text { Temperature upstream burner }\end{array}$} \\
\hline Average temperature in flame & $\mathrm{T}_{\mathrm{f}}$ & & $1600 \mathrm{~K}$ \\
\hline Gas volume expanding ratio & Rv & $R v=T_{f} / T_{0}$ & 5.5 \\
\hline Soot number concentration in flame & $\mathrm{Cnf}$ & $\mathrm{Cnf}=\mathrm{Cn}_{\mathrm{mix}} / \mathrm{Rv}$ & $4.604 \times 10^{10} \mathrm{~L}^{-1}$ \\
\hline \multicolumn{4}{|l|}{ Distance between soot clusters in flame: } \\
\hline Number of primary spherules in big cluster & $\mathrm{N}$ & & $4000[* *]$ \\
\hline Size of big cluster (take them as balls) & D & $D=d m N^{1 / 3}$ & $492 \mathrm{~nm}$ \\
\hline $\begin{array}{l}\text { Average distance between neighboring } \\
\text { clusters (even if all the clusters would } \\
\text { contain } 4000 \text { spherules) }\end{array}$ & $\mathbf{S}$ & $S=10 \mathrm{~cm} /\left(\mathrm{Cnf}^{1 / 3}-1\right)$ & $2.79 \times 10^{4} \mathrm{~nm}$ \\
\hline Ratio of S to D & $\mathrm{S} / \mathrm{D}$ & & $\overline{57}$ \\
\hline
\end{tabular}

* Data of MIRA-report No. $1965 / 10$

** [Heywood, 1988] 


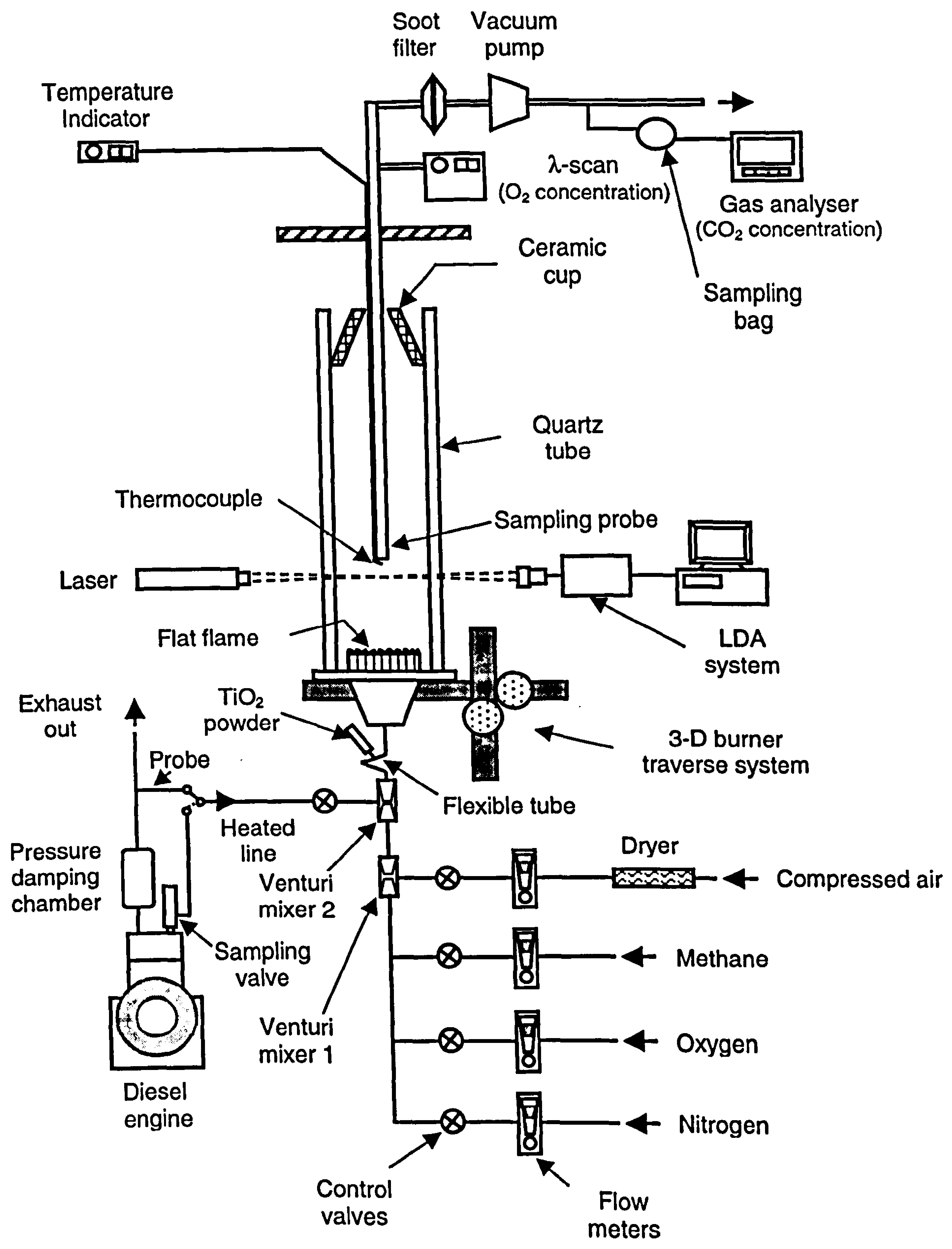

Fig. 3-1 Schematic diagram of the experimental rig 


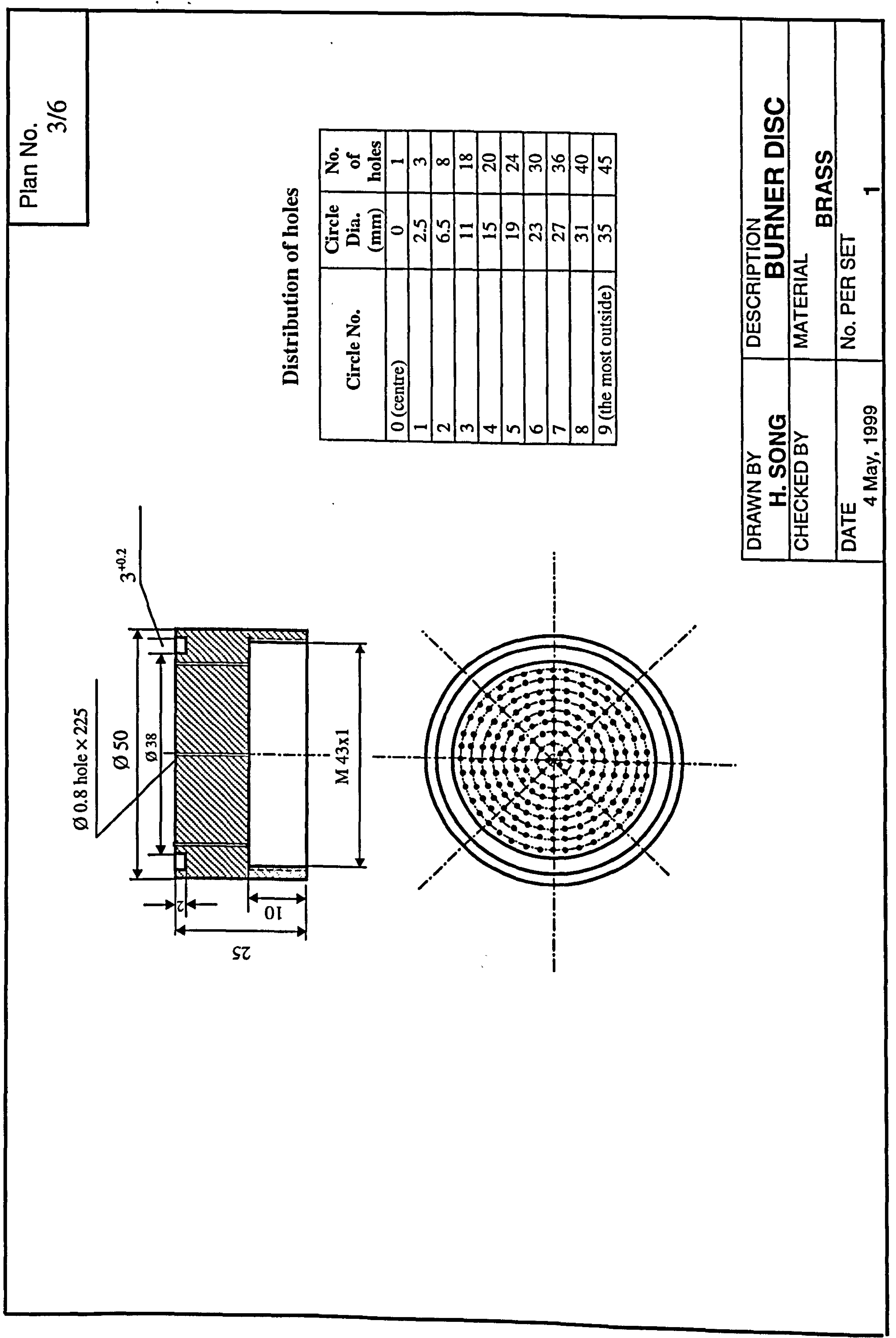

ڤั. 


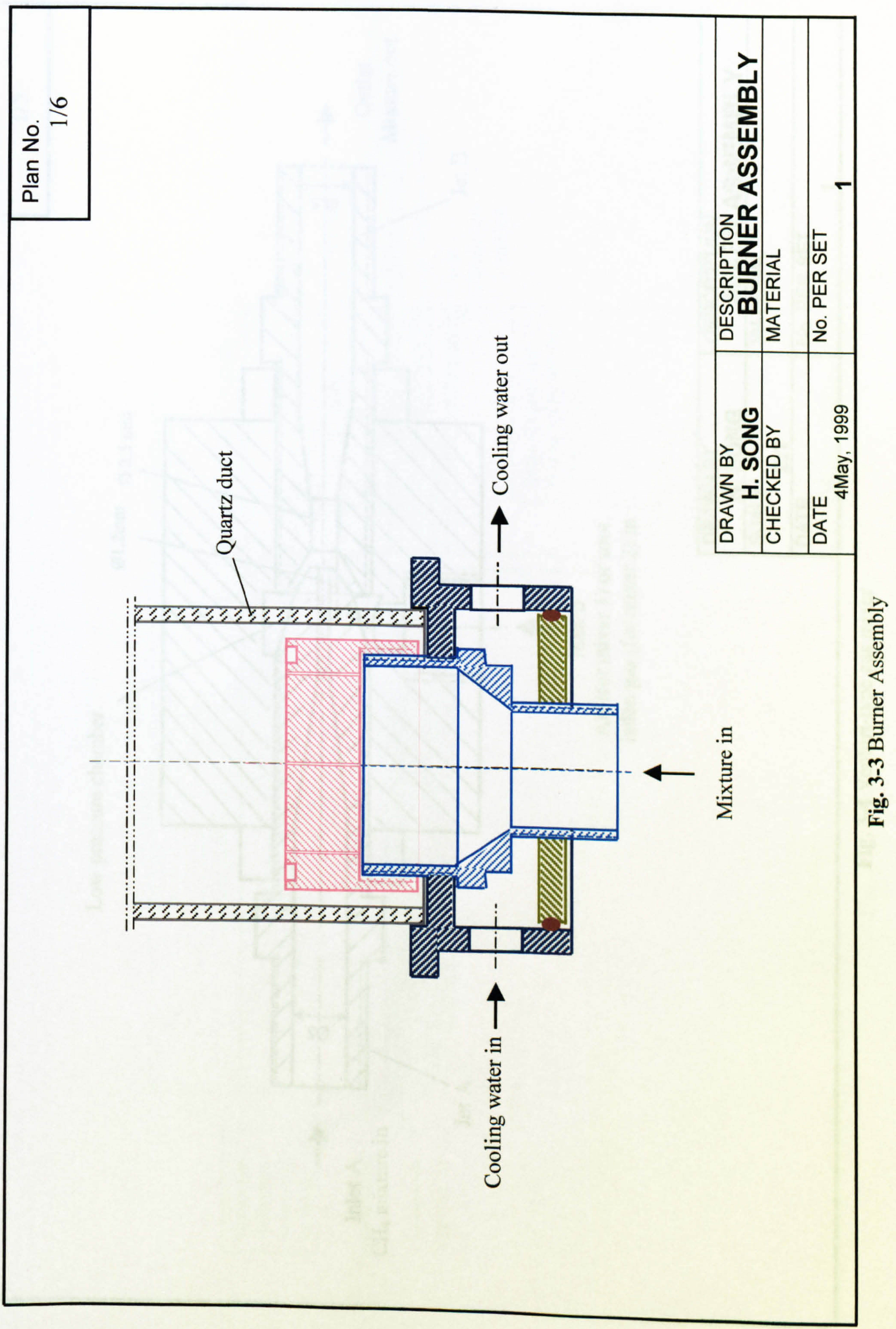




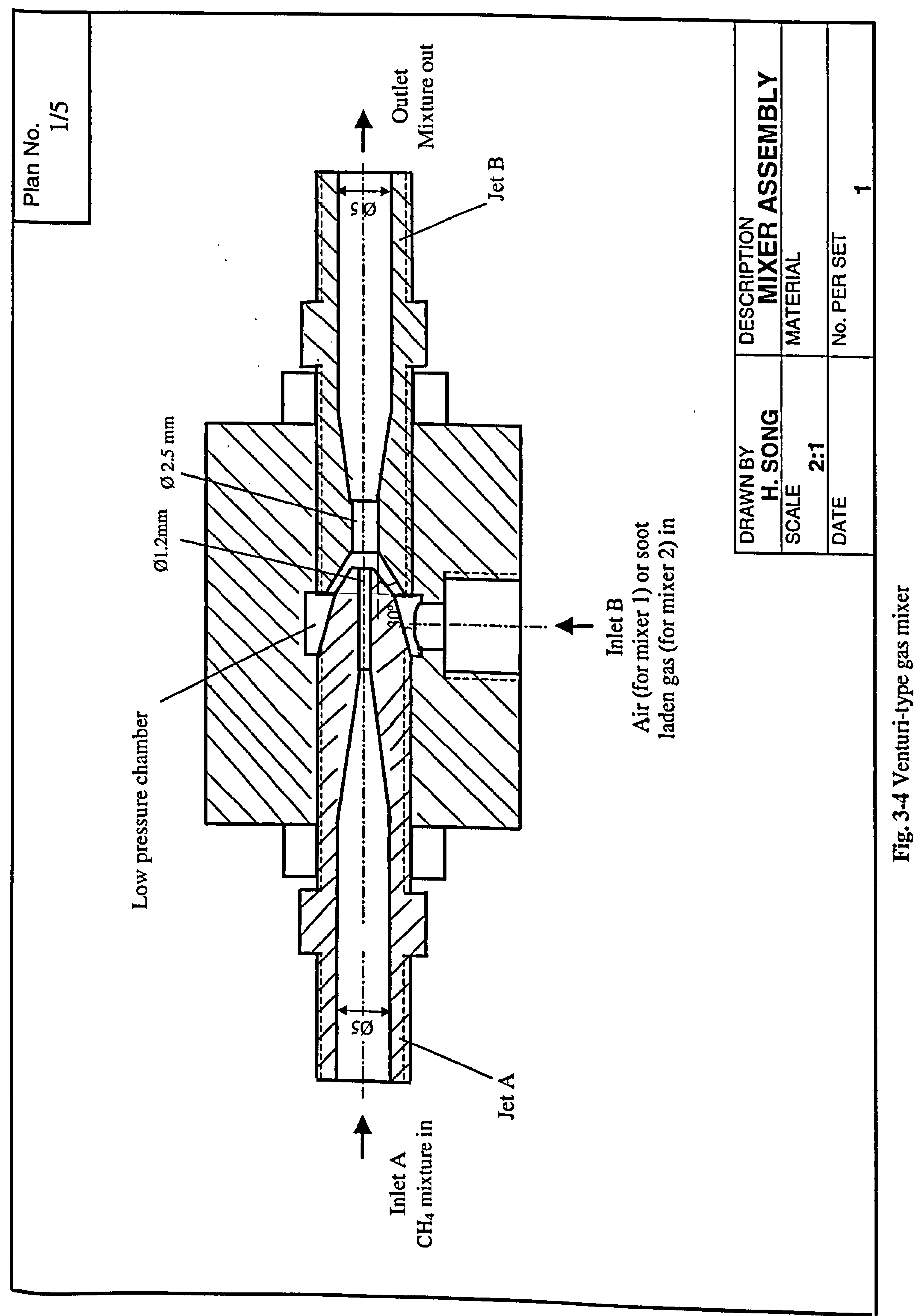




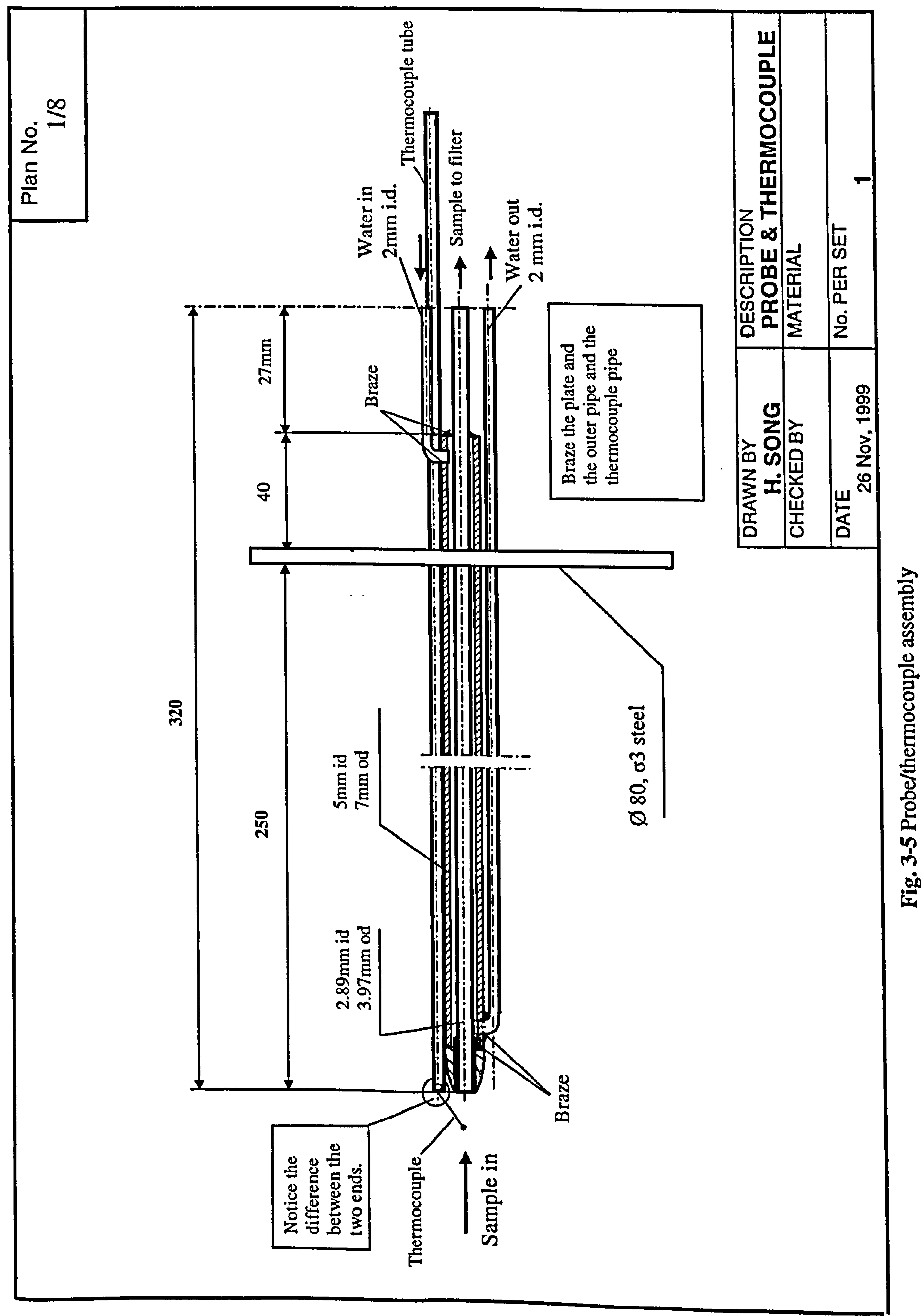




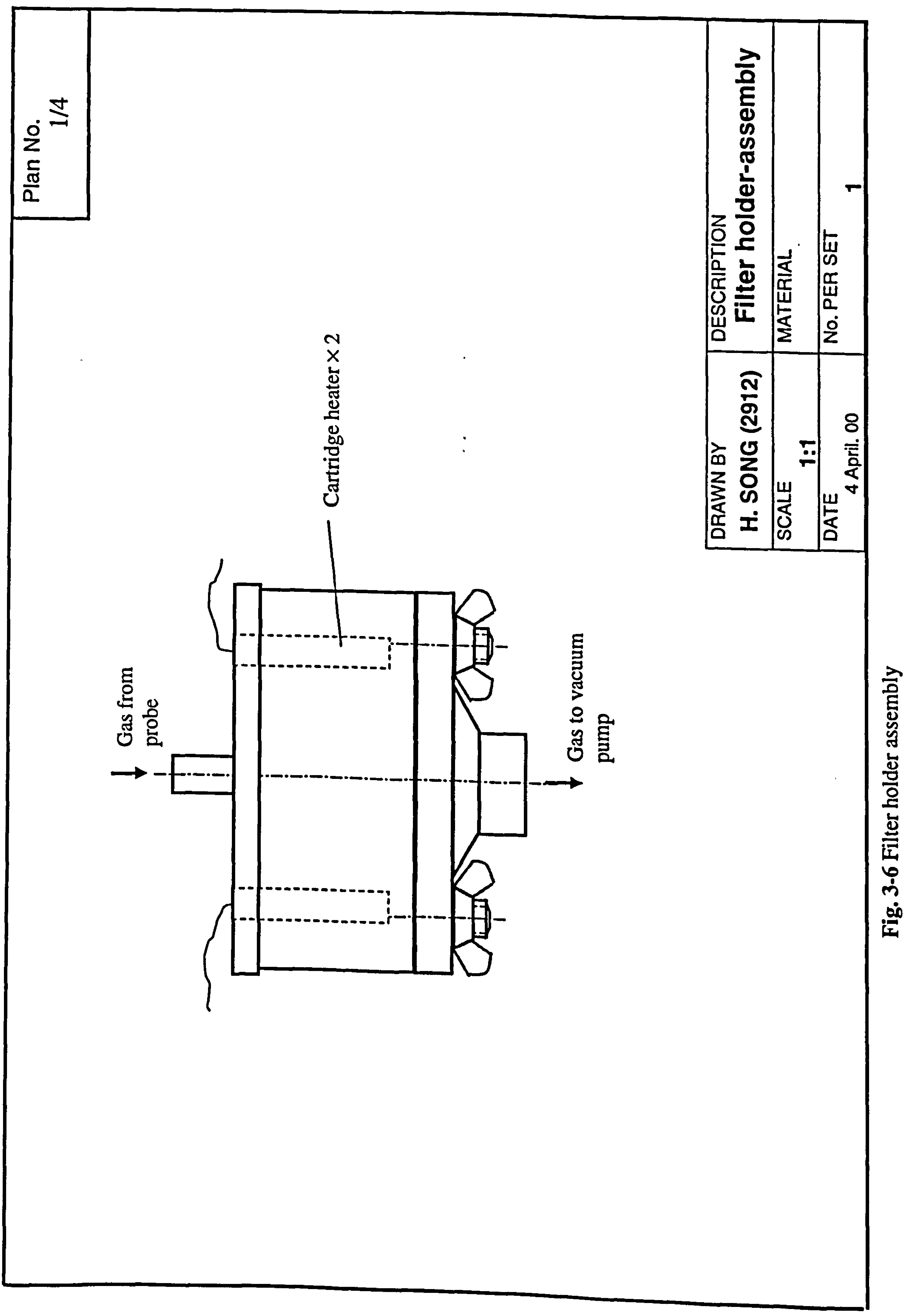




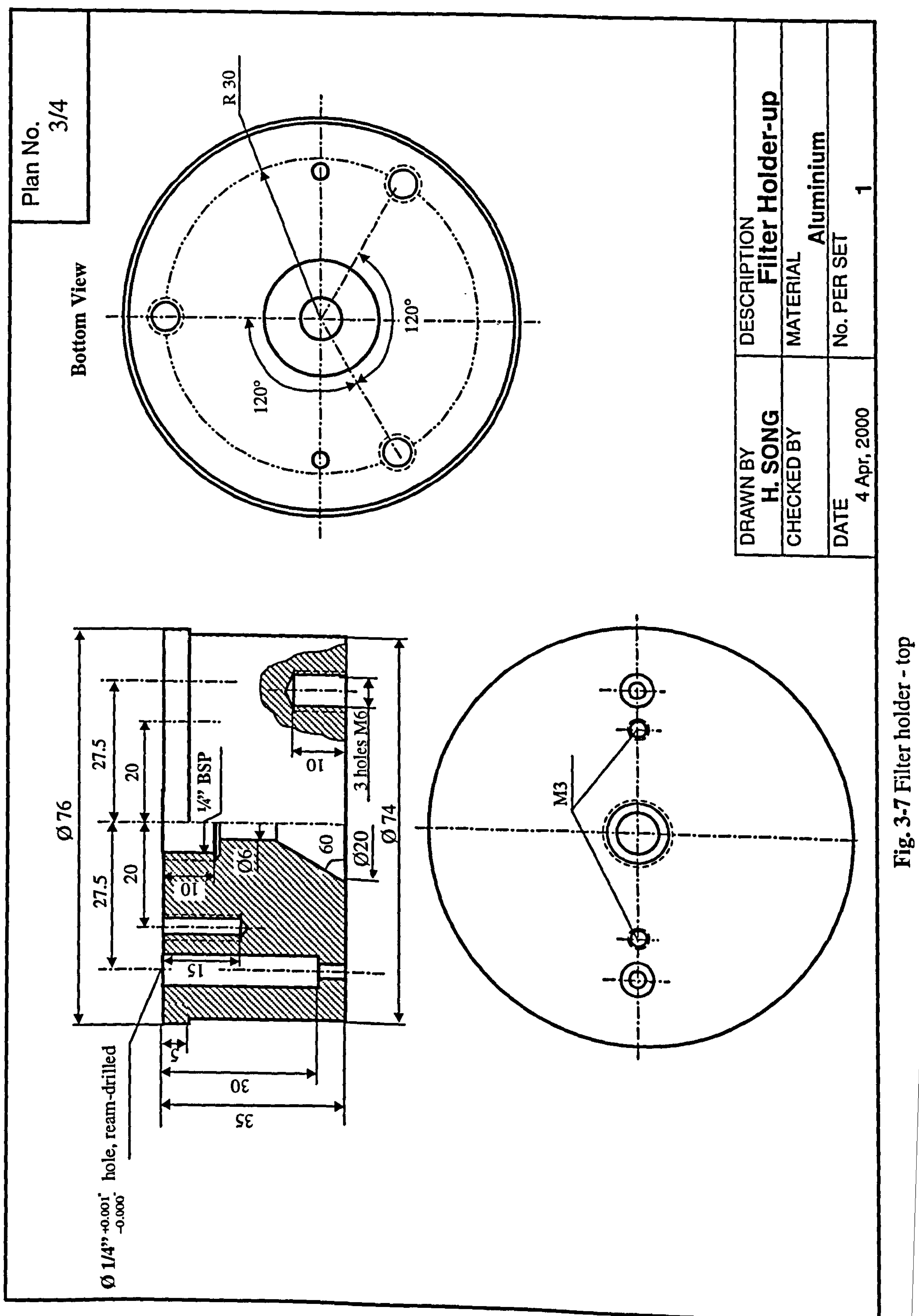




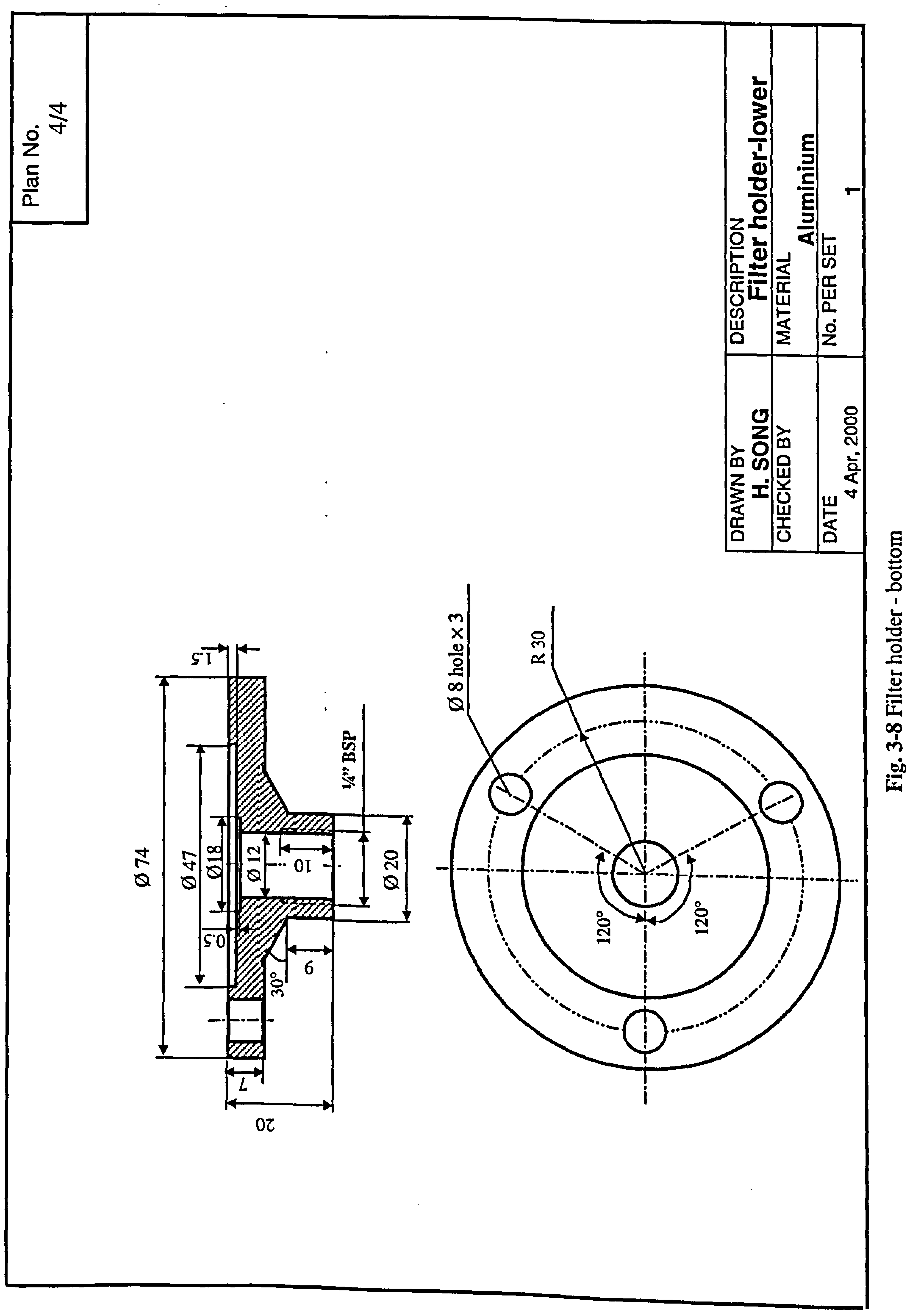




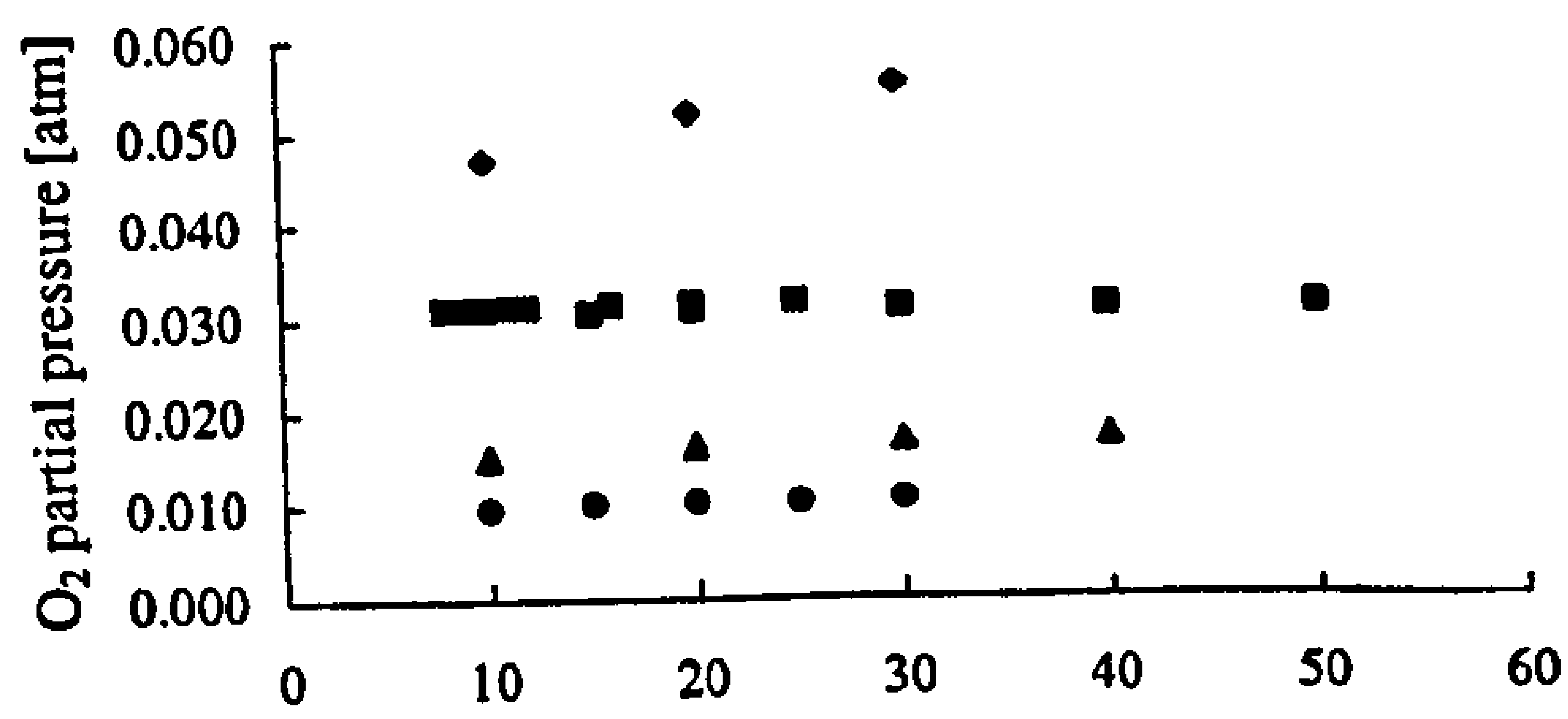

(a)

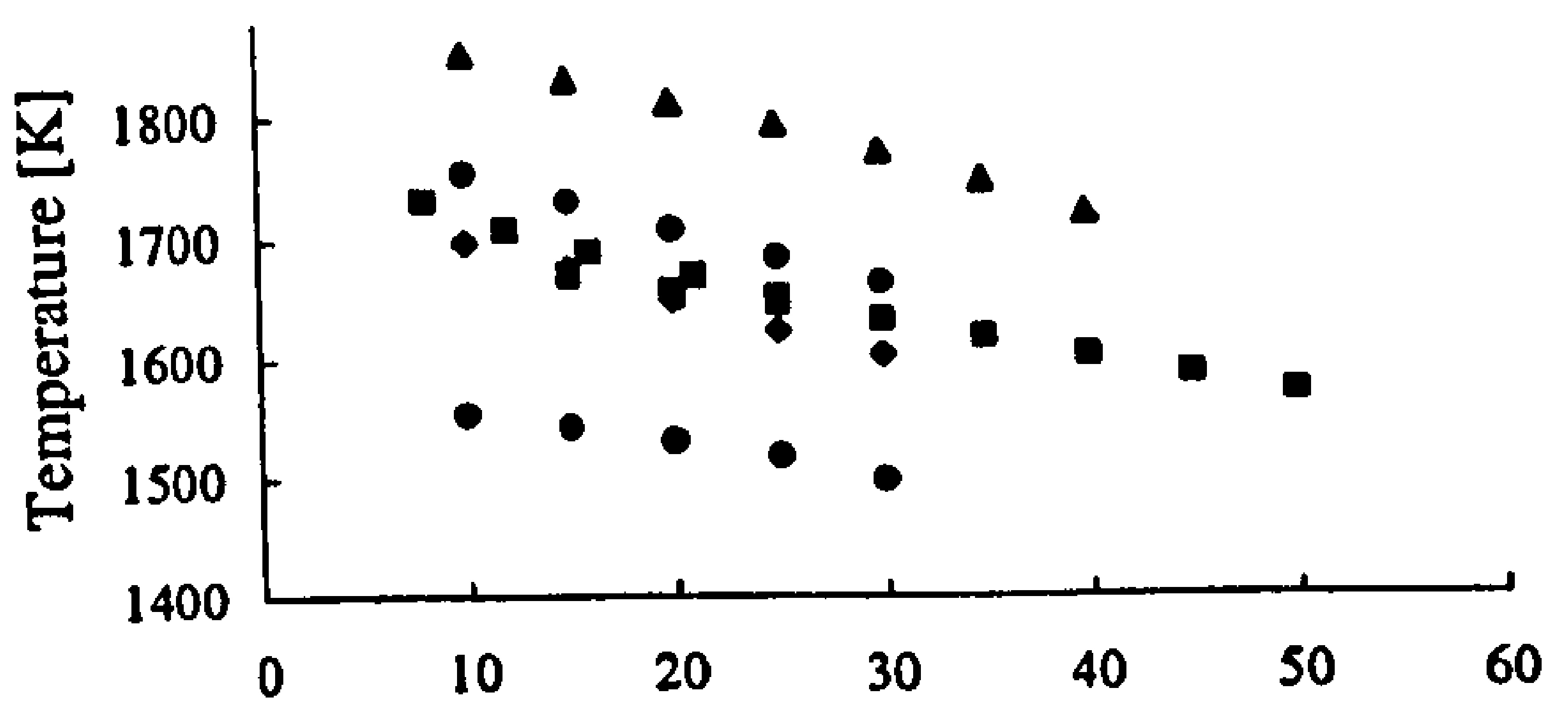

(b)

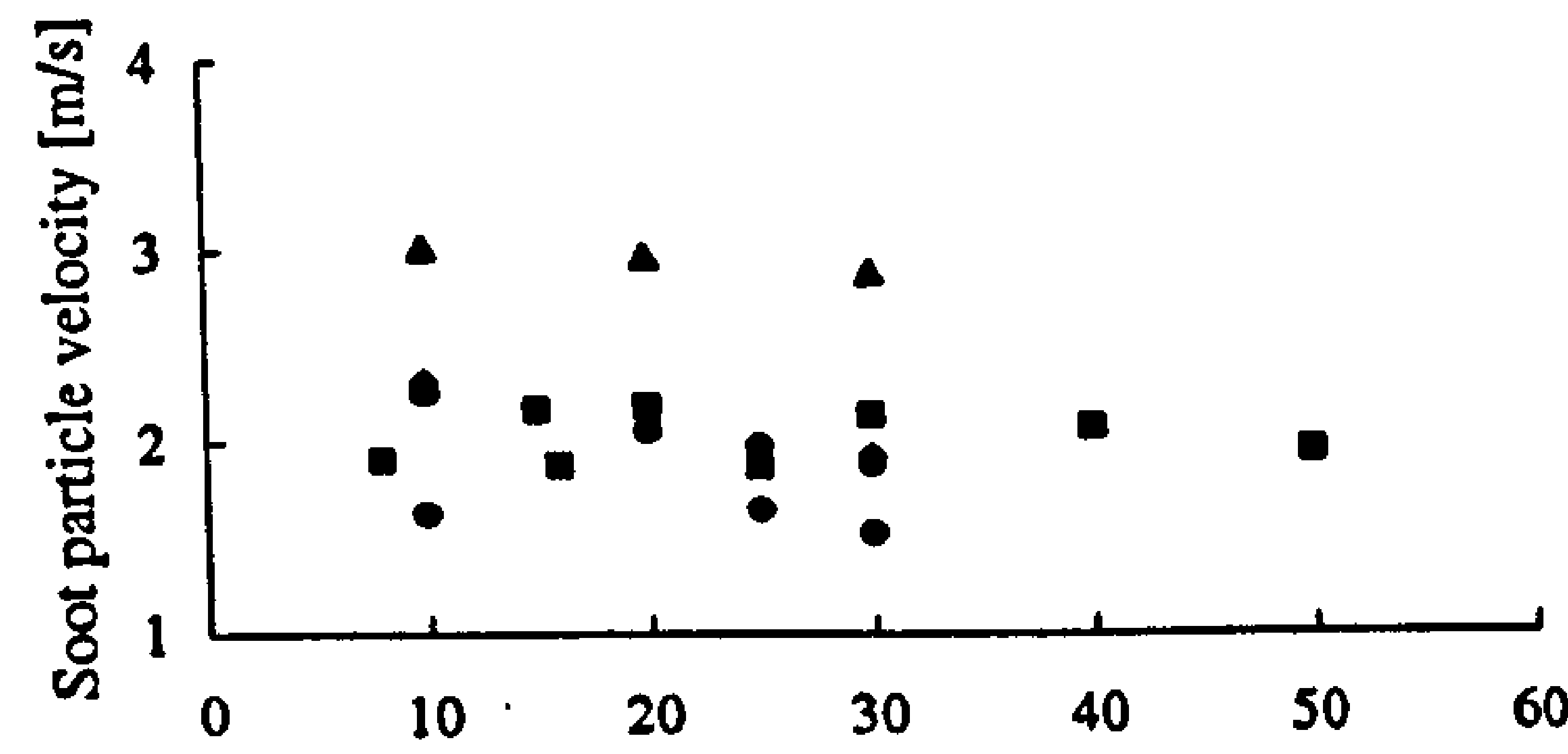

(c)

Height above burner [mm]

- Test No.: •Exh-1 $\bullet$ Exh-2 $\bullet$ Exh-3,4 $\triangle$ Exh-5,6 • Exh-7,8

Fig. 3-9 measured gas stream oxygen partial pressure, temperature, and soot particle velocity profiles along the quartz tube oxidizer centreline

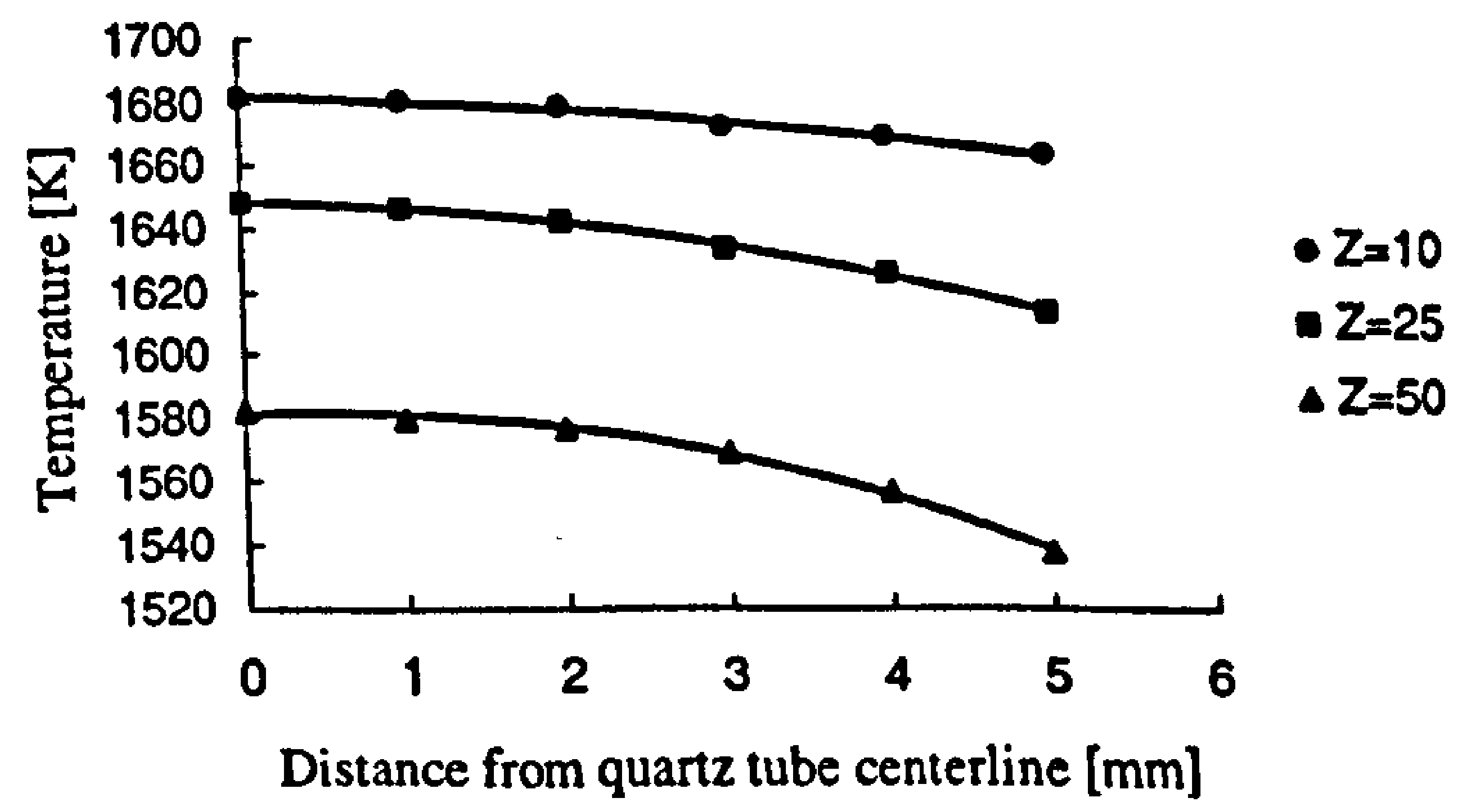

Fig 3-10 Temperature profiles over the radius of the oxidation quartz tube at different heights above the burner 


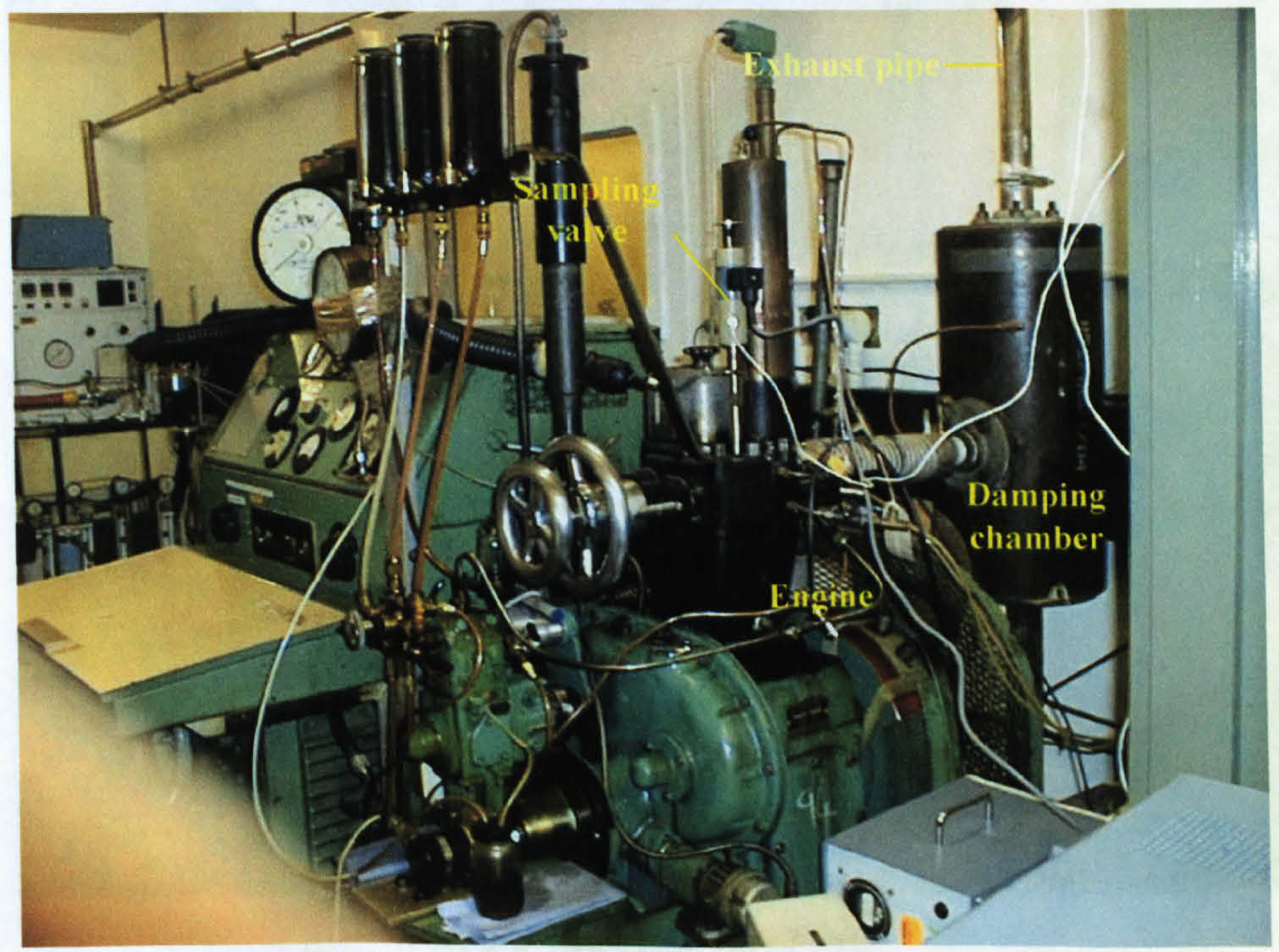

Pic. 3-1 The diesel engine

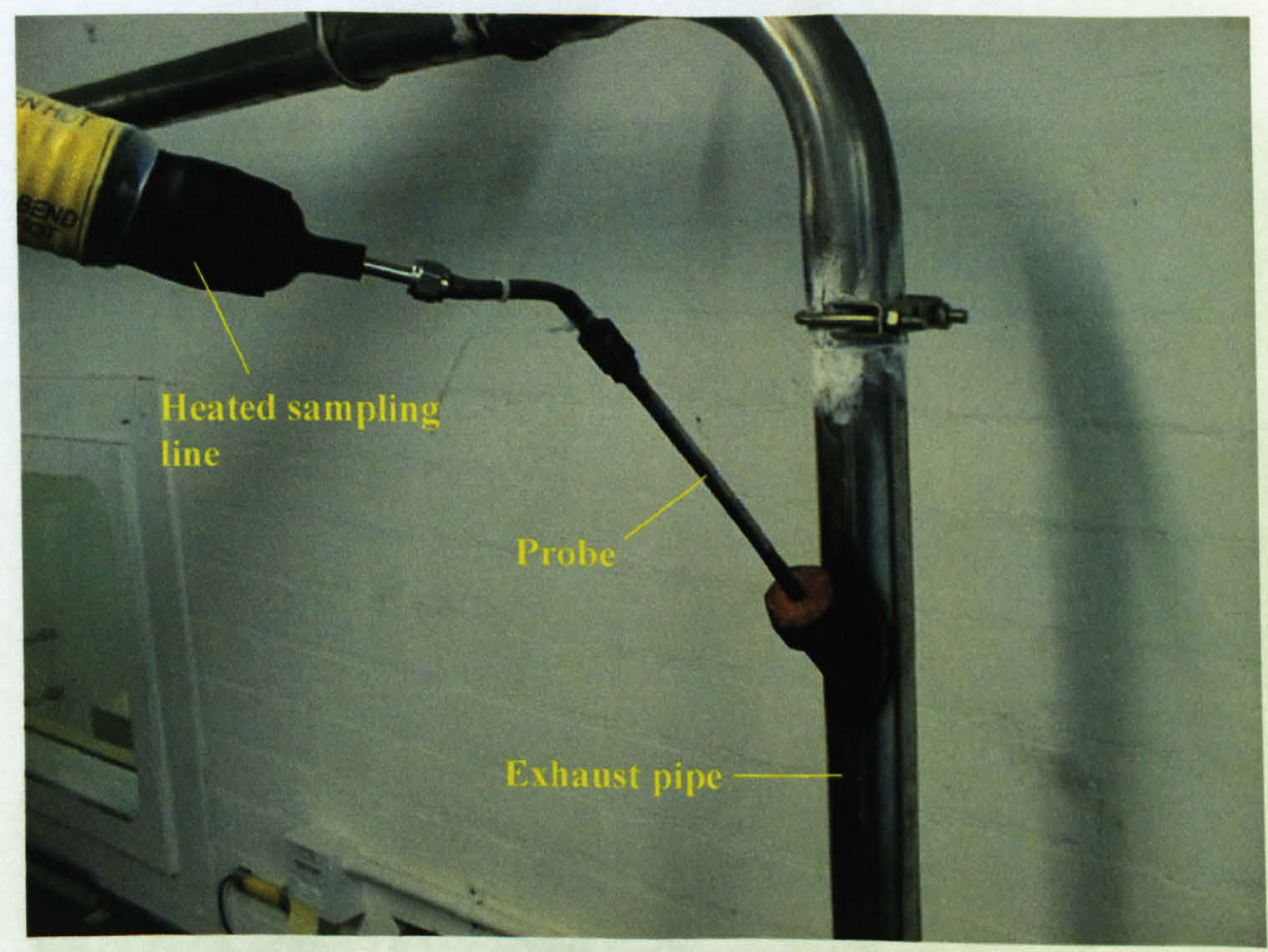

Pic 3-2 Probe in exhaust pipe and connected with heated line 


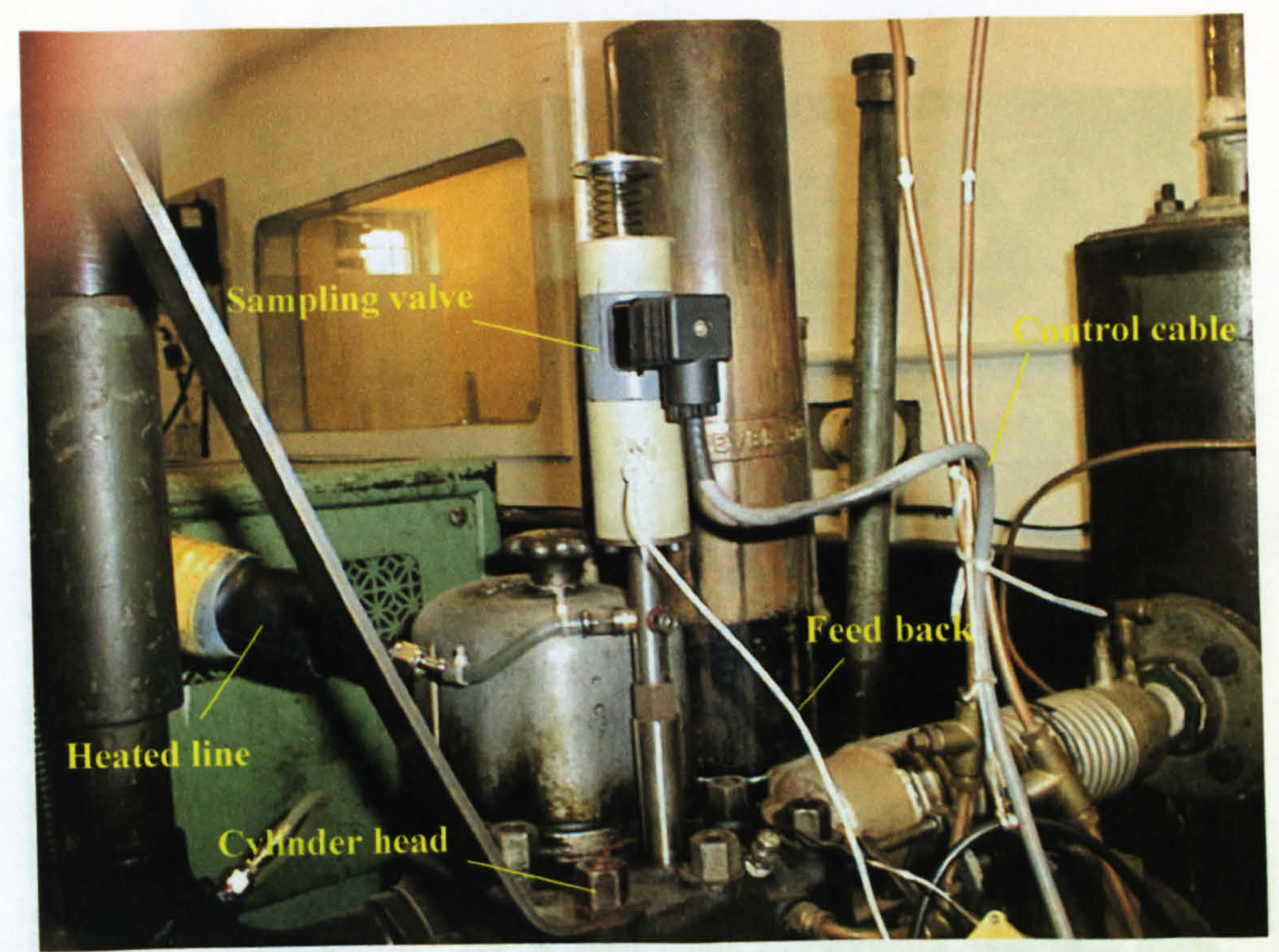

Pic. 3-3 Sampling valve

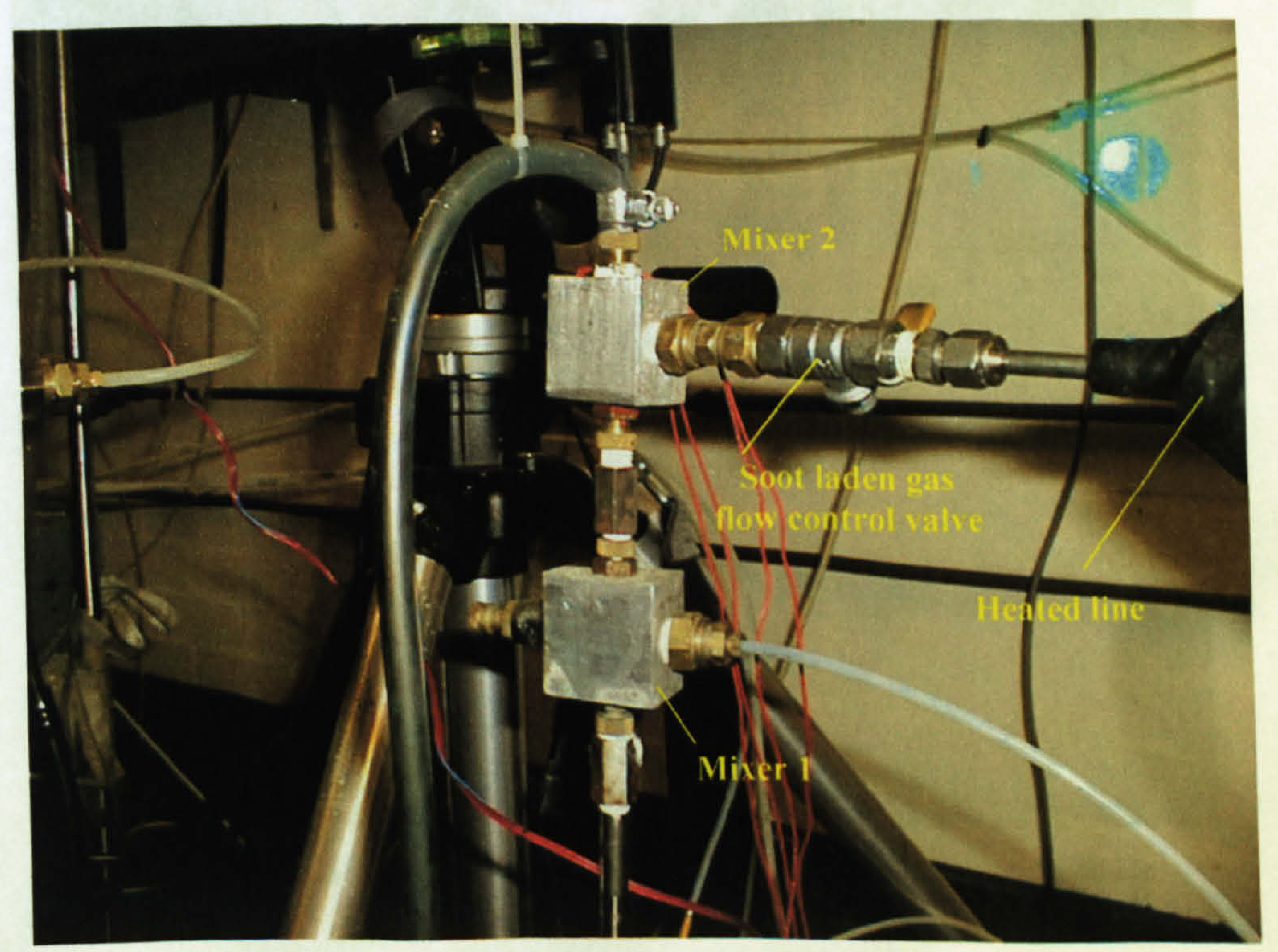

Pic. 3-4 Venturi-type gas mixers 


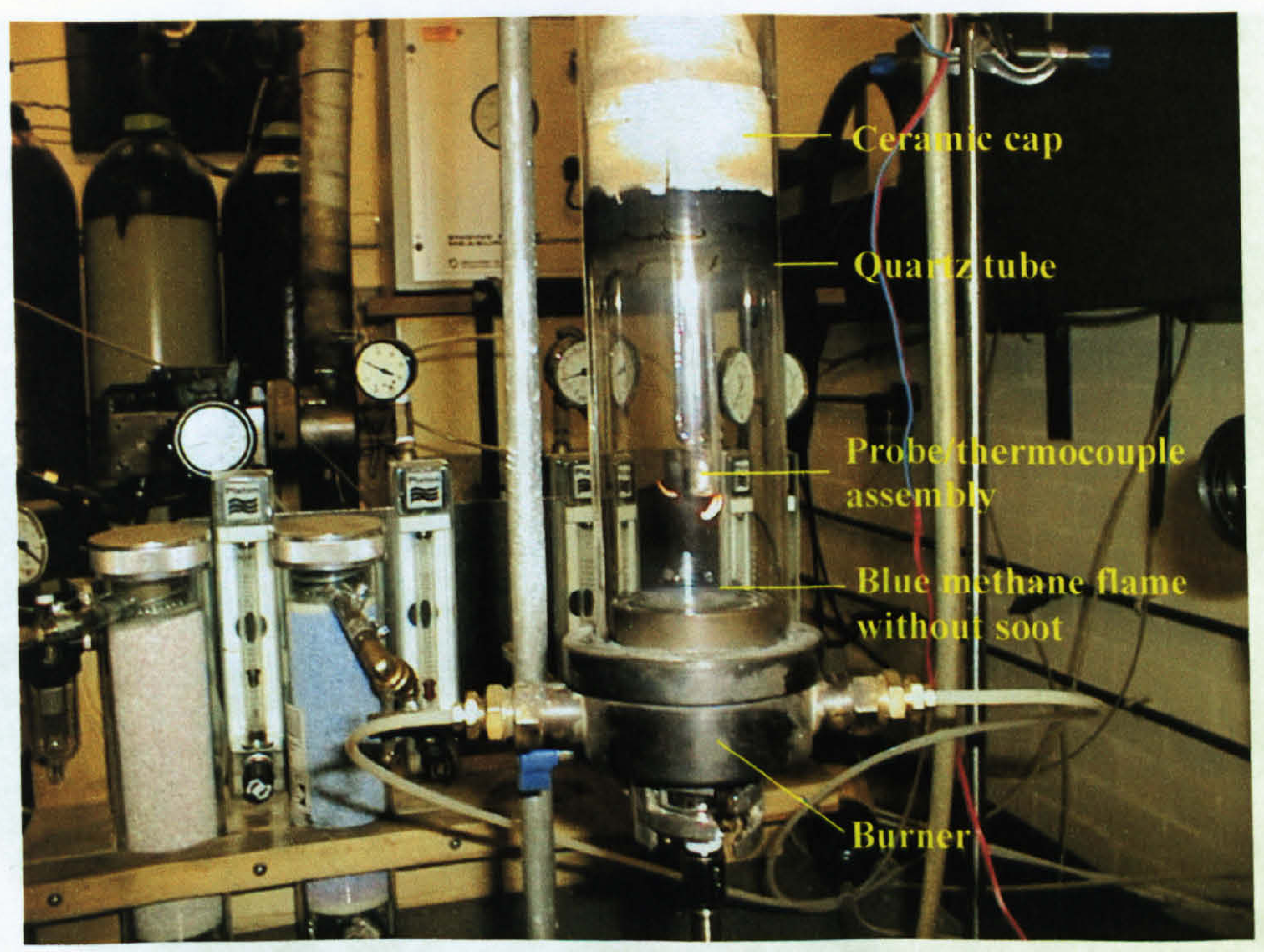

Pic 3-5 Fuel lean methane flame without introduction of diesel soot particles

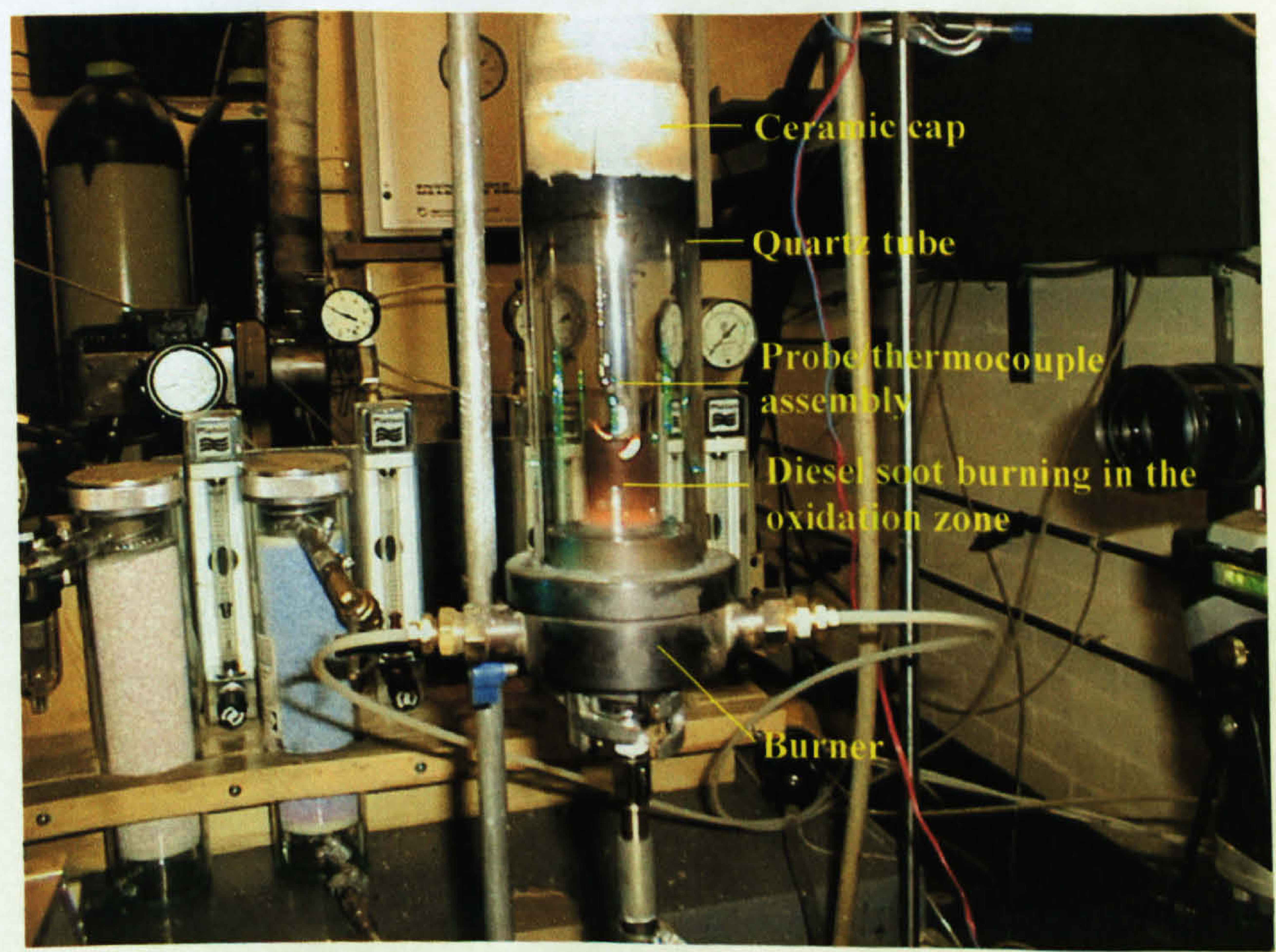

Pic 3-6 Fuel lean methane flame with burning diesel soot particles 


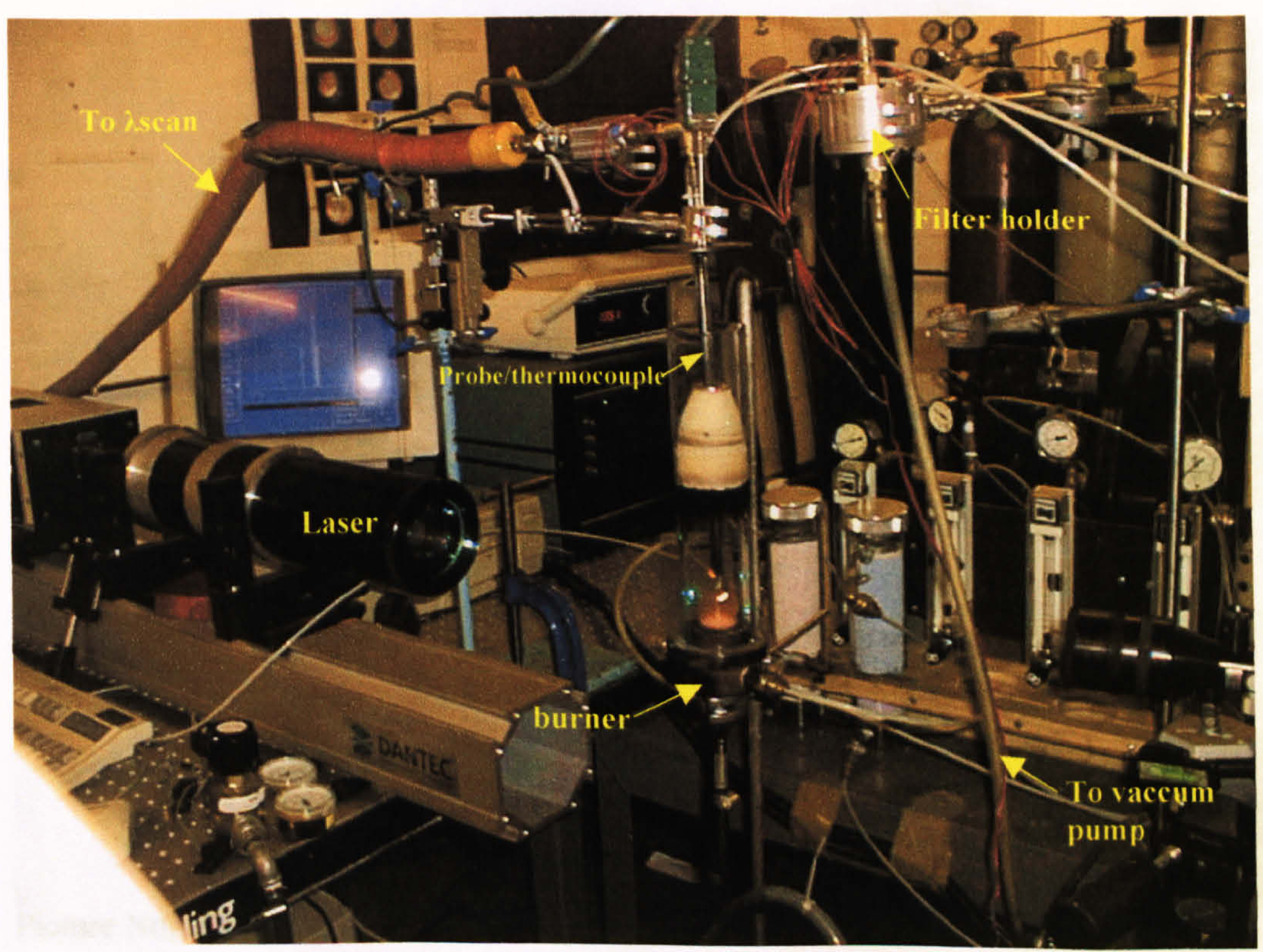

Pic. 3-7 Burner system and instrumentation 


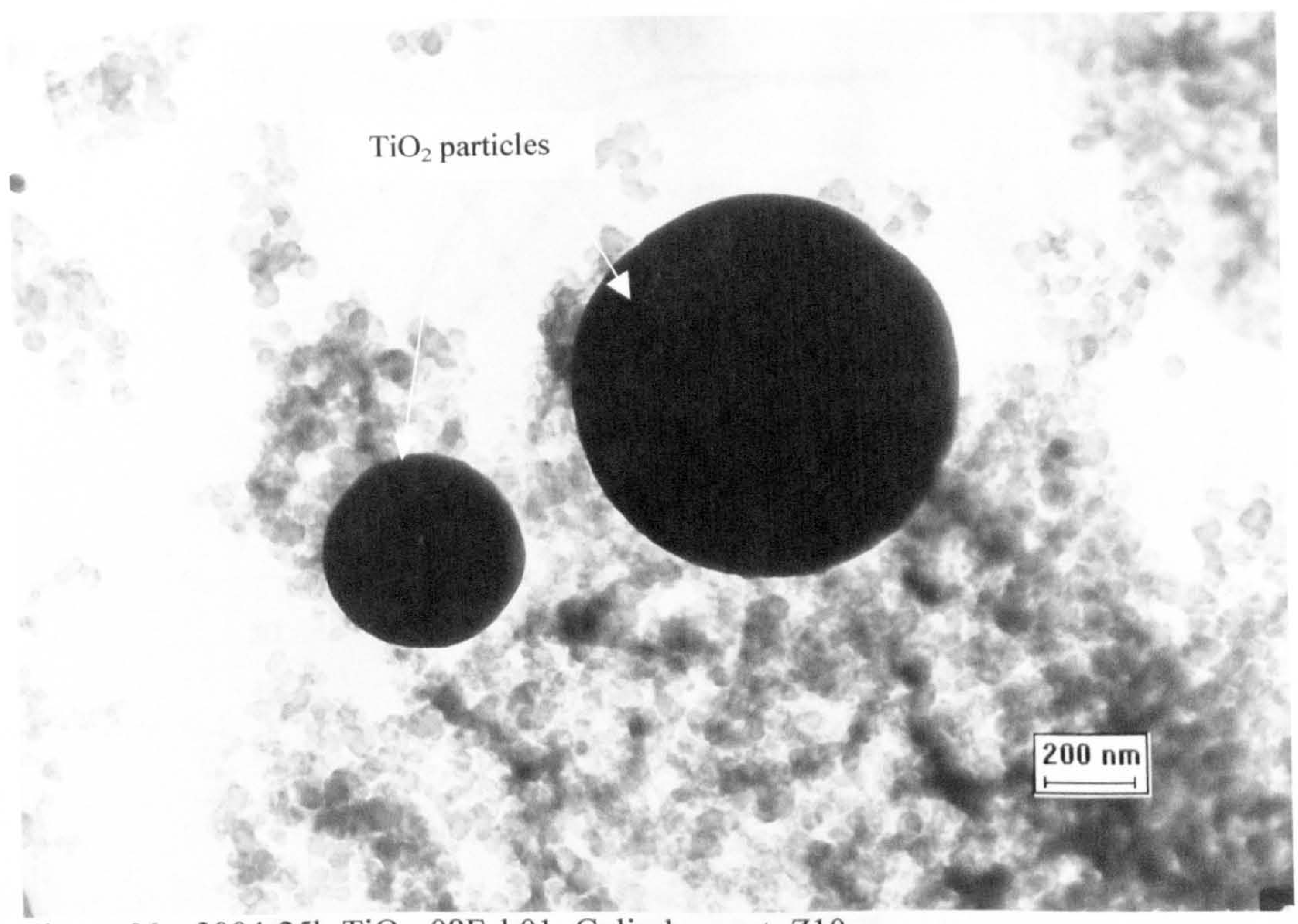

Picture No. 2004-25k-TiO 2 , 08Feb01, Cylinder soot, Z10
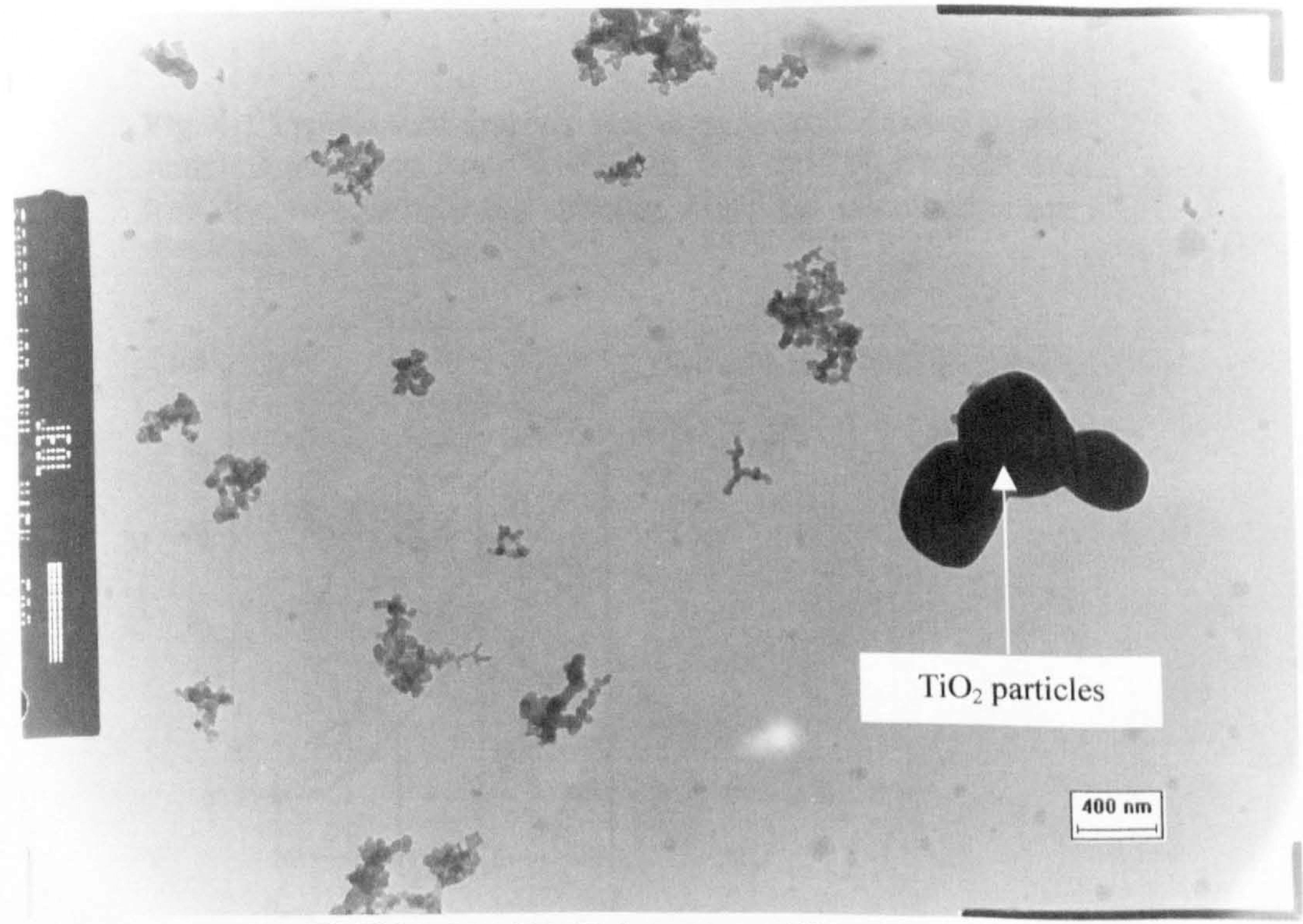

Picture No. 2239-15K-TiO 2 , 09Jul01, Exhaust soot, Z30

Pic. 3-8 Comparison of the sizes of $\mathrm{TiO}_{2}$ particles with those of diesel soot particles 

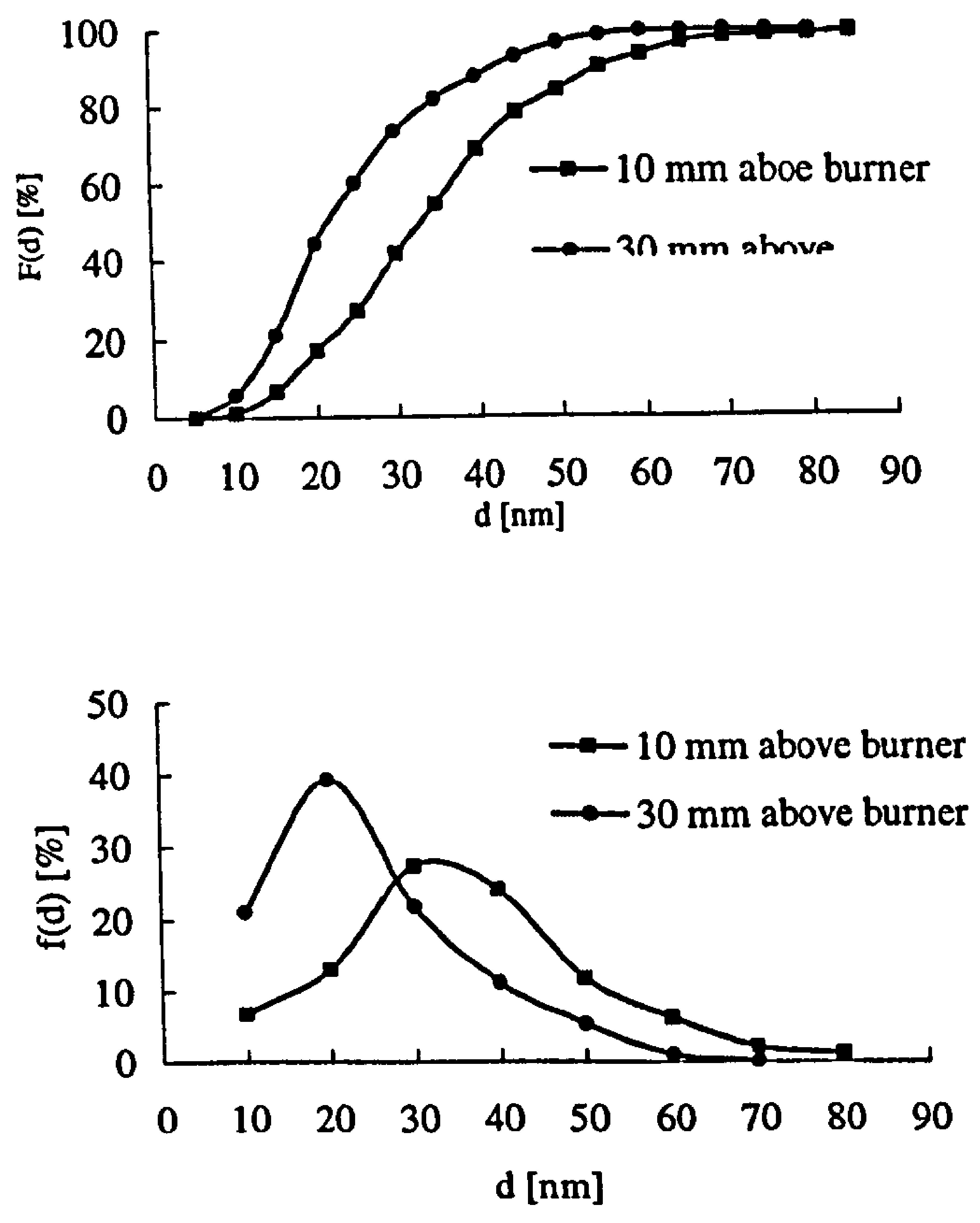

Fig. 4-1 Typical soot spherule size distributions at two different sampling positions. $\mathrm{Po}_{2}=0.051 \mathrm{~atm}, \mathrm{~T}=1652 \mathrm{~K}, \mathrm{t}=9.53 \mathrm{~ms}$. $f(d)$ : the size distribution density; $F(d)$ : the cumulative size distribution.

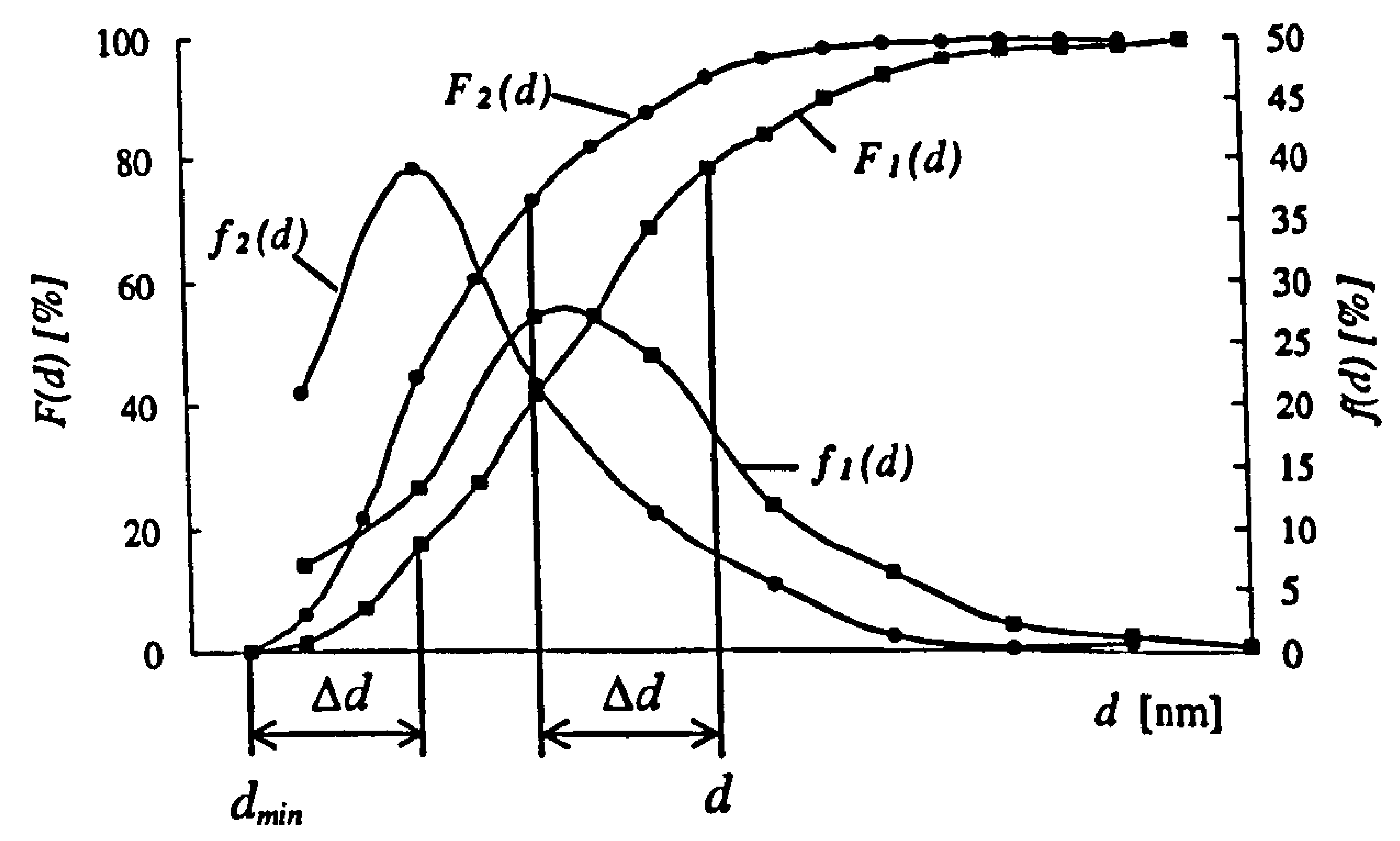

Fig 4-2 The relationship between two accumulative size distributions respectively measured at two heights above the burner 
Table 5-1 Comparison of decreases in number and volume mean diameters and diameter recession of soot due to oxidation in the burner post-flame gas stream

\begin{tabular}{c|c|c|c|c}
\hline Test No. & $\begin{array}{c}\text { Measuring } \\
\text { heights above the } \\
\text { burner [mm] }\end{array}$ & $\begin{array}{c}\text { Decrease in number } \\
\text { mean diameter* } \\
{[\mathrm{nm}]}\end{array}$ & $\begin{array}{c}\text { Decrease in volume } \\
\text { mean diameter* } \\
{[\mathrm{nm}]}\end{array}$ & $\begin{array}{c}\text { Diameter } \\
\text { recession** } \\
{[\mathrm{nm}]}\end{array}$ \\
\hline Prec-1 & 10,30 & 2 & 2 & 2 \\
Prex-1 & 10,30 & 8 & 9 & 15 \\
Exh-1 & 10,30 & 6 & 9 & 9 \\
Exh-2 & 8,25 & 5 & 4 & 7 \\
\hline
\end{tabular}

* Number (or volume) mean diameter decrease $=$ number (or volume) mean diameter of the soot spherules sampled at lower measuring height - number (or volume) mean diameter of the soot spherules sampled at higher measuring height

** Taking into account the complete burn-off of small soot spherules using the analytical method discussed in section 4.5.

Prec: Oxidation of diesel soot extracted from engine pre-chamber at $60^{\circ}-63^{\circ} \mathrm{CA}$ ATDC during the combustion stroke.

Prex: Oxidation of diesel soot extracted from engine pre-chamber at $20^{\circ}-23^{\circ} \mathrm{CA}$ ABDC during the exhaust stroke.

Exh: Oxidation of diesel soot extracted from engine exhaust pipe.

Table 5-2 Comparison of mean diameter surface/mass ratios with statistical surface/mass ratios

\begin{tabular}{c|c|c|c}
\hline $\begin{array}{c}\text { Soot sampling } \\
\text { position and phase }\end{array}$ & $\begin{array}{c}\text { Surface/mass ratio* }\left[\mathrm{m}^{2}\right. \\
\left.\mathrm{g}^{-1}\right] \text { (number mean } \\
\text { diameter }[\mathrm{nm}])\end{array}$ & $\begin{array}{c}\text { Surface/mass ratio* }\left[\mathrm{m}^{2}\right. \\
\left.\mathrm{g}^{-1}\right] \text { (volume mean } \\
\text { diameter }[\mathrm{nm}])\end{array}$ & $\begin{array}{c}\text { Overall statistical } \\
\text { surface/mass ratio*t } \\
{\left[\mathrm{m}^{2} \mathrm{~g}^{-1}\right]}\end{array}$ \\
\hline $\begin{array}{c}\text { Pre-chamber } \\
60-63^{\circ} \text { CA ATDC } \\
\text { combustion stroke }\end{array}$ & $70(43)$ & $60(50)$ & 52 \\
$10 \mathrm{~mm}$ above burner & $73(41)$ & $65(46)$ & 58 \\
$30 \mathrm{~mm}$ above burner & $77(39)$ & $68(44)$ & 60 \\
\hline $\begin{array}{c}\text { Pre-chamber } \\
20-23^{\circ} \text { CA ABDC }\end{array}$ & $71(42)$ & $64(47)$ & 57 \\
exhaust stroke & & $65(46)$ & 56 \\
$10 \mathrm{~mm}$ above burner & $75(40)$ & $81(37)$ & 69 \\
$30 \mathrm{~mm}$ above burner & $94(32)$ & $73(41)$ & 65 \\
\hline Exhaust pipe $\mathrm{d}$ & $83(36)$ & $71(42)$ & 78 \\
$15 \mathrm{~mm}$ above burner & $86(35)$ & $91(33)$ & 87 \\
$30 \mathrm{~mm}$ above burner & $103(29)$ & $103(29)$ & 62 \\
$50 \mathrm{~mm}$ above burner & $125(24)$ & & 56 \\
\hline
\end{tabular}

* Assuming the soot spherules had smooth surface and density of $2 \mathrm{~g} \mathrm{~cm}^{-3}$;

+ Assuming the soot spherules were separated from each other.

a. Test No. Prc-1: $\mathrm{T}=1785 \mathrm{~K}, \mathrm{Po}_{2}=0.030 \mathrm{~atm}, \mathrm{t}$ (soot residence time) $=7.303 \mathrm{~ms}$.

b. Test No. Prex-1: $\mathrm{T}=1800 \mathrm{~K}, \mathrm{Po}_{2}=0.048 \mathrm{~atm}, \mathrm{t}=7.324 \mathrm{~ms}$.

c. Test No. Exh-3: Height $15-30 \mathrm{~mm}, \mathrm{~T}=1653 \mathrm{~K}, \mathrm{Po}_{2}=0.031 \mathrm{~atm}, \mathrm{t}=6.860 \mathrm{~ms}$.

d. Test No. Exh-4: Height $30-50 \mathrm{~mm}, \mathrm{~T}=1604 \mathrm{~K}, \mathrm{PO}_{2}=0.031 \mathrm{~atm}, \mathrm{t}=9.721 \mathrm{~ms}$.

Surface/mass ratio (number (or volume) mean diameter) $=$ surface/mass ratio of a hyputhetical soot spherule whose diameter equals the number (or volume) mean diameter of all the sampled spherules.

Statistical surface/mass ratio $=\Sigma$ (surface of each individual spherule)/ $\Sigma$ (mass of each individual spherule) 


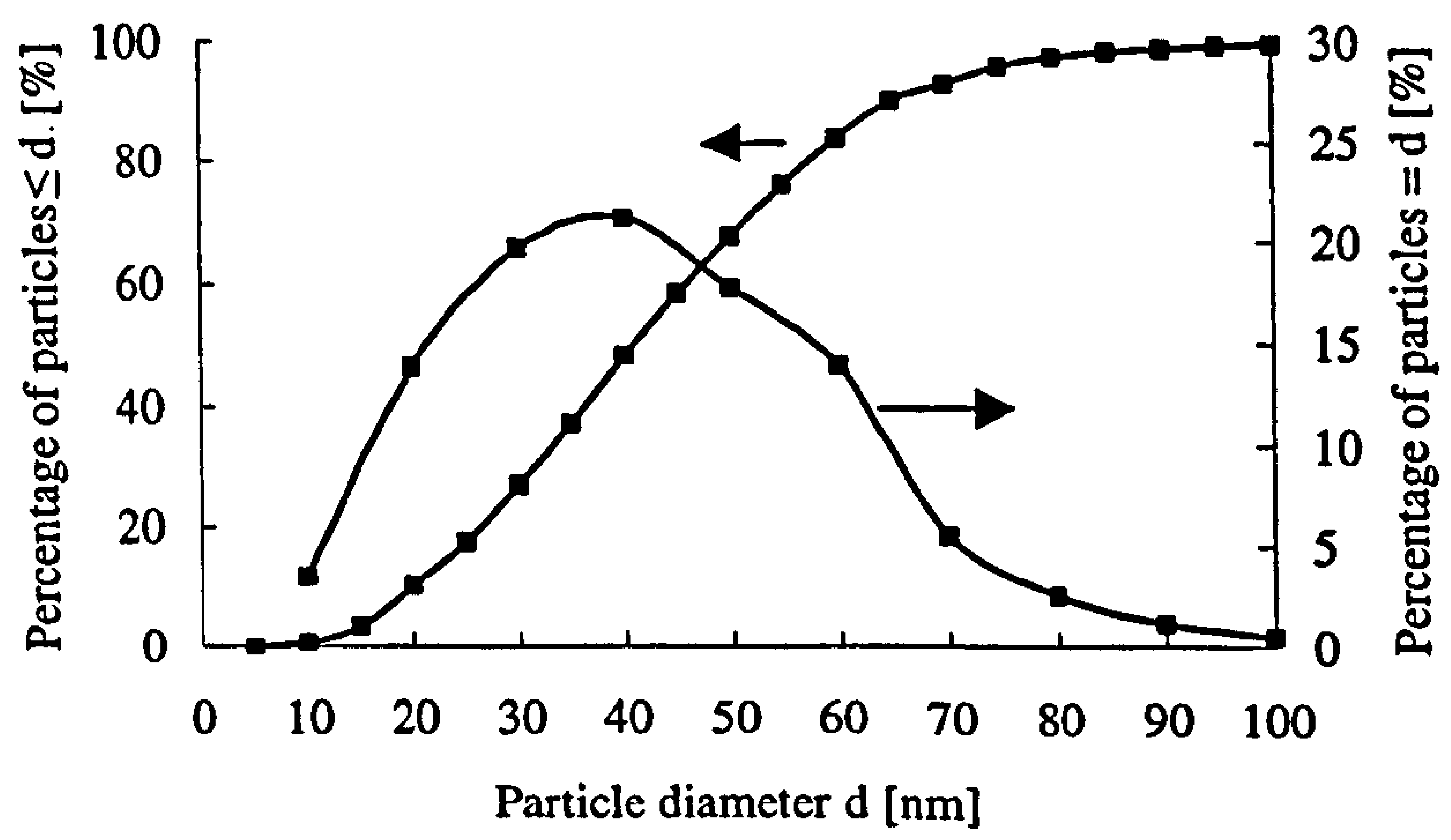

Fig. 5-1 Size distribution of raw soot spherules sampled from the engine pre-chamber at $60^{\circ}-63^{\circ} \mathrm{CA}$ ATDC during the combustion stroke

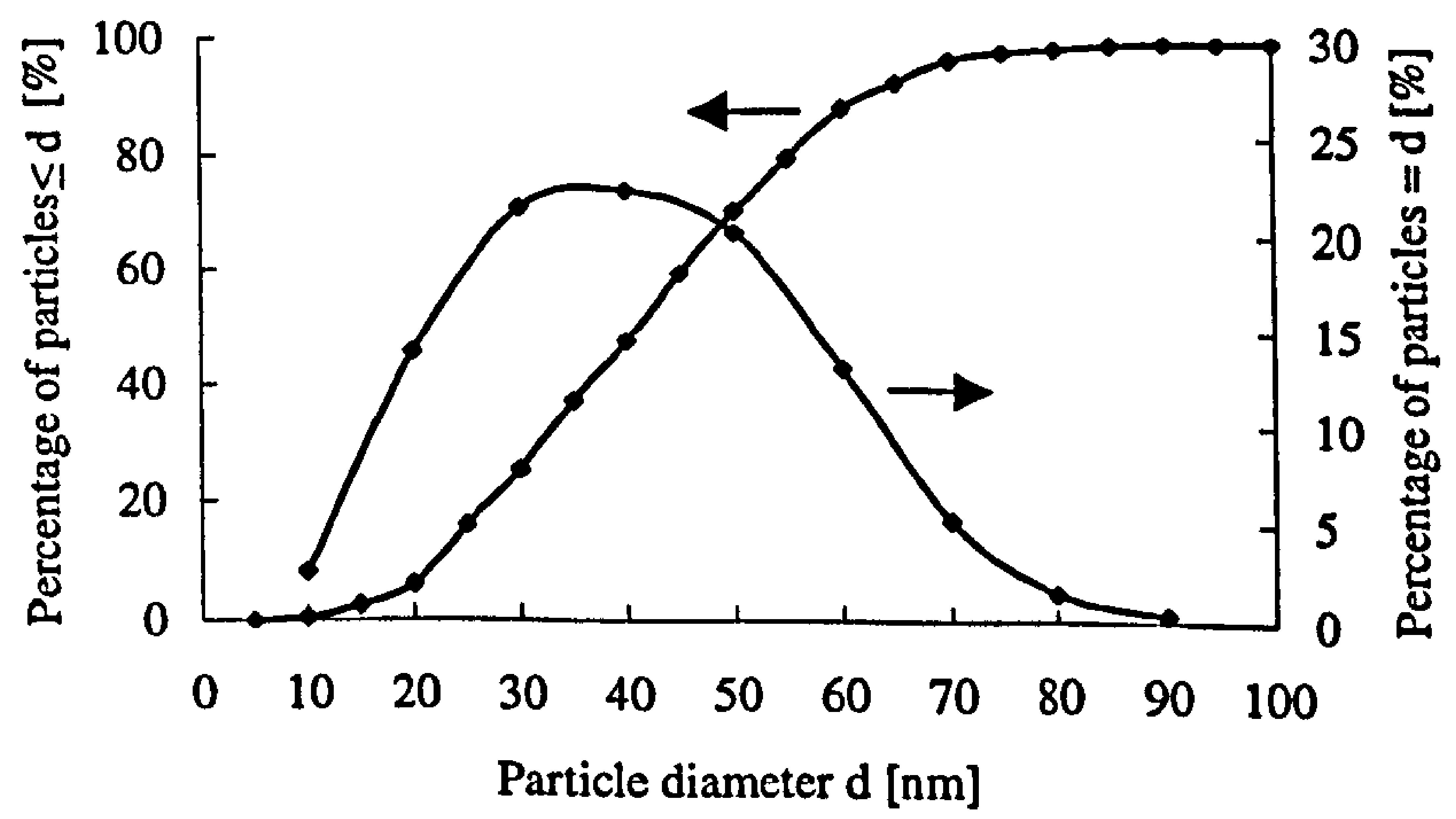

Fig. 5-2 Size distribution of raw soot spherules sampled from the engine pre-chamber at $20^{\circ}-23^{\circ} \mathrm{CA}$ ABDC during the exhaust stroke 


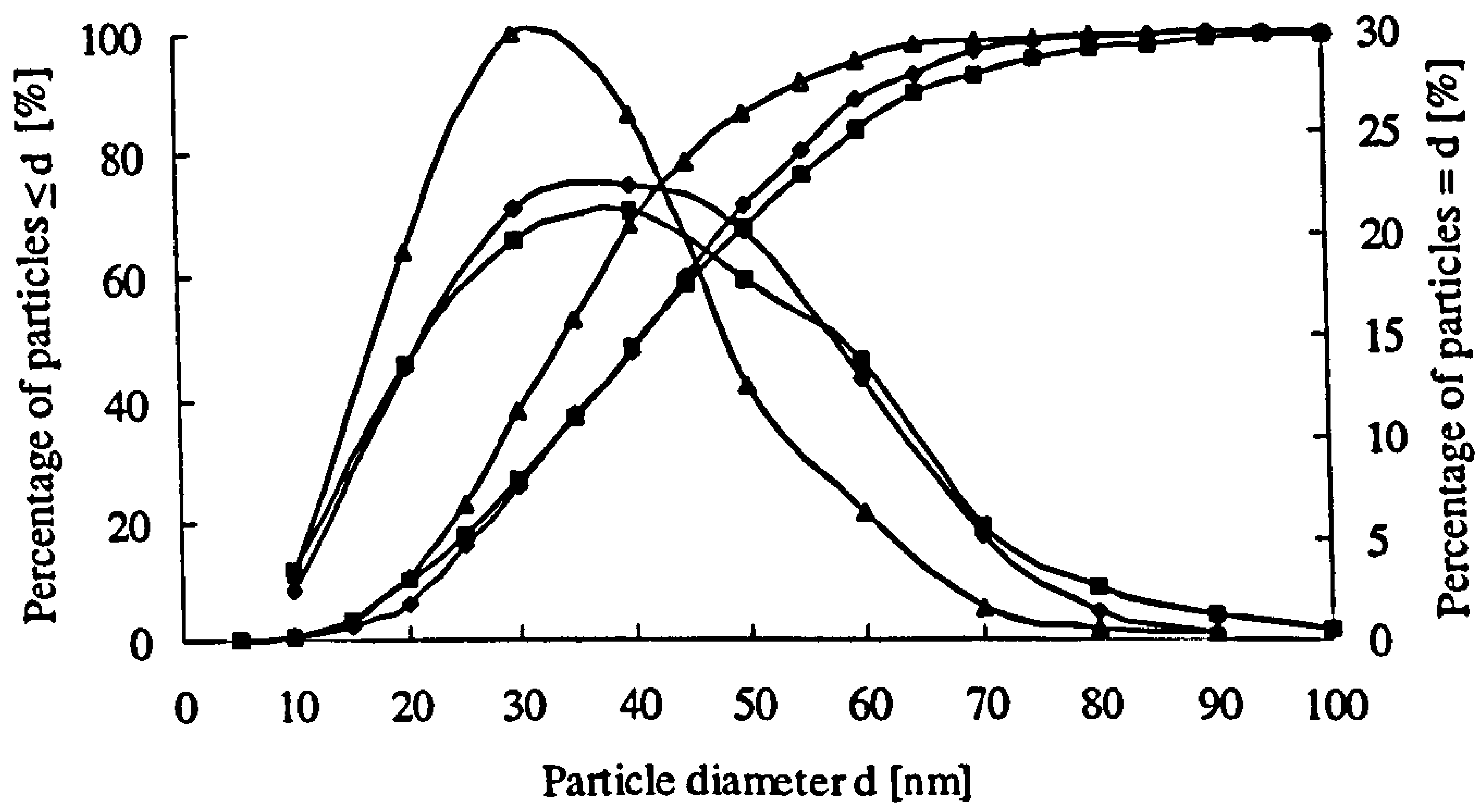

$\rightarrow-$ Pre-chamber $60^{\circ}-63^{\circ} \mathrm{CA}$ ATDC $\rightarrow-$ Pre-chamber $20^{\circ}-23^{\circ} \mathrm{CA}$ ABDC $\rightarrow$ Exhaust

(a) Spherule size distributions

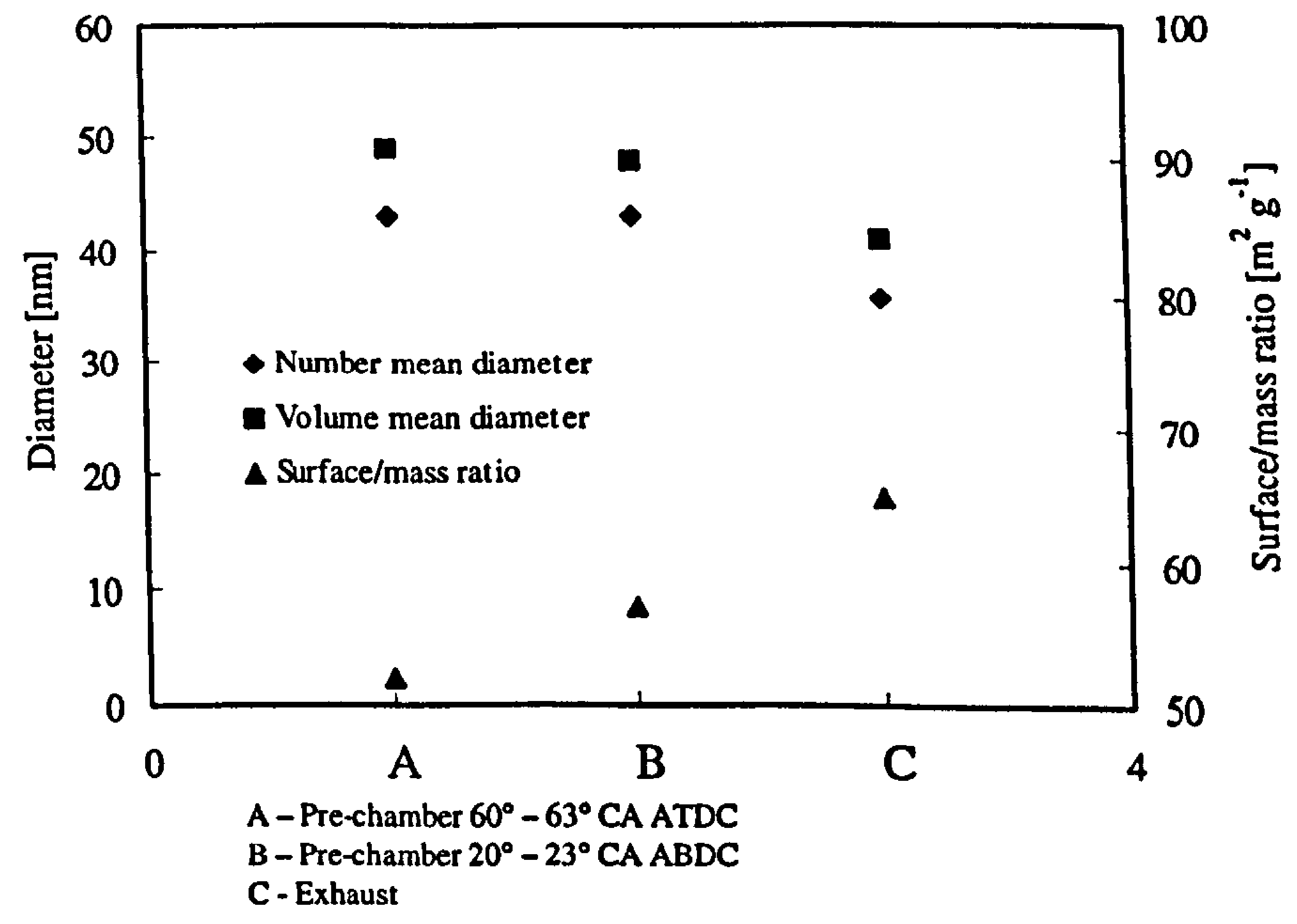

(b) Difference in various mean values

Fig.5-3 Comparison of different raw soot 


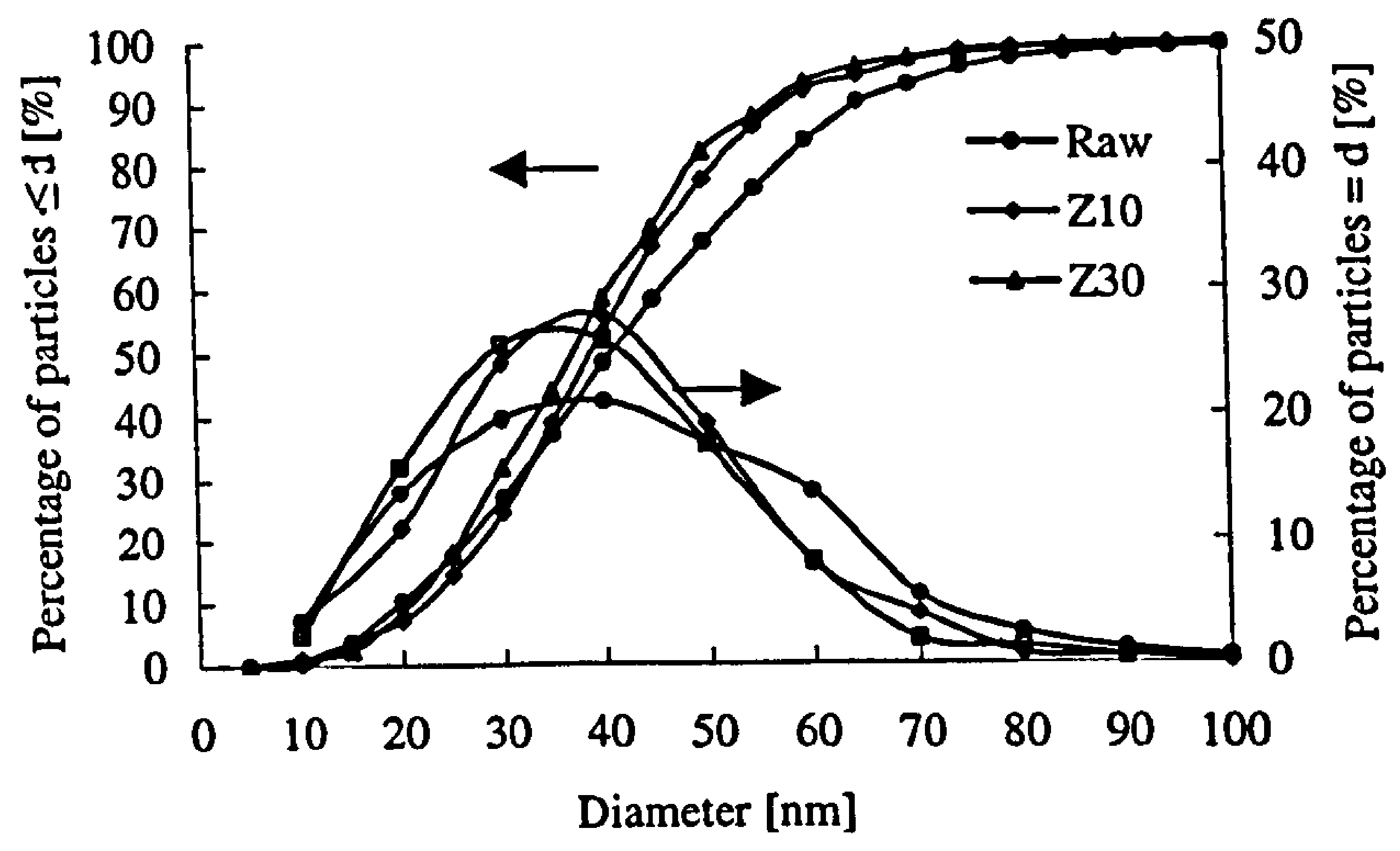

(a) Spherule size distributions

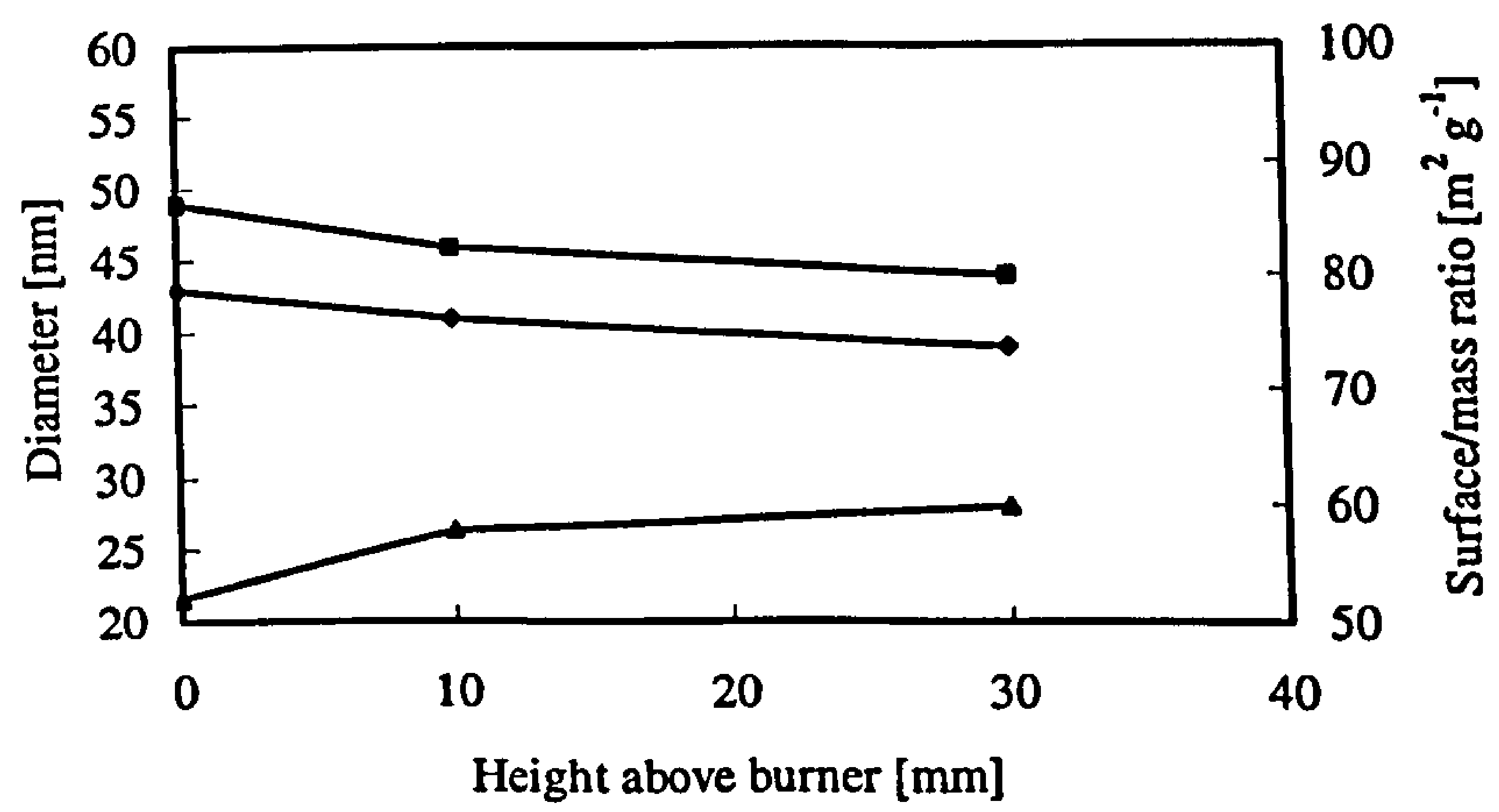

$\rightarrow$ Number mean diameter $\rightarrow$ Volume mean diameter $\rightarrow$ Surface/mass ratio

(b) Difference in various mean values

Fig. 5-4 Comparison of raw soot extracted from the engine pre-chamber at $60^{\circ}-63^{\circ} \mathrm{CA}$ ATDC during the combustion stroke with the soot oxidized in the burner post-flame gas 


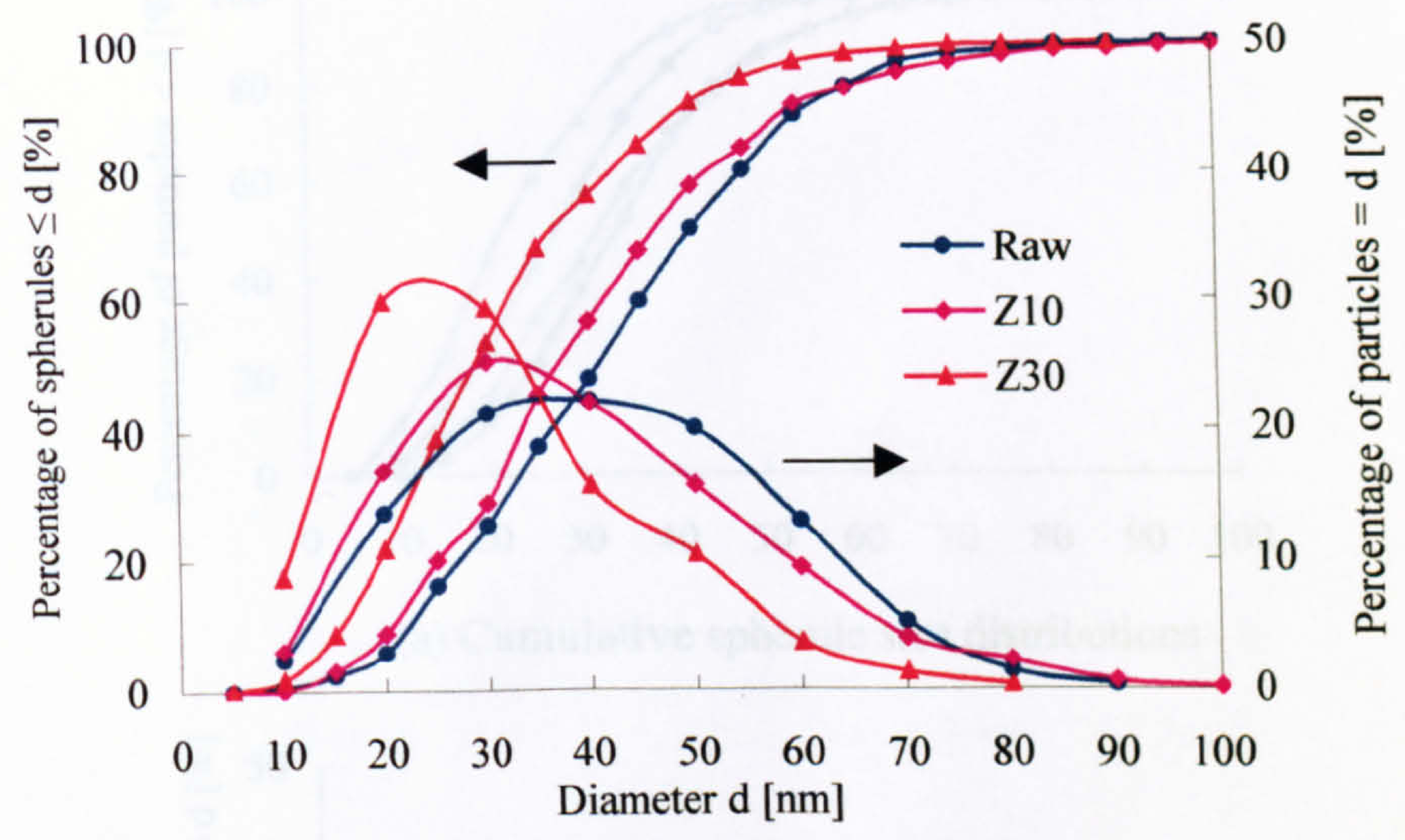

(a) Spherule size distributions

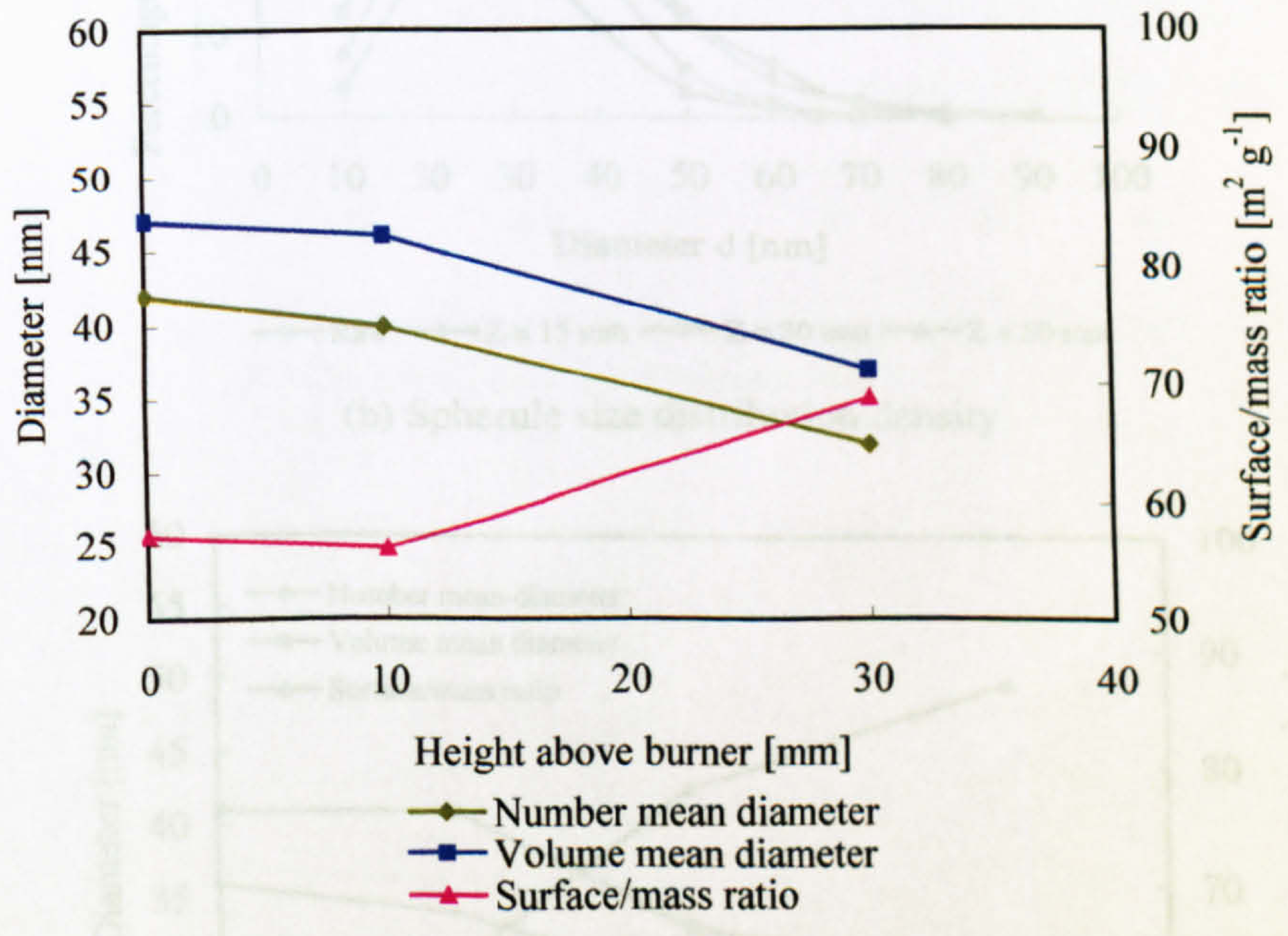

(b) Difference in various mean values

Fig. 5-5 Comparison of raw soot extracted from the engine pre-chamber at $20^{\circ}-23^{\circ} \mathrm{CA} \mathrm{ABDC}$ during the exhaust stroke with the soot oxidized in the burner post-flame gas 


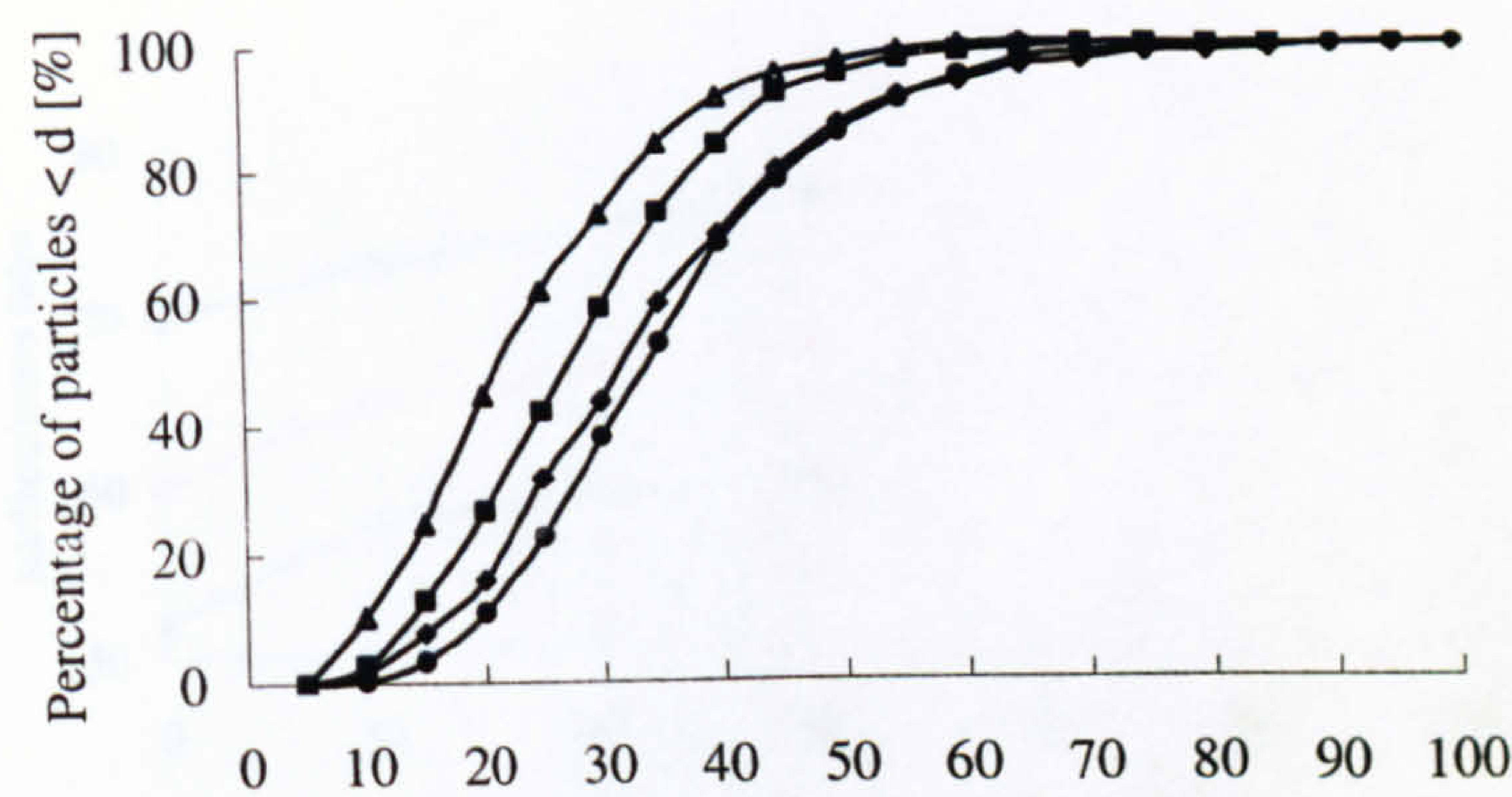

(a) Cumulative spherule size distributions

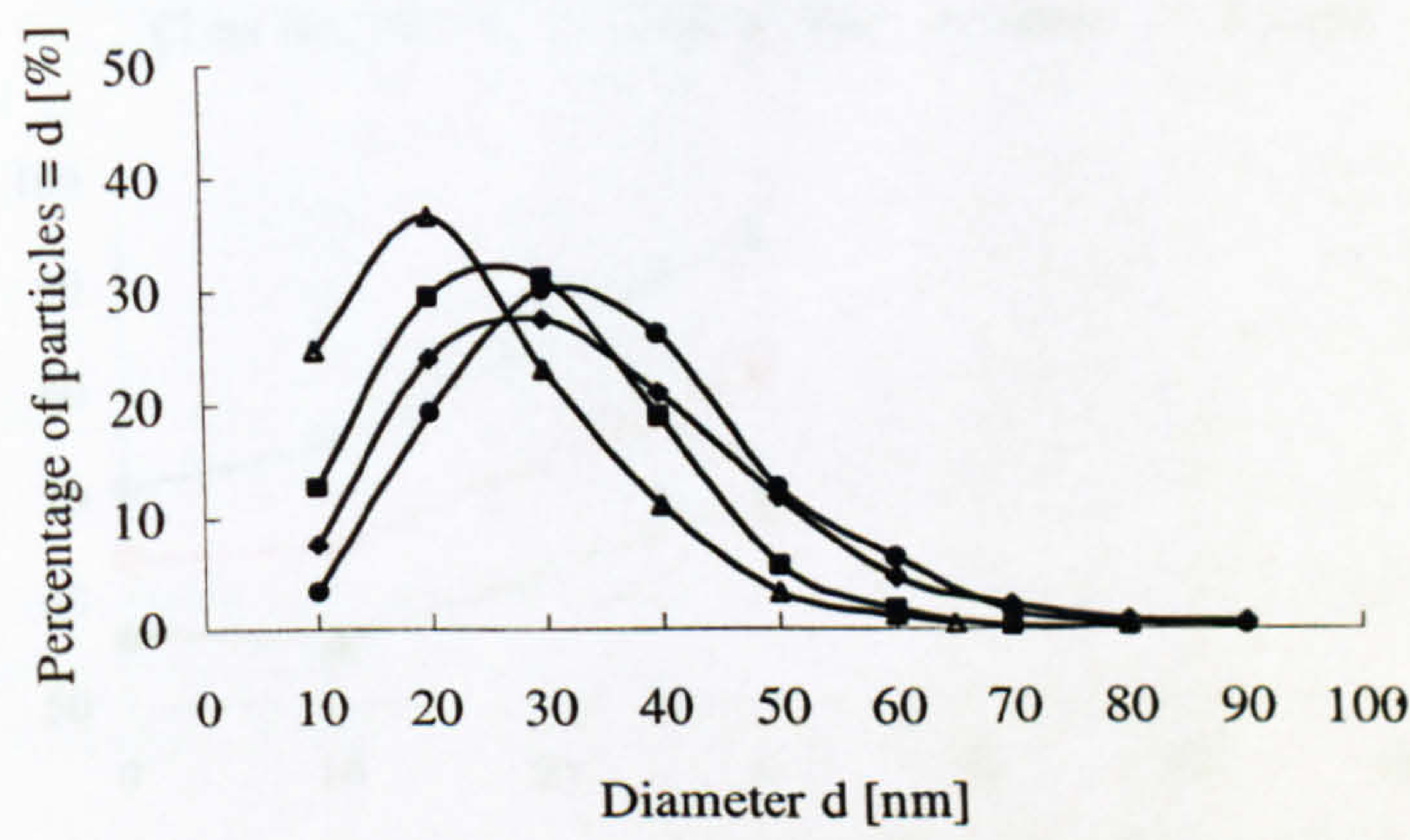

$\leftrightarrow$ Raw $\longrightarrow Z=15 \mathrm{~mm} \longrightarrow Z=30 \mathrm{~mm} \longrightarrow Z=50 \mathrm{~mm}$

(b) Spherule size distribution density

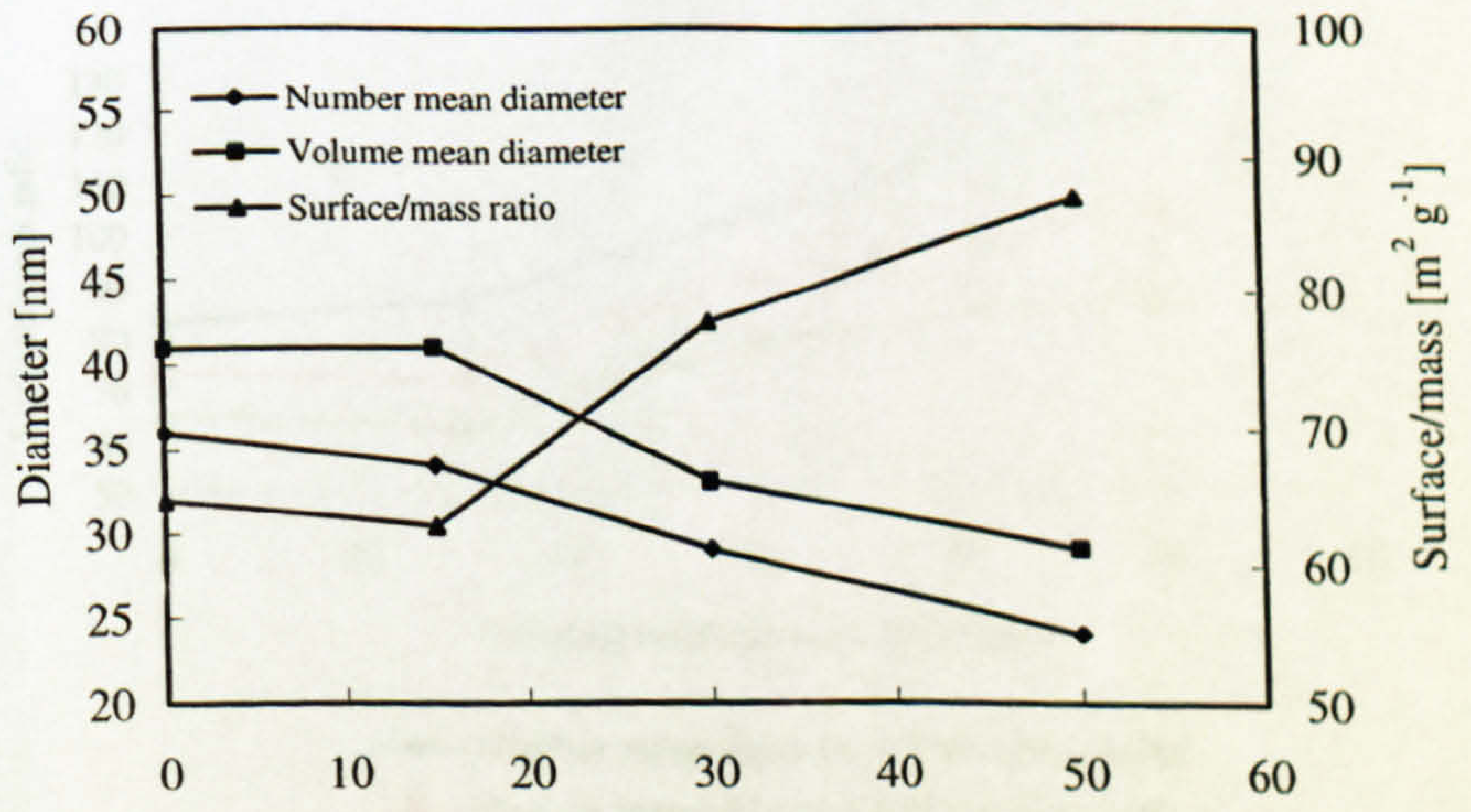

Height above burner [mm]

(c) Differences in various mean values

Fig. 5-6 Comparison of raw soot extracted from the engine exhaust with the soot oxidized in the burner post-flame gas 


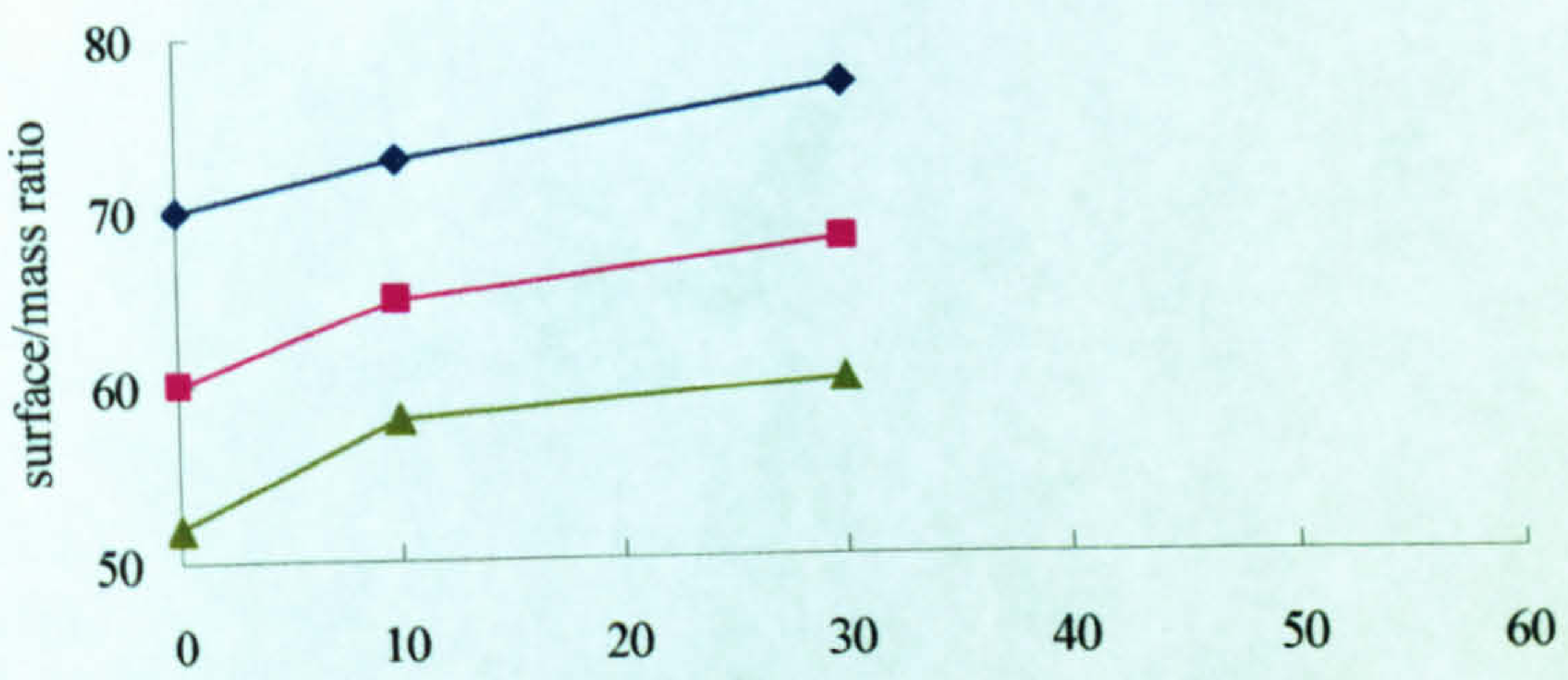

(a) Diesel soot extracted from the engine pre-chamber at $60^{\circ}$ $63^{\circ} \mathrm{CA}$ ATDC during the combustion stroke

(Test No. Prec-1: $\mathrm{T}=1785 \mathrm{~K}, \mathrm{Po}_{2}=0.03 \mathrm{~atm}, \mathrm{t}=7.3 \mathrm{~ms}$ )

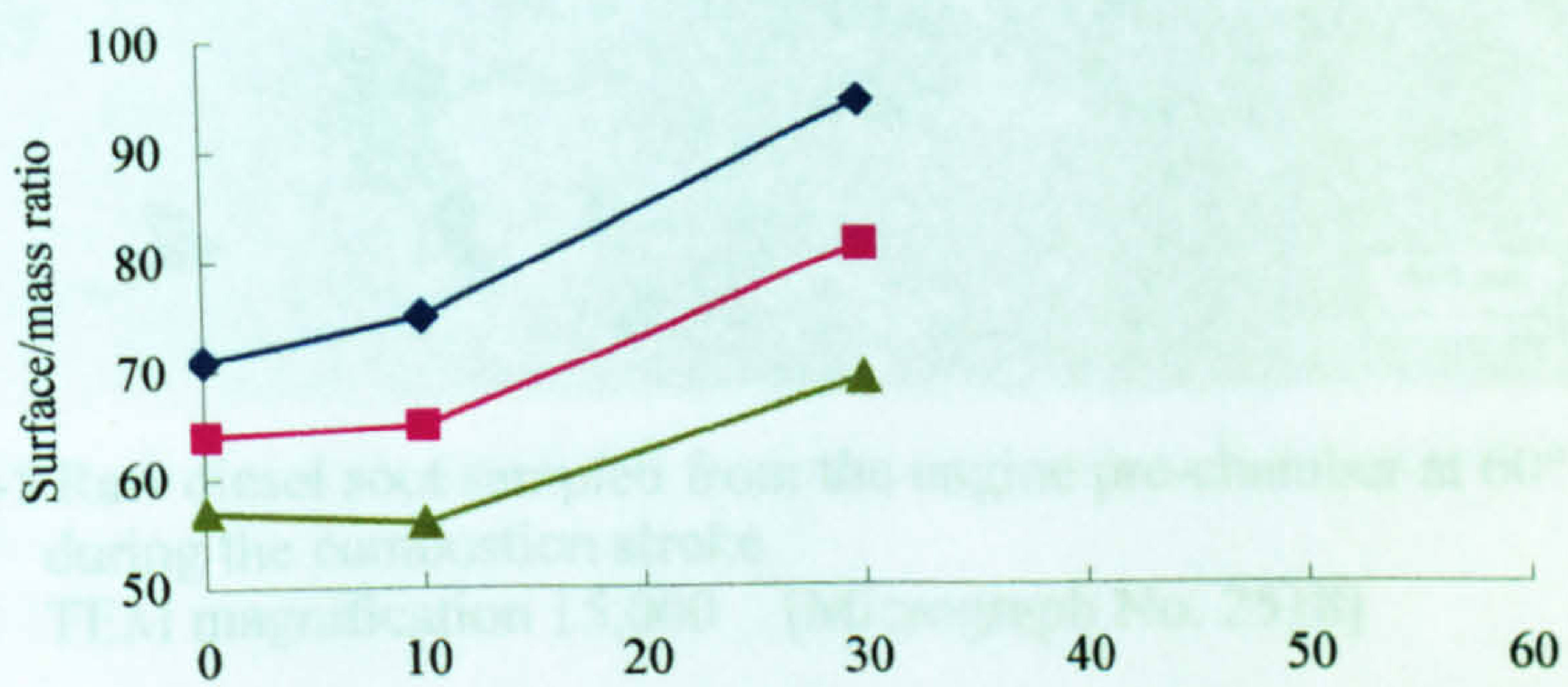

(b) Diesel soot extracted from the engine pre-chamber at $20^{\circ}$ $23^{\circ} \mathrm{CA} \mathrm{ABDC}$ during the exhaust stroke

(Test No. Prex-1: $\mathrm{T}=1800 \mathrm{~K}, \mathrm{Po}_{2}=0.048 \mathrm{~atm}, \mathrm{t}=7.3 \mathrm{~ms}$ )

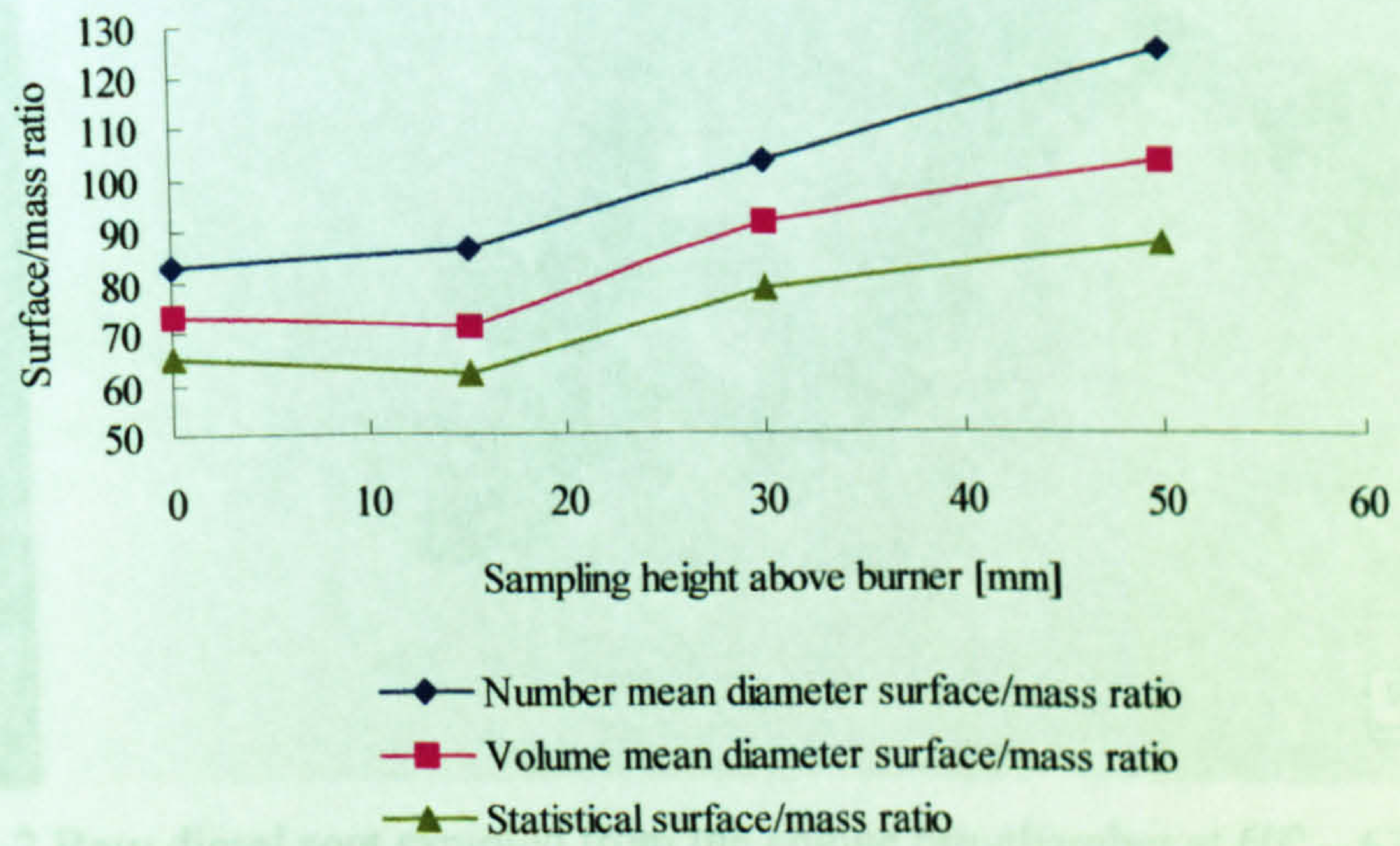

(b) Diesel soot extracted from the engine exhaust

(Test No. $Z=15-30 \mathrm{~mm}:$ Exh-3: $\mathrm{T}=1653 \mathrm{~K}, \mathrm{Po}_{2}=0.031 \mathrm{~atm}, \mathrm{t}=6.9 \mathrm{~ms}$;

$\mathrm{Z}=30-50 \mathrm{~mm}:$ Exh- $\left.4: \mathrm{T}=1653 \mathrm{~K}, \mathrm{Po}_{2}=0.031 \mathrm{~atm}, \mathrm{t}=9.7 \mathrm{~ms}\right)$

NB: Sampling height 0 represents raw soot sampled from the engine

Fig. 5-7 Comparison of surface/mass ratios of diesel soot spherules using different calculation methods and at different sampling positions 


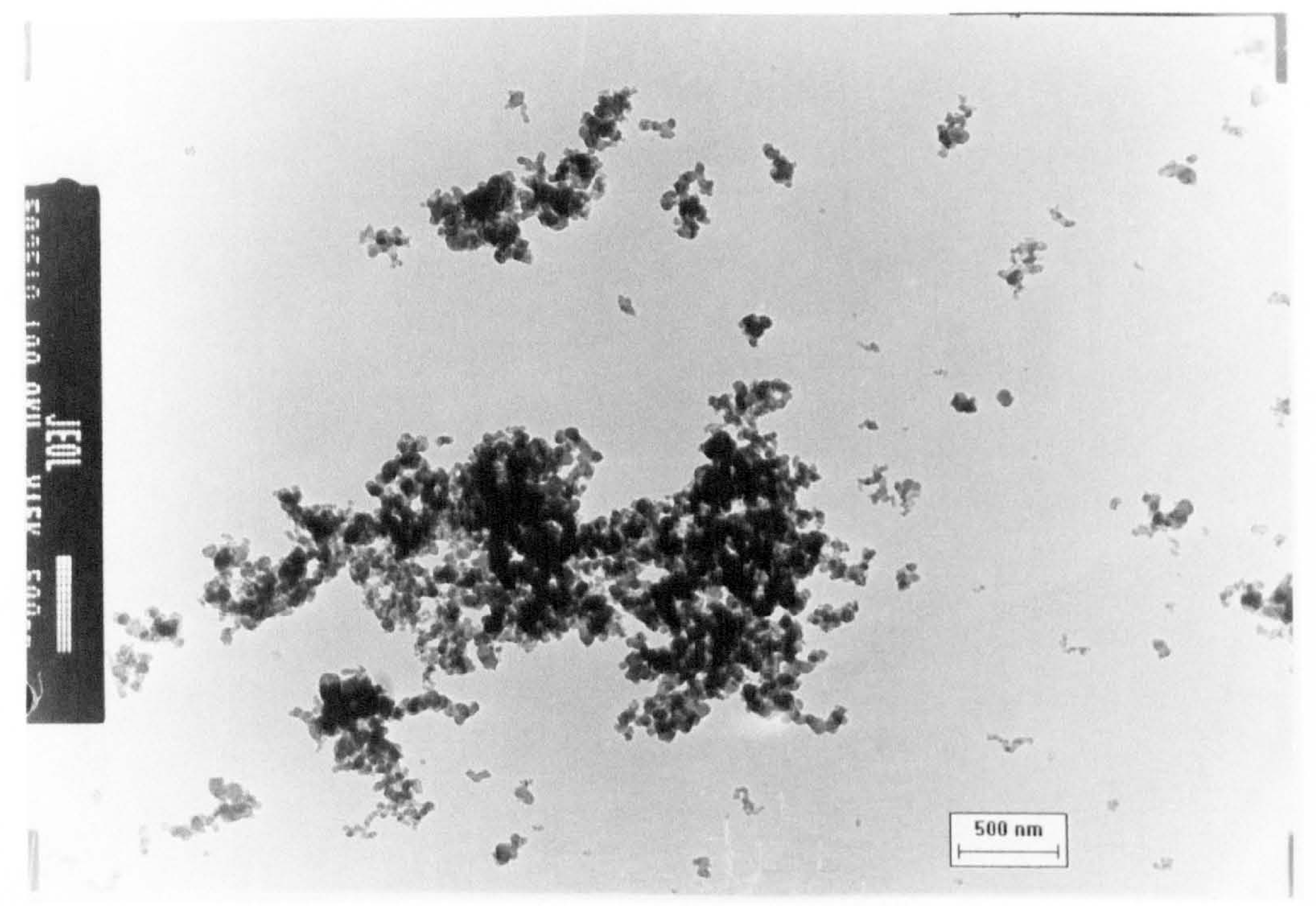

Pic. 5-1 Raw diesel soot sampled from the engine pre-chamber at $60^{\circ}-63^{\circ} \mathrm{CA}$ ATDC during the combustion stroke

TEM magnification 15,000 [Micrograph No. 2518]
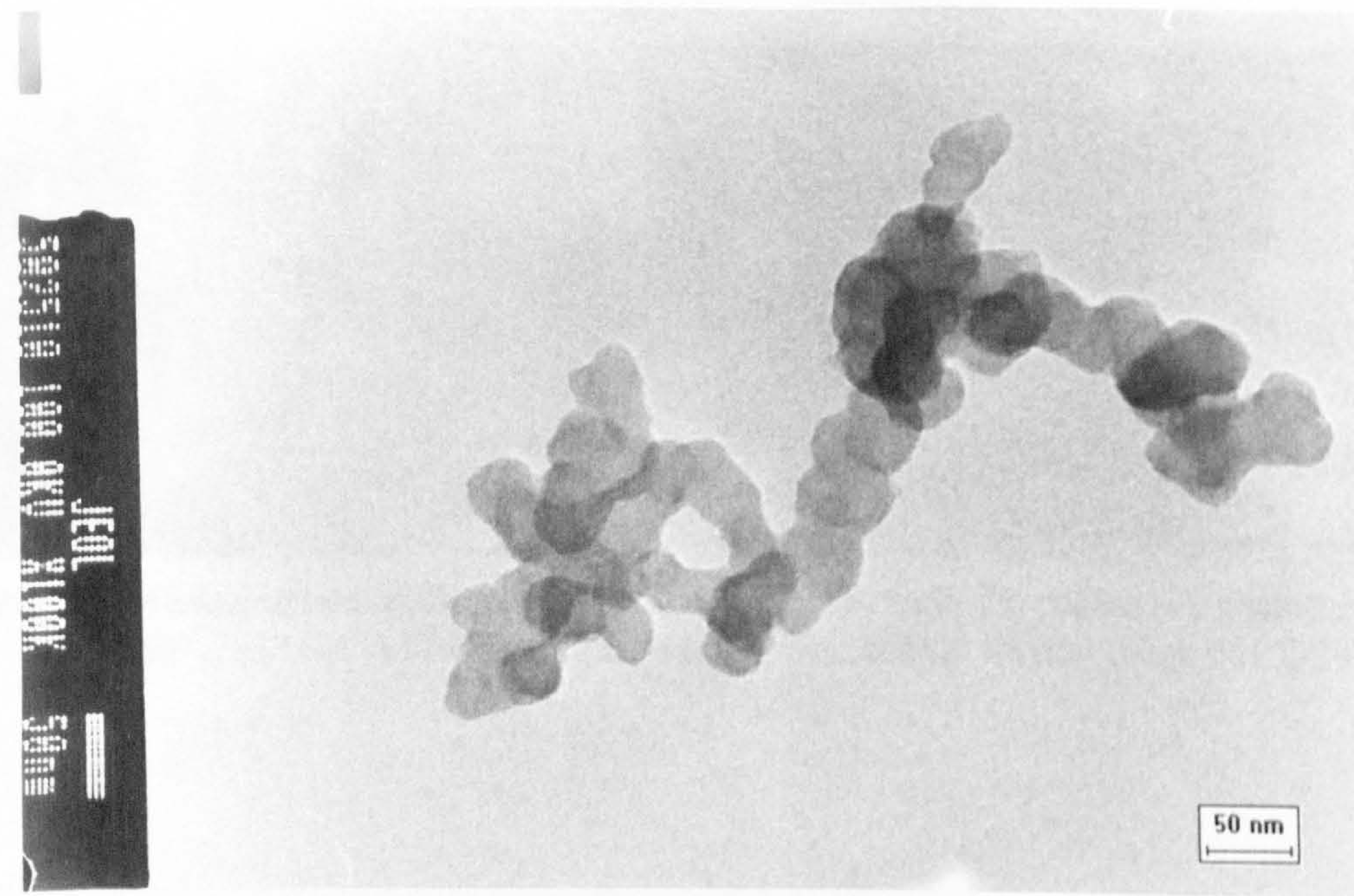

Pic 5-2 Raw diesel soot sampled from the engine pre-chamber at $60^{\circ}-63^{\circ} \mathrm{CA}$ ATDC during the combustion stroke

TEM magnification 100,000 [Micrograph No.2510] 

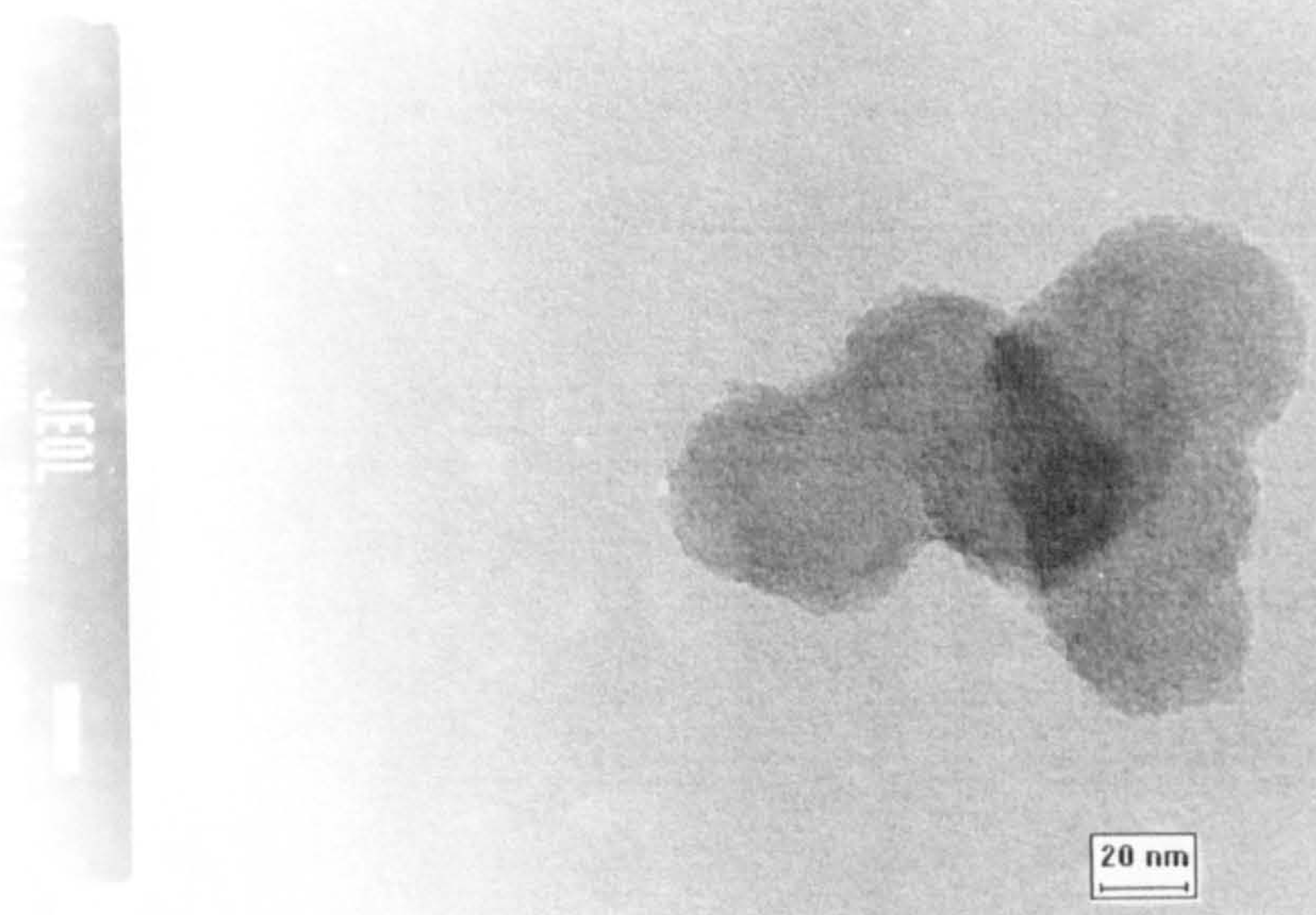

Pic. 5-3 Raw diesel soot sampled from the engine pre-chamber at $60^{\circ}-63^{\circ} \mathrm{CA}$ ATDC during the combustion stroke

TEM magnification 200,000 [Micrograph No. 2309]

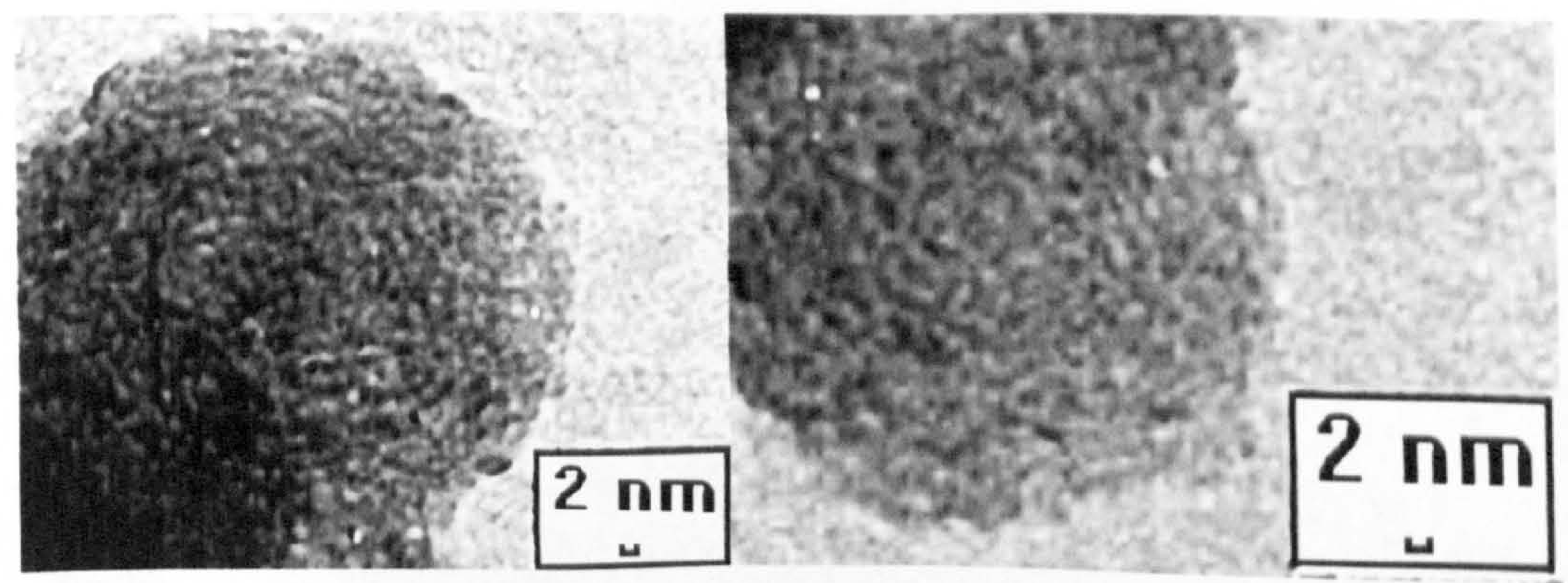

Pic. 5-4 Microstructure of diesel soot spherule sampled from the engine pre-chamber at $60^{\circ}-63^{\circ} \mathrm{CA}$ ATDC during the combustion stroke [Micrograph No.2309] 


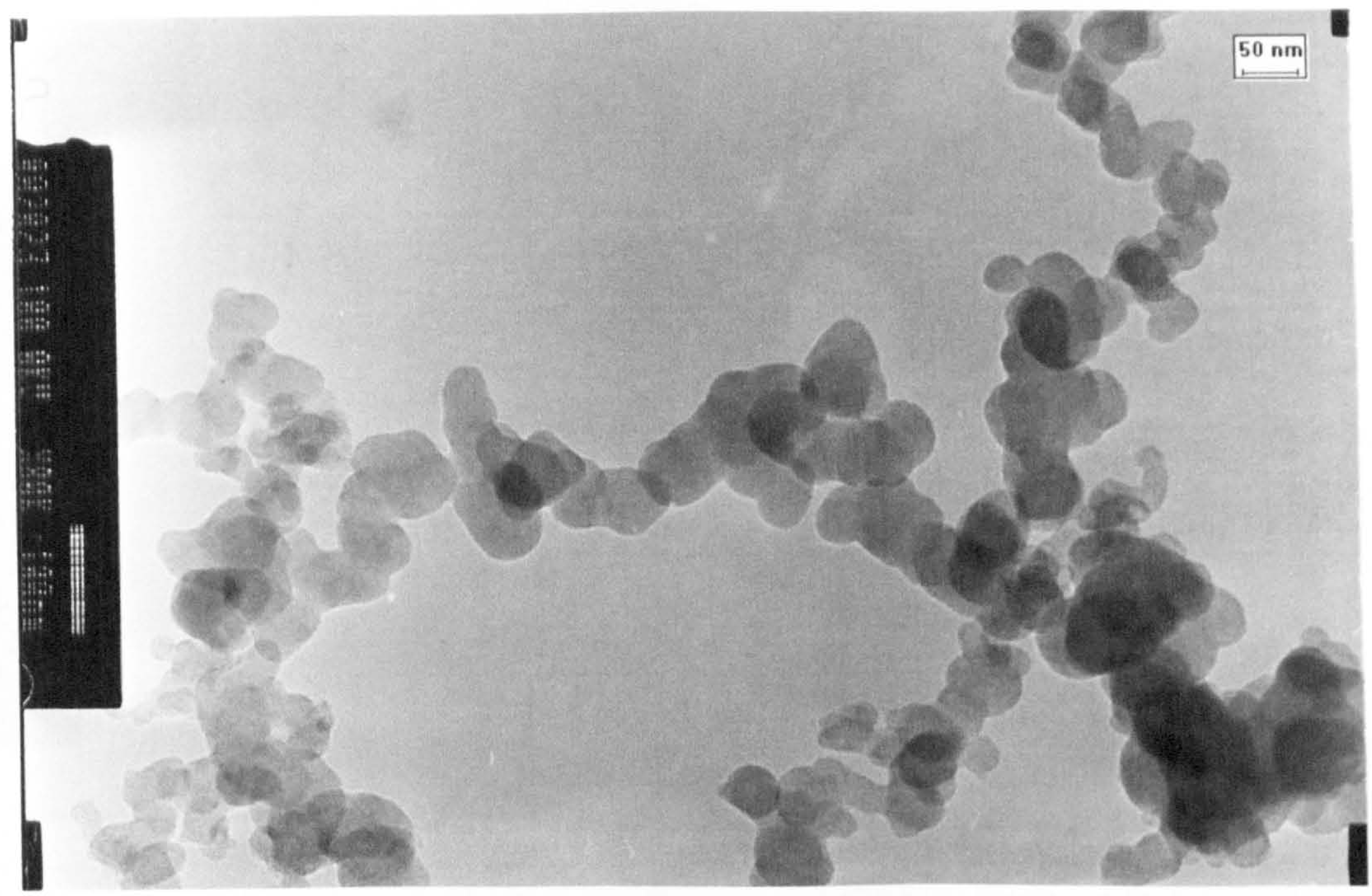

Pic. 5-5 Raw diesel soot sampled from the engine pre-chamber at $20^{\circ}-23^{\circ} \mathrm{ABDC}$ during the exhaust stroke TEM magnification 80,000 [Micrograph No.2023]

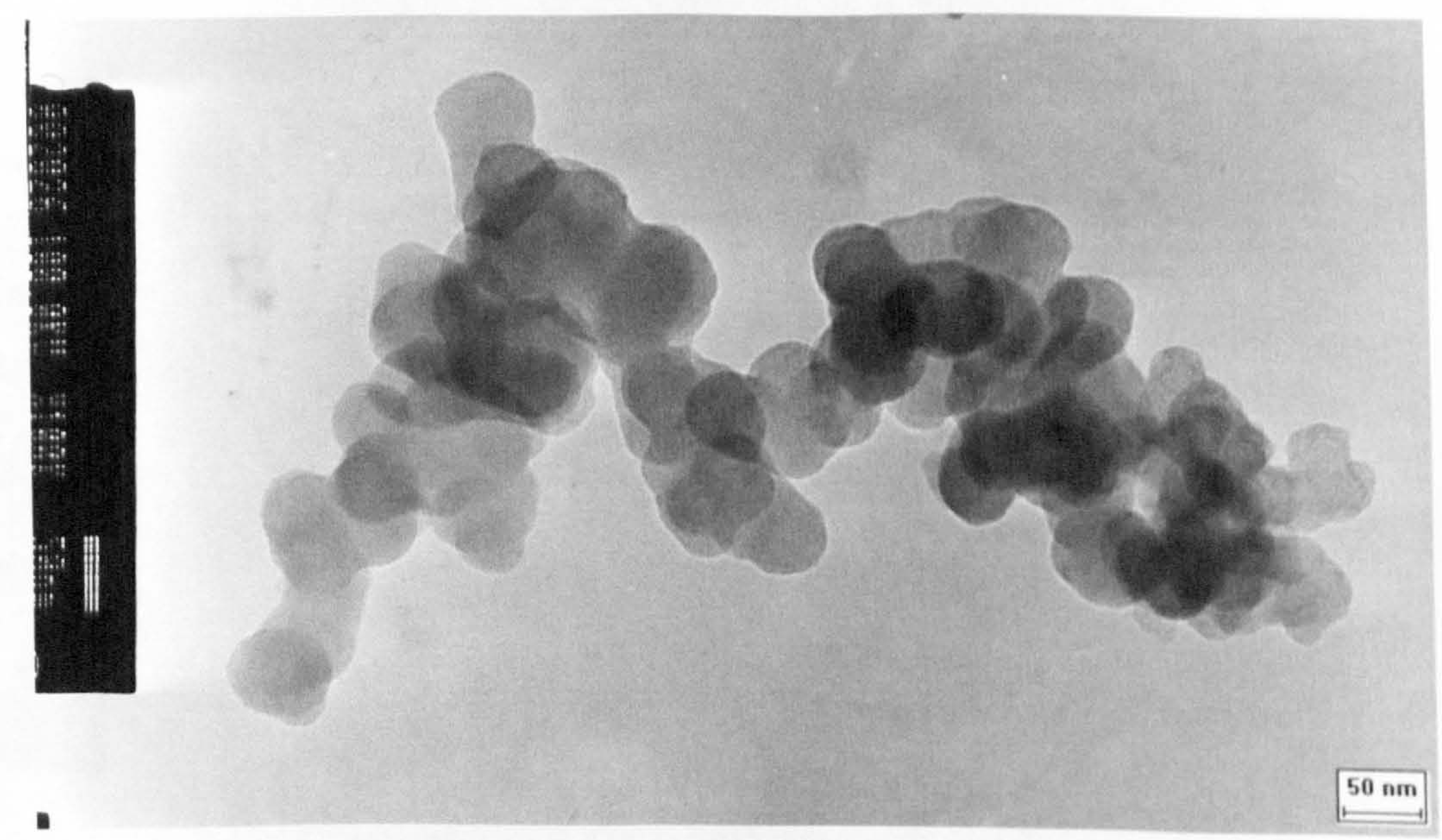

Pic. 5-6 Raw diesel soot sampled from the engine pre-chamber at $20^{\circ}-23^{\circ} \mathrm{ABDC}$ during the exhaust stroke

TEM magnification 100,000 [Micrograph No.2026] 

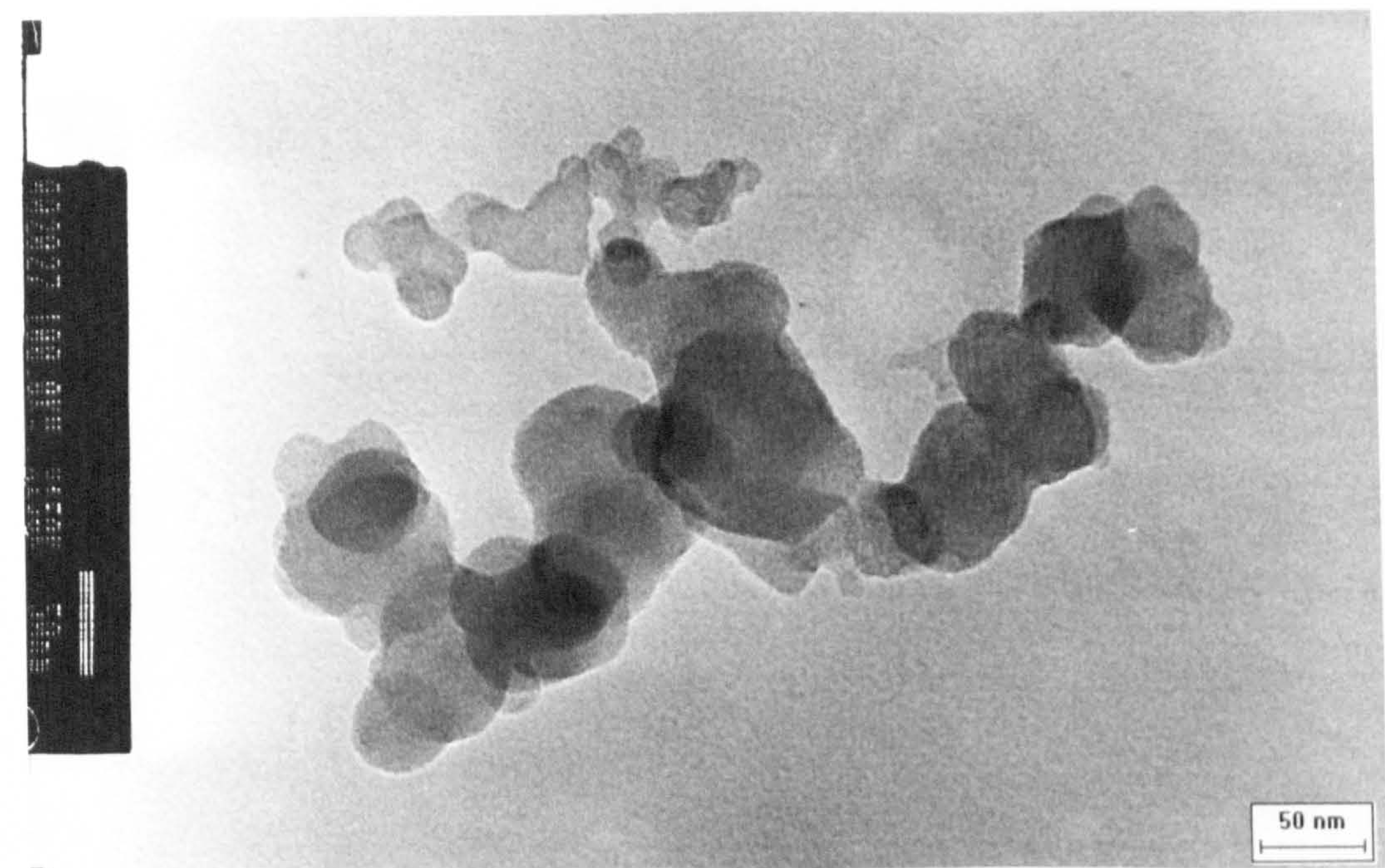

$-$

Pic. 5-7 Raw diesel soot sampled from the engine pre-chamber at $20^{\circ}-23^{\circ}$ ABDC during the exhaust stroke

TEM magnification 150,000 [Micrograph No.2027]

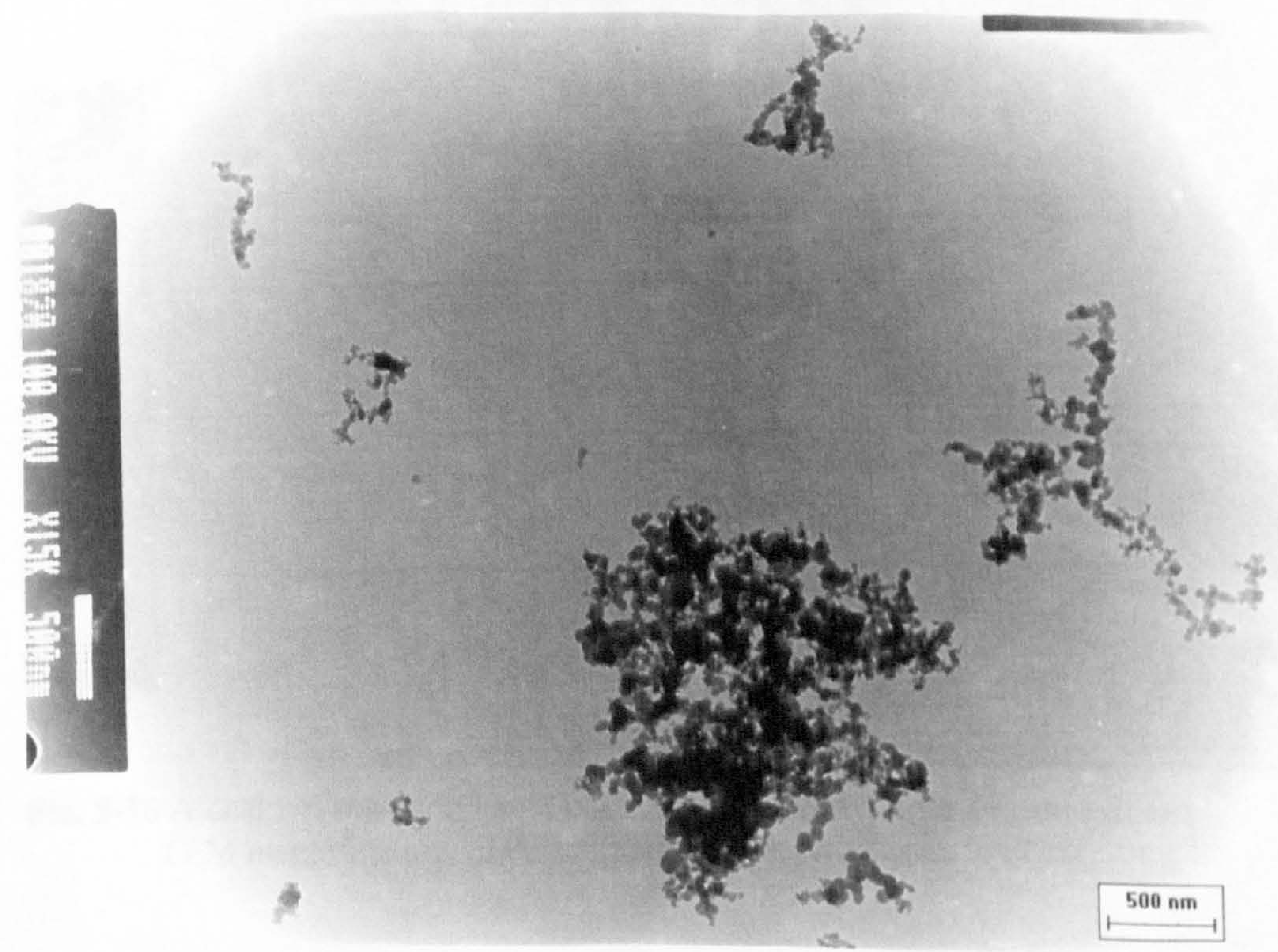

Pic. 5-8 Raw diesel soot sampled from the engine exhaust

TEM magnification 15,000 [Micrograph No. 1820] 

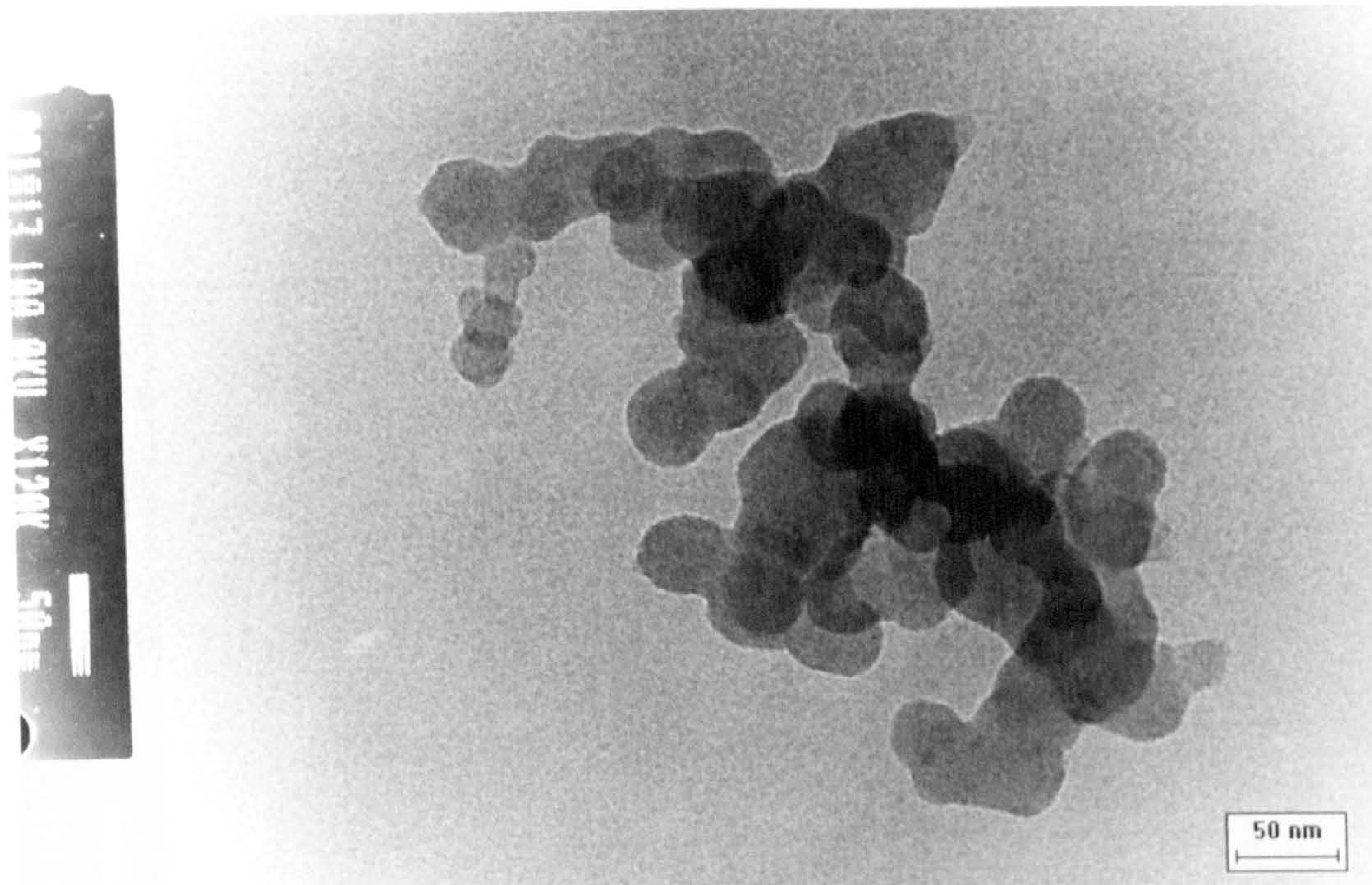

Pic. 5-9 A cluster of raw diesel soot particles sampled from the engine exhaust TEM magnification 120,000 [Micrograph No. 1813]
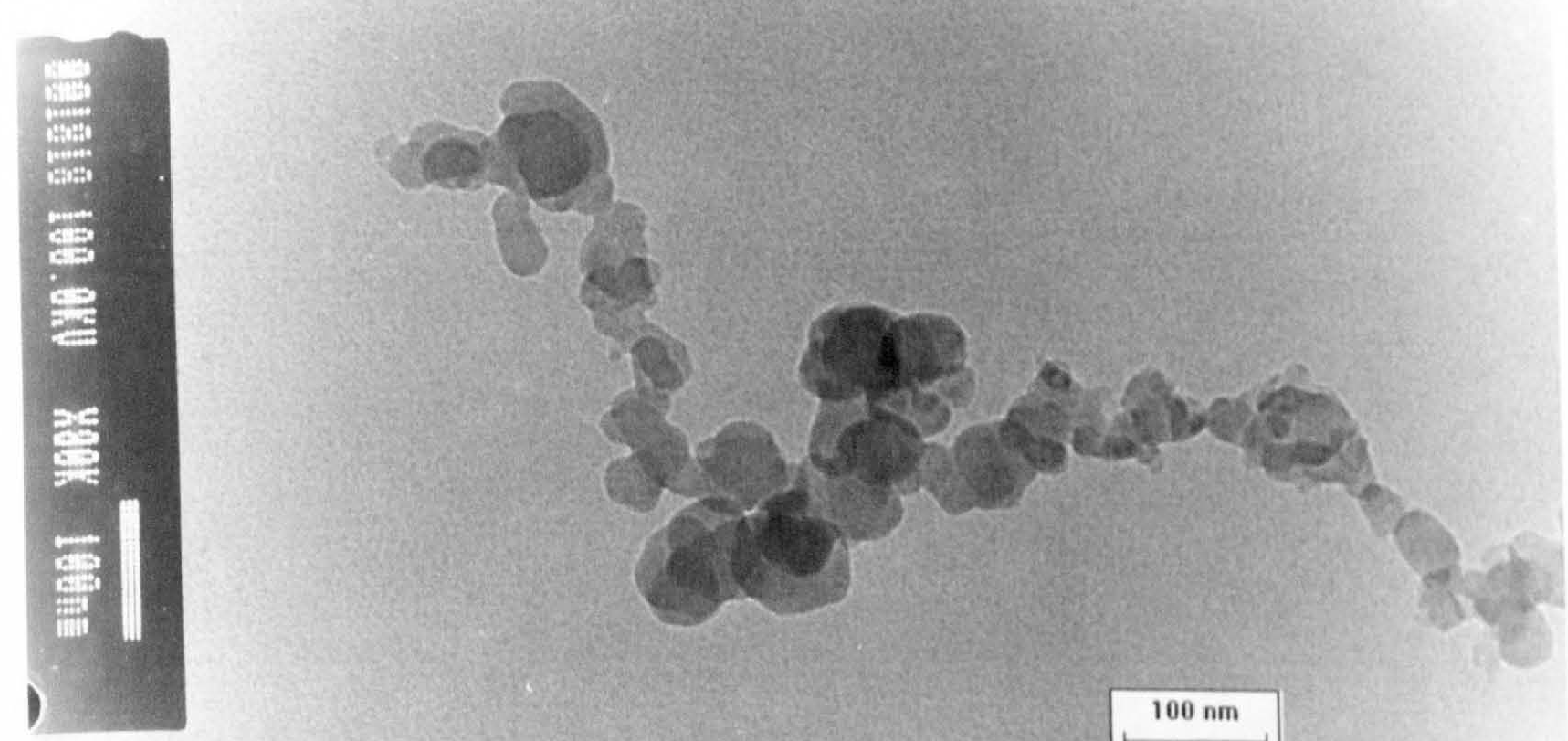

$100 \mathrm{~nm}$

Pic. 5-10 A chain of raw diesel soot particles sampled from the engine exhaust TEM magnification 80,000 [Micrograph No. 1818] 


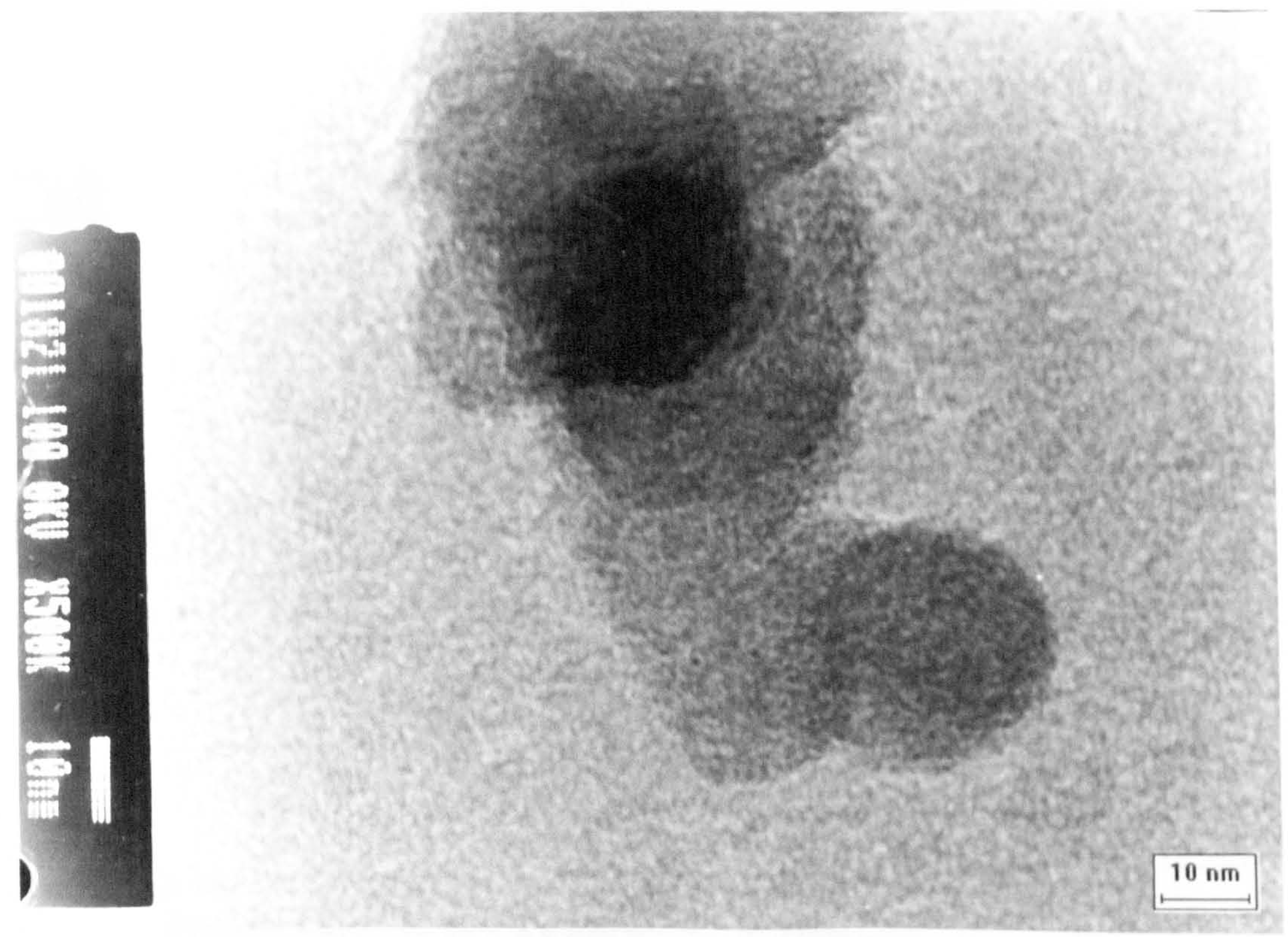

Pic 5-11 Raw diesel soot sampled from the engine exhaust

TEM magnification 500,000 [Micrograph No. 1821]

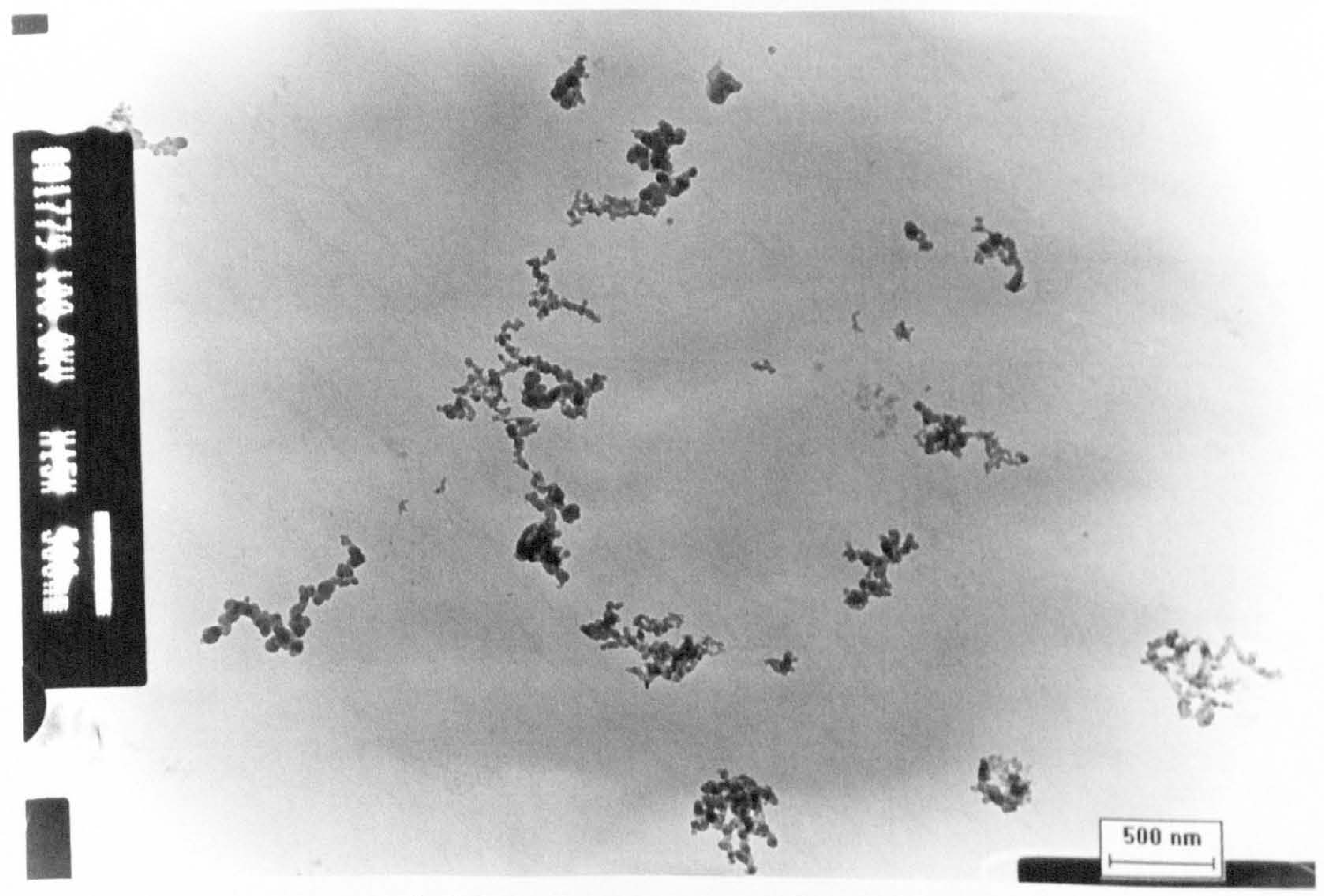

Pic. 5-12 Diesel soot sampled from the burner post-flame gas.

Test No. exh-3; Sampling position: $Z=30 \mathrm{~mm}$.

TEM magnification 15,000 [Micrograph No. 1779] 


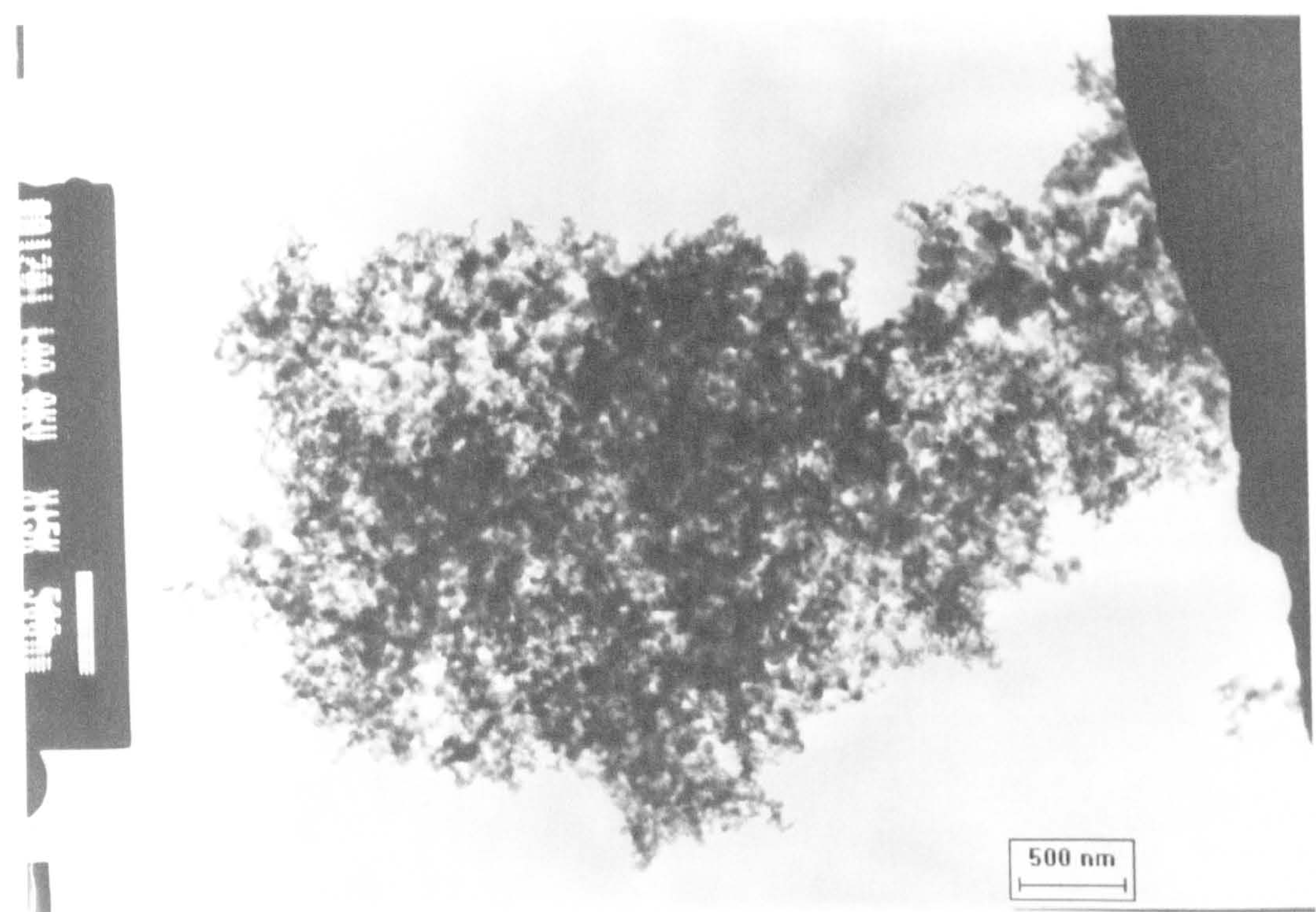

Pic. 5-13 A big diesel soot cluster sampled from the burner post-flame gas Test No. Exh-8; Sampling position: $Z=20 \mathrm{~mm}$.

TEM magnification 15,000 [Micrograph No. 1201] 


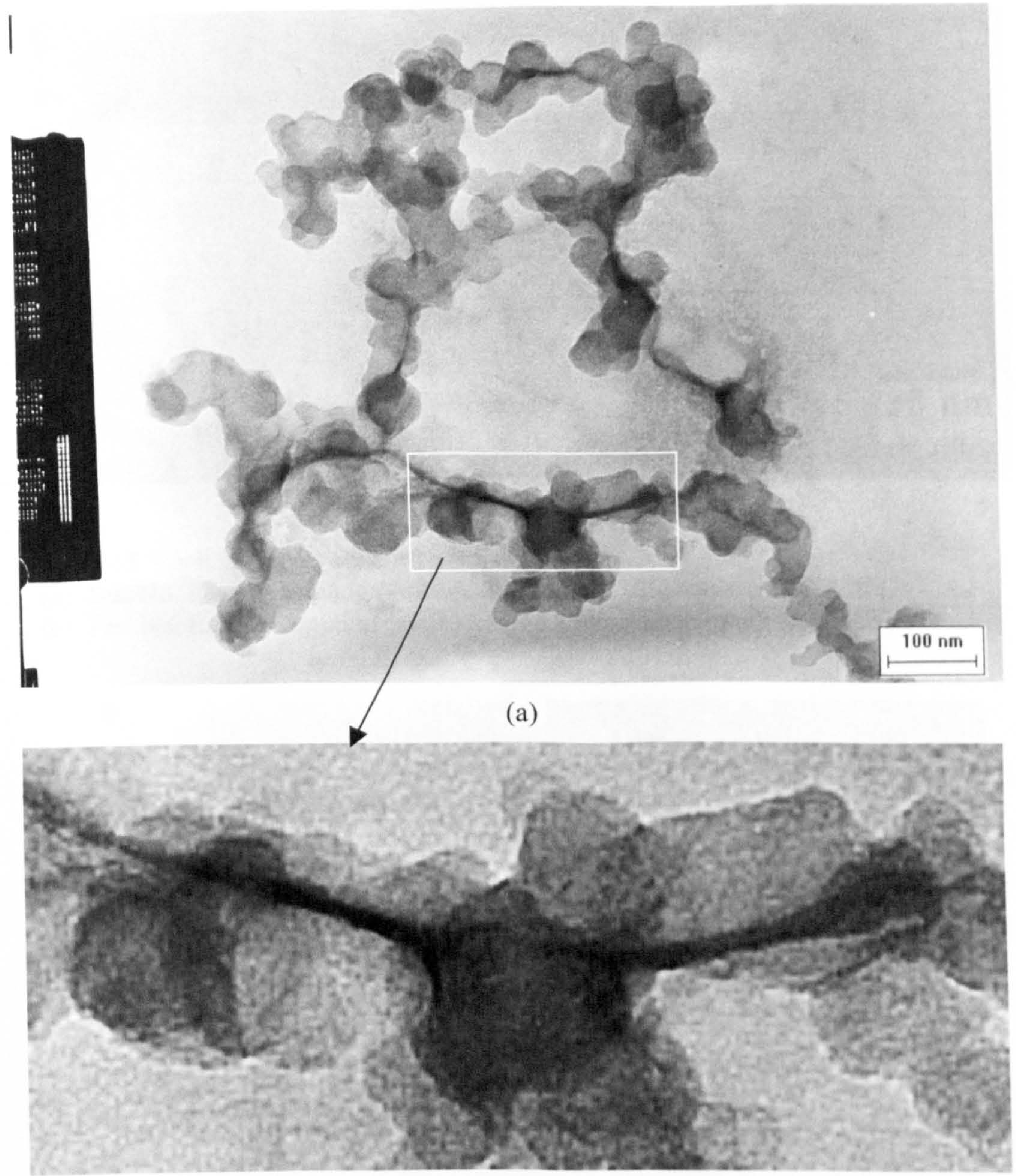

(b)

Pic. 5-14 Soot particles linked by "String"

Test No. Prex-1; Sampling position: $Z=30 \mathrm{~mm}$.

[Micrograph No. 2015] 


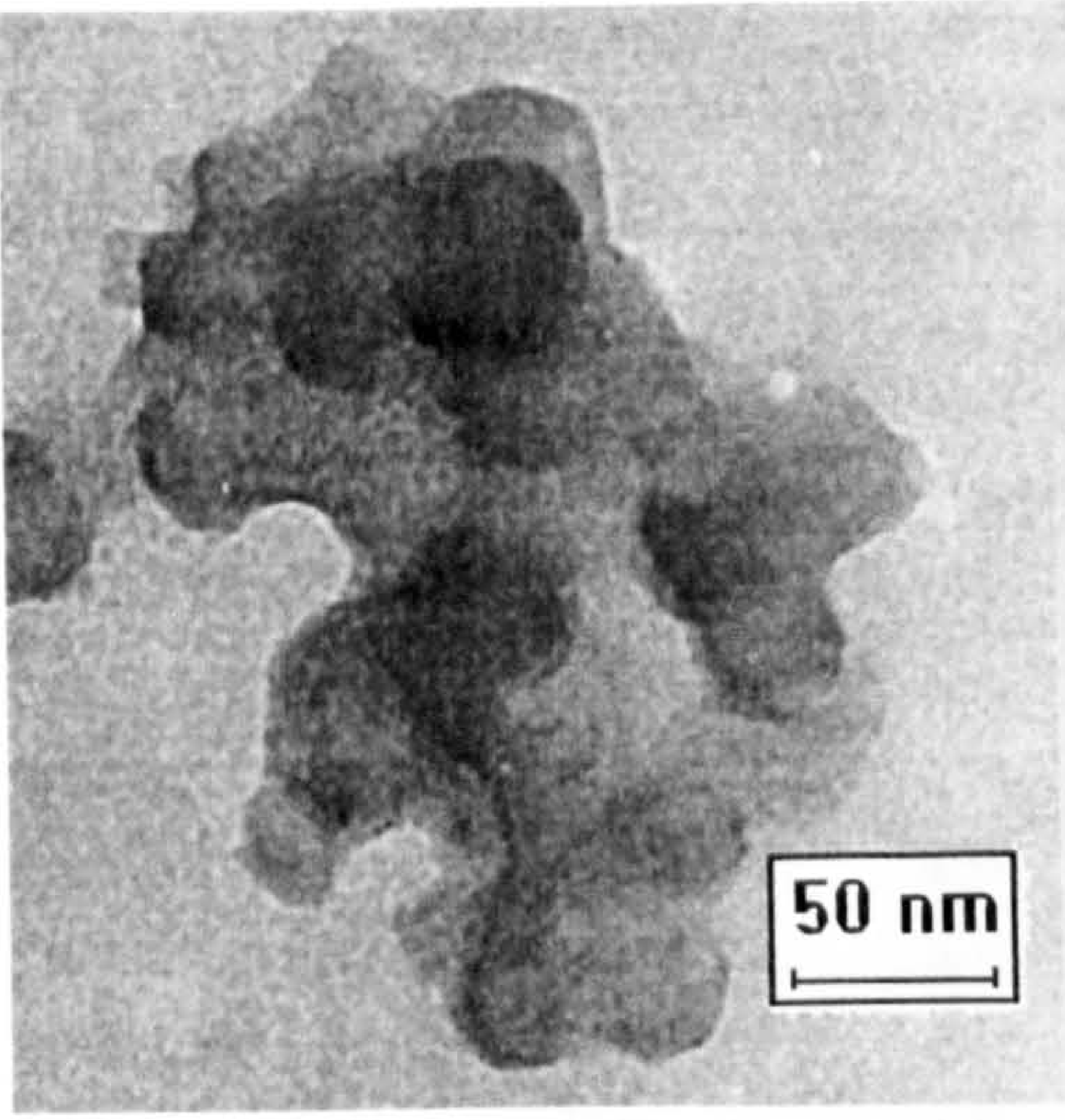

(a)

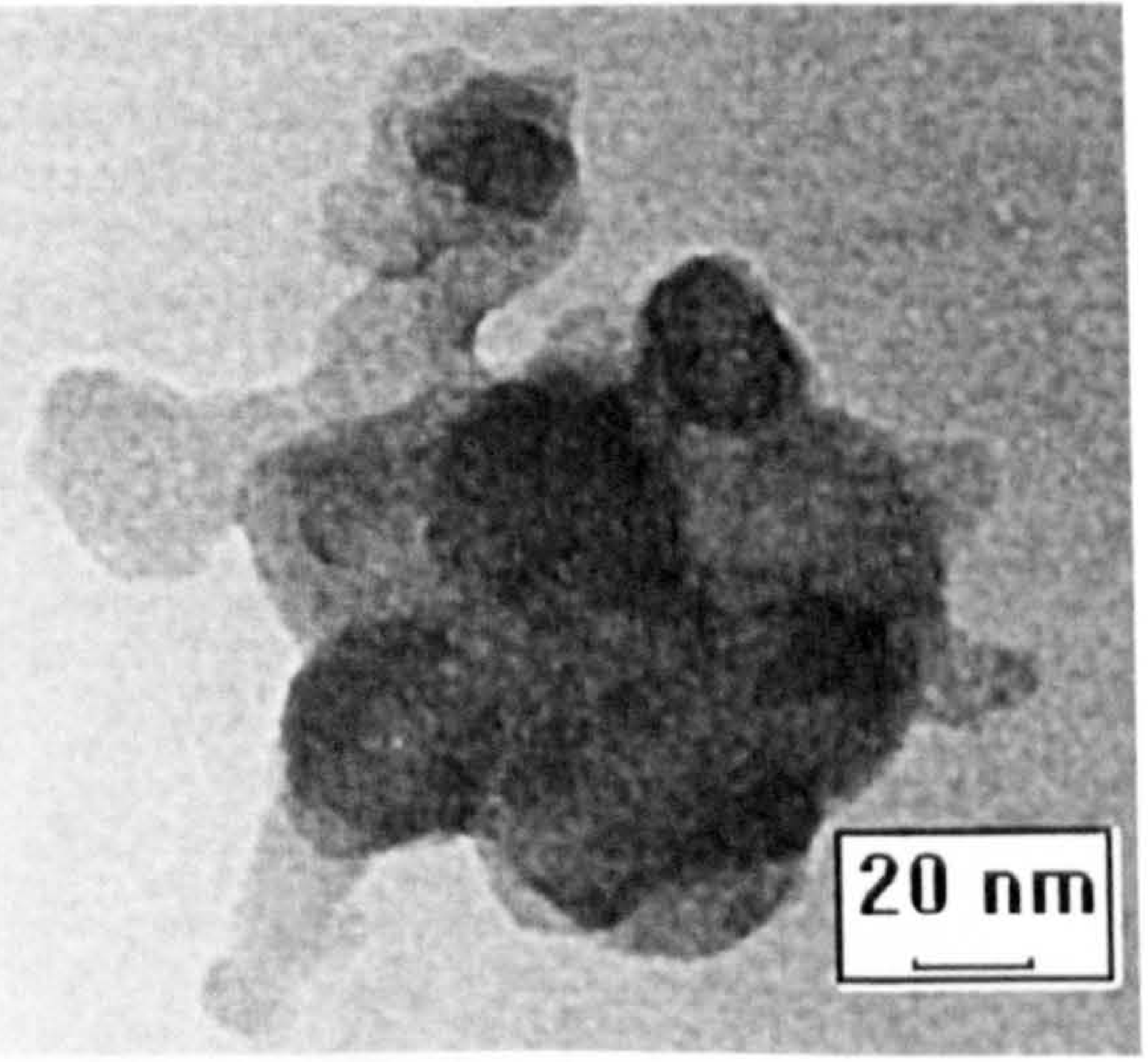

(b)

Pic. 5-15 Small spherules attached onto a big one

(a) Test No. Prc-1; Sampling position: $Z=50 \mathrm{~mm}$. [Micrograph No. 2289]

(b) Test No. Exh-3; Sampling position: $Z=15 \mathrm{~mm}$. [Micrograph No. 1805]

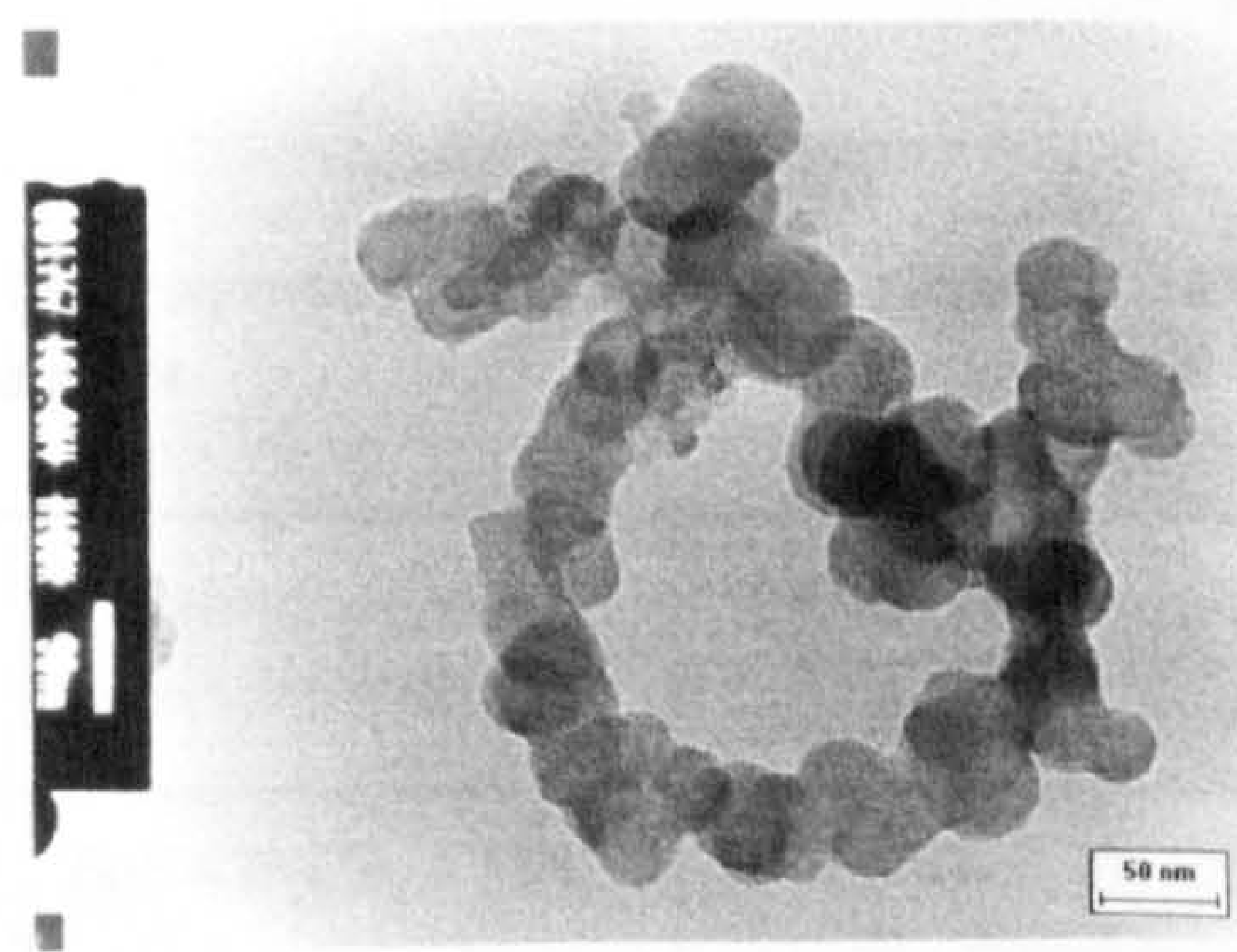

(a) [Micrograph No. 1767]

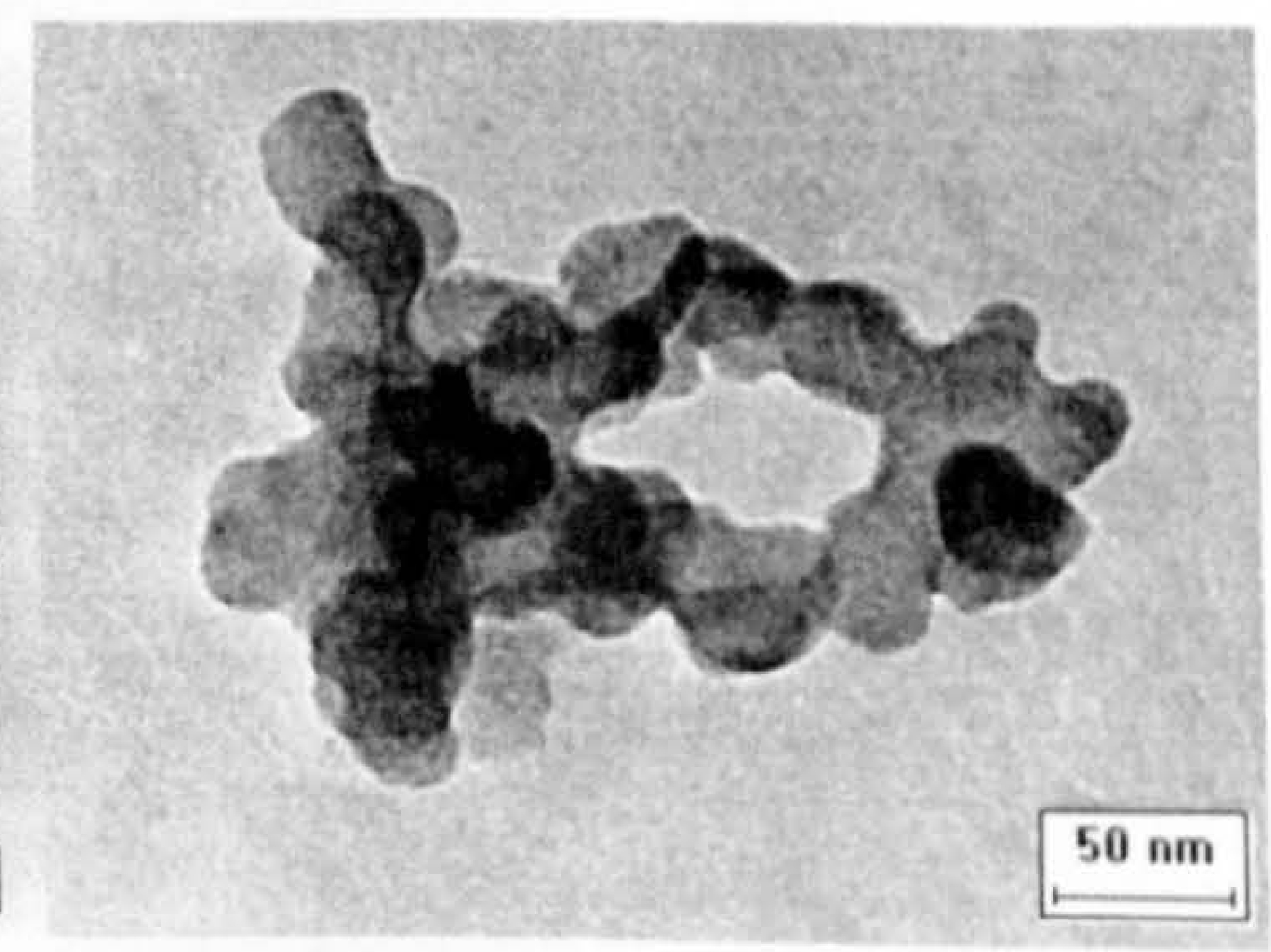

(b) [Micrograph No. 1924]

Pic. 5-16 Diesel soot rings

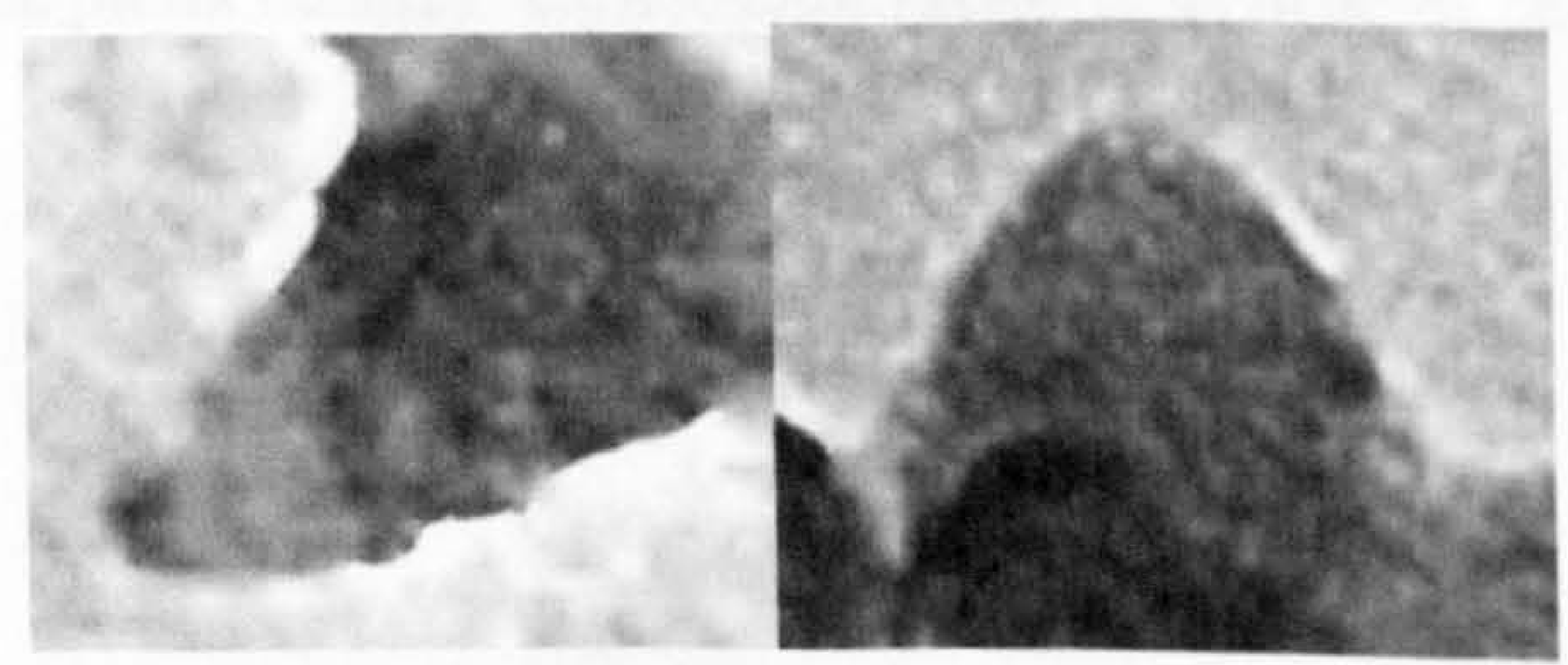

(a) "Bamboo shoot"

(b) "Peach tip"

[Micrograph No. 1381] [Micrograph No. 2281]

Pic. 5-17 Soot particles shaped like "Bamboo shoot" and "Peach tip" 
Table 6-1 Experimental oxidation rates of exhaust diesel soot and predictions by the Nagle and Strickland-Constable formula and the Lee et al. formula

\begin{tabular}{|c|c|c|c|c|c|}
\hline \multirow{2}{*}{ Test No. } & \multicolumn{2}{|c|}{ Oxidation conditions } & \multirow{2}{*}{$\begin{array}{l}\text { Experimental } \\
\text { oxidation rate } \\
{\left[10^{-4} \mathrm{~g} \mathrm{~cm}^{-2} \mathrm{~s}^{-1}\right]}\end{array}$} & \multicolumn{2}{|c|}{$\begin{array}{l}\text { Predicted oxidation rate } \\
\qquad\left[10^{-4} \mathrm{~g} \mathrm{~cm}^{-2} \mathrm{~s}^{-1}\right]\end{array}$} \\
\hline & $\mathrm{Po}_{2}$ [atm] & $\mathbf{T}[\mathbf{K}]$ & & $\begin{array}{c}\text { Nagle and } \\
\begin{array}{c}\text { Strickland-Constable } \\
\text { formula }\end{array} \\
\end{array}$ & Lee et al. formula \\
\hline Exh-1 & 0.051 & 1652 & 1.57 & 1.78 & 0.37 \\
\hline Exh-2 & 0.031 & 1690 & 1.56 & 2.50 & 0.55 \\
\hline Exh-3 & 0.031 & 1660 & 1.31 & 2.95 & 0.67 \\
\hline Exh-4 & 0.031 & 1604 & 0.62 & 3.37 & 0.67 \\
\hline Exh-5 & 0.016 & 1823 & 2.57 & 3.58 & 0.78 \\
\hline Exh-6 & 0.016 & 1796 & 1.32 & 2.72 & 0.85 \\
\hline Exh-7 & 0.010 & 1710 & 0.41 & 1.84 & 0.25 \\
\hline Exh-8 & 0.010 & 1531 & 0.08 & 0.68 & 0.07 \\
\hline
\end{tabular}

Note: Prefix "Exh" refers to raw soot extracted from the engine exhaust and oxidized in the burner quartz tube oxidizer.

Table 6-2 Experimental oxidation rates of diesel soot extracted from the engine pre-chamber

\begin{tabular}{c|c|c|c|c|}
\hline \multirow{2}{*}{ Test No. } & \multirow{2}{*}{$\begin{array}{c}\text { Sampling valve } \\
\text { timing }\end{array}$} & \multicolumn{2}{|c|}{ Oxidation conditions } & Experimental oxidation rate \\
\cline { 3 - 4 } & & $\mathrm{Po}_{2}[\mathrm{~atm}]$ & $\mathrm{T}[\mathrm{K}]$ & $\left.0.4 \mathrm{~g} \mathrm{~cm}^{-2} \mathrm{~s}^{-1}\right]$ \\
\hline Prec-1 & $60^{\circ}-63^{\circ} \mathrm{CA}$ ATDC & 0.030 & 1785 & 0.22 \\
Prex-1 & $20^{\circ}-23^{\circ} \mathrm{CA}$ ABTC & 0.048 & 1800 & 1.45 \\
Prex-2 & $20^{\circ}-23^{\circ} \mathrm{CA} \mathrm{ABTC}$ & 0.027 & 1745 & 0.91 \\
\hline
\end{tabular}

Note: Prefix "Pre" refers to raw soot extracted from the engine pre-combustion chamber by means of the high speed sampling valve at the timing shown and subsequently oxidized in the burner quartz tube oxidizer. Letter "c" in the prefix denotes "combustion stroke"; " $x$ " denotes "exhaust stroke". 


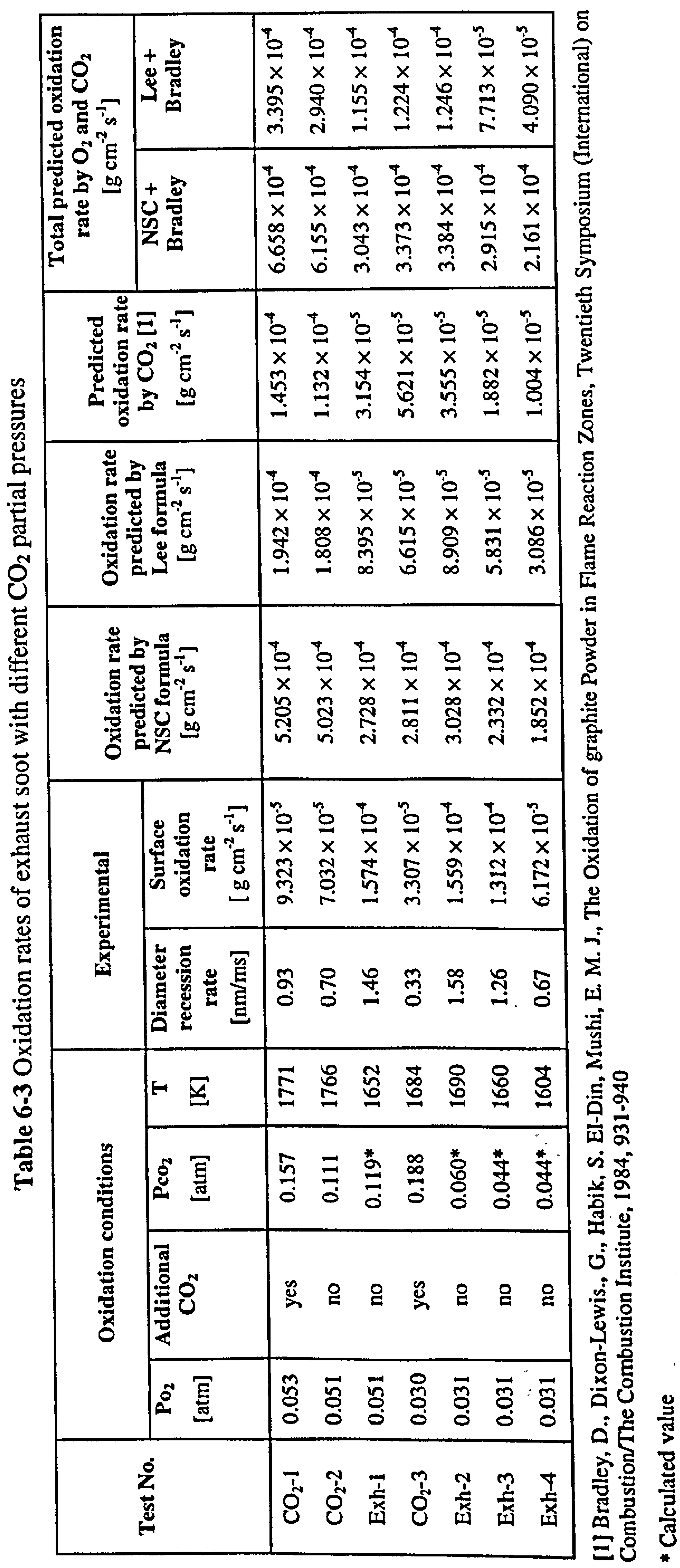



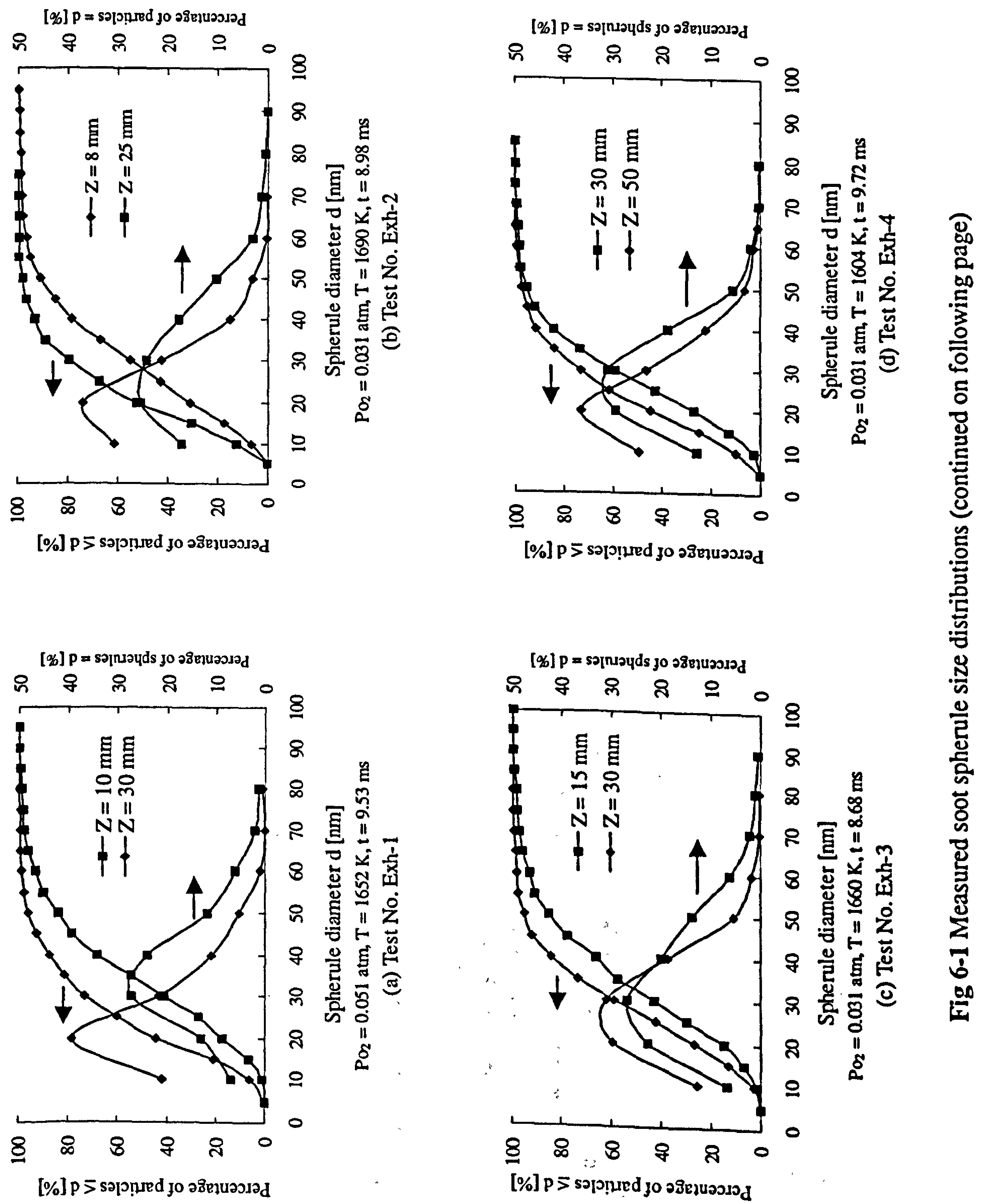

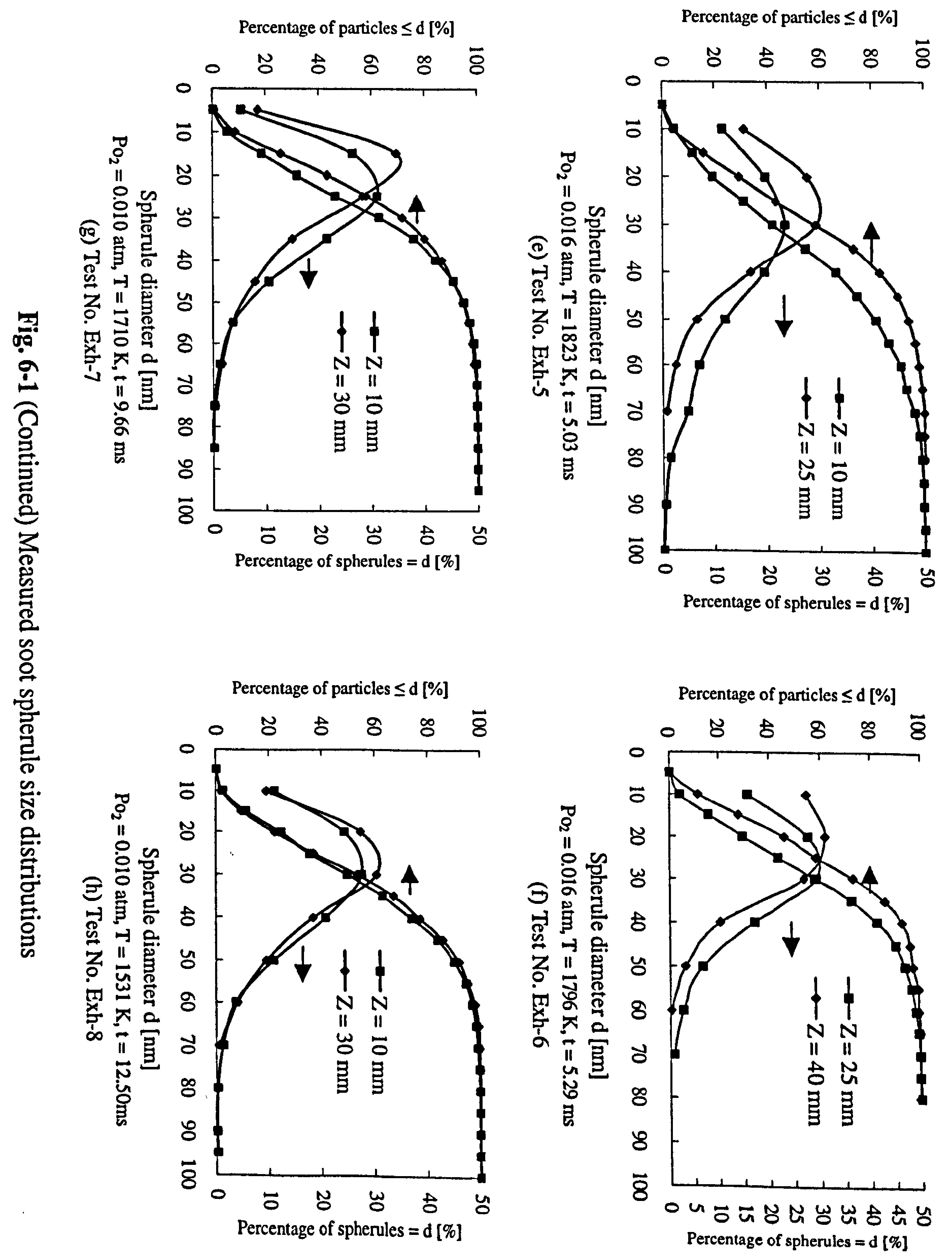


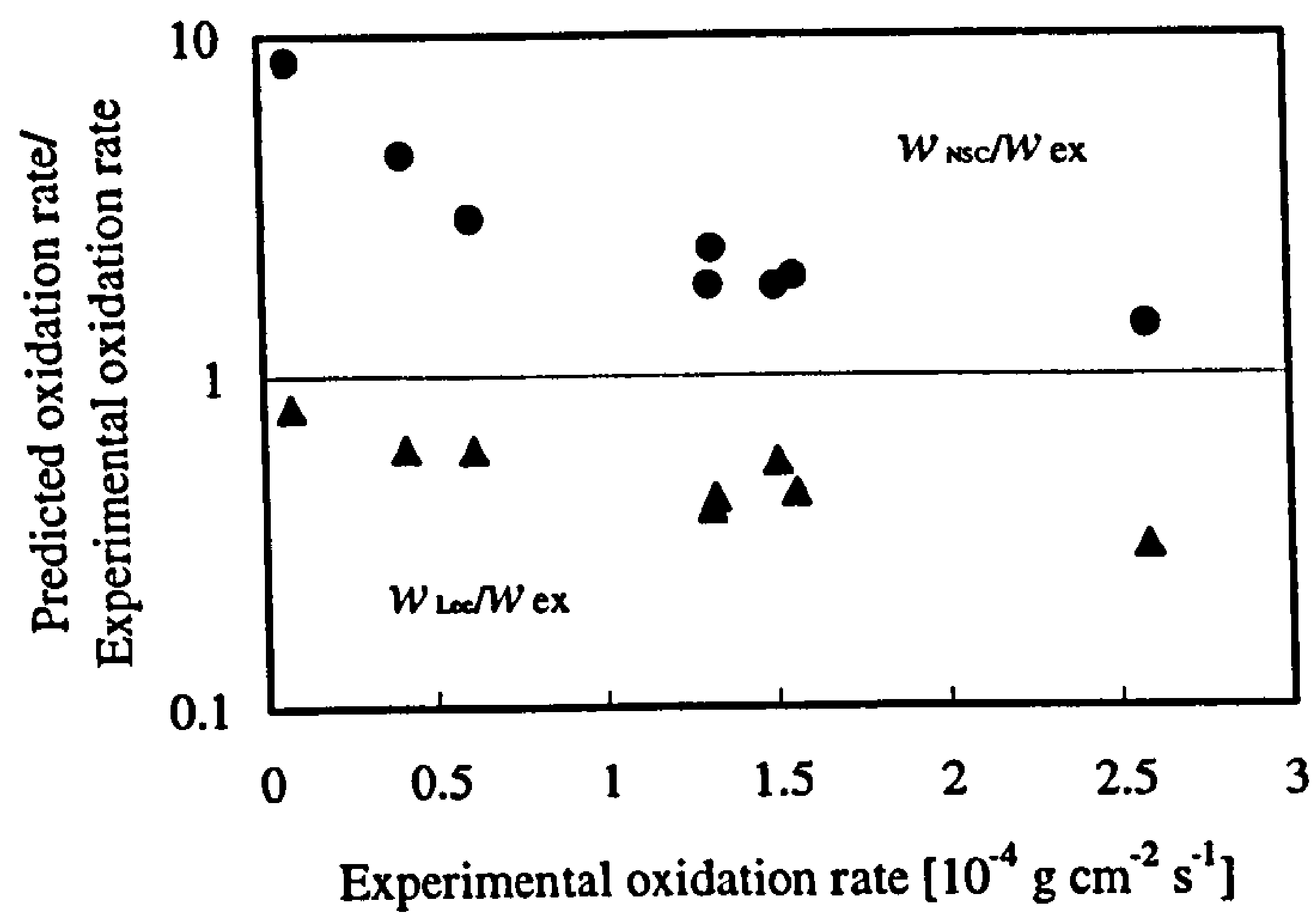

(a)

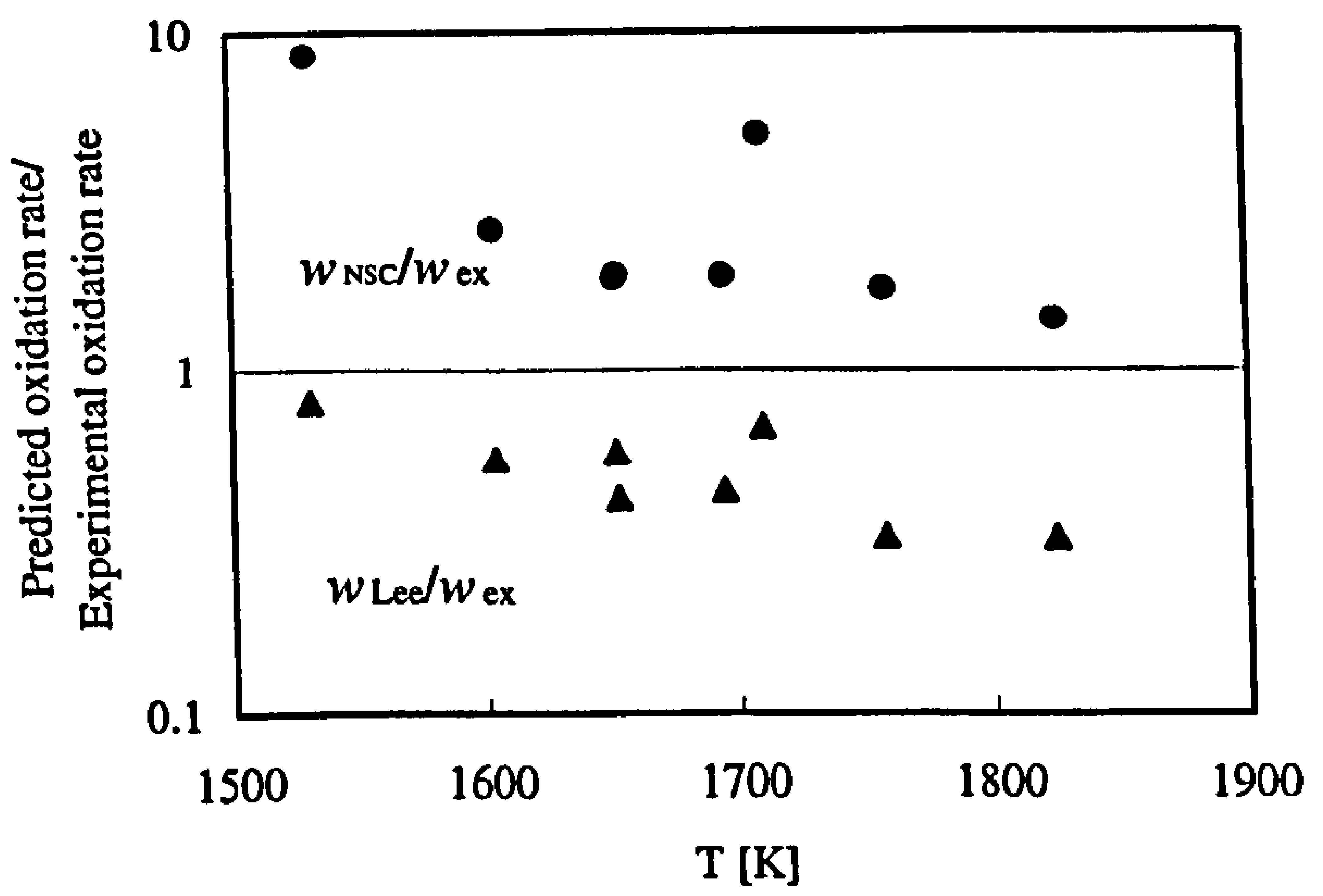

(b)

Fig. 6-2 Comparison between the soot oxidation results of this study with the Nagle and Strickland-Constable formula and the Lee formula. $w_{\mathrm{NSC}}, w_{\text {Lee: }}$ : predicted oxidation rate by the Nagle and Strickland-Constable formula and by the Lee et al. formula, respectively; $w_{\text {ex: }}$ : experimental oxidation rate from the present work (continued on following page) 


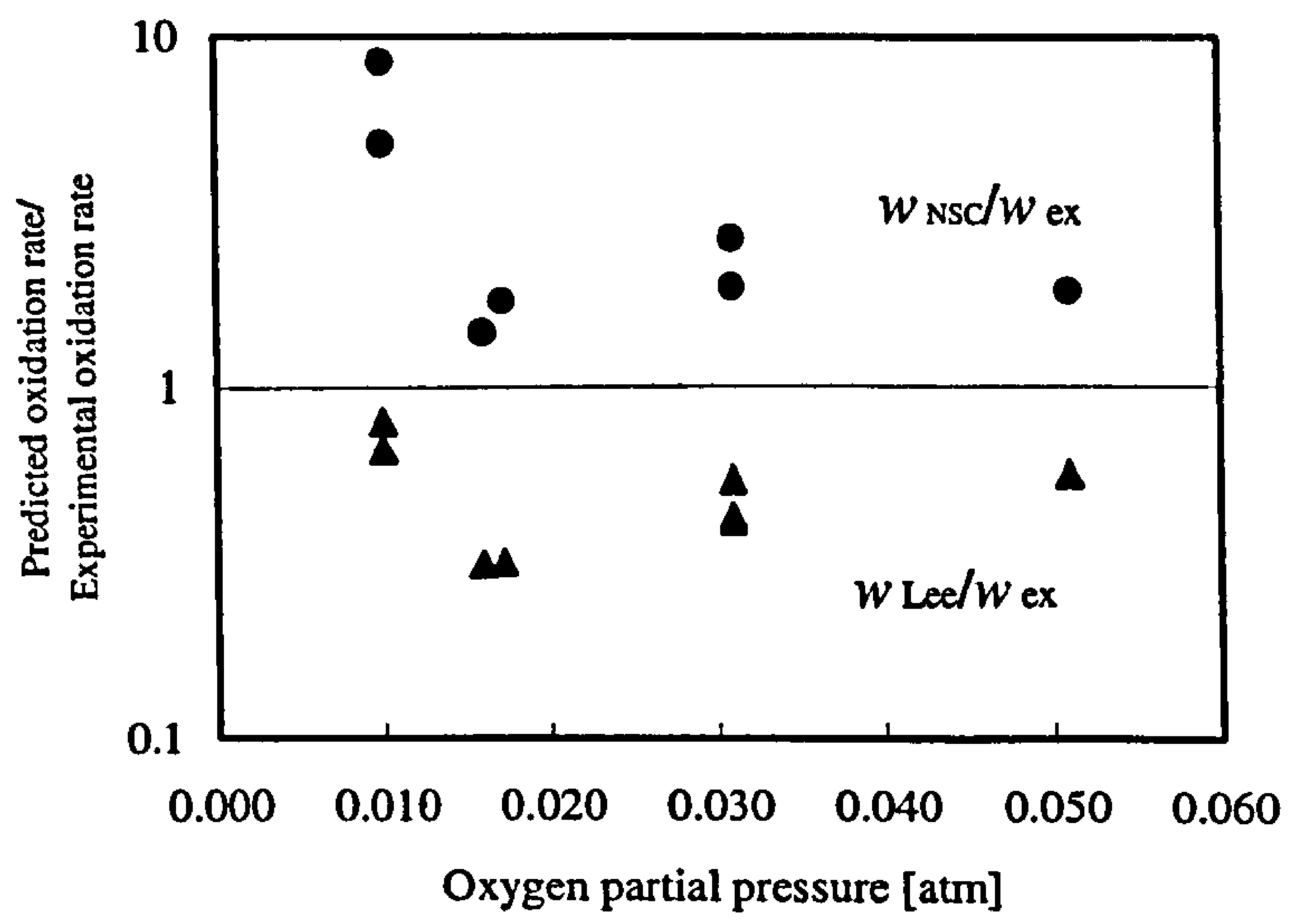

(c)

Fig. 6-2(continued) Comparison between the soot oxidation results of this study with the Nagle and Strickland-Constable formula and the Lee formula. $w_{\mathrm{NSC}}, w_{\text {Lee }}$ : predicted oxidation rate by the Nagle and Strickland-Constable formula and by the Lee et al formula, respectively; $w_{\text {ex }}$ : experimental oxidation rate from the present work

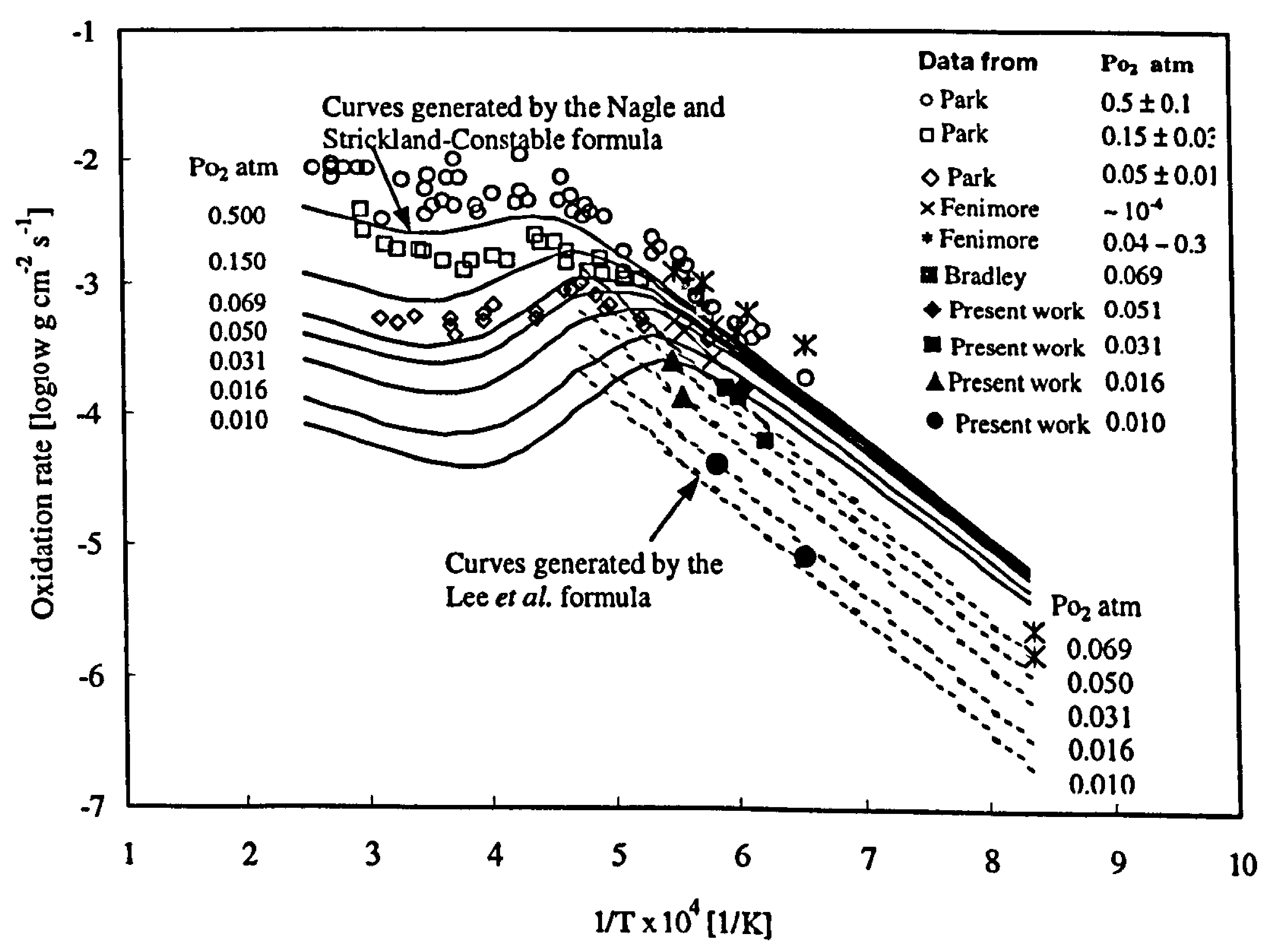

Fig. 6-3 Comparison of the predictions by the Nagle and Strickland-Constable formula and the Lee et al formula with experimental results 


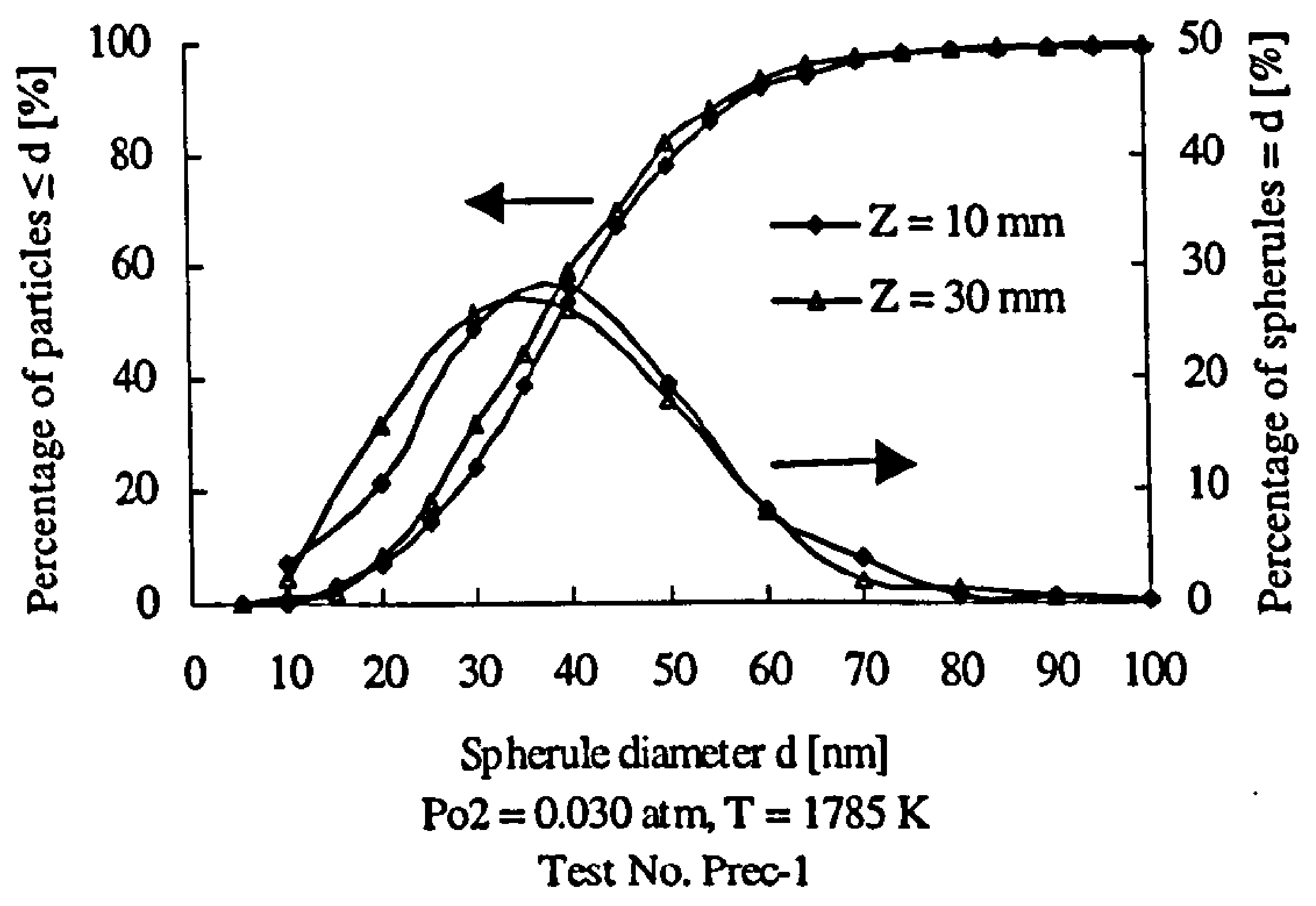

Fig. 6-4 Measured spherule size distributions for the pre-chamber soot sampled at $60^{\circ}-63^{\circ} \mathrm{CA}$ ATDC during the combustion stroke

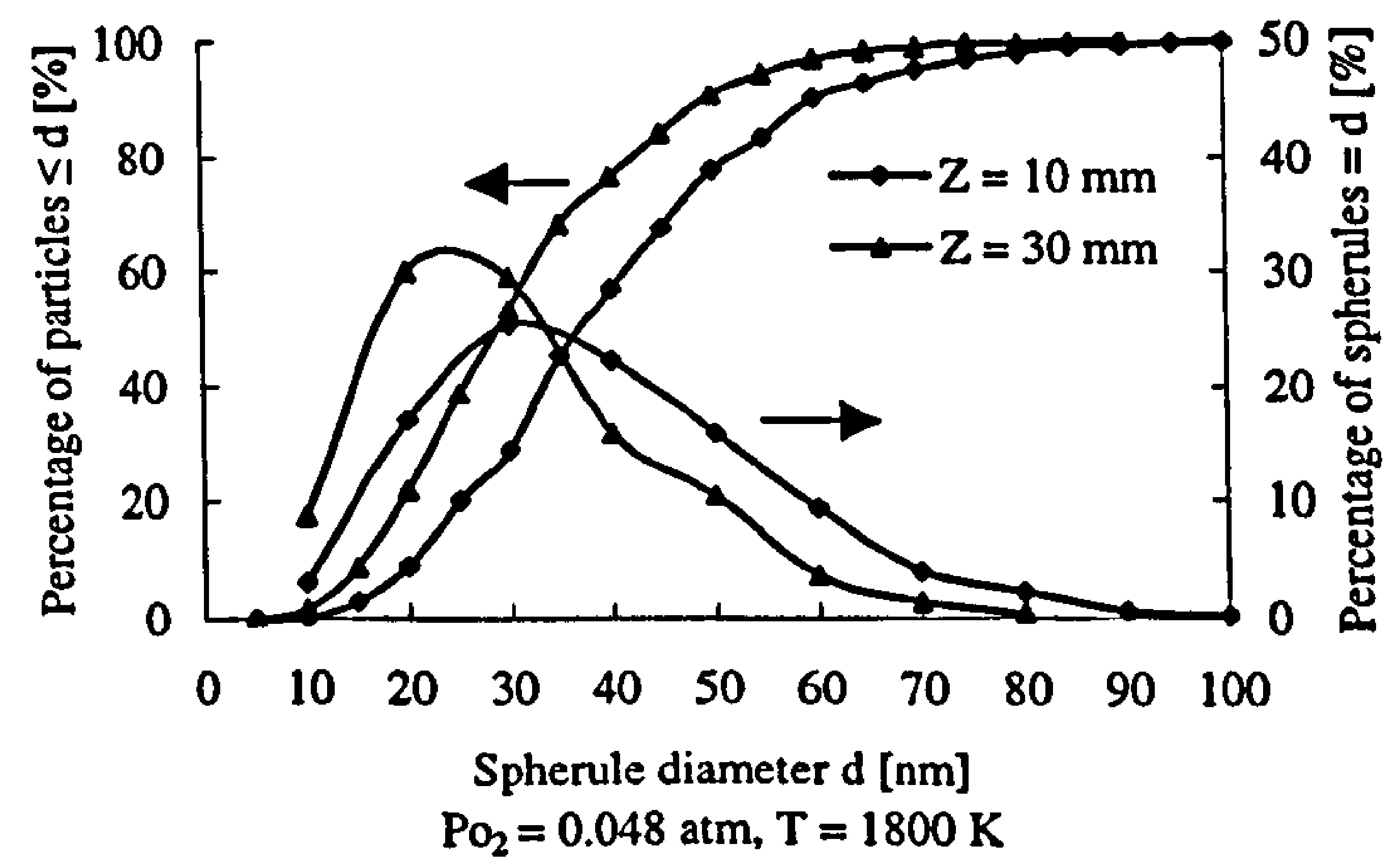

(a) Test No. Prex-1

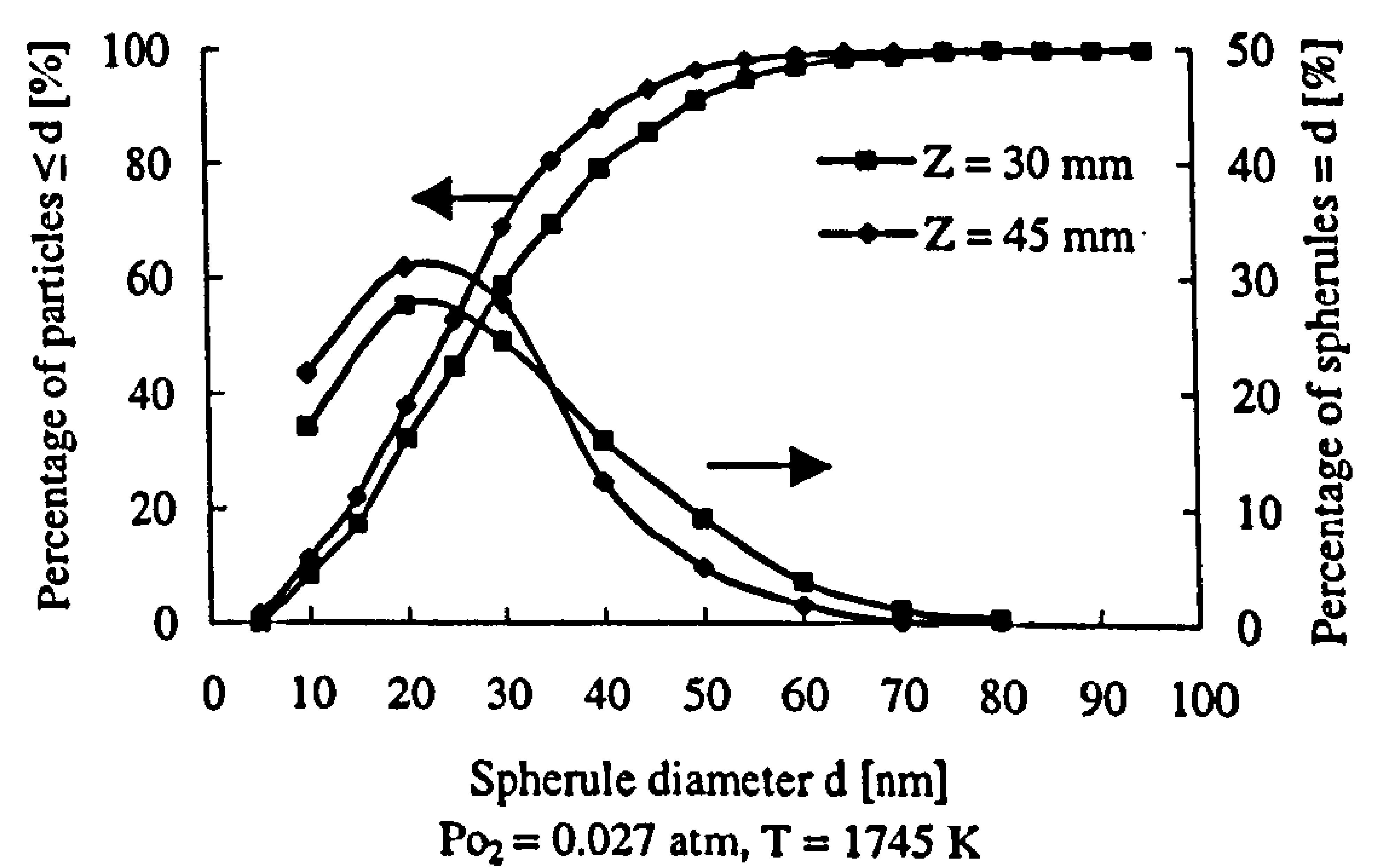

(b) Test No. Prex-2

Fig. 6-5 Measured spherule size distributions for the pre-chamber soot sampled at $20^{\circ}-23^{\circ} \mathrm{CA}$ ABDC during the exhaust stroke 


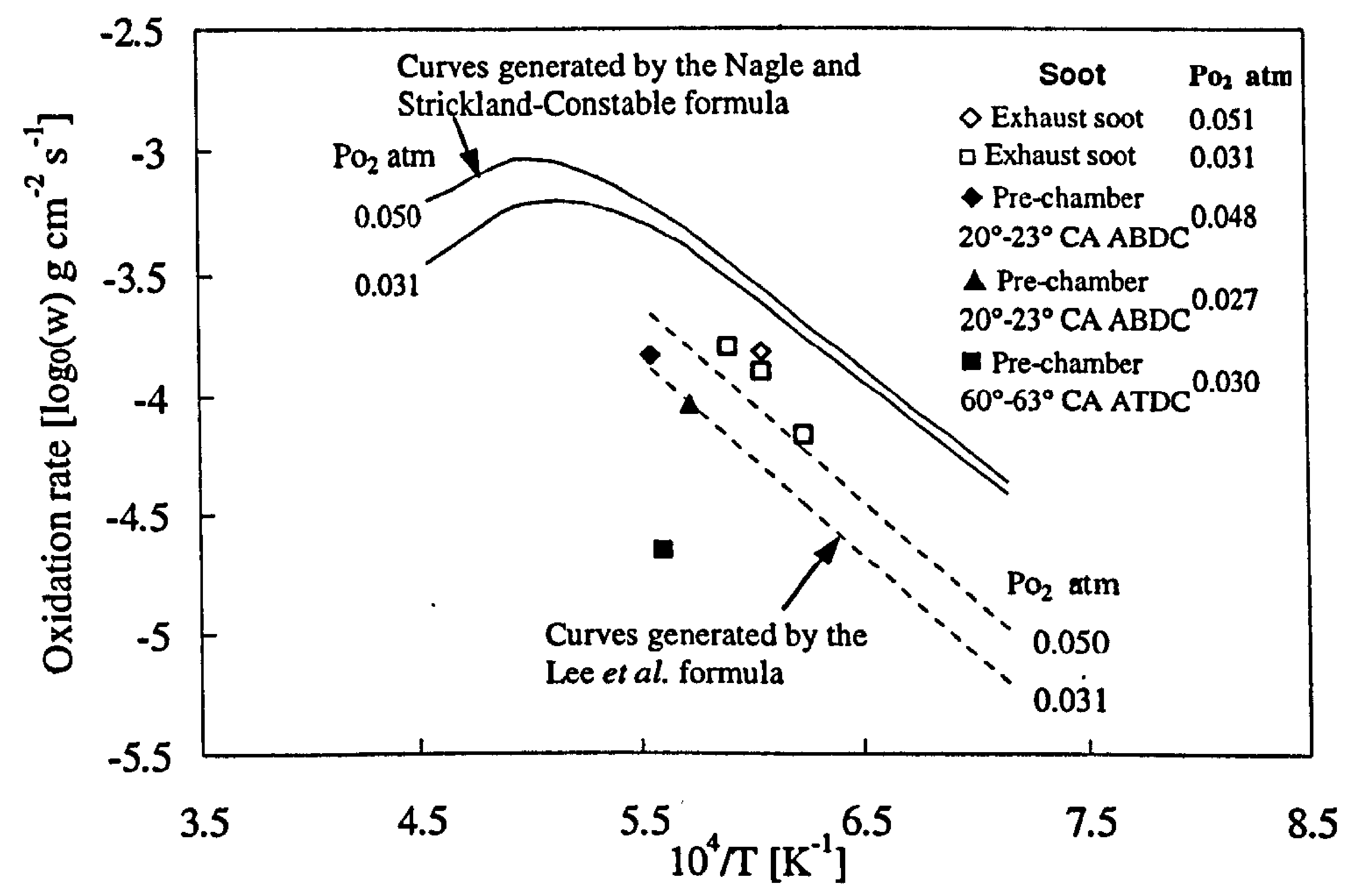

Fig. 6-6 Comparison of the oxidation rates of pre-ctramber soot with exhaust soot 


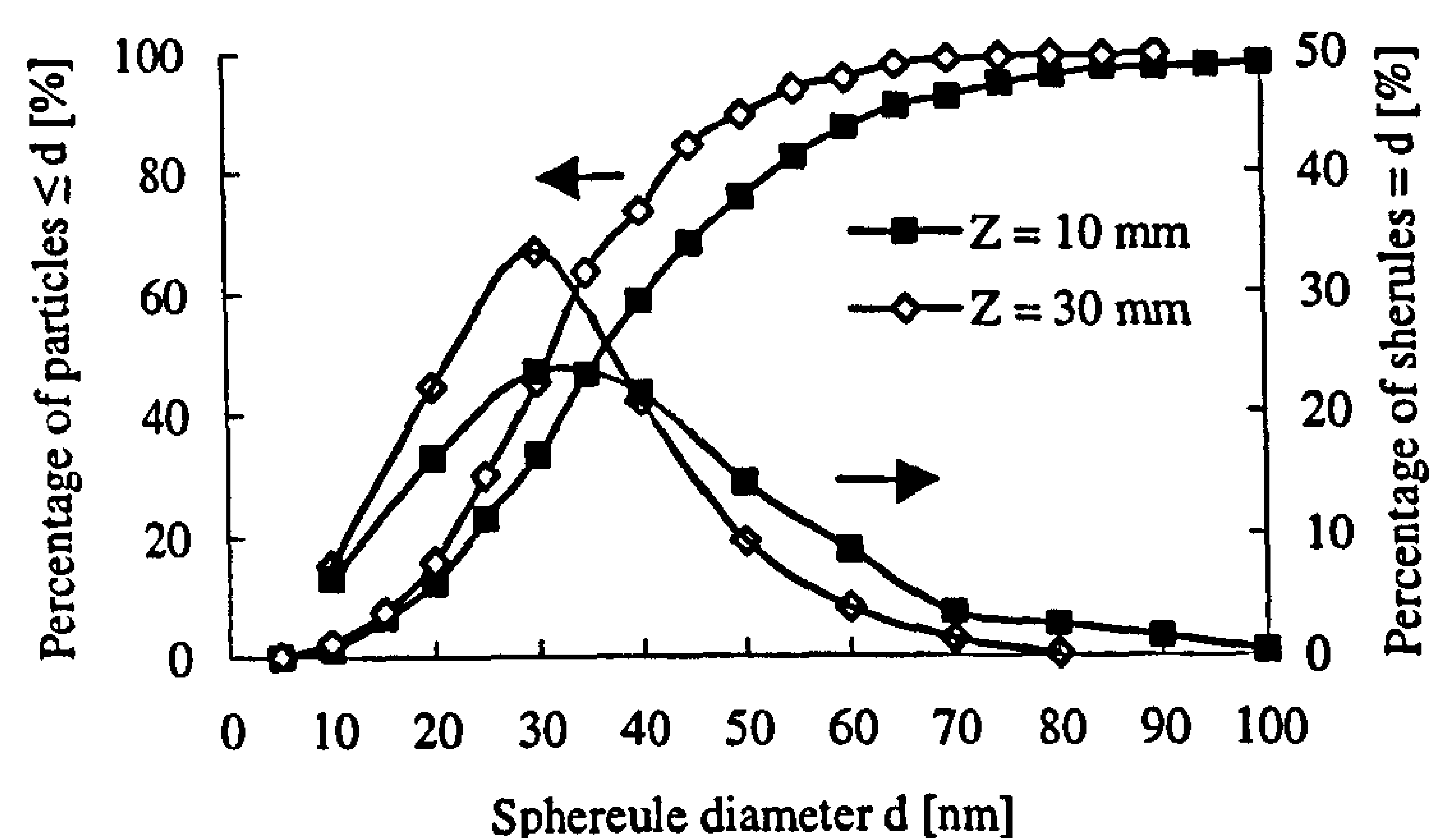

$\mathrm{PCO}_{2}=0.157 \mathrm{~atm}, \mathrm{Po}_{2}=0.053 \mathrm{~atm}, \mathrm{~T}=1771 \mathrm{~K}$

(a) Test No. $\mathrm{CO}_{2}-1$

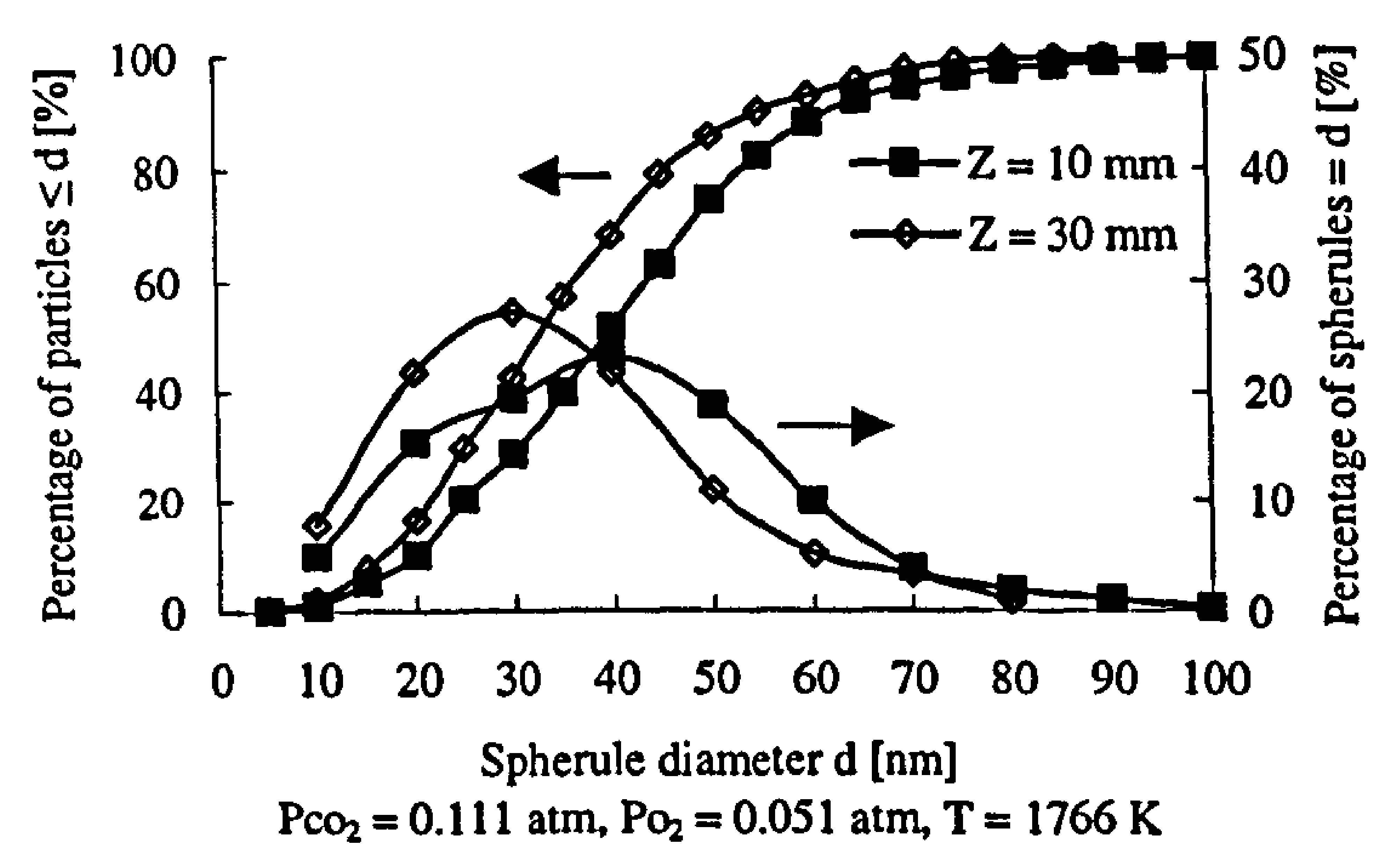

(b) Test No. $\mathrm{CO}_{2}-2$

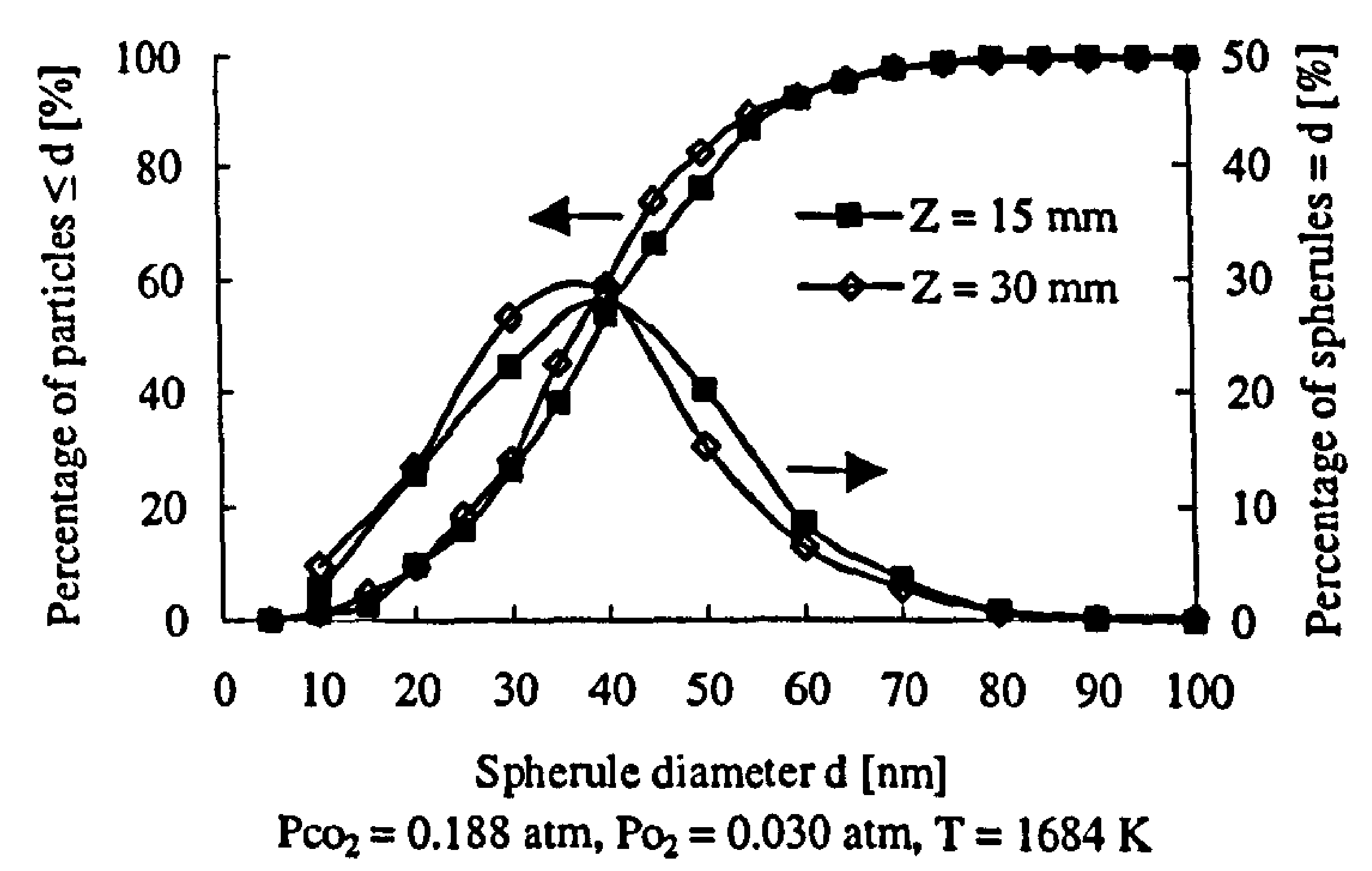

(c) Test No. $\mathrm{CO}_{2}-3$

Fig. 6-7 Measured spherule size distributions for the exhaust soot oxidized with additional $\mathrm{CO}_{2}$ injection 


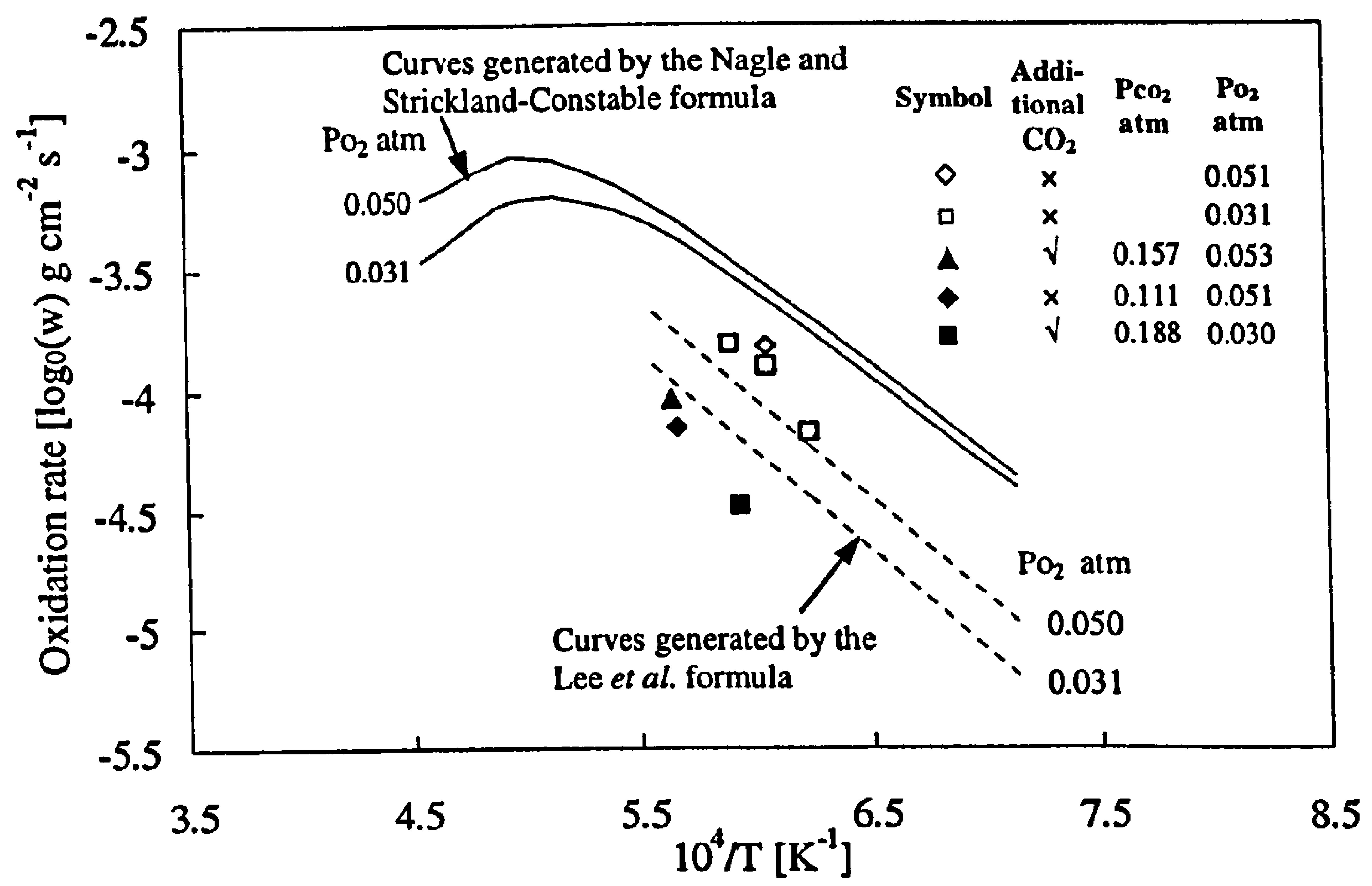

Fig. 6-8 Comparison of oxidation rates of exhaust soot with and without additional $\mathrm{CO}_{2}$ supply 


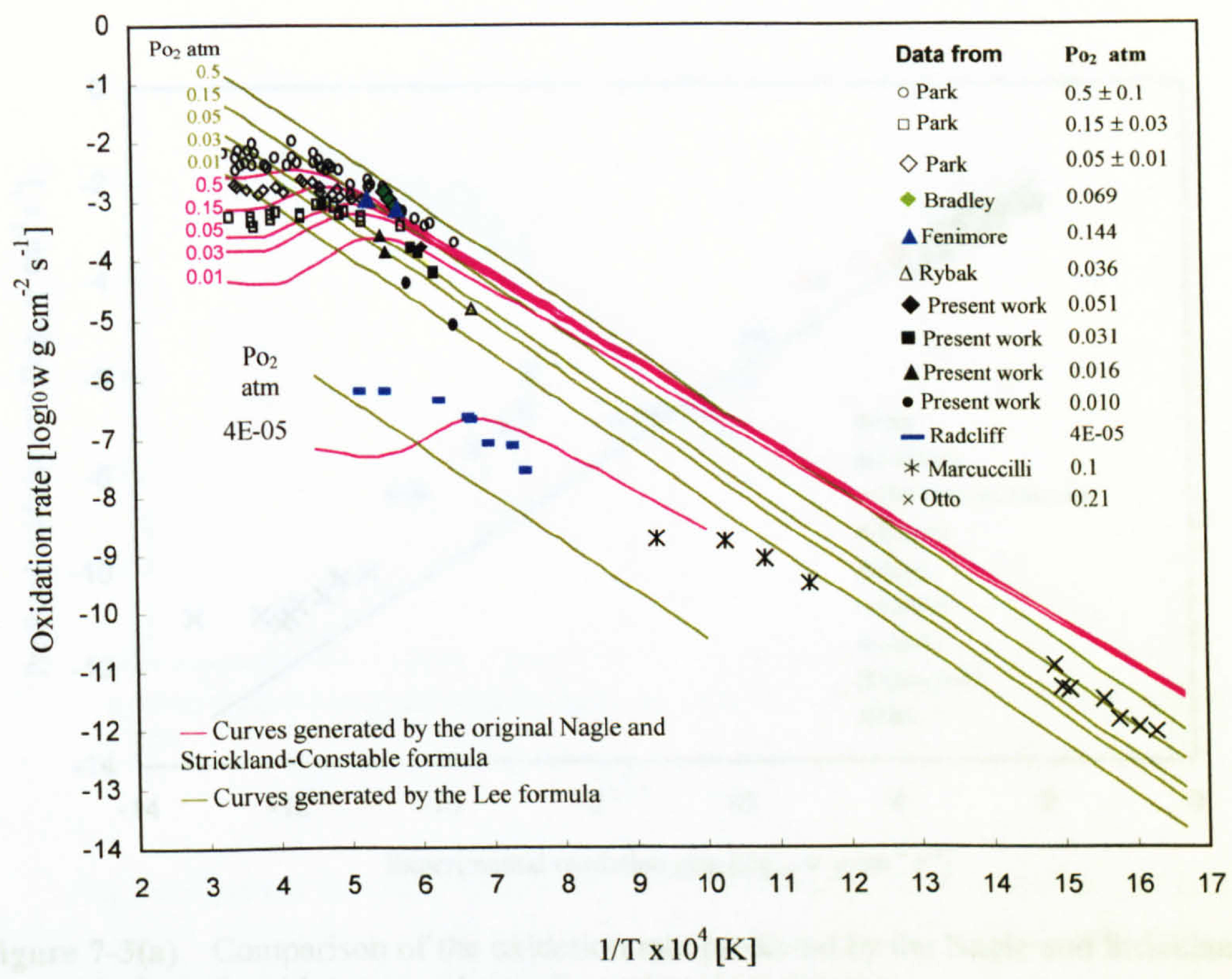

Fig 7-1 Comparison of the Nagle and Strickland-Constable formula with the Lee formula

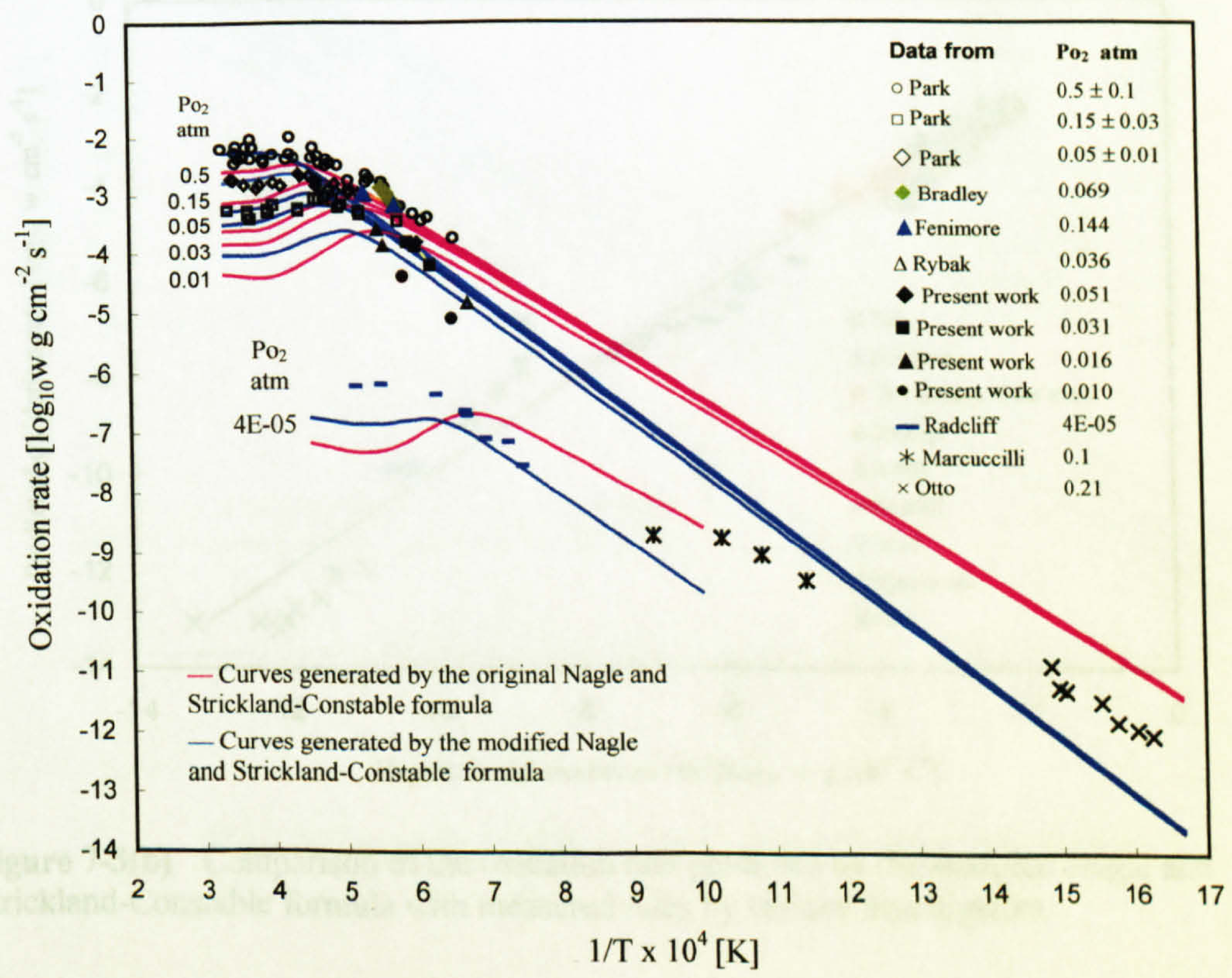

Fig. 7-2 Comparison of the modified and the original Nagle and StricklandConstable formula 


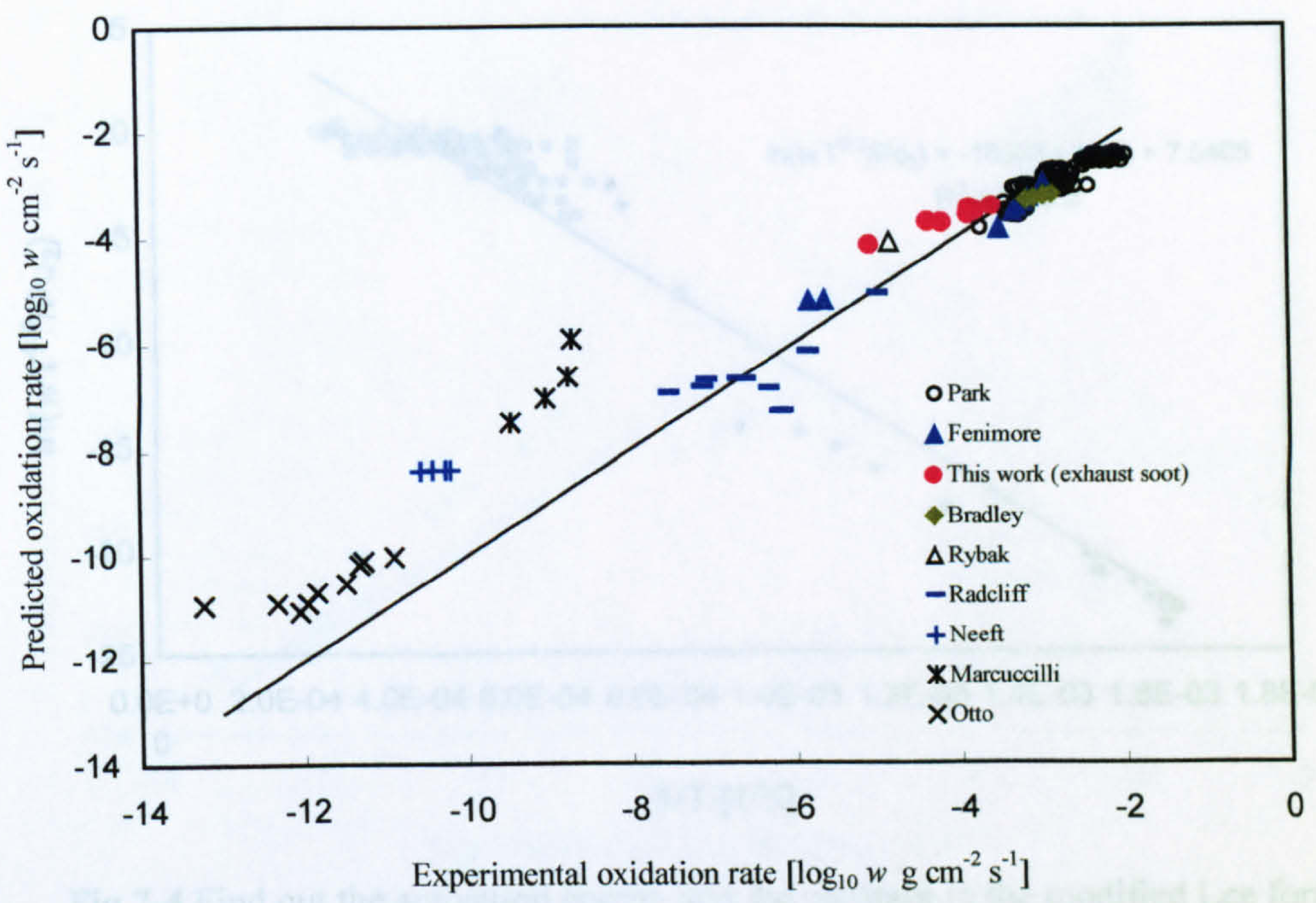

Figure 7-3(a) Comparison of the oxidation rate predicted by the Nagle and StricklandConstable formula with measured rates by various investigators

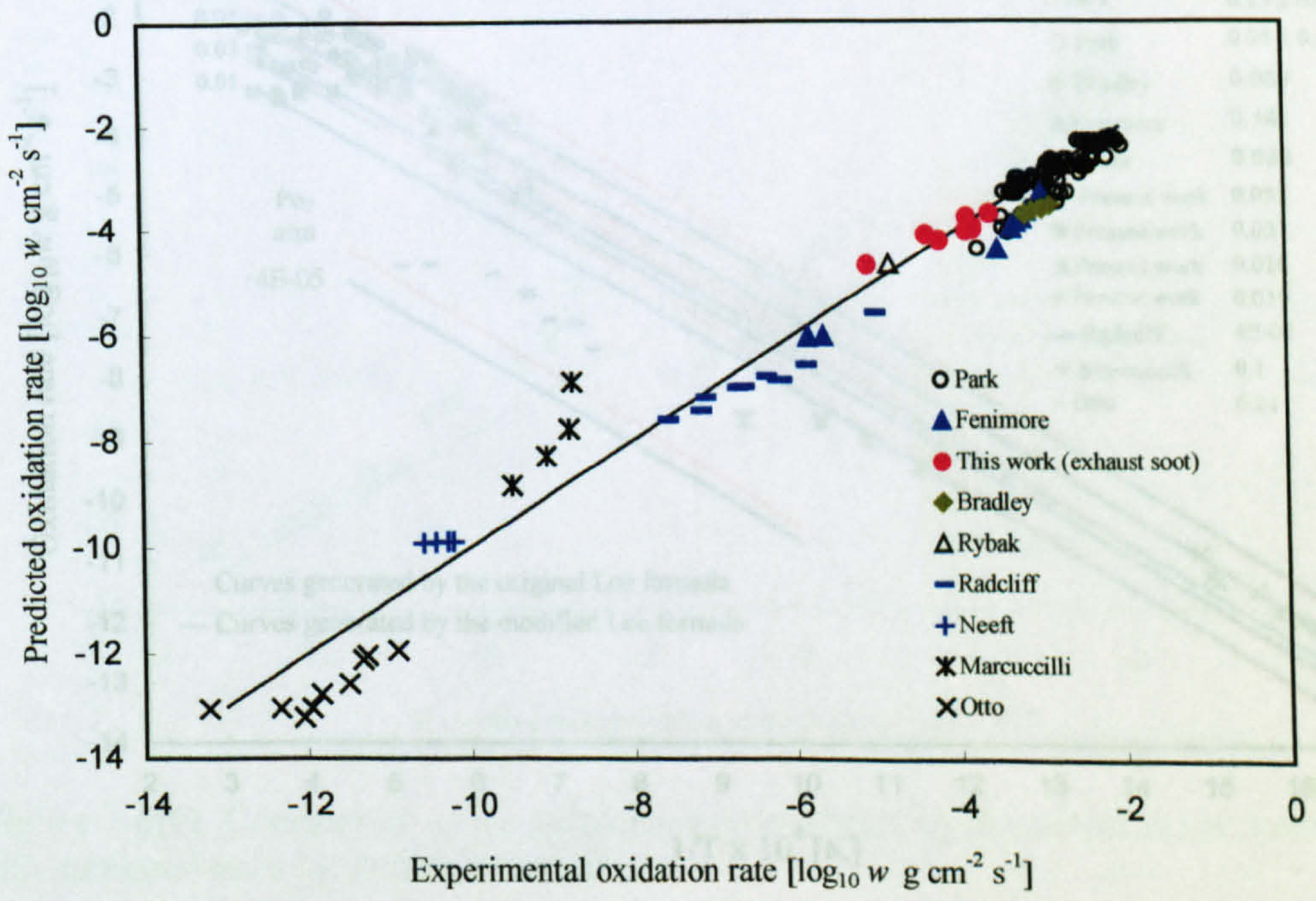

Figure 7-3(b) Comparison of the oxidation rate predicted by the modified Nagle and Strickland-Constable formula with measured rates by various investigators 


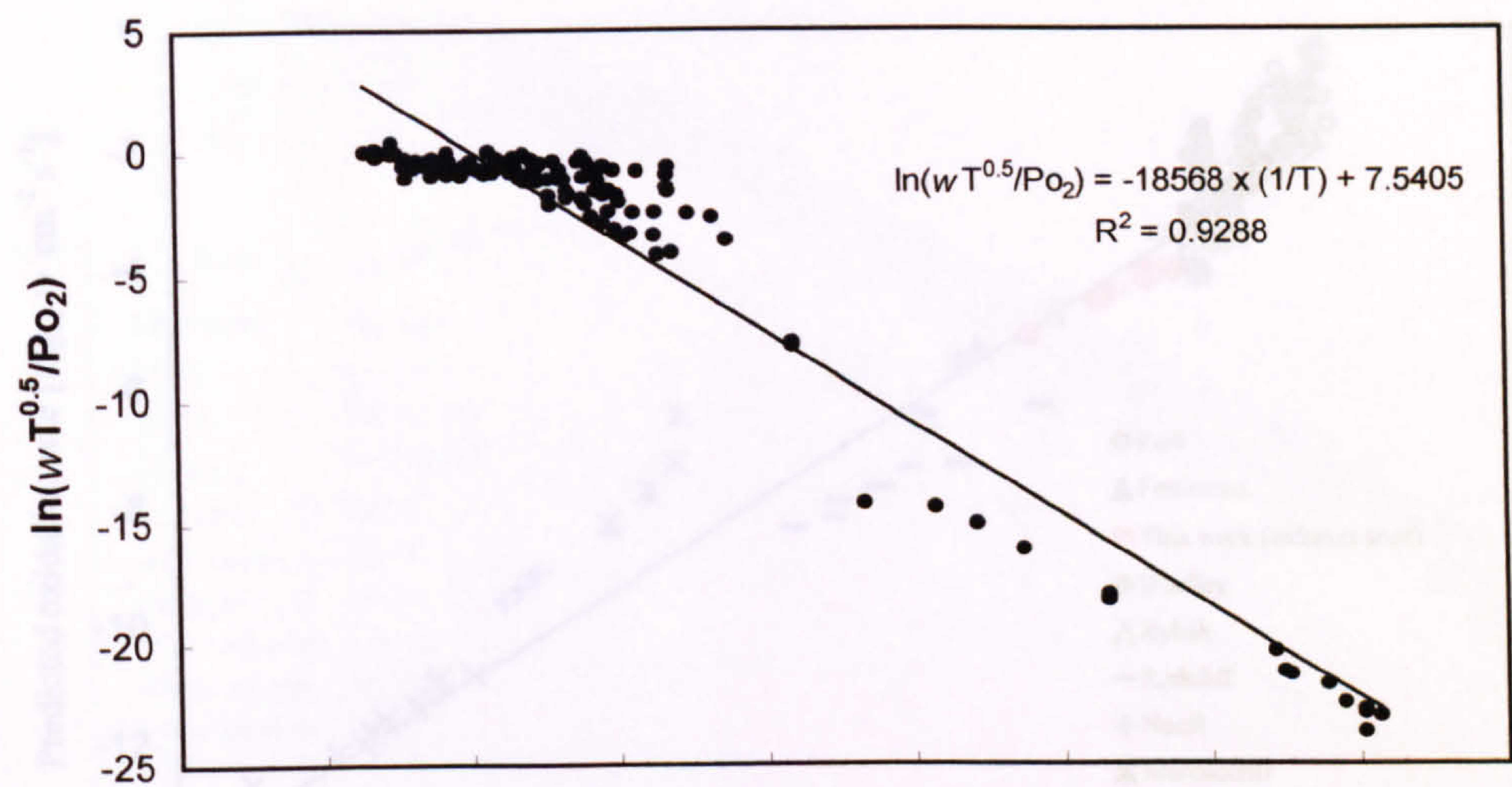

0.0E+0 2.0E-04 4.0E-04 6.0E-04 8.0E-04 1.0E-03 1.2E-03 1.4E-03 1.6E-03 1.8E-03 0

$1 / \mathrm{T}[1 / \mathrm{K}]$

Fig 7-4 Find out the activation energy and the constant in the modified Lee formula

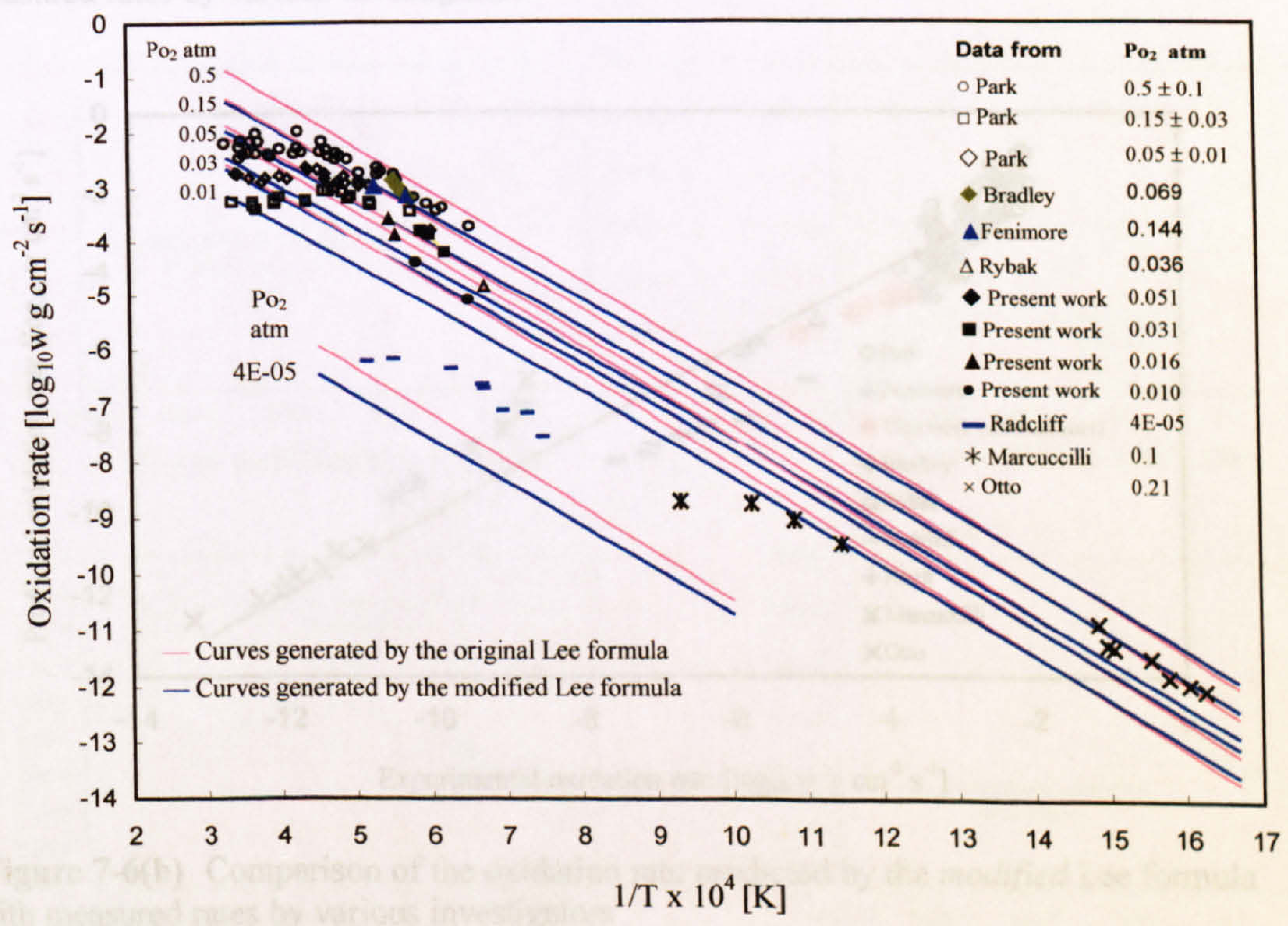

Fig 7-5 Comparison of the modified and the original Lee formula 


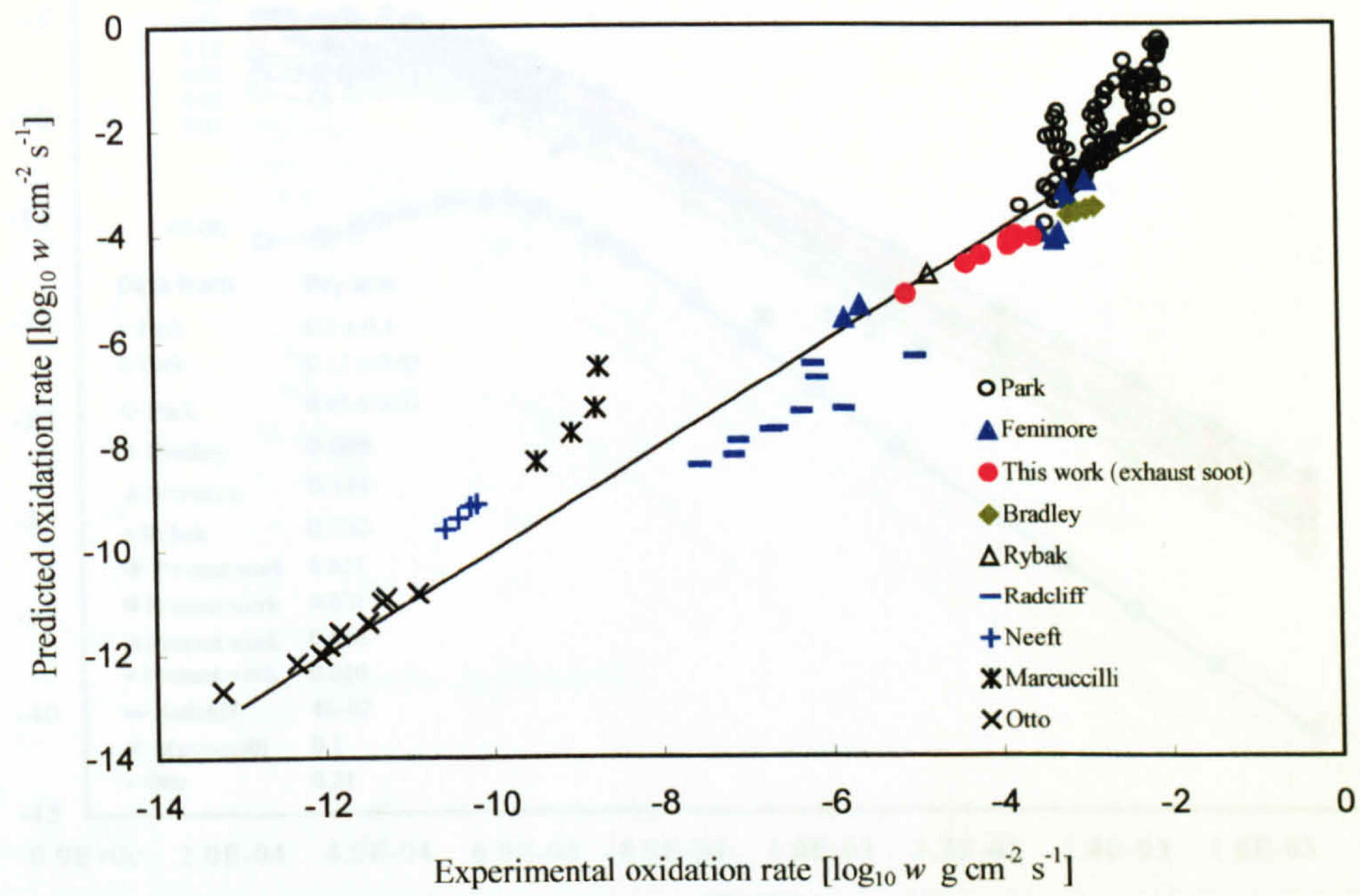

Figure 7-6(a) Comparison of the oxidation rate predicted by the Lee formula with measured rates by various investigators

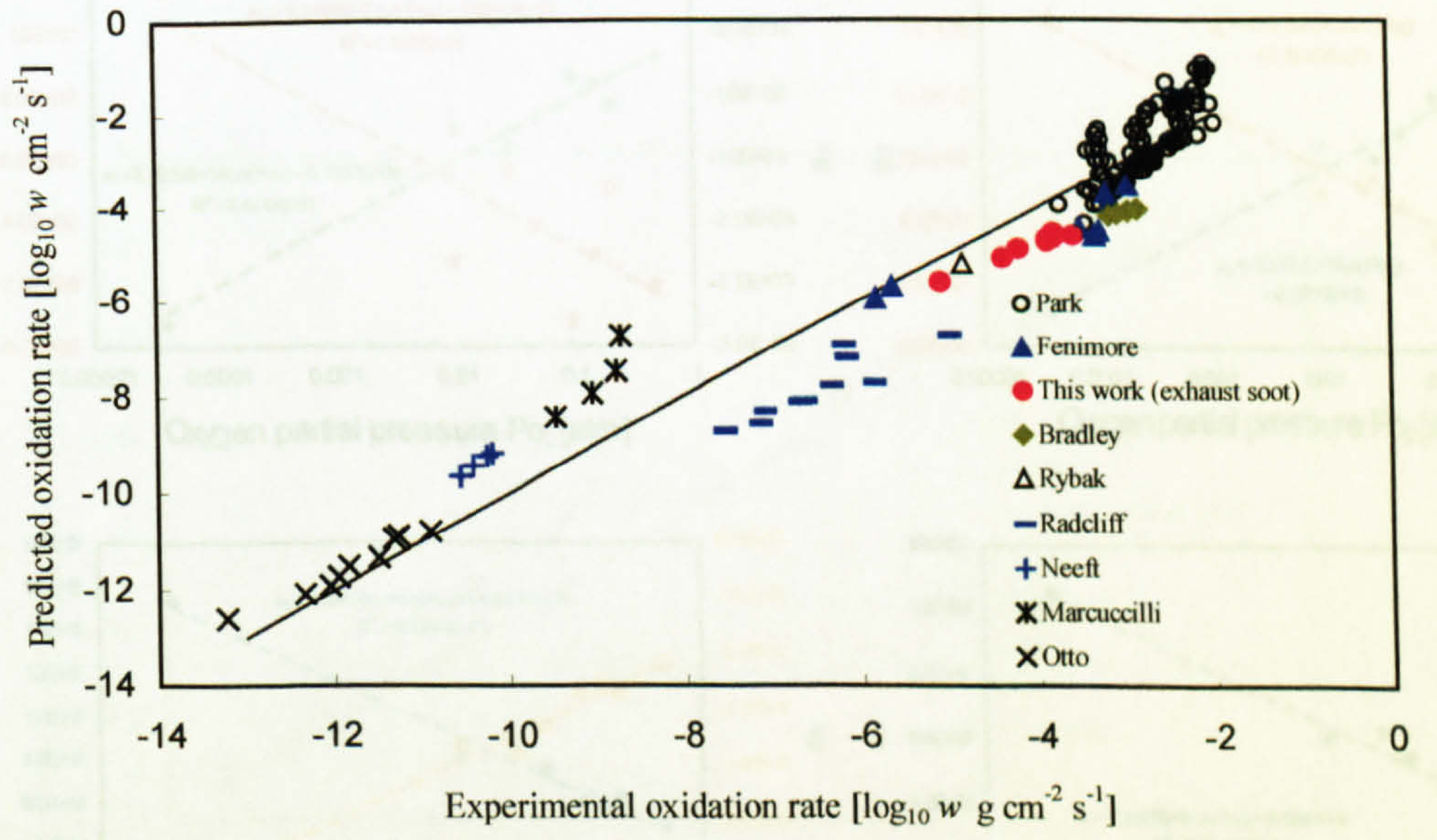

Figure 7-6(b) Comparison of the oxidation rate predicted by the modified Lee formula with measured rates by various investigators 


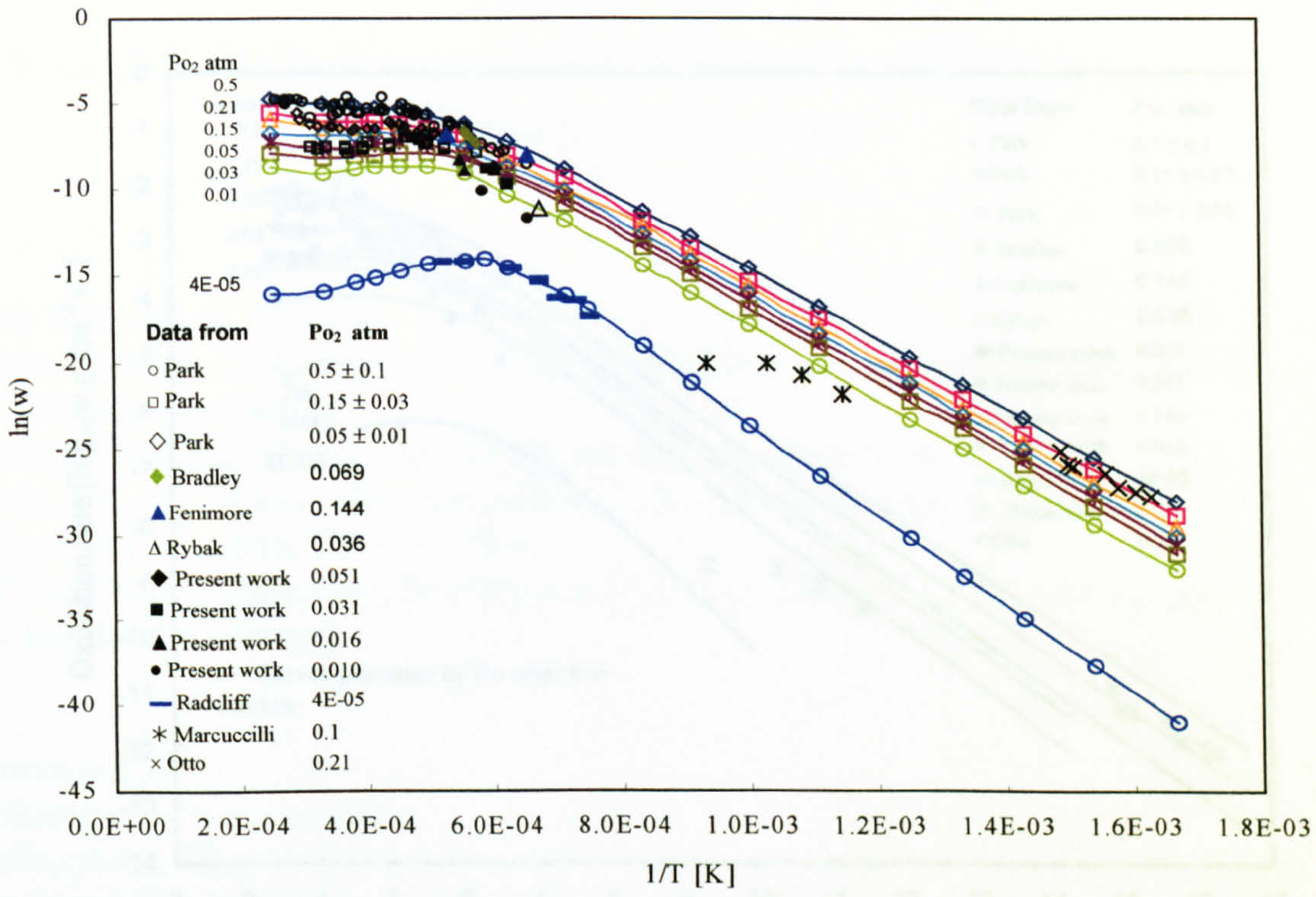

Fig. 7-7 Target curves of the empirical formula
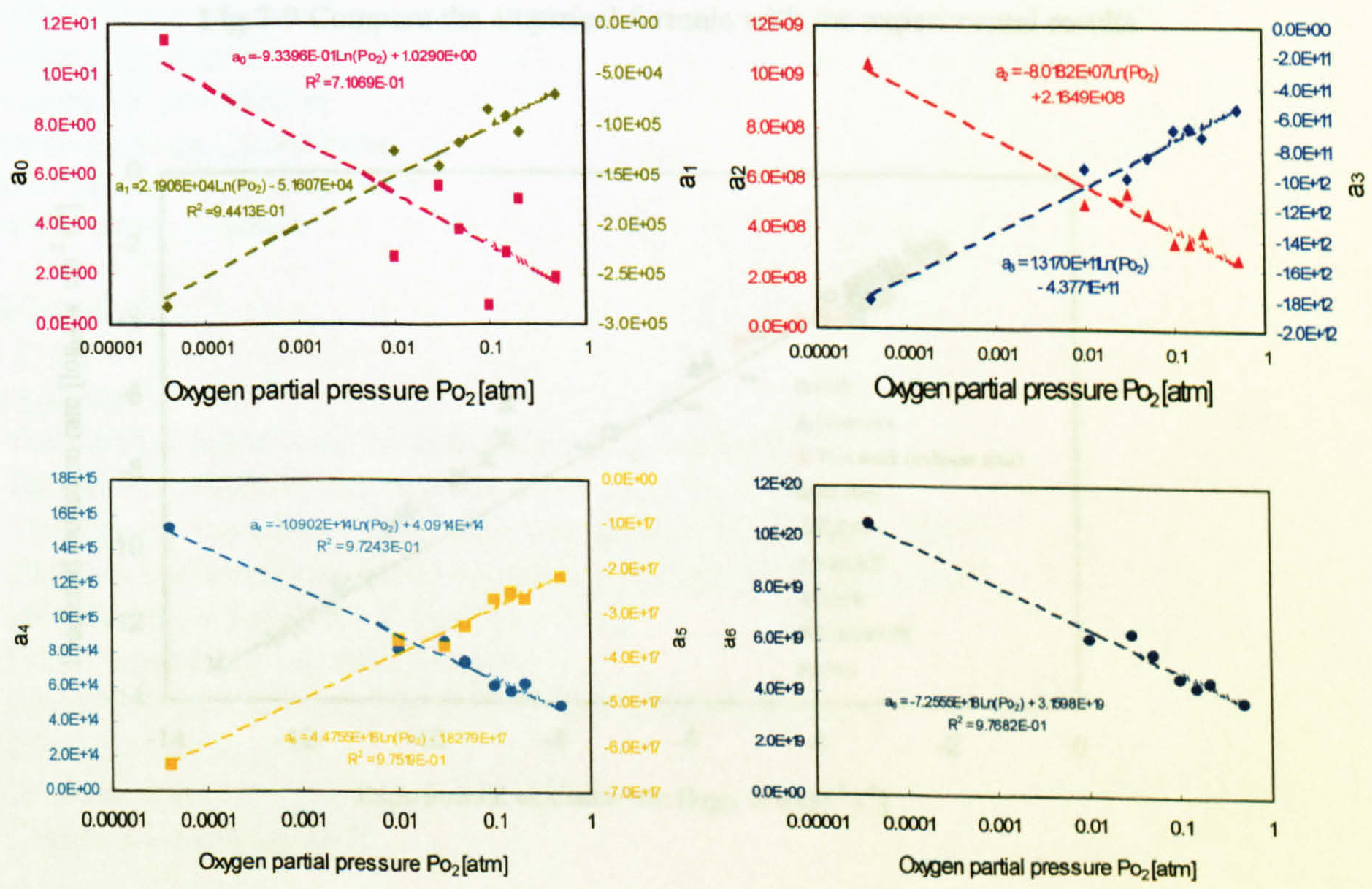

Fig 7-8 Constants as functions of oxygen partial pressure 


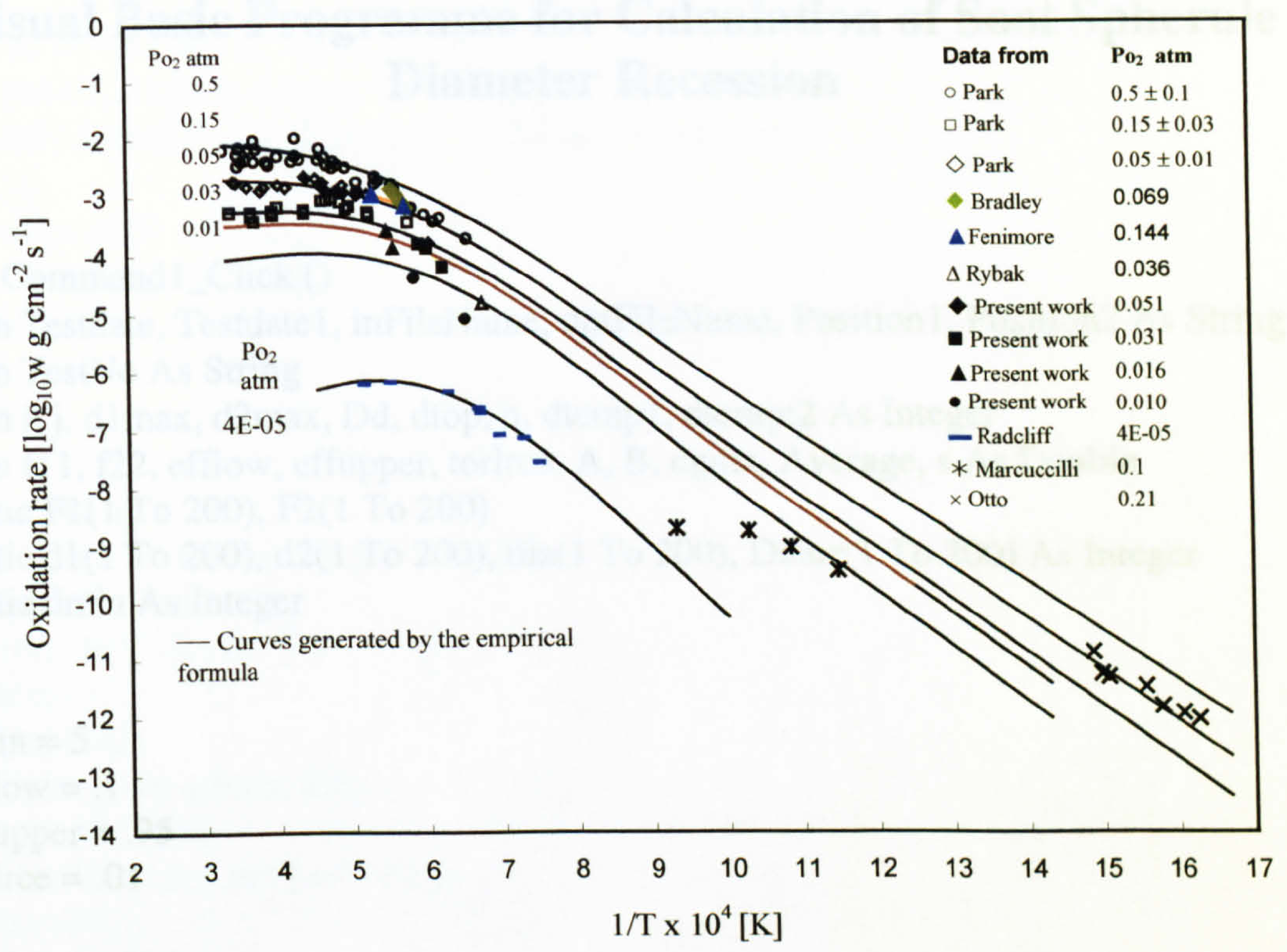

Fig 7-9 Compare the empirical formula with the experimental results

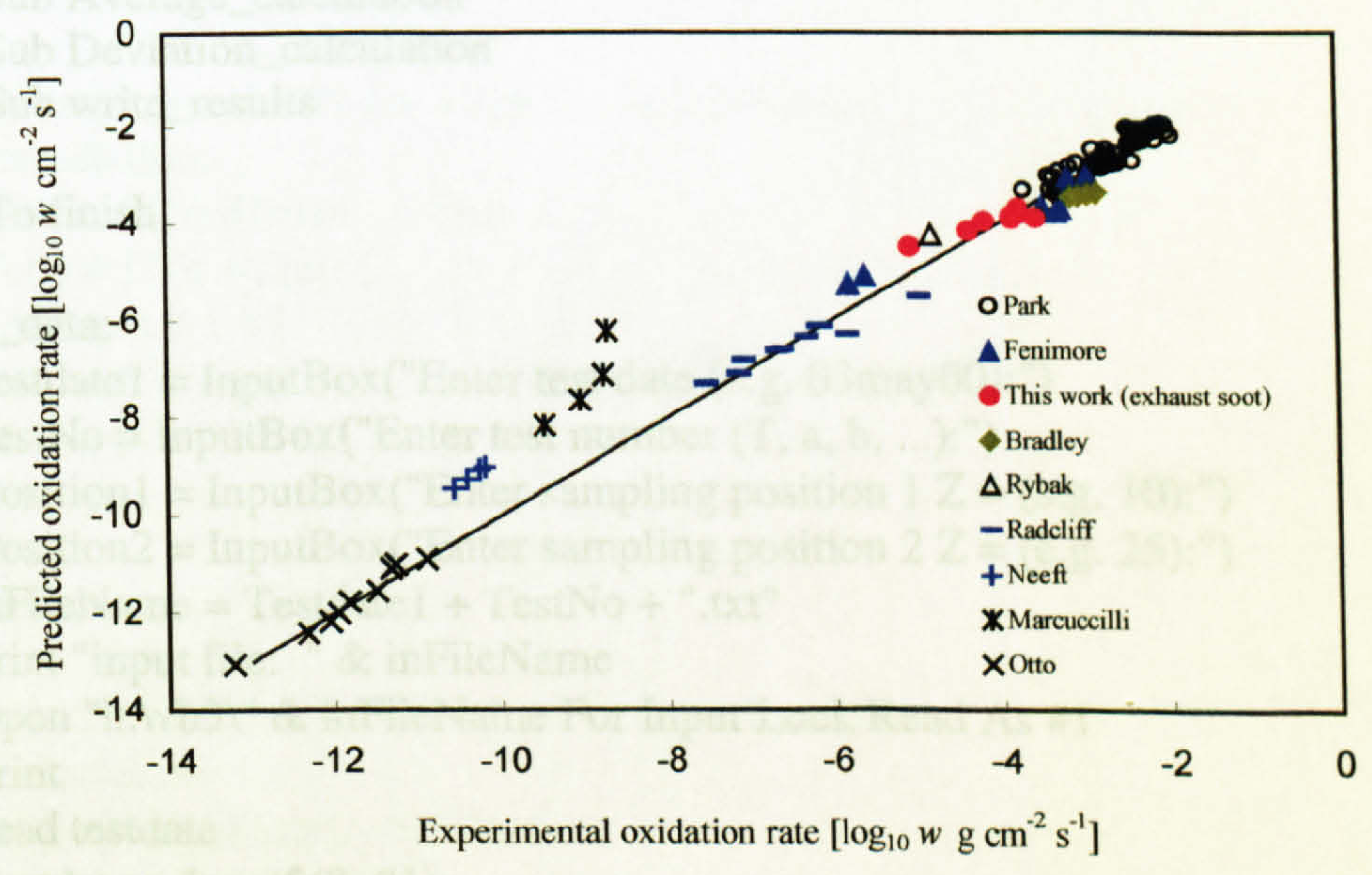

Figure 7-10 Comparison of the oxidation rate predicted by the empirical formula with measured rates by various investigators 


\section{Appendix}

\section{Visual Basic Programme for Calculation of Soot Spherule Diameter Recession}

\section{Sub Command1_Click ()}

Dim Testdate, Testdate1, inFileName, outFileName, Position1, Position2 As String Dim TestNo As String Dim i, j, d1max, d2max, Dd, dtop, n, dtemp1, dtempt2 As Integer

Dim f11, f22, efflow, effupper, torlrce, A, B, cgma, Average, s As Double Static F1(1 To 200), F2(1 To 200)

Static d1(1 To 200), d2(1 To 200), dia(1 To 200), Ddarr(1 To 200) As Integer

Static dmin As Integer

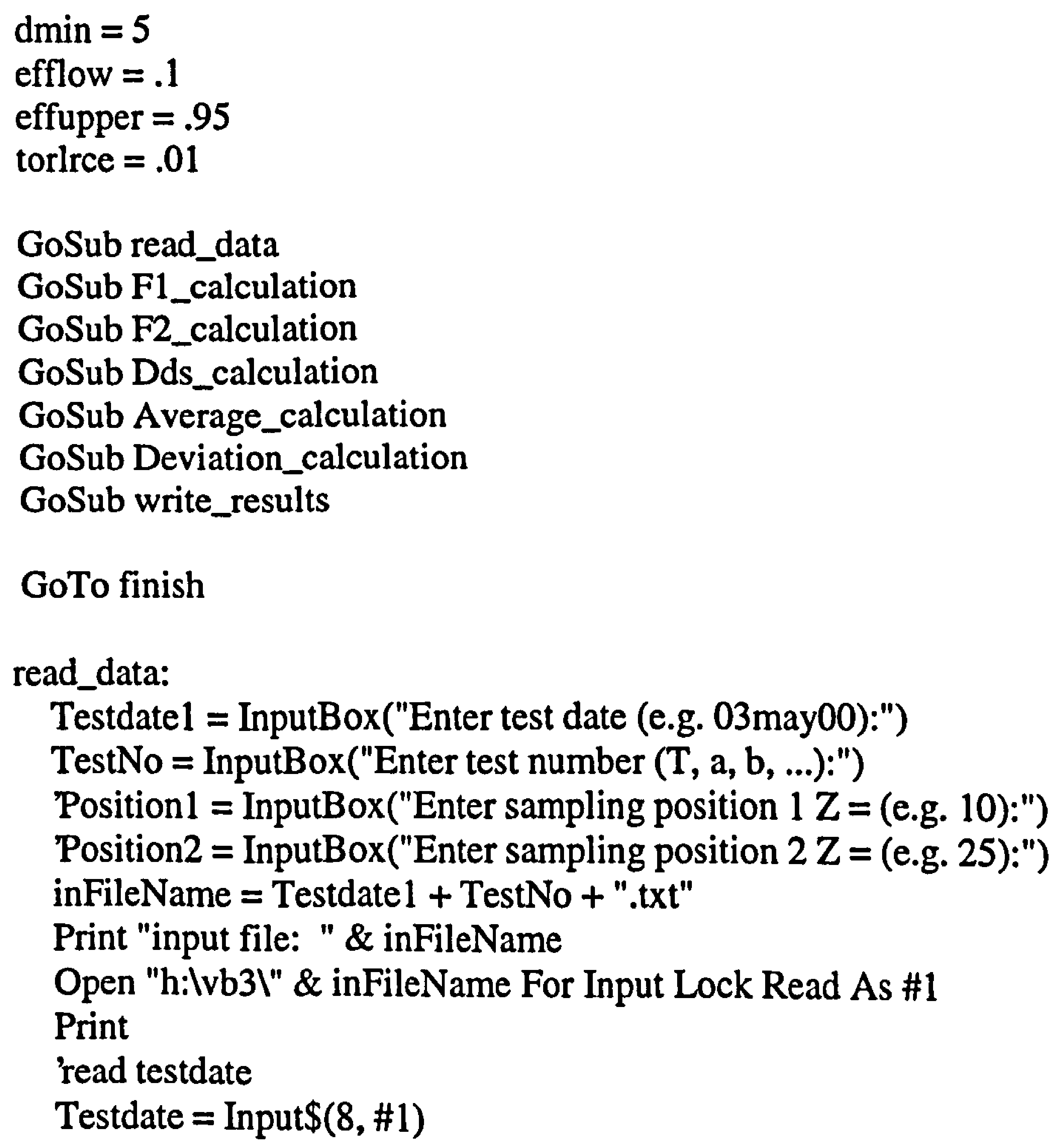

GoTo finish

read_data:

Testdate1 = InputBox("Enter test date (e.g. 03may00):")

TestNo = InputBox ("Enter test number (T, a, b, ...):")

Position $1=$ InputBox ("Enter sampling position $1 \mathrm{Z}=$ (e.g. 10):")

Position2 = InputBox("Enter sampling position $2 \mathrm{Z}=$ (e.g. 25):")

inFileName $=$ Testdate $1+$ TestNo + ".txt"

Print "input file: " \& inFileName

Open "h:lvb3।" \& inFileName For Input Lock Read As \#1

Print

'read testdate

Testdate $=\operatorname{Input} \$(8, \# 1)$

'check if the opened input file is right If StrComp(testdate, Testdate 1, 1) $>0$ Then

Print "The input file is not what wanted!"

'Close \#1 
GoTo finish

End If

'read d1 $\max$ and $\mathrm{d} 2 \max$

Input \#1, d1 max, d2max

Print "d1max = " \& d1 max \& " d2max = " \& d2max

'assign $\mathrm{d} 1$ (i) and d2(i)

For $i=5$ To 200 Step 5

$\mathrm{d} 1(\mathrm{i})=\mathrm{i}$

$\mathrm{d} 2(\mathrm{i})=\mathrm{i}$

Next $i$

read F1(i)

For $\mathrm{i}=5$ To $\mathrm{d} 1 \mathrm{max}$ Step 5

Input \#1, F1(i)

Print "F1 [" \& i \& "] = ", F1(i)

Next $i$

'read F2(i)

For $\mathrm{i}=5$ To d2max Step 5

Input \#1, F2(i)

Print "F2[" \& i \& "] = ", F2(i)

Next $i$

'read positions

Input \#1, Position1, Position2

Print "The input data was for: " \& Testdate \& Position1 \& Position2

Close \#1

Return

'Calculate values of $\mathrm{F} 1$ for all ds by liner insertion

F1_calculation:

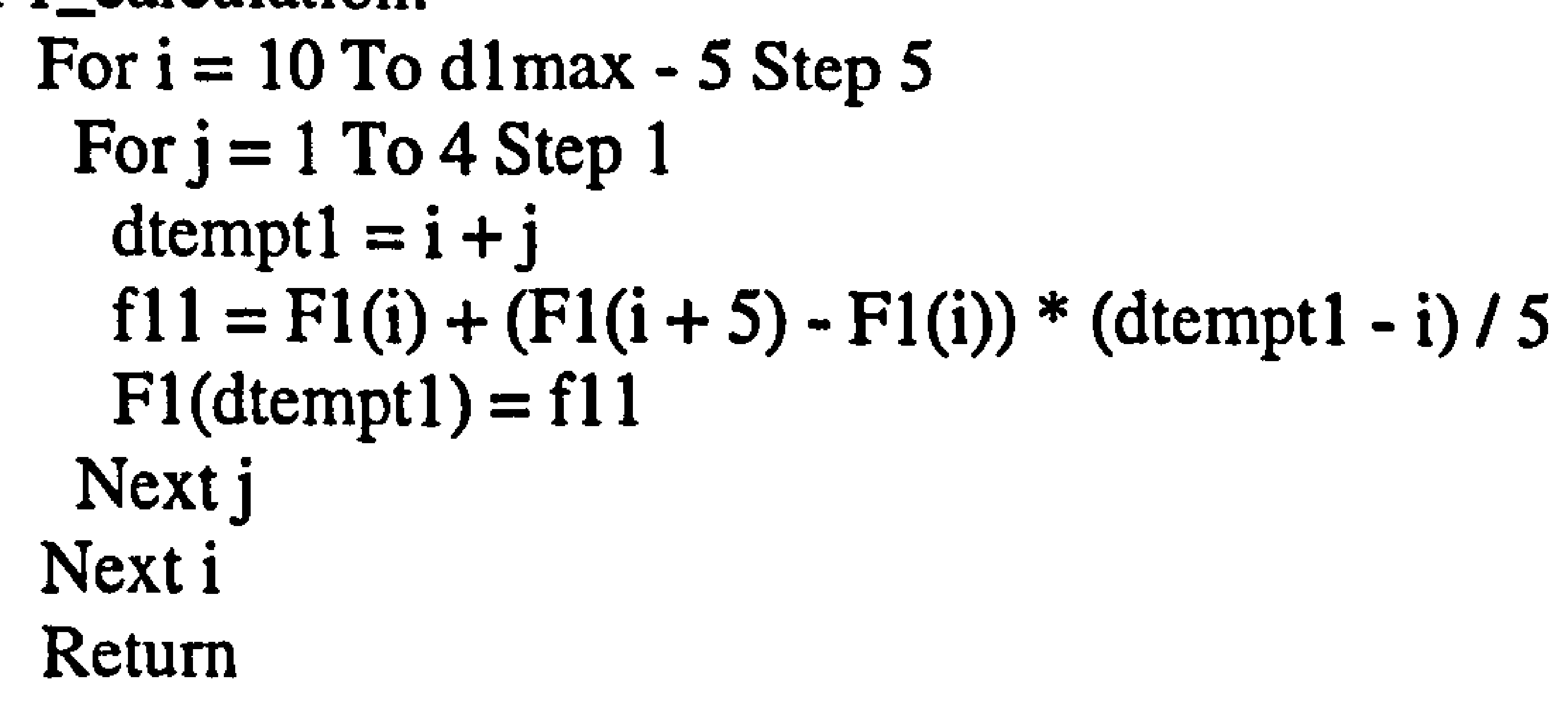

'Calculate values of $\mathrm{F} 2$ for all ds by liner insertion

F2_calculation:

For $\mathrm{i}=10$ To $\mathrm{d} 2 \mathrm{max}-5$ Step 5

For $j=1$ To 4 Step 1

dtempt $2=\mathbf{i}+\mathbf{j}$

$\mathrm{f} 22=\mathrm{F} 2(\mathrm{i})+(\mathrm{F} 2(\mathrm{i}+5)-\mathrm{F} 2(\mathrm{i})) *(\mathrm{dtempt} 2-\mathrm{i}) / 5$

$\mathrm{F} 2$ (dtempt2) $=\mathrm{f} 22$

Next $j$

Next i

Return 


\section{'Calculate Dds}

Dds_calculation:

$\mathrm{n}=0$

For $\mathrm{i}=1$ To 200 Step 1

$\operatorname{Ddarr}(\mathbf{i})=1000$

Next i

For $d=d \min +5$ To dl max Step 1

If $(\mathrm{F} 1(\mathrm{~d})<$ efflow Or $\mathrm{F} 1$ (d) $>$ effupper) Then GoTo d_continue

For Dd $=1$ To 60 Step 1

If $(\mathrm{d}-\mathrm{Dd}<\mathrm{dmin})$ Then GoTo d_continue

If $(d-D d>d 2 \max )$ Then GoTo dd_continue

If (F2(d - Dd) < efflow Or F2(d - Dd) > effupper) Then GoTo dd_continue

$A=F 2(d-D d)$

$B=(F 1(d)-F 1(d \min +D d)) /(1-F 1(d m i n+D d))$

If $(\mathrm{A}>=.0001$ And $\mathrm{B}>=.0001)$ Then

If (A / B > $=1$ - torlrce And A / B $<=1+$ torlrce) Then

Print $n+1 \&$ " $d=$ " \& d \& " Dd = " \& Dd \& "; "

Print " $A=$ " \& $A \&$ " $B=" \& B \&$ " $A / B=" \& A / B$

$\mathrm{n}=\mathrm{n}+\mathbf{1}$

$\operatorname{dia}(n)=d$

$\operatorname{Ddarr}(\mathrm{n})=\mathrm{Dd}$

Print $n \&$ " $d=" \& d \&$ " $d d=" \& D d \&$ " A/B = " \& A / B

GoTod_continue

End If

End If

dd_continue:

Next Dd

d_continue:

Next d

$\mathrm{dtop}=\mathrm{d}$

Return

'Calculate the average of Dds

Average_calculation:

cgma $=0$

$\mathrm{n}=\mathbf{0}$

For $\mathrm{i}=1$ To dtop Step 1

If (Ddarr(i) $\diamond 1000)$ Then

cgma $=$ cgma + Ddarr(i)

$\mathrm{n}=\mathrm{n}+1$

End If 
Next i

Average $=\mathrm{cgma} / \mathrm{n}$

'cout <<"'n";

Print "average = " \& Average \& " $n=" \& n$

\section{Return}

Calculate standard deviation

Deviation_calculation:

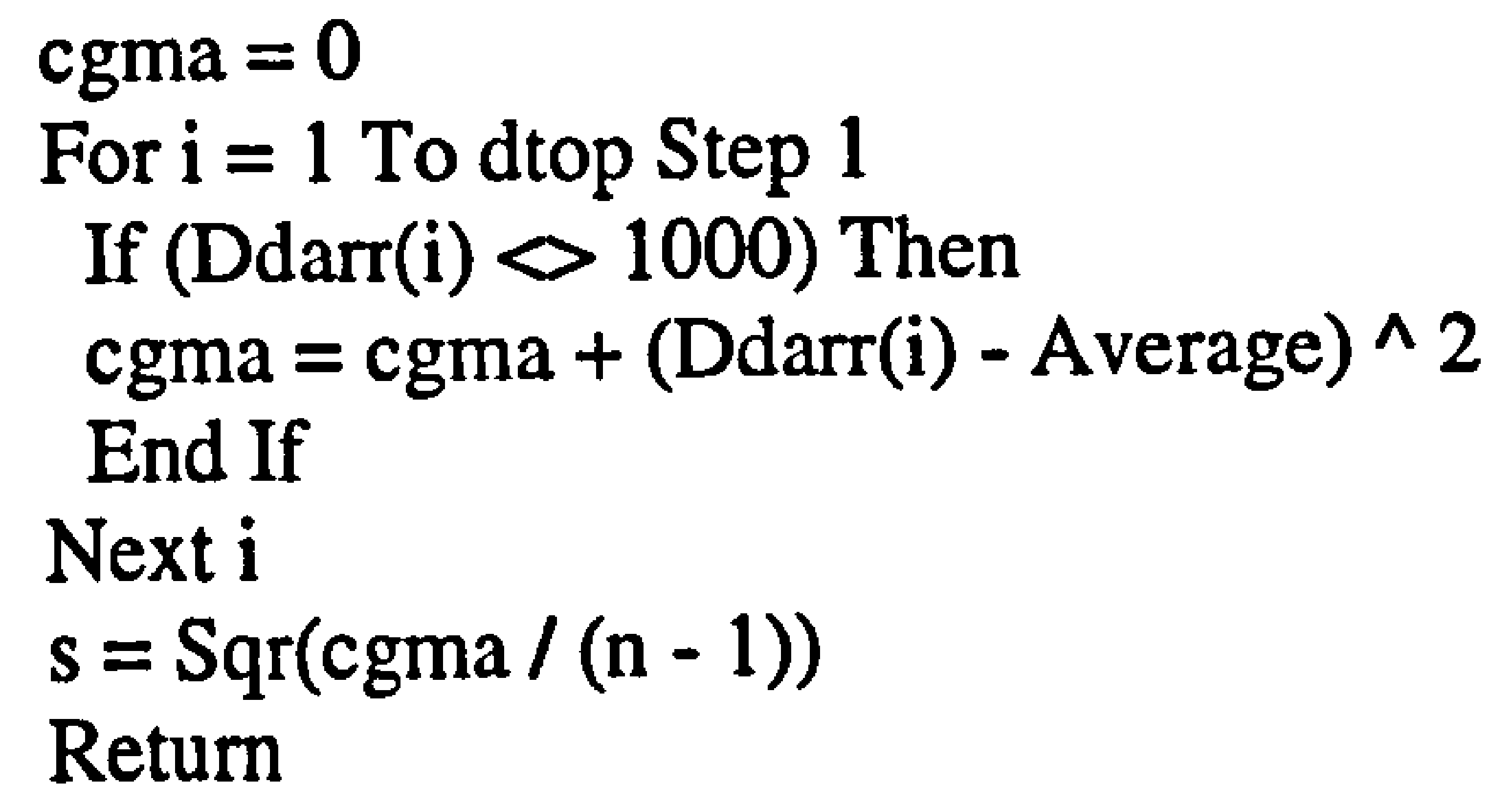

'write calculation results to file write_results:

outFileName $=$ Testdate $1+$ "o" + ".txt"

Open "h:Ivb3l" \& outFileName For Output As \#2

Print \#2, "Test date: " \& Testdate

Print \#2, "Sampling positions: " \& Position1 \& " - " \& Position2

Print \#2, "Calculation date: " \& Date

Print \#2,

Print \#2, "Input data (for check):"

Print \#2, "F1[5] - F1[" \& d1 max \& "]:"

For $\mathrm{i}=5$ To dl max Step 5

Print \#2, "F[" \& i; "] = " \& F1(i)

Next i

Print \#2, "F2[5] - F2[" \& d2max \& "]:"

For $\mathrm{i}=5$ To $\mathrm{d} 2 \mathrm{max}$ Step 5

Print \#2, "F2[" \& i \& "] = " \& F2(i)

Next $i$

Print \#2, "

Print \#2, "dmin = " \& dmin

Print \#2, "Effective F1 range = " \& efflow \& " to " \& effupper

Print \#2, "A/B torlorence $=1+-"$ \& torlrce

Print \#2," -

Print \#2, " n diameter[nm] dd[nm]"

Print \#2,

For $\mathrm{i}=1$ To $\mathrm{n}$ Step 1

Print \#2, i, dia(i), Ddarr(i) 
Next i

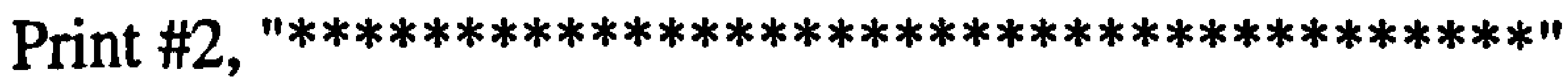

Print \#2, "Average Dd = " \& Average

Print \#2, "n = " \& n

Print \#2, "Standard deviation = " \& s 